\title{
Filling the Glass
}

Citation for published version (APA):

Boselie, J. J. L. M. (2017). Filling the Glass: optimism as a protective factor against pain-induced executive functioning impairments. [Doctoral Thesis, Maastricht University]. Datawyse / Universitaire Pers Maastricht. https://doi.org/10.26481/dis.20170921jb

\section{Document status and date:}

Published: 01/01/2017

DOI:

10.26481/dis.20170921jb

Document Version:

Publisher's PDF, also known as Version of record

\section{Please check the document version of this publication:}

- A submitted manuscript is the version of the article upon submission and before peer-review. There can be important differences between the submitted version and the official published version of record.

People interested in the research are advised to contact the author for the final version of the publication, or visit the DOI to the publisher's website.

- The final author version and the galley proof are versions of the publication after peer review.

- The final published version features the final layout of the paper including the volume, issue and page numbers.

Link to publication

\footnotetext{
General rights rights.

- You may freely distribute the URL identifying the publication in the public portal. please follow below link for the End User Agreement:

www.umlib.nl/taverne-license

Take down policy

If you believe that this document breaches copyright please contact us at:

repository@maastrichtuniversity.nl

providing details and we will investigate your claim.
}

Copyright and moral rights for the publications made accessible in the public portal are retained by the authors and/or other copyright owners and it is a condition of accessing publications that users recognise and abide by the legal requirements associated with these

- Users may download and print one copy of any publication from the public portal for the purpose of private study or research.

- You may not further distribute the material or use it for any profit-making activity or commercial gain

If the publication is distributed under the terms of Article $25 \mathrm{fa}$ of the Dutch Copyright Act, indicated by the "Taverne" license above, 


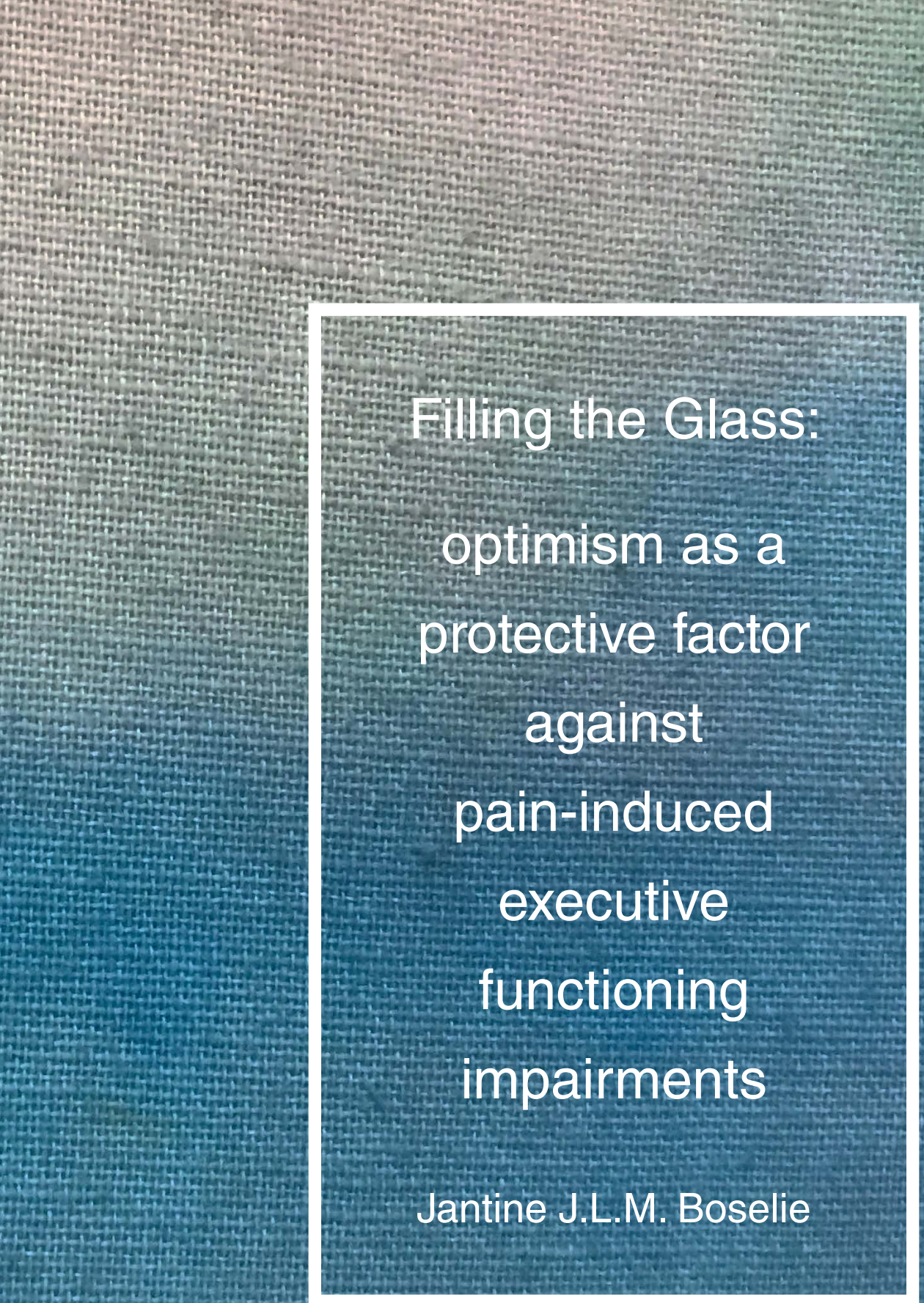




\title{
Filling the Glass
}

\section{optimism as a protective factor against pain- induced executive functioning impairments}

\section{PROEFSCHRIFT}

\author{
ter verkrijging van de graad van doctor aan de Universiteit Maastricht, \\ op gezag van de Rector Magnificus, Prof. dr. Rianne M. Letschert, \\ volgens het besluit van het College van Decanen, \\ in het openbaar te verdedigen \\ op donderdag 21 september 2017 om 12:00 uur \\ door
} Jantine Johanna Lidwina Maria Boselie 
PROMOTOR

Prof. Dr. M. L. Peters

\section{COPROMOTOR}

Dr. L. M. G. Vancleef

\section{BEOORDELINGSCOMMISSIE}

Prof. Dr. J. W. S. Vlaeyen (voorzitter)

Prof. Dr. A. W. M. Evers, Universiteit Leiden

Dr. A. C. Martijn

Dr. D. M. L. van Ryckeghem, Universiteit Luxemburg, L | Universiteit Gent, B.

Prof. Dr. J.A.M.C.F. Verbunt

The research presented in this dissertation was performed at the department of Clinical Psychological Science (CPS) of Maastricht University.

This dissertation was financially supported by grant 022.003.038 from NWO, The Netherlands Organization for Scientific Research, awarded to the Dutch-Flemish Research School of Experimental Psychopathology. 


\section{Table of contents}

Chapter 1 Introduction

Chapter 2 Increasing optimism abolishes pain-induced impairments in executive task performance

Chapter 3 The effects of experimental pain and induced optimism on working memory task performance

Chapter 4 Increasing optimism protects against pain-induced impairments in task shifting performance

Chapter 5 Family matters: exploring the working mechanism of the Best Possible Self manipulation to induce optimism

Chapter 6 Filling the glass: effects of a positive psychology intervention on executive task performance in chronic pain patients

Chapter 7 General Discussion

Valorisation Addendum

Samenvatting - Dutch Summary

Dankwoord - Acknowledgements 167

Curriculum Vitae 

Chapter one

Introduction 



\section{PAIN}

Pain is adaptive when it acts as a warning signal for potential danger. It enables an individual to avoid or escape harm, promoting survival. Pain is therefore hard to ignore [32]. Experiencing pain is unavoidable, but fortunately, in most cases it is only temporary. Sometimes, however, pain persists longer than three months (i.e., chronic pain [78]). When pain persists, it loses its adaptive function to signal danger. Experiencing persistent pain constitutes a major health care problem in the western world, with almost 1 out of 5 adult Europeans reporting chronic pain of moderate to severe intensity [13]. Patients report living with chronic pain to be devastating and disabling, causing marked emotional, behavioural and physiological problems [13; 22]. It has a negative impact on mood, social relationships, and quality of life [13; 59; 72] and is associated with more social isolation, loss of work productivity, and unemployment $[13 ; 14 ; 110]$.

\section{EXECUTIVE FUNCTIONING}

Executive functioning is an umbrella term that describes multiple high-level cognitive processes and behavioural abilities [8; $12 ; 48 ; 79]$. It encompasses the ability to actively monitor behaviour, inhibit or facilitate certain responses, and optimise one's approach to unfamiliar circumstances [48; 79; 105]. Three core executive functions that are often postulated are: (I) inhibition of prepotent responses (i.e., inhibition), (II) updating and monitoring of working memory representations (i.e., updating), and (III) shifting between mental sets or tasks (i.e., shifting) [79]. Inhibition refers to the ability to purposely inhibit automatic prepotent responses. An example in daily life is refraining from using the clutch when driving an automatic car or resisting the urge to eat chocolate while on a diet. Updating is being able to actively update, manipulate and monitor relevant information held in working memory. For instance, performing mental math requires keeping partial results in mind while solving the problem [84]. Shifting is the ability to switch flexibly and fluently between mental sets or tasks [48; 80; 105], enabling a person for example to switch between different languages in a conversation. A cognitive process that enables executive functioning is attention. Attention enables the processing of information, whereby it is possible to selectively attend to some aspects of information, while disregarding other aspects [91].

\section{PAIN, CHRONIC PAIN AND EXECUTIVE FUNCTIONING}

Considering the particularly aversive and alarming nature of pain, it is not surprising that our attention is automatically directed towards the pain. But redirecting attention towards pain comes with a cost: all other concerns, tasks, and goals are negatively af- 
fected. Numerous studies demonstrated that experimentally induced pain impairs executive task performance $[24-26 ; 32 ; 69 ; 70 ; 81 ; 96 ; 115]$. The influence of pain on attention has predominantly been tested with dual-task paradigms that present painful stimuli during task performance (i.e., the primary task). The interruptive ability of pain is then inferred by the amount of performance degradation on the primary task. Pain seems to be especially disruptive to task performance when it is novel, and the threatvalue and pain intensity is high [16; 32]. In a study by Moore and colleagues [81] the effect of pain on attention was systematically examined. Healthy participants performed several cognitive tasks three times: with concurrent painful heat stimulation, warm heat stimulation and without any stimulation. Participant's cognitive task performance declined in the pain condition compared to the other conditions, although this was not a consistent finding. The findings from this study indicated that especially tasks that demand continuous attention and involved higher executive functions seemed to be affected by the experience of concurrent pain. Buhle and Wager [16] designed a novel paradigm to examine the relationship between pain and task performance on a trial-by-trial basis. Furthermore, in order to place continuous demand on executive processes, the task was calibrated to ensure that the task was sufficiently challenging for each participant. Participants were asked to perform an executive functioning task, while receiving low, medium or high painful heat stimulation during task execution. These heat levels were calibrated prior task execution for each participant. A trial lasted 50 seconds, during which the participants performed the executive task and experienced painful heat stimulation. After the heat stimulation ended, participants were asked immediately to rate the pain intensity of the heat stimulus. Sensitive trial-by-trial analyses indicated that high heat levels deteriorated executive task performance compared to the low heat level. Mediation analyses indicated that this relationship between heat and executive task performance was fully explained by the self-reported trial-bytrial pain intensity ratings.

The effects of pain on executive task performance are predominantly derived from laboratory studies that examine experimentally induced pain in healthy participants. This approach is highly suitable for testing the causal effects of pain on executive functioning and which factors may moderate or increase pain-induced impairments. But pain outside of the laboratory is rarely predictable and delivered in a controlled condition and has greater emotional and motivational significance [34]. It is therefore not surprising that many people with chronic pain report executive functioning deficits. In a study by McCracken and Iverson [75] the most frequently reported cognitive complaints by chronic pain patients were forgetfulness, difficulty finishing tasks and difficulty with attention, with more than half of the patients endorsing at least one of these complaints. Many chronic patients even state that these deficits in executive functioning are more disturbing and disabling than the pain experience itself, especially when it compromises a patient's ability to perform daily activities, professional work productivity and employment status $[13 ; 14 ; 52 ; 110]$. These self-reported deficits by chronic pain 
patients are supported by reviews and meta-analysis that show small to moderate executive functioning impairments in chronic pain patients $[11 ; 12 ; 50-52 ; 59 ; 83 ; 86]$. More specifically, chronic pain impairs the performance on complex tasks that tap into the previously mentioned executive functions: inhibition, updating and shifting $[11 ; 12$; $65 ; 82 ; 83]$.

\section{OPTIMISM}

Dispositional optimism is characterized by generalized and global positive outcome expectancies [97]. In other words, individuals with high levels of optimism have the tendency to expect that good things will happen in the future. This definition is based on the expectancy-value model of motivation [19]. It assumes that behaviour reflects the pursuit of goals, which is defined as internal representations of a desired state [7]. The model proposes two aspects that influence goal-directed behaviour. First, if a goal is perceived as more important, the value that is given is greater, resulting in more effort displayed to attain the goal. Second, motivation is determined by the expectancy of goal attainment. Doubt may increase withdrawal from effort towards goal attainment, while confidence in reaching a goal will foster perseverance and continued effort, even when it is difficult to carry on.

Optimistic individuals are more likely to continue displaying effort to facilitate goal achievement [93; 108]. As noted above, the tendency to expect positive outcomes probably motivates an optimist to continue pursuing a goal, as they belief that they will obtain the goal. Optimists are more persistent in their academic and professional efforts over time: they are more likely to complete college [106] and acquire more income in the decade following law school [101]. Similarly, optimists showed more persistence on an insolvable anagram task in the laboratory [108]. In daily life, however, individuals generally pursue multiple goals simultaneously. Optimists tend to deal with this conflict by increasing effort when the circumstances are favourable, while decreasing effort when the circumstances are unfavourable [87]. Similarly, optimists tend to increase effort for high-priority goals, increasing the likelihood of attaining the goal, and decrease effort for low-priority goals [45]. This tendency was demonstrated in a study in which students received information that stressed the importance of doing well on the final exam, making it a high-priority goal. One week prior to the exam, students received a practice exam. Among optimistic students, the practice exam was used more often, but only when goal-priority was high [45]. These findings also extend to clinical outcomes. When an optimist deems a treatment program as important, greater commitment to the treatment was displayed [46].

Optimism has also a substantial impact on an individual's ability to cope with adversity [20]. When confronted with a stressor, an optimist will be more inclined to display approach coping strategies aimed at eliminating, reducing, or managing stressors, and 
less inclined to use avoidance coping strategies seeking to ignore, avoid, or withdraw from stressors [107]. In other words, optimistic individuals tend to focus less on the negative aspects of stressors and more on strategies that help them cope with the stressful experience. These active-coping tendencies are associated with better psychological adjustment to a range of various adverse life events [3; 29], which are a risk factor for developing psychopathology [27; 28].

The beneficial effects of optimism also translate to interpersonal relationships. Optimists are less likely to withdraw from social activities due to cancer treatments [17], receive better social support [15], tend to be more determined in their attempts to resolve problems within a relationship [5], and experiences more supportiveness from partners and report better relationship quality [5; 109]. In the context of health and health promotion, optimism is associated with selectively attending to and reducing health risks related to potentially serious health problems [3]. Higher levels of optimism predict a better immune response following vaccination [23; 68], better and faster recovery and less rehospitalisation after surgery $[21 ; 37 ; 66 ; 74 ; 98 ; 99]$, and even longer longevity [49; 111].

\section{OPTIMISM AND PAIN}

The beneficial effects of optimism are also demonstrated in relation to chronic pain and physical limitations: optimists invest more effort to reach personal and health goals despite pain or limitations $[1 ; 30]$. One might argue that this higher tendency to pursue goal achievement may in fact be potentially harmful for chronic pain patients. Pain itself is often not alleviated, thus pursuing the goal to abolish the pain experience may lead to disappointment and increased likelihood of experiencing goal conflict [107]. Goal conflict arises when pursuing one goal is at the cost of other goals [107] and results in decrements in overall well-being [36; 95]. However, more optimistic individuals are able to cope with this conflict more efficiently and are more flexible in applying different coping strategies [20; 56; 102]. Moreover, as discussed previously, optimism is associated with more active-coping tendencies [20]. These coping tendencies are associated with improved health outcomes in individuals experiencing chronic pain [63; 92; 113]. More importantly, optimists disengage more easily from a goal that is evaluated as unattainable and are more likely to replace rather than give up goals [4; 56; 94]. Moreover, studies have indicated that optimists are actually less vulnerable for experiencing disappointment, even after receiving a cancer diagnosis [35], cancer treatment [2; 18], and experiencing a failed in vitro fertilization attempt [73].

Optimism can also reduce the experienced intensity of pain [57; 74]. For instance, in the study by Hanssen and colleagues [57], participants in the optimism condition reported less pain intensity during a cold-water task compared to participants that received a neutral manipulation. In this study, situational pain catastrophizing mediated 
the relation between optimism and pain [57]. In another study [44], participants were pre-screened for optimism. Both optimists and pessimists were randomized to a placebo or no-placebo condition after which they were exposed to a cold-water task. In the placebo condition, participants were informed that the cream that was applied would block the pain from the cold-water task. Optimism was associated with less pain in the placebo condition compared to the control condition. These findings indicate that optimism increases the responsiveness to placebo induced pain relief.

\section{OPTIMISM, PAIN AND EXECUTIVE FUNCTIONING}

To summarize, optimists are more likely to continue displaying effort to facilitate goal achievement (even in the context of pain), cope better with stressors, experience more social support and reduced health risks. There are several theoretical and empirical explanations why optimism may protect against executive functioning impairments due to (chronic) pain. Within the context of competing limited resource models [31; 32] we propose two potential mechanisms. The first potential mechanism is the allocation of resources. Both cognitive and self-regulation resources are considered to be limited. Self-regulation is the ability to control or alter emotions and thoughts, enabling behaviour to vary adaptively from moment to moment $[9 ; 19]$. When an individual is confronted with a pain experience, resources are directed towards the pain in order to cope with this aversive experience. However, directing these resources towards the pain demand will render them unavailable for additional demands, causing resources to be fatigued and task performance to decline [9; 10; 54]. In other words, pain competes with executive task performance for limited resources. There is compelling evidence from brain-imaging research that pain processing and executive task functioning engages overlapping neural networks and interconnected brain regions [89; 104; 116]. Optimism may increase motivation to continue allocating resources towards task performance, despite less resources being available.

The second possible mechanism is that optimism preserves or redirects attention towards executive task performance. Our attention is often captured by the most salient stimuli in our environment. As pain functions as a warning signal of potential harm, its salience is understandably high. Attention is therefore more likely directed towards the pain at the expense of accurate executive task performance. Optimism may increase an individual's ability to preserve attention for accurate executive task performance, by either decreasing pain intensity or pain-induced negative thought patterns. Decreasing pain intensity will decrease its salience, reducing the interruptive nature of pain, making it possible to direct attention towards accurate executive task performance. Alternatively, optimism may reduce pain-induced negative thought patterns. Chronic pain patients often worry and ruminate about their pain experience and report more pain catastrophizing $[33 ; 64 ; 75 ; 103]$. As optimism is associated with less worry, 
rumination and pain catastrophizing $[53 ; 58 ; 76 ; 112]$ all available attention resources can be dedicated towards executive task performance instead of being consumed by negative thought patterns. That attention can be redirected is in line with the integrative neurocognitive model [69; 71] that proposes that bottom-up and top-down variables can modulate the ability of pain to capture an individual's attention at the expense of accurate task performance [71]. Optimism may increase modulation by increasing top-down variables (e.g., motivation, goal perseverance and effort [30; 93; 100; 114; 117]).

Another theoretical explanation for the protective ability of optimism is proposed by the broaden-and-build theory [38-40]. This theory states that strengthening positive behaviours, emotions and cognitions causes an upward mutually reinforcing spiral to ensue, in which broadening thinking patterns and building durable resources results in further positive emotions, in turn enhancing emotional well-being [38; 39; 41-43]. Optimism may act as a protective factor, by (re) directing an individual's attention (i.e., the broaden hypothesis) towards accurate task performance and/or increasing cognitive or self-regulation resources (i.e., the build hypothesis).

\section{OPTIMISM MANIPULATION}

If optimism can act as a protective factor against the deteriorating effects of pain on executive functioning, a necessary step is being able to increase optimism. Both heritable $[85 ; 90]$ and environmental factors (e.g., secure attachment to caregivers, selfesteem, and financial security; [60-62]) contribute to the level of dispositional optimism. Although optimism has been defined as an enduring personality trait, optimism levels can change over time $[6 ; 101]$. Moreover, a brief writing and imagery exercise, called Best Possible Self (BPS) was developed [88] to increase (temporary) optimism. The BPS is a positive future thinking technique based on work by King [67]. Participants are asked to write about and imagine a life in the future where everything turned out for the best. Prior studies $[47 ; 57 ; 88$ ] have shown that the BPS manipulation is effective in increasing positive affect and optimism in the laboratory. Daily imagery of BPS over a period of two weeks even caused sustained increases in optimism. This increase in optimism remained significant after controlling for positive affect [77].

\section{AIM AND OBJECTIVES OF THE DISSERTATION}

Experiencing chronic pain causes marked emotional, behavioural and physiological problems. But imagine for a moment, the last time you experienced pain. Now imagine, dealing with the pain while trying to complete a difficult and demanding task (e.g., writing a dissertation). You will probably agree that completing the task will not be an easy 
assignment. Pain grasps our attention, compromising accurate task performance. Impairments in executive functioning can be devastating and disabling, impacting employment status [13] and self-perceived burden among chronic pain patients [55]. Since the pain itself often persists, having means to diminish the burden of living with chronic pain and reducing executive functioning impairments due to chronic pain is imperative. The overall aim of this dissertation is to examine whether optimism can act as a protective factor against pain related executive functioning impairments. In order to achieve this aim, five objectives are formulated:

I. To examine whether experimentally induced pain deteriorates executive task performance in healthy participants

II. To examine whether Induced optimism counteracts pain-induced deteriorations in executive task performance in healthy participants

III. To examine whether possible protective effects of optimism generalises to different executive functions (i.e., updating, and shifting)

IV. To identify factors that contribute to the effectiveness of the manipulation to induce (temporary) optimism in healthy participants

$\checkmark$. To examine whether increasing the emotional well-being of chronic pain patients via an online positive psychology intervention improves executive task performance (i.e., inhibition, updating and shifting)

\section{OUTLINE OF THE DISSERTATION}

Chapter 2 presents an experimental study that examined whether experimentally induced pain (Cold Pressor Task; CPT) deteriorates subsequent executive task performance (i.e., updating) and whether an optimism induction (BPS) can counteract this sustained deteriorating effect of pain on executive task performance (i.e., operationspan task performance). The executive functioning task followed the pain induction to allow testing the hypothesis that pain has sustained deteriorating effects on executive functioning, thereby reflecting self-regulatory fatigue. We hypothesized that pain would impede subsequent operation-span task performance and that optimism would protect against this deterioration (objective I and II). Chapter 3 describes two successive experiments that examined whether the protective ability of optimism generalises to a different task measuring updating ability. In the first study, 2-back task performance was assessed following experimentally induced pain (i.e., CPT). In the second study, participants completed the 2-back task twice: once with continuous oscillating painful heat stimulation, and once without any stimulation. We hypothesized that pain would decrease both subsequent (study 1) and concurrent (study 2) 2-back task performance and that optimism would protect against this deterioration (objective I, II and III). Chapter 4 describes a study that examined whether the protective effect of manipulated optimism can be extended to the executive function shifting. Participants completed a 
shifting task once with and once without concurrent painful heat stimulation. We hypothesized that pain would decrease shifting task performance and that optimism would counteract this pain-induced deterioration (objective I, II and III). Chapter 5 reports on the BPS manipulation in more detail. Prior studies [47; 57; 88] have demonstrated that the BPS manipulation is effective in increasing positive affect and optimism (i.e., increasing positive future expectancies and decreasing negative future expectancies). However, possible working mechanisms that contribute to the effectiveness of the BPS manipulation remain unclear. Linguistic analysis was used to investigate differences in BPS narratives, as compared to control narratives (i.e., writing about a typical day; TD). Moreover, the BPS narratives were rated on qualitative classifications. We hypothesized that specific content (i.e., words related to positive emotions, personal family life and professional life) are more present in BPS descriptions compared to TD descriptions, (ii) more goals (i.e., within the domains: family, love life, career, social life, social involvement and personal growth) and (iii) better quality (i.e., more effort, concreteness, openness and creativity) of the BPS narratives will predict more effectiveness of the BPS manipulation (objective IV). Chapter 6 presents a study examining whether beneficial effects of optimism as seen in the laboratory with experimentally induced pain and healthy participants can be extended to a chronic pain population. Patients were randomized in a positive psychology internet-based intervention or a waiting list control condition. The intervention consisted of positive psychology exercises that particularly target optimism, positive emotions and self-compassion. Before and after the intervention or waiting-list period, executive functioning was measured online with tasks measuring the three core executive functions (i.e., inhibition, updating and shifting). We hypothesized that that the positive psychology intervention, compared to the waiting list condition, would lead to (1) an increase in positive and decrease in negative states and traits and (2) improved executive (i.e., updating, shifting and inhibition) task performance (objective V). Chapter 7 will provide a general overview of the main findings, including possible implications and limitations of the studies. Throughout this chapter, findings are discussed and recommendations for future research will be made. 


\section{REFERENCES}

[1] Affleck G, Tennen H, Zautra A, Urrows S, Abeles M, Karoly P. Women's pursuit of personal goals in daily life with fibromyalgia: A value-expectancy analysis. Journal of Consulting and Clinical Psychology 2001;69(4):587-596.

[2] Allison PJ, Guichard C, Gilain L. A prospective investigation of dispositional optimism as a predictor of health-related quality of life in head and neck cancer patients. Quality of Life Research: An International Journal of Quality of Life Aspects of Treatment, Care \& Rehabilitation 2000;9(8):951-960.

[3] Aspinwall LG, Brunhart SM. Distinguishing optimism from denial: Optimistic beliefs predict attention to health threats. Personality and Social Psychology Bulletin 1996;22(10):993-1003.

[4] Aspinwall LG, Richter L. Optimism and self-mastery predict more rapid disengagement from unsolvable tasks in the presence of alternatives. Motivation and Emotion 1999;23(3):221-245.

[5] Assad KK, Donnellan MB, Conger RD. Optimism: an enduring resource for romantic relationships. Journal of personality and social psychology 2007;93(2):285.

[6] Atienza AA, Stephens MAP, Townsend AL. Role stressors as predictors of changes in womens' optimistic expectations. Personality and Individual Differences 2004;37(3):471-484.

[7] Austin JT, Vancouver JB. Goal constructs in psychology: Structure, process, and content. Psychological bulletin 1996;120(3):338.

[8] Banich MT. Executive function the search for an integrated account. Current Directions in Psychological Science 2009;18(2):89-94.

[9] Baumeister RF, Heatherton TF, Tice DM. Losing control: Academic Press San Diego, CA, 1994.

[10] Baumeister RFHTF. Self-Regulation Failure: An Overview. Psychological Inquiry 1996;7(1):1.

[11] Berryman C, Stanton TR, Bowering KJ, Tabor A, McFarlane A, Moseley GL. Evidence for working memory deficits in chronic pain: a systematic review and meta-analysis. Pain 2013;154(8):1181-1196.

[12] Berryman C, Stanton TR, Bowering KJ, Tabor A, McFarlane A, Moseley GL. Do people with chronic pain have impaired executive function? A meta-analytical review. Clinical Psychology Review 2014;34(7):563579.

[13] Breivik H, Collett B, Ventafridda V, Cohen R, Gallacher D. Survey of chronic pain in Europe: Prevalence, impact on daily life, and treatment. Eur J Pain 2006;10(4):287-333.

[14] Breivik H, Eisenberg E, O'Brien T. The individual and societal burden of chronic pain in Europe: the case for strategic prioritisation and action to improve knowledge and availability of appropriate care. BMC Public Health 2013;13:1229.

[15] Brissette I, Scheier MF, Carver CS. The role of optimism in social network development, coping, and psychological adjustment during a life transition. Journal of Personality and Social Psychology 2002;82(1):102-111.

[16] Buhle J, Wager TD. Performance-dependent inhibition of pain by an executive working memory task. Pain 2010;149(1):19-26.

[17] Carver CS, Lehman JM, Antoni MH. Dispositional pessimism predicts illness-related disruption of social and recreational activities among breast cancer patients. Journal of personality and social psychology 2003;84(4):813.

[18] Carver CS, Pozo-Kaderman C, Harris SD, Noriega V, Scheier MF, Robinson DS, Ketcham AS, Moffat FL, Clark KC. Optimism versus pessimism predicts the quality of women's adjustment to early stage breast cancer. Cancer 1994;73(4):1213-1220.

[19] Carver CS, Scheier MF. On the self-regulation of behavior. New York, NY US: Cambridge University Press, 1998.

[20] Carver CS, Scheier MF, Segerstrom SC. Optimism. Clinical Psychology Review 2010;30(7):879-889.

[21] Chamberlain K, Petrie K, Azariah R. The role of optimism and sense of coherence in predicting recovery following surgery. Psychology and Health 1992;7(4):301-310.

[22] Chapman CR, Gavrin J. Suffering: the contributions of persistent pain. The Lancet 1999;353(9171):22332237. 
[23] Costanzo ES, Lutgendorf SK, Kohut ML, Nisly N, Rozeboom K, Spooner S, Benda J, McElhaney JE. Mood and cytokine response to influenza virus in older adults. The Journals of Gerontology Series A: Biological Sciences and Medical Sciences 2004;59(12):1328-1333.

[24] Crombez G, Eccleston C, Baeyens F, Eelen P. The disruptive nature of pain: An experimental investigation. Behaviour Research and Therapy 1996;34(11-12):911-918.

[25] Crombez G, Eccleston C, Baeyens F, Eelen P. Habituation and the interference of pain with task performance. Pain 1997;70(2):149-154.

[26] Crombez G, Eccleston C, Baeyens F, Eelen P. Attentional disruption is enhanced by the threat of pain. Behaviour Research and Therapy 1998;36(2):195-204.

[27] Dohrenwend BP. Adversity, stress, and psychopathology: Oxford University Press, 1998.

[28] Dohrenwend BP. The role of adversity and stress in psychopathology: Some evidence and its implications for theory and research. Journal of health and social behavior 2000:1-19.

[29] Dougall AL, Hyman KB, Hayward MC, McFeeley S, Baum A. Optimism and Traumatic Stress: The Importance of Social Support and Coping1. Journal of Applied Social Psychology 2001;31(2):223-245.

[30] Duke J, Leventhal H, Brownlee S, Leventhal EA. Giving up and replacing activities in response to illness. The Journals of Gerontology: Series B: Psychological Sciences and Social Sciences 2002;57B(4):P367P376.

[31] Eccleston C. Chronic pain and attention: A cognitive approach. British Journal of Clinical Psychology 1994;33(4):535-547.

[32] Eccleston C, Crombez G. Pain demands attention: A cognitive-affective model of the interruptive function of pain. Psychological Bulletin 1999;125(3):356-366.

[33] Eccleston C, Crombez G, Aldrich S, Stannard C. Worry and chronic pain patients: a description and analysis of individual differences. Eur J Pain 2001;5(3):309-318.

[34] Edens JL, Gil KM. Experimental induction of pain: Utility in the study of clinical pain. Behavior Therapy 1995;26(2):197-216.

[35] Epping-Jordan JE, Compas BE, Osowiecki DM, Oppedisano G, Gerhardt C, Primo K, Krag DN. Psychological adjustment in breast cancer: processes of emotional distress. Health Psychology 1999;18(4):315.

[36] Falleti MG, Maruff P, Collie A, Darby DG. Practice effects associated with the repeated assessment of cognitive function using the CogState battery at 10-minute, one week and one month test-retest intervals. Journal of Clinical and Experimental Neuropsychology 2006;28(7):1095-1112.

[37] Fitzgerald TE, Tennen H, Affleck G, Pransky GS. The relative importance of dispositional optimism and control appraisals in quality of life after coronary artery bypass surgery. Journal of behavioral medicine 1993;16(1):25-43.

[38] Fredrickson BL. What good are positive emotions? Review of general psychology 1998;2(3):300.

[39] Fredrickson BL. The role of positive emotions in positive psychology: The broaden-and-build theory of positive emotions. American psychologist 2001;56(3):218.

[40] Fredrickson BL. The broaden-and-build theory of positive emotions. Philosophical transactions-royal society of london series b biological sciences 2004:1367-1378.

[41] Fredrickson BL. Positive emotions broaden and build. Advances in experimental social psychology 2013;47(1):53.

[42] Fredrickson BL, Joiner T. Positive emotions trigger upward spirals toward emotional well-being. Psychological Science 2002;13(2):172-175.

[43] Garland EL, Fredrickson B, Kring AM, Johnson DP, Meyer PS, Penn DL. Upward spirals of positive emotions counter downward spirals of negativity: Insights from the broaden-and-build theory and affective neuroscience on the treatment of emotion dysfunctions and deficits in psychopathology. Clinical Psychology Review 2010;30(7):849-864.

[44] Geers AL, Wellman JA, Fowler SL, Helfer SG, France CR. Dispositional optimism predicts placebo analgesia. The Journal of Pain 2010;11(11):1165-1171.

[45] Geers AL, Wellman JA, Lassiter GD. Dispositional optimism and engagement: the moderating influence of goal prioritization. Journal of personality and social psychology 2009;96(4):913. 
[46] Geers AL, Wellman JA, Seligman LD, Wuyek LA, Neff LA. Dispositional optimism, goals, and engagement in health treatment programs. Journal of behavioral medicine 2010;33(2):123-134.

[47] Geschwind N, Meulders M, Peters ML, Vlaeyen JW, Meulders A. Can experimentally induced positive affect attenuate generalization of fear of movement-related pain? The Journal of Pain 2015;16(3):258269.

[48] Gilbert SJ, Burgess PW. Executive function. Current Biology 2008;18(3):R110-R114.

[49] Giltay EJ, Geleijnse JM, Zitman FG, Hoekstra T, Schouten EG. Dispositional Optimism and All-Cause and Cardiovascular Mortality ina Prospective Cohort of Elderly Dutch Men and Women. Archives of general psychiatry 2004;61(11):1126-1135.

[50] Glass JM. Cognitive dysfunction in fibromyalgia and chronic fatigue syndrome: new trends and future directions. Current rheumatology reports 2006;8(6):425-429.

[51] Glass JM. Cognitive dysfunction in fibromyalgia syndrome. Journal of Musculoskeletal Pain 2010;18(4):367-372.

[52] Glass JM, Park DC. Cognitive dysfunction in fibromyalgia. Current rheumatology reports 2001;3(2):123127.

[53] Goodin BR, Glover TL, Sotolongo A, King CD, Sibille KT, Herbert MS, Cruz-Almeida Y, Sanden SH, Staud R, Redden DT. The association of greater dispositional optimism with less endogenous pain facilitation is indirectly transmitted through lower levels of pain catastrophizing. The Journal of Pain 2013;14(2):126135.

[54] Gopher D, Armony L, Greenshpan Y. Switching tasks and attention policies. Journal of Experimental Psychology: General 2000;129(3):308-339.

[55] Greve KW, Love JM, Sherwin E, Mathias CW, Ramzinski P, Levy J. Wisconsin Card Sorting Test in chronic severe traumatic brain injury: Factor structure and performance subgroups. Brain Injury 2002;16(1):2940.

[56] Hanssen M, Vancleef L, Vlaeyen J, Hayes A, Schouten E, Peters M. Optimism, motivational coping and well-being: Evidence supporting the importance of flexible goal adjustment. Journal of Happiness Studies 2015;16(6):1525-1537.

[57] Hanssen MM, Peters ML, Vlaeyen JW, Meevissen YM, Vancleef LM. Optimism lowers pain: Evidence of the causal status and underlying mechanisms. Pain 2013;154(0):53-58.

[58] Hanssen MM, Vancleef LM, Vlaeyen JW, Peters ML. More optimism, less pain! The influence of generalized and pain-specific expectations on experienced cold-pressor pain. Journal of behavioral medicine 2014;37(1):47-58.

[59] Hart RP, Martelli MF, Zasler ND. Chronic pain and neuropsychological functioning. Neuropsychology review 2000;10(3):131-149.

[60] Heinonen K, Räikkönen K, Keltikangas-Järvinen L. Dispositional optimism: Development over 21 years from the perspectives of perceived temperament and mothering. Personality and Individual Differences 2005;38(2):425-435.

[61] Heinonen K, Räikkönen K, Keltikangas-Järvinen L. Self-esteem in early and late adolescence predicts dispositional optimism-pessimism in adulthood: A 21-year longitudinal study. Personality and Individual Differences 2005;39(3):511-521.

[62] Heinonen K, Räikkönen K, Matthews KA, Scheier MF, Raitakari OT, Pulkki L, Keltikangas-Järvinen L. Socioeconomic status in childhood and adulthood: Associations with dispositional optimism and pessimism over a 21-year follow-up. J Pers 2006;74(4):1111-1126.

[63] Higgins N, Bailey SJ, LaChapelle DL, Harman K, Hadjistavropoulos T. Coping styles, pain expressiveness, and implicit theories of chronic pain. The Journal of psychology 2015;149(7):737-750.

[64] Kane MJ, Brown LH, McVay JC, Silvia PJ, Myin-Germeys I, Kwapil TR. For whom the mind wanders, and when: An experience-sampling study of working memory and executive control in daily life. Psychological science 2007;18(7):614-621.

[65] Keogh E, Cavill R, Moore DJ, Eccleston C. The effects of menstrual-related pain on attentional interference. Pain 2014;155(4):821-827. 
[66] King KB, Rowe MA, Kimble LP, Zerwic JJ. Optimism, coping, and long-term recovery from coronary artery surgery in women. Research in nursing \& health 1998;21(1):15-26.

[67] King LA. The health benefits of writing about life goals. Personality and Social Psychology Bulletin 2001;27(7):798-807.

[68] Kohut ML, Cooper MM, Nickolaus MS, Russell DR, Cunnick JE. Exercise and psychosocial factors modulate immunity to influenza vaccine in elderly individuals. The Journals of Gerontology Series A: Biological Sciences and Medical Sciences 2002;57(9):M557-M562.

[69] Legrain V, Crombez G, Verhoeven K, Mouraux A. The role of working memory in the attentional control of pain. Pain 2011;152(2):453-459.

[70] Legrain V, Damme SV, Eccleston C, Davis KD, Seminowicz DA, Crombez G. A neurocognitive model of attention to pain: behavioral and neuroimaging evidence. Pain 2009;144(3):230-232.

[71] Legrain V, Van Damme S, Eccleston C, Davis KD, Seminowicz DA, Crombez G. A neurocognitive model of attention to pain: behavioral and neuroimaging evidence. Pain 2009;144(3):230-232.

[72] Linton SJ, Bergbom S. Understanding the link between depression and pain. Scandinavian Journal of Pain 2011;2(2):47-54.

[73] Litt MD, Tennen H, Affleck G, Klock S. Coping and Cognitive factors in adaptation toin vitro fertilization failure. Journal of behavioral medicine 1992;15(2):171-187.

[74] Mahler H, Kulik J. Optimism, pessimism and recovery from coronary bypass surgery: Prediction of affect, pain and functional status. Psychology, health \& medicine 2000;5(4):347-358.

[75] McCracken LM, Iverson GL. Predicting complaints of impaired cognitive functioning in patients with chronic pain. Journal of pain and symptom management 2001;21(5):392-396.

[76] McGregor BA, Bowen DJ, Ankerst DP, Andersen MR, Yasui Y, McTiernan A. Optimism, perceived risk of breast cancer, and cancer worry among a community-based sample of women. Health Psychology 2004;23(4):339.

[77] Meevissen YMC, Peters ML, Alberts HJEM. Become more optimistic by imagining a best possible self: Effects of a two week intervention. Journal of Behavior Therapy and Experimental Psychiatry 2011;42(3):371-378.

[78] Merskey HE. Classification of chronic pain: Descriptions of chronic pain syndromes and definitions of pain terms. Pain 1986.

[79] Miyake A, Friedman NP, Emerson MJ, Witzki AH, Howerter A. The unity and diversity of executive functions and their contributions to complex 'frontal lobe' tasks: A latent variable analysis. Cognitive Psychology 2000;41(1):49-100.

[80] Miyake A, Friedman NP, Emerson MJ, Witzki AH, Howerter A, Wager TD. The Unity and Diversity of Executive Functions and Their Contributions to Complex "Frontal Lobe" Tasks: A Latent Variable Analysis. Cognitive Psychology 2000;41(1):49-100.

[81] Moore DJ, Keogh E, Eccleston C. The interruptive effect of pain on attention. The Quarterly Journal of Experimental Psychology 2012;65(3):565-586.

[82] Moore DJ, Keogh E, Eccleston C. Headache impairs attentional performance. Pain 2013;154(9):18401845.

[83] Moriarty O, McGuire BE, Finn DP. The effect of pain on cognitive function: a review of clinical and preclinical research. Progress in Neurobiology 2011;93(3):385-404.

[84] Morris N, Jones DM. Memory updating in working memory: The role of the central executive. British journal of psychology 1990;81(2):111-121.

[85] Mosing MA, Zietsch BP, Shekar SN, Wright MJ, Martin NG. Genetic and environmental influences on optimism and its relationship to mental and self-rated health: A study of aging twins. Behavior genetics 2009;39(6):597-604.

[86] Park DC, Glass JM, Minear M, Crofford L. Cognitive function in fibromyalgia patients. Arthritis \& Rheumatism 2001;44(9):2125-2133.

[87] Pavlova MK, Silbereisen RK. Dispositional Optimism Fosters Opportunity-Congruent Coping With Occupational Uncertainty. J Pers 2013;81(1):76-86. 
[88] Peters ML, Flink IK, Boersma K, Linton SJ. Manipulating optimism: Can imagining a best possible self be used to increase positive future expectancies? The Journal of Positive Psychology 2010;5(3):204-211.

[89] Peyron R, Laurent B, Garcia-Larrea L. Functional imaging of brain responses to pain. A review and metaanalysis (2000). Neurophysiologie Clinique/Clinical Neurophysiology 2000;30(5):263-288.

[90] Plomin R, Scheier MF, Bergeman CS, Pedersen NL, Nesselroade JR, McClearn GE. Optimism, pessimism and mental health: A twin/adoption analysis. Personality and individual differences 1992;13(8):921930.

[91] Posner MI, Boies SJ. Components of attention. Psychological review 1971;78(5):391.

[92] Ramírez-Maestre C, Esteve R. Disposition and adjustment to chronic pain. Current pain and headache reports 2013;17(3):312.

[93] Rasmussen HN, Wrosch C, Scheier MF, Carver CS. Self-Regulation Processes and Health: The Importance of Optimism and Goal Adjustment. J Pers 2006;74(6):1721-1747.

[94] Rasmussen HN, Wrosch C, Scheier MF, Carver CS. Self-regulation processes and health: the importance of optimism and goal adjustment. J Pers 2006;74(6):1721-1747.

[95] Reimers S, Maylor EA. Task Switching Across the Life Span: Effects of Age on General and Specific Switch Costs. Developmental Psychology 2005;41(4):661-671.

[96] Ryckeghem D, Crombez G, Eccleston C, Legrain V, Damme S. Keeping pain out of your mind: The role of attentional set in pain. Eur J Pain 2013;17(3):402-411.

[97] Scheier MF, Carver CS. Optimism, coping, and health: Assessment and implications of generalized outcome expectancies. Health Psychology 1985;4(3):219-247.

[98] Scheier MF, Matthews KA, Owens JF, Magovern GJ, Lefebvre RC, Abbott RA, Carver CS. Dispositional optimism and recovery from coronary artery bypass surgery: the beneficial effects on physical and psychological well-being. Journal of Personality and Social Psychology 1989;57(6):1024.

[99] Scheier MF, Matthews KA, Owens JF, Schulz R, Bridges MW, Magovern GJ, Carver CS. Optimism and rehospitalization after coronary artery bypass graft surgery. Archives of internal medicine 1999;159(8):829-835.

[100] Schmitz U, Saile H, Nilges P. Coping with chronic pain: Flexible goal adjustment as an interactive buffer against pain-related distress. Pain 1996;67(1):41-51.

[101] Segerstrom SC. Optimism and resources: Effects on each other and on health over 10 years. J Res Pers 2007;41(4):772-786.

[102] Segerstrom SC, Nes LS. When Goals Conflict But People Prosper: The Case of Dispositional Optimism. J Res Pers 2006;40(5):675-693.

[103] Segerstrom SC, Tsao JC, Alden LE, Craske MG. Worry and rumination: Repetitive thought as a concomitant and predictor of negative mood. Cognitive Therapy and Research 2000;24(6):671-688.

[104] Seminowicz DA, Davis KD. Pain enhances functional connectivity of a brain network evoked by performance of a cognitive task. Journal of neurophysiology 2007;97(5):3651-3659.

[105] Smith EE, Jonides J. Storage and executive processes in the frontal lobes. Science 1999;283(5408):16571661.

[106] Solberg Nes L, Evans DR, Segerstrom SC. Optimism and college retention: mediation by motivation, performance, and adjustment1. Journal of Applied Social Psychology 2009;39(8):1887-1912.

[107] Solberg Nes L, Segerstrom SC. Dispositional Optimism and Coping: A Meta-Analytic Review. Personality and Social Psychology Review 2006;10(3):235-251.

[108] Solberg Nes L, Segerstrom SC, Sephton SE. Engagement and Arousal: Optimism's Effects During a Brief Stressor. Personality and Social Psychology Bulletin 2005;31(1):111-120.

[109] Srivastava S, McGonigal KM, Richards JM, Butler EA, Gross JJ. Optimism in close relationships: How seeing things in a positive light makes them so. Journal of personality and social psychology 2006;91(1):143.

[110] Stewart WF, Ricci JA, Chee E, Morganstein D, Lipton R. Lost productive time and cost due to common pain conditions in the US workforce. Jama 2003;290(18):2443-2454. 
[111] Tindle HA, Chang Y-F, Kuller LH, Manson JE, Robinson JG, Rosal MC, Siegle GJ, Matthews KA. Optimism, cynical hostility, and incident coronary heart disease and mortality in the Women's Health Initiative. Circulation 2009;120(8):656-662.

[112] Tucker RP, Wingate LR, O'Keefe VM, Mills AC, Rasmussen K, Davidson CL, Grant DM. Rumination and suicidal ideation: The moderating roles of hope and optimism. Personality and Individual Differences 2013;55(5):606-611.

[113] Turk DC, Rudy TE. Cognitive factors and persistent pain: A glimpse into Pandora's box. Cognitive Therapy and Research 1992;16(2):99-122.

[114] Van Damme S, Legrain V, Vogt J, Crombez G. Keeping pain in mind: a motivational account of attention to pain. Neuroscience \& Biobehavioral Reviews 2010;34(2):204-213.

[115] Vancleef LM, Peters ML. The interruptive effect of pain on attention. J Pain 2006;7(1):21-22.

[116] Wager TD, Smith EE. Neuroimaging studies of working memory. Cognitive, Affective, \& Behavioral Neuroscience 2003;3(4):255-274.

[117] Wrosch C, Scheier MF. Personality and quality of life: The importance of optimism and goal adjustment. Quality of Life Research: An International Journal of Quality of Life Aspects of Treatment, Care \& Rehabilitation 2003;12(Suppl1):59-72. 


\section{Chapter two}

\section{Increasing optimism abolishes pain-induced impairments in executive task performance}

Published as: Boselie JJLM, Vancleef LM, Smeets T, Peters ML. Increasing optimism abolishes pain-induced impairments in executive task performance. Pain 2014; 155(2):334-340. 


\section{ABSTRACT}

Coping with the demands of pain diminishes self-regulatory capacity and causes selfregulatory fatigue, which then leads to deteriorated executive task performance. It has been suggested that optimism can counteract the depletion of self-regulatory capacity. This study employed a 2 (optimism / no-optimism) x 2 (pain / no-pain) between-subjects design to explore whether (1) experimentally induced pain (Cold Pressor Task) deteriorates subsequent executive task performance and (2) whether an optimism induction can counteract this sustained deteriorating effect of pain on executive task performance. Results indicated that while pain led to significantly worse performance on the executive functioning task in the no-optimism condition, this sustained deteriorating effect of pain on task performance was abolished in the optimism condition. This finding is imperative, as it suggests that optimism may be an important factor to implement in current psychological treatment approaches to diminish the negative impact of chronic pain on the ability to function in daily life. 


\section{INTRODUCTION}

Pain interrupts, interferes, and deteriorates executive task performance as pain attracts an individual's attention $[14 ; 22 ; 23 ; 38]$. Prior studies on the interruptive effect of pain have routinely adopted dual task paradigms that present painful stimuli during executive tasks performance $[14 ; 38 ; 39]$. Although this approach is highly suitable for testing the effects of pain on attention, it does not allow for the examination of whether pain might have sustained deteriorating effects on task performance [57]. The experience of pain may fatigue self-regulation resources, leading to deterioration in executive task performance [54]. Self-regulation is the ability to control or alter thoughts, emotion and behaviour [7; 15]. Coping with the demands of pain requires self-regulation, but this capacity is limited [23; 54; 57]. Self-regulation ability, to some extent, depends on executive functioning capacity, the ability to actively monitor behaviour, thoughts and memory [53]. Ironically, self-regulatory efforts reduce executive functioning ability [13; $31 ; 34 ; 54]$, causing a downward spiral to ensue in which self-regulatory demands cause self-regulatory fatigue, reducing executive functioning capacity, making it more difficult to meet additional self-regulatory demands [14; 57].

People differ in their executive functioning and self-regulatory capacity [9]. One important individual difference variable in this respect may be optimism [48; 55; 64]. Optimism reflects an individual's tendency to expect that good things will happen in the future [46]. Optimism has a substantial impact on an individual's ability to cope with adversity, as optimists are more inclined to display approach coping strategies that are aimed at eliminating or managing stressors [58; 59]. When confronted with pain, optimists are more likely to continue investing effort to obtain their goals $[1 ; 16 ; 21]$ and show better adaptation to pain [2; 12]. These beneficial effects of optimism may be related to higher self-regulatory and executive functioning capacity, leading to higher goal perseverance and adaptation to the challenges of pain [48; 64].

This study examines whether optimism abolishes the deteriorating effect of pain on executive task performance. In the present study, the executive functioning task followed the pain induction to allow testing the hypothesis that pain has sustained deteriorating effects on executive functioning, thereby reflecting self-regulatory fatigue. In order to demonstrate that optimism causally influences the impact of pain on executive task performance, we employed an optimism induction manipulation. This manipulation is able to induce a temporary optimistic state and has previously been found to diminish self-regulatory fatigue [32] and pain sensitivity [30].

In summary, in order to test the hypotheses that (1) experimentally induced pain will deteriorate subsequent executive task performance and (2) an optimism induction counteracts this sustained deteriorating effect of pain on executive task performance, we set up an experiment in which participants completed an executive functioning task after being subjected to either painful cold water or comfortably warm water. Moreover, half of the participants received an optimism manipulation prior to the painful or non-painful water task. 


\section{METHODS}

\section{Participants}

A total of 80 healthy undergraduates from Maastricht University participated in the study. Exclusion criteria were suffering from a chronic pain disorder or currently experiencing pain, cardiovascular disease or Reynaud disease. Six participants were excluded from the analysis because they were non-native Dutch speakers. Although the inclusion criteria only stated that a good comprehension of Dutch language was required, remembering unrelated one syllable Dutch words may add a level of complexity to the executive functioning task (see measures) for non-native Dutch speakers. The remaining 74 participants ( 16 males) had a mean age of 21.9 years $(S D=2.29)$. Participants were randomly assigned to one of the four conditions: (i) optimism and pain ( $n=20 ; 5$ males), (ii) optimism and no-pain ( $n=18 ; 4$ males), (iii) no-optimism and pain ( $n=17 ; 3$ males) and (iv) no-optimism and no-pain ( $n=19 ; 4$ males). Participants were informed during the recruitment that there was a possibility that they would be assigned to a pain condition. Participants received a gift voucher of 10 euro for their participation. The standing human subject's ethics committee of the Faculty of Psychology and Neuroscience, Maastricht University approved the study protocol.

\section{Manipulations}

\section{Optimism manipulation}

Optimism was induced by the Best Possible Self (BPS) manipulation, a positive future thinking technique based on work by King [35]. BPS has been proven effective in increasing positive affect and positive future expectancies [30; 41]. Participants were instructed to carry out a writing and imagery exercise. Half of the participants were assigned to the BPS condition ( $n=38$ ), which required them to write about a life in the future where everything turned out for the best. The other half of the participants were assigned to the control condition ( $n=36)$, which consisted of writing about a typical day (TD). The instructions were as follows [41; 52]. BPS condition: "Think about your best possible self' means that you imagine yourself in the future, after everything has gone as well as it possibly could. You have worked hard and succeeded at accomplishing all the goals of your life. Think of this as the realization of your dreams, and that you have reached your full potential". TD condition: "Think about your typical day' means that you take notice of ordinary details of your day that you usually don't think about. These might include particular classes or meetings you attend to, people you meet, things you do, typical thoughts you have during the day. Think of this as moving through your typical day, hour after hour". 
Both manipulations had the same procedural format: participants were requested to think for 1 minute about what to write, then to write uninterrupted for 15 minutes, followed by 5 minutes of imaging the story they had just finished writing. Instructions were given both verbally and in writing.

\section{Pain manipulation}

In the pain condition ( $n=37$ ) the Cold Pressor Task (CPT) was used to induce a painful sensation. The water tank consisted of a plexiglas box (JULABO Labortechnik GmbH, Seelbach, Germany) filled with water that was kept constant at $2^{\circ} \mathrm{C}$ using an electrical immersion cooler (JULABO type FT200) and a circulation pump (JULABO type ED-19). The immersion duration was set at a maximum of 3 minutes [17]. Participants were explicitly informed that the procedure could be painful and that they could stop the task at any point without consequences. The instructions before immersion were as follows: 'The aim of the task is to submerge your right hand in this cold water tank for as long as possible until you cannot take it anymore. When you cannot take it any longer, you are allowed to remove your hand from the water. Try, however, to hold on as long as possible'. Participants were not aware of the pre-set time limit. If the 3 minutes maximum was achieved, the experimenter signalled the participant to remove the hand from the water.

Participants in the no-pain condition $(n=37)$ followed the same procedure, with the exception that the water temperature was a comfortable $34^{\circ} \mathrm{C}$ (warm water control task; WWCT). Furthermore, to match immersion times of the CPT, participants were randomly requested to remove their hand out of the water at 1, 2, or 3 minutes after immersion [49].

\section{Executive functioning}

\section{Operation-span task}

The operation-span task [62] is a working memory task that requires active maintenance of stored information while concurrently processing another source of information. In the operation-span task participants have to remember and recall unrelated words in their order of presentation while simultaneously solving arithmetic problems. Processing the arithmetic problems interferes with recruitment of strategies, such as rehearsal or grouping, to maintain the stored information (i.e., the words). The operation-span task relies on executive functioning capacity to overcome this interference and to help maintain and recall the presented words [36; 42]. For this reason, the operation-span task is thought to reflect executive functioning [6; 33].

The task consists of two procedural aspects. First, participants read aloud a mathematical problem that consists of two arithmetic operations on one side of the equation and an offered solution on the other side of the equation. The first operation is a multiplication or division problem, the second operation contains an addition or subtraction problem (e.g., is $(6 / 2)+5=8$ ?). The equation is presented centrally on a computer 
screen. After reading the mathematical problem aloud, the participant verbally states whether the offered solution is correct or incorrect, which the experimenter registers on an answer form. Second, behind each equation a one syllable word is presented, which has to be remembered for later serial recall (e.g., is $(6 / 2)+5=8$ ? bread). The presented word is also read aloud by the participant. The presentation of the equation and word combination disappears from the screen when the participant presses the space key, introducing a 100-msec blank interval before the next equation and word combination appears. The presentation of equation and word combinations continue until a question mark is presented on the screen. This signals the participant to start to write down the words in that trial, in order of presentation, on an answer sheet. The participants are informed that they should report as many words as were presented and it is emphasized that the order of the words is important and that they are allowed to guess. There is no time constraint on this recall task.

In total, the operation-span task comprises 12 trials, preceded by one practice trial. One trial can consist of 2, 3, 4 or 5 equation and word combinations, which are presented sequentially. Every possible trial length (e.g. 2, 3, 4 or 5) is displayed three times. The presentation sequence of trials is randomized, which eliminates any strategy that is built on knowledge about the amount of words that need to be remembered [25]. Total duration of the operation-span task is approximately 12 minutes.

To ensure that the working memory load is high, an accuracy level of at least $85 \%$ for the processing component (e.g. correct response to the mathematical problems) of the operation-span task is required. Data from participants who fail to achieve the preset accuracy rate of $85 \%$ are excluded from the analyses [18]. The operation-span task score is calculated with the partial credit unit scoring (PCU) procedure [18; 49]. The PCU represents the mean proportion of words that is recalled correctly. When 3 words are remembered correctly in a trial with 4 words, the score of this trial will be .75 [49]. The PCU score consists of the summed trial scores, which is divided by the total number of trials (e.g., 12). Scores range from 0 (no words recalled) to 1 (every word in every trial recalled correctly).

\section{Individual difference variables}

\section{Optimism}

The Life Orientation Test-Revised [LOT-R; 47] was used to assess the level of dispositional optimism. The LOT-R has 10 items that are rated on a 5-point Likert scale, ranging from 1 (strongly disagree) to 5 (strongly agree). There are 3 positively phrased items (e.g., 'I'm always optimistic about my future'), 3 negatively phrased items (e.g., 'I rarely count on good things happening to me') and 4 filler items. The total score on the LOT-R is calculated from the positive and negative items and ranges from 10 to 30, with higher 
scores reflecting higher levels of optimism. The LOT-R has been found to be a reliable and valid measurement instrument [30; 47].

\section{Pain Catastrophizing}

The Pain Catastrophizing Scale [PCS; 60] is a 13-item scale that assesses catastrophic pain-related cognitive emotional processes. The participant has to recall former occurrences of pain and indicate to what degree they experienced the stated thoughts and feelings while experiencing pain (e.g., 'I keep thinking about how much it hurts'). Items are rated on a 5- point Likert scale, ranging from 0 (not at all) to 4 (all the time). The total PCS score can range from 0 to 52 , with a higher score indicating greater pain catastrophizing [40]. Previous research had demonstrated that the PCS is a reliable and valid measurement instrument [40].

\section{Manipulation checks}

\section{Future Expectancies}

The Future Expectancies Scale [FEX; 30] was administered to assess positive and negative future expectancies. The FEX consists of 20 statements regarding positive (e.g., 'people will admire you' or 'you will be able to cope easily with pressure') and negative (e.g., 'things will not turn out as you had hoped' or 'you will have health problems') future events. There are 10 positive and 10 negative items; that cover 5 different domains (work, health, personal, social and general). Participants rated the likelihood that they would experience the specific events on a 7-point Likert scale, ranging from 1 (not at all likely to occur) to 7 (extremely likely to occur). Higher scores reflect a higher estimated likelihood of positive (FEX-Pos) or negative (FEX-Neg) future events, with scores ranging from 10 to 70 . The internal consistency has previously been demonstrated to be satisfactory [30].

\section{Positive and Negative mood}

The Positive and Negative Affect Schedule [PANAS; 63] is a 20-item self-report measure of positive (PA, 10 items) and negative (NA, 10 items) affect. Participants indicated the degree to which a certain feeling (e.g., anxious) was present at that moment on a 5-point Likert scale ranging from 1 (not at all) to 5 (extremely). Subscale scores can range from 10 to 50, with higher scores on NA items reflecting higher levels of subjective distress and sadness. By contrast, higher scores on the PA scores correspond to higher levels of pleasurable feelings. The PANAS has been demonstrated to be valid and reliable [19]. 


\section{Pain outcome measures}

Pain intensity

Pain intensity after the CPT/ WWCT was measured with a Visual Analogue Scale (VAS, $100 \mathrm{~mm}$ ) with the labels 'no pain at all' at one end and 'extreme pain' on the other. Participants rated their pain intensity after withdrawing their hand from the WWCT or CPT on a VAS that was presented on the computer.

\section{Pain tolerance}

Pain tolerance is a behavioural measure of endurance and is defined as the immersion duration in seconds from the moment that the hand is placed in the water until the moment the hand is withdrawn from the water.

\section{Procedure}

Participants signed an informed consent form after receiving specific information about the procedure of their condition (i.e. whether the water temperature was $2^{\circ} \mathrm{C}$ or $34^{\circ} \mathrm{C}$ ). Then they filled out the questionnaires, including the FEX, PANAS, LOT-R, and the PCS via computer.

Next, participants either received the BPS manipulation (optimism; $n=38$ ) or the TD manipulation (no-optimism; $n=36$ ). Then the FEX and the PANAS were administered a second time. Participants completed either the CPT $(n=37)$ until tolerance was reached or the WWCT ( $n=37$ ) with a pre-set immersion time of 1,2 , or 3 minutes. Following withdrawal of the hand from the water current pain intensity was rated on the VAS. Next, participants performed the operation-span task after which they were thanked for their participation and received the remuneration. Participants were debriefed via email when data collection for the study was completed.

\section{Data analyses}

Data were checked for normality and internal consistency of the FEX, LOT-R, PCS and the PANAS questionnaires was calculated. A two-way ANOVA (optimism condition $x$ pain) was conducted to check for baseline differences between conditions in age, pain catastrophizing (PCS), optimism (LOT-R, FEX) and positive and negative affect (PANAS).

Next, manipulation checks were conducted. First, the effectiveness of the optimism manipulation on changes in self-reported positive and negative future expectancies and positive and negative affect was tested with a repeated measure ANOVA with time (pre vs. post manipulation) as within subjects factor and optimism condition (BPS vs. TD) as between subjects factor. This analysis was followed-up within each condition with paired samples t-tests. Second, to check whether the pain manipulation was successful, an independent samples t-test (pain vs. no pain) was conducted with pain intensity as 
dependent variable. In addition, because a previous study showed that the BPS manipulation decreased reported pain intensity during the cold pressor test [30], differences in pain intensity scores and pain tolerance between the BPS and TD condition were examined with an independent samples t-test within the pain condition only.

The main analysis consisted of a 2 (optimism condition: BPS vs. TD) $\times 2$ (pain condition: pain vs. no-pain) ANOVA to test the hypothesized interaction effect of pain and optimism on executive task performance. Participants not reaching pain tolerance within the maximum immersion period of three minutes were excluded from this analysis, because these participants may not experience self-regulatory fatigue. Additionally, participants who failed to achieve the pre-set accuracy rate of $85 \%$ on the operationspan task were excluded from this analysis. Planned follow-up analyses were conducted to test the hypothesis that pain has a deteriorating effect on cognitive task performance in the TD condition, but not in the BPS condition.

All analyses were repeated with baseline positive and negative affect, dispositional optimism and pain catastrophizing as covariates in separate analyses. Because these analyses yielded similar results, only the analyses without covariates will be reported. In addition, repeating the analyses while including the six non-native Dutch speakers did not alter the pattern of results.

\section{RESULTS}

\section{Baseline descriptives}

Age, the internal consistency and mean questionnaires scores of the participants $(N=74)$ are presented in Table 1 per condition. Supporting successful randomization, two-way ANOVAs did not reveal significant differences in age, positive and negative affect, dispositional optimism, or pain catastrophizing at baseline.

\section{Optimism (BPS) manipulation check}

The results of the repeated measures ANOVAs revealed a significant time $x$ optimism condition interaction for positive future expectancies $\left(F(1,72)=7.76, p=.007, n p^{2}=\right.$ $.10)$, negative future expectancies $\left(F(1,72)=7.29, p=.009, n p^{2}=.09\right)$, and positive affect $\left(F(1,72)=10.06, p=.002, n p^{2}=.12\right)$. For negative affect, only the main effect of time was significant $\left(F(1,72)=13.01, p=.001, n p^{2}=.15\right)$. Table 2 presents the results of the follow-up paired samples t-test. After receiving the BPS manipulation participants reported significantly more positive future expectancies on the FEX-pos and significantly less negative future expectancies on the FEX-neg and less negative affect on the PANASNA. Furthermore, a trend towards significantly more positive affect on the PANAS-PA was found. Participants who received the TD manipulation reported a significant de- 
crease in positive and negative affect on the PANAS. These results replicate previous findings that used this optimism manipulation [30; 41].

\section{Pain (CPT) manipulation check}

An independent samples t-test revealed a significant difference in pain intensity $(t(72)=$ $20.43, p<.001, d=4.82,95 \% \mathrm{Cl}$ of $d[3.91,5.73])$. Participants in the pain condition reported significantly higher pain $(M=67.89, S D=19.27)$ than participants in the nopain condition $(M=1.61, S D=4.34)$.

\section{Pain intensity}

Within the pain condition, a t-test for independent groups was used to compare reported pain intensity of participants in the BPS and TD condition. Participants in the BPS condition $(M=68.80, S D=19.70)$ did not report lower pain intensity compared to participants in the TD condition $(M=66.82, S D=19.30)$ with $t(35)=0.31, p=.76, d=.10$, $95 \% \mathrm{Cl}$ of $d[-0.57,0.76]$.

\section{Pain tolerance}

Similar to pain intensity, an independent samples t-test was conducted within the pain condition, to compare pain tolerance of participants in the BPS and TD condition. Participants in the BPS condition $(M=72.40, S D=57.19)$ did not significantly differ in pain tolerance compared to participants in the TD condition $(M=67.18, S D=56.34)$, with $t$ (35) $=0.28, p=.78, d=.09,95 \% \mathrm{Cl}$ of $d[-0.57,0.75]$.

Although we aimed to match the average immersion time in the no-pain condition to those in the pain condition, immersion times were significantly longer in the no-pain condition $(M=115.14, S D=55,46$ vs. $M=70.00, S D=56.07, t(72)=3.48, p=.001, d=$ $.82,95 \% \mathrm{Cl}$ of $d[0.33,1.31])$.

\section{Executive task performance}

Seven participants ( 5 males) in the pain condition were excluded from the analyses of executive task performance, because they reached the preset tolerance time of 3 minutes ( 4 in the BPS condition, 3 in the TD condition) and therefore may not have experienced self-regulatory fatigue. Moreover, one participant (TD and no-pain condition) was excluded because the pre-set accuracy level of $85 \%$ for the processing component of the operation-span task was not obtained (see measures for details).

A 2 (optimism condition: BPS vs. TD) $\times 2$ (pain condition: pain vs. no pain) ANOVA with executive task performance (PCU score) as dependent variable revealed a significant optimism $x$ pain interaction effect $\left(F(1,62)=5.10, p=.03, n p^{2}=.08\right)$. Planned 
follow-up analyses demonstrated that, pain had a significant deteriorating effect on executive task performance in participants in the TD and pain condition $(M=0.67, S D=$ 0.12 ) compared to participants in the TD and no-pain condition $(M=0.79, S D=0.11)$ with $t(30)=-2.90, p=.01, d=1.08,95 \% \mathrm{Cl}$ of $d[0.32,1.84]$. Of crucial importance, and confirming our second hypothesis, the deteriorating effect of pain on executive task performance was not present when participants received the BPS manipulation. Participants in the BPS and pain condition $(M=0.77, S D=0.11)$ did not significantly differ with regards to their executive task performance when compared to participants in the BPS and no-pain condition $(M=0.76, S D=0.10)$ with $t(32)=.11, p=.91, d=.10,95 \% \mathrm{Cl}$ of $d$ $[-0.59,0.79]$. The results per condition are displayed in Figure 1.

We repeated the analyses including the 7 participants who did not reach pain tolerance within the 3 minute immersion period. Although the optimism $x$ pain interaction did not reach significance $\left(F(1,69)=2.54, p=.12, n p^{2}=.04\right)$, the planned follow-up analyses within conditions showed a similar pattern as the main analyses: pain deteriorated executive task performance in participants in the TD condition (pain: $M=0.69, S D$ $=0.12$; no pain: $M=0.79, S D=0.11 ; t(33)=-2.50, p=.02, d=.90,95 \% \mathrm{Cl}$ of $d$ $[0.18,1.62]$ ) but not in the BPS condition (pain: $M=0.75, S D=0.11$; no-pain condition: $M=0.76, S D=0.10 ; t(36)=-0.45, p=.66, d=.10,95 \% \mathrm{Cl}$ of $d[-0.55,0.75])$.

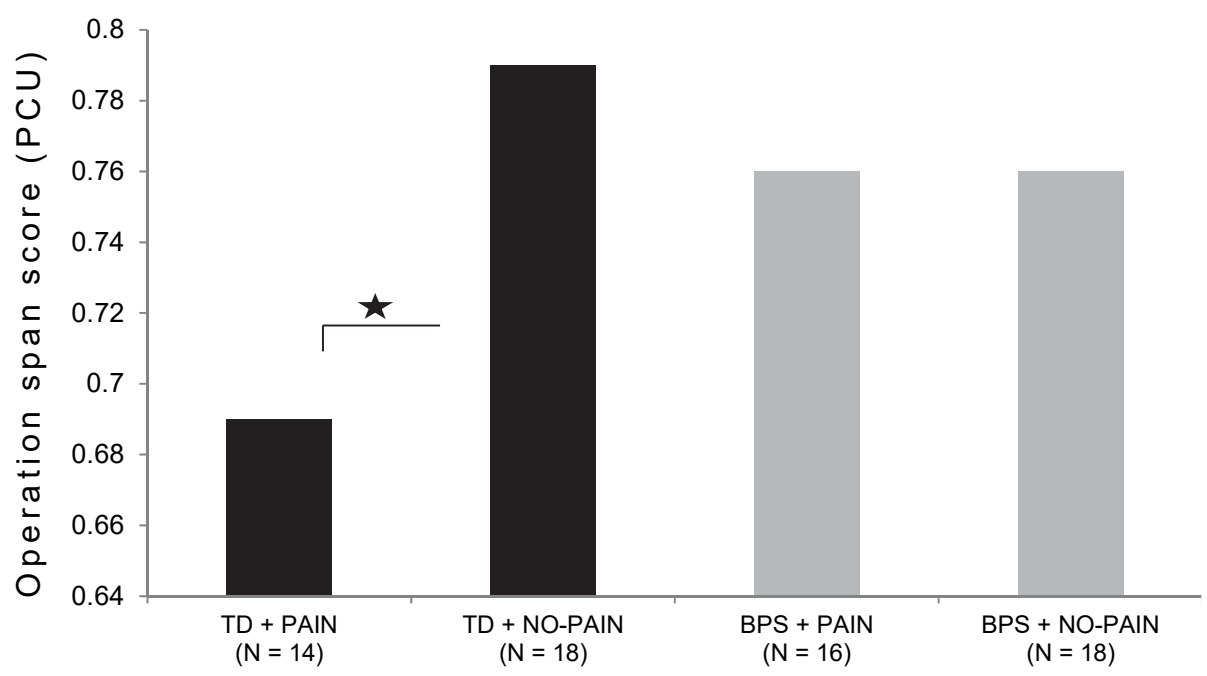

Figure 1: results on the operation-span task (PCU) per condition represents a significance level of $p<.05$. 

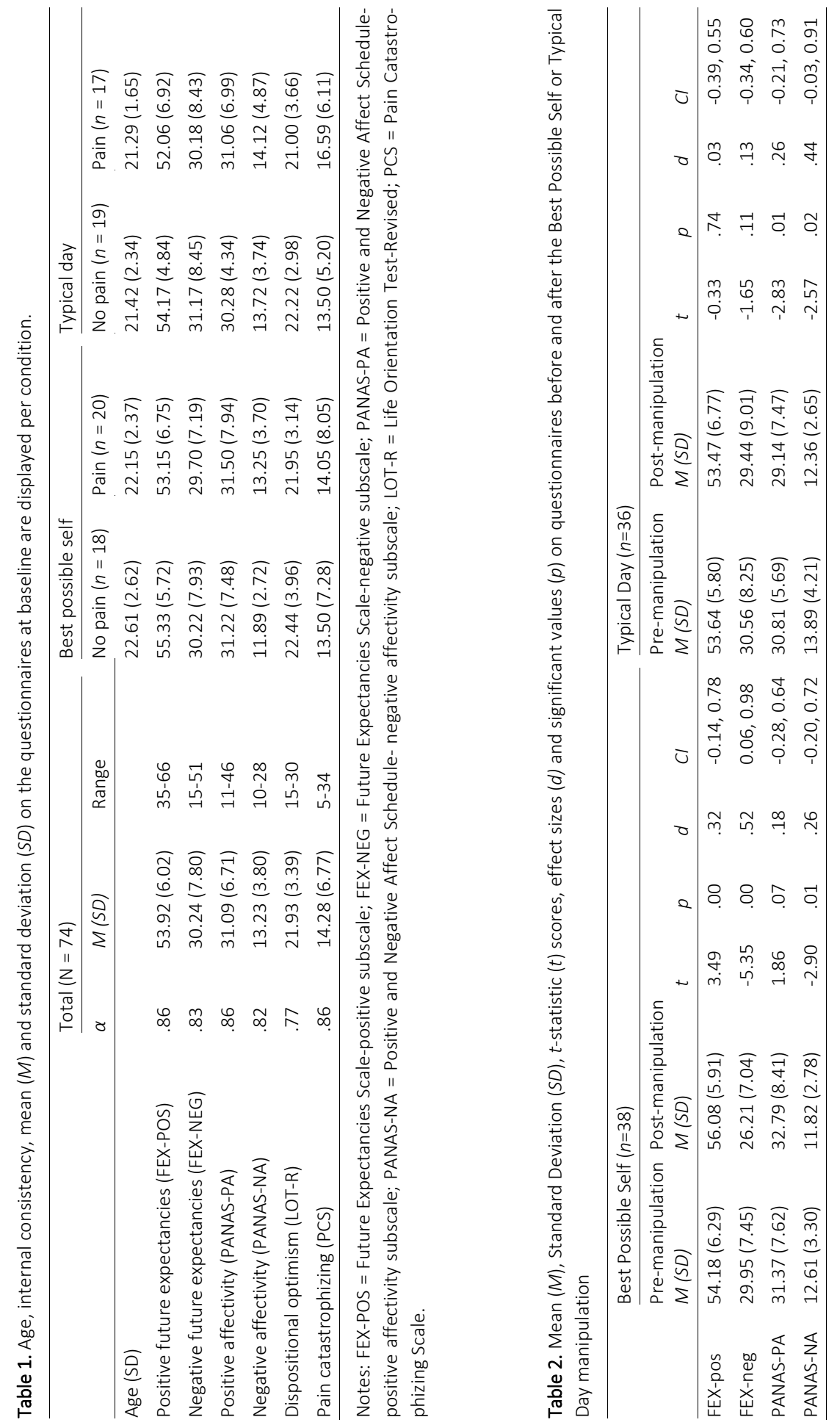


\section{DISCUSSION}

The results of the present study demonstrate that experimentally induced pain has a sustained deteriorating effect on subsequent executive task performance, and that inducing a temporary optimistic state can abolish this sustained deteriorating effect of pain on executive task performance.

Prior studies have demonstrated that pain interrupts attention and interferes with task performance predominantly by presenting a pain stimulus while simultaneously performing an executive functioning task $[14 ; 38]$. In contrast, this study presented the executive functioning task after enduring a painful stimulus to examine whether pain has sustained deteriorating effects on subsequent task performance. As hypothesized, the results show that pain has sustained deteriorating effects, which may reflect selfregulatory fatigue. When an individual is confronted with a pain experience, selfregulatory resources are directed towards the pain in order to cope with this aversive experience. However, directing these resources towards the pain demand will render them unavailable for additional demands, causing self-regulation resources to be fatigued and task performance to decline $[7 ; 8 ; 28]$.

Although we assume that the deteriorating effect of pain on executive functioning reflects self-regulatory fatigue, alternative explanations for the observed sustained deteriorating effect of pain are possible. As the time period between the pain manipulation and executive working memory task was relatively short, the experience of residual pain could account for the deterioration in task performance. However, the cold pressor task has the advantage that pain rapidly decreases following stimulus termination [24]. Alternatively, acute stress may have caused the deterioration in executive task performance. Higher cortisol levels have been associated with larger decrements in executive task performance following a cold pressor task [49].

The primary purpose of this study was to examine whether optimism can protect against the sustained deteriorating effects of pain on executive task performance. A temporary optimistic state was induced with the Best Possible Self (BPS) manipulation, which entails a writing and visualization exercise [17, 22]. Although optimism has been defined as an enduring trait, optimism levels can change over time [3; 8]. Previously it has been shown that daily imagery of BPS over a period of two weeks lead to sustained increases in optimism. This increase in optimism remained significant after controlling for positive affect and was not moderated by initial levels of dispositional optimism [37]. Using a single session of BPS writing and imagery, current results replicate prior findings $[30 ; 41]$ in that the manipulation leads to significantly higher levels of positive affect and future expectancies and a decrease of negative future expectancies. Importantly, confirming our second hypothesis, the deteriorating effect of pain on executive task performance was not present in participants that received the optimism manipulation. This finding is indicative of the fact that optimism acts as a protective factor that may en- 
hance self-regulatory capacity, abolishing the sustained deterioration effect of pain on executive task performance.

These findings might have clinical implications for patients with chronic pain. It has been proposed that chronic pain patients may suffer from chronic self-regulatory fatigue, causing problems in every domain that requires self-regulation [54]. Being able to accurately plan, organize, inhibit and alter behaviour, emotions, and cognitions are essential abilities for individuals to function in daily life. Hence, increasing selfregulatory capacity will enable an individual with chronic pain to rely less on others, restoring their sense of independence potentially reducing self-perceived burden among chronic pain patients [29]. When chronic pain patients do in fact experience chronic self-regulatory fatigue, it is essential to try and restore self-regulatory capacity, perhaps by interventions designed to enhance optimism and positive affect. Possible interventions are acceptance and commitment therapy [56; 61], mindfulness-based cognitive therapy $[11 ; 20]$, positive psychotherapy [27] or implementing positive psychology exercises $[10 ; 43 ; 51 ; 52]$ in current treatment approaches such as cognitivebehavioural therapy [32].

Previous studies showed that optimism increases the likelihood of goal achievement, as optimists tend to continue displaying effort to obtain their goals, even when confronted with pain $[1 ; 16 ; 21]$. One might argue that this higher tendency to pursue goal achievement may in fact be potentially harmful for chronic pain patients. Pain itself often cannot be remediated, thus pursuing the goal to abolish the pain experience may lead to disappointment and increased likelihood of experiencing goal conflict [58]. Goal conflict arises when pursuing one goal is at the cost of other goals [58] and can lead to decrements in overall well-being [26; 45]. However, more optimistic individuals are able to cope with this conflict more efficiently and are able to disengage from a goal that is evaluated as unattainable $[4 ; 16 ; 44 ; 50]$.

Some limitations should be taken in consideration when interpreting the current results. Although randomization was applied and participants did not differ on individual variables, such as dispositional optimism or pain catastrophizing, it cannot be excluded that participants may have differed on their executive functioning ability, which may have confounded the results. In order to eliminate this confounding, future research should include a pre-measure of executive functioning. Additionally, recall duration of the operation-span task was not measured, which may have introduced a betweensubjects factor that cannot be controlled for in the analyses. Furthermore, in addition to optimism, the BPS manipulation also increased positive affect. Therefore, it is not possible to disentangle the protective effects of these two interrelated constructs on paininduced impairments in executive task performance.

It should be noted that the current study did not replicate the previous finding that the BPS manipulation reduced pain intensity reports after the pain manipulation [30]. Although both studies used the CPT as pain manipulation, these studies differed on two procedural aspects, which may have caused the lack of replication of the previous find- 
ing. First, in the study of Hanssen and colleagues [30] a pre-determined fixed immersion time of 1 minute had to be achieved as opposed to reaching pain tolerance in the present study. Second, we only assessed pain intensity once after immersion, compared to several pain intensity assessments during and after immersion in the study by Hanssen and colleagues [30]. The very act of rating pain intensity can influence subsequent pain intensity ratings [5].

In conclusion, the present study shows that pain deteriorates performance on a subsequent executive functioning task. Additionally, a brief optimism induction was able to significantly abolish the sustained deteriorating effect of pain on executive functioning. We aim to extend these findings in chronic pain patients to examine whether optimism can be utilized to diminish the impact of pain on executive functioning, when pain itself often cannot be remediated. 


\section{LITERATURE}

[1] Affleck G, Tennen H, Zautra A, Urrows S, Abeles M, Karoly P. Women's pursuit of personal goals in daily life with fibromyalgia: A value-expectancy analysis. Journal of Consulting and Clinical Psychology 2001;69(4):587-596.

[2] Allison PJ, Guichard C, Gilain L. A prospective investigation of dispositional optimism as a predictor of health-related quality of life in head and neck cancer patients. Quality of Life Research: An International Journal of Quality of Life Aspects of Treatment, Care \& Rehabilitation 2000;9(8):951-960.

[3] Apkarian AV, Sosa Y, Krauss BR, Thomas PS, Fredrickson BE, Levy RE, Harden RN, Chialvo DR. Chronic pain patients are impaired on an emotional decision-making task. Pain 2004;108(1-2):129-136.

[4] Aspinwall LG, Richter L. Optimism and self-mastery predict more rapid disengagement from unsolvable tasks in the presence of alternatives. Motivation and Emotion 1999;23(3):221-245.

[5] Barceló F, Knight RT. Both random and perseverative errors underlie WCST deficits in prefrontal patients. Neuropsychologia 2002;40(3):349-356.

[6] Basso MR, Lowery N, Ghormley C, Bornstein RA. Practice effects on the Wisconsin Card Sorting Test-64 Card version across 12 months. The Clinical Neuropsychologist 2001;15(4):471-478.

[7] Baumeister RF, Heatherton TF, Tice DM. Losing control: Academic Press San Diego, CA, 1994.

[8] Baumeister RFHTF. Self-Regulation Failure: An Overview. Psychological Inquiry 1996;7(1):1.

[9] Berger A, Kofman O, Livneh U, Henik A. Multidisciplinary perspectives on attention and the development of self-regulation. Progress in Neurobiology 2007;82(5):256-286.

[10] Boselie JJ, Vancleef LM, Smeets T, Peters ML. Increasing optimism abolishes pain-induced impairments in executive task performance. Pain 2014;155(2):334-340.

[11] Boselie JJLM, Vancleef LMG, Smeets T, Peters ML. Increasing optimism abolishes pain-induced impairments in executive task performance. $\operatorname{PAIN}^{\circledR}(0)$.

[12] Brenes GA, Rapp SR, Rejeski WJ, Miller ME. Do optimism and pessimism predict physical functioning? Journal of Behavioral Medicine 2002;25(3):219-231.

[13] Bridgett DJ, Oddi KB, Laake LM, Murdock KW, Bachmann MN. Integrating and differentiating aspects of self-regulation: Effortful control, executive functioning, and links to negative affectivity. Emotion 2013;13(1):47-63.

[14] Buhle J, Wager TD. Performance-dependent inhibition of pain by an executive working memory task. Pain 2010;149(1):19-26.

[15] Carver CS, Scheier MF. On the self-regulation of behavior. New York, NY US: Cambridge University Press, 1998.

[16] Carver CS, Scheier MF, Segerstrom SC. Optimism. Clinical Psychology Review 2010;30(7):879-889.

[17] Chen AC, Dworkin SF, Haug J, Gehrig J. Human pain responsivity in a tonic pain model: Psychological determinants. Pain 1989;37(2):143-160.

[18] Conway ARA, Kane MJ, Bunting MF, Hambrick DZ, Wilhelm O, Engle RW. Working memory span tasks: A methodological review and user's guide. Psychonomic Bulletin \& Review 2005;12(5):769-786.

[19] Crawford JR, Henry JD. The Positive and Negative Affect Schedule (PANAS): Construct validity, measurement properties and normative data in a large non-clinical sample. British Journal of Clinical Psychology 2004;43(3):245-265.

[20] Diamond A. Executive functions. Annual review of psychology 2013;64:135-168.

[21] Duke J, Leventhal H, Brownlee S, Leventhal EA. Giving up and replacing activities in response to illness. The Journals of Gerontology: Series B: Psychological Sciences and Social Sciences 2002;57B(4):P367P376.

[22] Eccleston C. Chronic pain and attention: A cognitive approach. British Journal of Clinical Psychology 1994;33(4):535-547.

[23] Eccleston C, Crombez G. Pain demands attention: A cognitive-affective model of the interruptive function of pain. Psychological Bulletin 1999;125(3):356-366. 
[24] Edens JL, Gil KM. Experimental induction of pain: Utility in the study of clinical pain. Behavior Therapy 1995;26(2):197-216.

[25] Engle RW, Cantor J, Carullo JJ. Individual differences in working memory and comprehension: A test of four hypotheses. Journal of Experimental Psychology: Learning, Memory, and Cognition 1992;18(5):972992.

[26] Falleti MG, Maruff P, Collie A, Darby DG. Practice effects associated with the repeated assessment of cognitive function using the CogState battery at 10-minute, one week and one month test-retest intervals. Journal of Clinical and Experimental Neuropsychology 2006;28(7):1095-1112.

[27] Glass JM. Cognitive dysfunction in fibromyalgia syndrome. Journal of Musculoskeletal Pain 2010;18(4):367-372.

[28] Gopher D, Armony L, Greenshpan Y. Switching tasks and attention policies. Journal of Experimental Psychology: General 2000;129(3):308-339.

[29] Greve KW, Love JM, Sherwin E, Mathias CW, Ramzinski P, Levy J. Wisconsin Card Sorting Test in chronic severe traumatic brain injury: Factor structure and performance subgroups. Brain Injury 2002;16(1):2940.

[30] Hanssen MM, Peters ML, Vlaeyen JW, Meevissen YM, Vancleef LM. Optimism lowers pain: Evidence of the causal status and underlying mechanisms. Pain 2013;154(0):53-58.

[31] Hofmann W, Schmeichel BJ, Baddeley AD. Executive functions and self-regulation. Trends in Cognitive Sciences 2012;16(3):174-180.

[32] In Den Bosch-Meevissen Y, Peters ML, Alberts HJ. Dispositional optimism, optimism priming, and prevention of ego depletion. European Journal of Social Psychology 2014;44(6):515-520.

[33] Kane M, Engle R. The role of prefrontal cortex in working-memory capacity, executive attention, and general fluid intelligence: An individual-differences perspective. Psychonomic Bulletin \& Review 2002;9(4):637-671.

[34] Kaplan S, Berman MG. Directed Attention as a Common Resource for Executive Functioning and SelfRegulation. Perspectives on Psychological Science 2010;5(1):43-57.

[35] King LA. The health benefits of writing about life goals. Personality and Social Psychology Bulletin 2001;27(7):798-807.

[36] Lehto J. Are Executive Function Tests Dependent on Working Memory Capacity? Quarterly Journal of Experimental Psychology: Section A 1996;49(1):29-50.

[37] Meevissen YMC, Peters ML, Alberts HJEM. Become more optimistic by imagining a best possible self: Effects of a two week intervention. Journal of Behavior Therapy and Experimental Psychiatry 2011;42(3):371-378.

[38] Moore DJ, Keogh E, Eccleston C. The interruptive effect of pain on attention. The Quarterly Journal of Experimental Psychology 2012;65(3):565-586.

[39] Moore DJ, Keogh E, Eccleston C. The effect of threat on attentional interruption by pain. Pain 2013;154(1):82-88.

[40] Osman A, Barrios FX, Gutierrez PM, Kopper BA, Merrifield T, Grittmann L. The Pain Catastrophizing Scale: Further psychometric evaluation with adult samples. Journal of Behavioral Medicine 2000;23(4):351365.

[41] Peters ML, Flink IK, Boersma K, Linton SJ. Manipulating optimism: Can imagining a best possible self be used to increase positive future expectancies? The Journal of Positive Psychology 2010;5(3):204-211.

[42] Rainville P, Feine JS, Bushnell MC, Duncan GH. A psychophysical comparison of sensory and affective responses to four modalities of experimental pain. Somatosensory \& motor research 1992;9(4):265-277.

[43] Rashid T, Ostermann RF. Strength-based assessment in clinical practice. Journal of clinical psychology 2009;65(5):488-498.

[44] Rasmussen HN, Wrosch C, Scheier MF, Carver CS. Self-regulation processes and health: the importance of optimism and goal adjustment. J Pers 2006;74(6):1721-1747.

[45] Reimers S, Maylor EA. Task Switching Across the Life Span: Effects of Age on General and Specific Switch Costs. Developmental Psychology 2005;41(4):661-671. 
[46] Scheier MF, Carver CS. Optimism, coping, and health: Assessment and implications of generalized outcome expectancies. Health Psychology 1985;4(3):219-247.

[47] Scheier MF, Carver CS, Bridges MW. Distinguishing optimism from neuroticism (and trait anxiety, selfmastery, and self-esteem): A reevaluation of the Life Orientation Test. Journal of Personality and Social Psychology 1994;67(6):1063-1078.

[48] Schmitz U, Saile H, Nilges P. Coping with chronic pain: Flexible goal adjustment as an interactive buffer against pain-related distress. Pain 1996;67(1):41-51.

[49] Schoofs D, Wolf OT, Smeets T. Cold pressor stress impairs performance on working memory tasks requiring executive functions in healthy young men. Behavioral Neuroscience 2009;123(5):1066-1075.

[50] Segerstrom SC, Nes LS. When Goals Conflict But People Prosper: The Case of Dispositional Optimism. J Res Pers 2006;40(5):675-693.

[51] Seligman ME, Steen TA, Park N, Peterson C. Positive psychology progress: empirical validation of interventions. American Psychologist 2005;60(5):410.

[52] Sheldon KM, Lyubomirsky S. How to increase and sustain positive emotion: The effects of expressing gratitude and visualizing best possible selves. The Journal of Positive Psychology 2006;1(2):73-82.

[53] Smith EE, Jonides J. Storage and executive processes in the frontal lobes. Science 1999;283(5408):16571661.

[54] Solberg Nes L, Carlson CR, Crofford LJ, de Leeuw R, Segerstrom SC. Self-regulatory deficits in fibromyalgia and temporomandibular disorders. Pain 2010;151(1):37-44.

[55] Solberg Nes L, Carlson CR, Crofford LJ, de Leeuw R, Segerstrom SC. Individual differences and selfregulatory fatigue: optimism, conscientiousness, and self-consciousness. Personality and Individual Differences 2011;50(4):475-480.

[56] Solberg Nes L, Carlson CR, Crofford LJ, Leeuw Rd, Segerstrom SC. Self-regulatory deficits in fibromyalgia and temporomandibular disorders. Pain 2010;151(1):37-44.

[57] Solberg Nes L, Roach AR, Segerstrom SC. Executive functions, self-regulation, and chronic pain: A review. Annals of Behavioral Medicine 2009;37(2):173-183.

[58] Solberg Nes L, Segerstrom SC. Dispositional Optimism and Coping: A Meta-Analytic Review. Personality and Social Psychology Review 2006;10(3):235-251.

[59] Solberg Nes L, Segerstrom SC, Sephton SE. Engagement and Arousal: Optimism's Effects During a Brief Stressor. Personality and Social Psychology Bulletin 2005;31(1):111-120.

[60] Sullivan MJL, Bishop SR, Pivik J. The Pain Catastrophizing Scale: Development and validation. Psychological Assessment 1995; 7(4):524-532.

[61] Thorsell J, Finnes A, Dahl J, Lundgren T, Gybrant M, Gordh T, Buhrman M. A comparative study of 2 manual-based self-help interventions, acceptance and commitment therapy and applied relaxation, for persons with chronic pain. The Clinical journal of pain 2011;27(8):716-723.

[62] Turner ML, Engle RW. Is working memory capacity task dependent? Journal of Memory and Language 1989;28(2):127-154.

[63] Watson D, Clark LA, Tellegen A. Development and validation of brief measures of positive and negative affect: The PANAS scales. Journal of Personality and Social Psychology 1988;54(6):1063-1070.

[64] Wrosch C, Scheier MF. Personality and quality of life: The importance of optimism and goal adjustment. Quality of Life Research: An International Journal of Quality of Life Aspects of Treatment, Care \& Rehabilitation 2003;12(Suppl1):59-72. 


\section{Chapter three}

\section{The effects of experimental pain and induced optimism on working memory task performance}

Published as: Boselie JJLM, Vancleef LM, Peters ML. The effects of experimental pain and induced optimism on working memory task performance. Scandinavian Journal of Pain 2016; 12:25-32. 


\section{ABSTRACT}

Pain can interrupt, interfere, and deteriorate executive task performance. Optimism, the tendency to expect that good things happen in the future, has been shown to protect against the pain-induced deterioration in executive task performance. In two successive experiments, we tested whether experimental pain negatively impacts on subsequent or concurrent working memory task performance and whether this can be reduced by the induction of a temporary optimistic state. The 2-back task was used to measure working memory functioning. Optimism was induced by means of a writing and visualization exercise. Study 1 examined working memory task performance after pain induction by means of the cold pressor test. Study 2 examined working memory task performance during heat pain stimulation. Results indicated that cold pressor pain did not impair subsequent task performance (study 1) but concurrent painful heat stimulation did significantly deteriorate task performance (study 2). The optimism manipulation did not counteract this pain-induced working memory task performance deterioration. 


\section{GENERAL INTRODUCTION}

Persistent pain may not only lead to physical disability, but also to difficulties in executive functioning. Executive functioning, encompassing the ability to actively monitor behaviour, inhibit or facilitate certain responses, and optimise one's approach to unfamiliar circumstances, is necessary for accurate task performance [18; 30; 43]. Several studies have demonstrated that experimentally induced pain impairs concurrent $[6 ; 10$ 12; 31] and subsequent executive task performance [5; 41]. Moreover, persistent pain has been shown to impair executive functioning in chronic pain patients [3; 33]. These pain-related deteriorations have been reported on various aspects of executive functioning, including working memory performance, task switching and inhibition of dominant responses [31; 33; 49].

Optimism, the tendency to expect that good things will happen in the future [7], has been associated with beneficial coping strategies [36; 44] and applying different coping strategies more flexibly [36; 44]. But also with more goal attainment despite pain [1; 13], reduced pain intensity [19; 27], better and faster recovery and less rehospitalisation after surgery $[8 ; 23 ; 27 ; 39 ; 40]$. Recently, we have demonstrated that optimism can diminish the deteriorating effect of experimentally induced pain on working memory performance [5] as measured with the operation-span task. In this study, optimism was manipulated by a best possible self-manipulation (BPS) [35] after which participants received either the painful cold pressor task or a non-painful task. Subsequent performance on the operation-span task was worse for participants in the painful cold pressor condition, but not when they had received the optimism manipulation [5].

This paper describes two studies that were set up to further examine the protective effect of manipulated optimism on pain-induced working memory task performance deterioration, and to examine whether this generalizes to a different working memory task, i.e. the 2-back task [26]. Both the 2-back and operation-span task are considered to measure updating and monitoring of working memory representations [30]. In study 1 , the 2-back task was administered after completion of the cold pressor test. Study 2 used concurrent heat pain stimulation during 2-back task performance. Concurrent heat pain has previously been demonstrated to impair 2-back task performance [31; 32]. It was hypothesized that (i) pain will decrease subsequent (study 1) and concurrent (study 2) 2-back task performance and (ii) an optimism induction counteracts the deteriorating effect of pain on working memory task performance. 


\section{STUDY 1}

\section{METHODS}

\section{Participants}

A total of 81 (17 males; mean age $=21.35, S D=4.28$ ) healthy undergraduates from Maastricht University participated in this study. Exclusion criteria were suffering from a chronic pain disorder, cardiovascular disease, Reynaud disease or pain complaints at the moment of testing. This study had a 2 (optimism: optimism vs. no-optimism) $\times 2$ (pain: pain vs. no-pain) $\times 2$ (time: pre-score vs. post-score on the 2-back task) mixed factorial design. Participants were randomly assigned to one of the four conditions: (i) optimism and pain ( $n=21,5$ males, mean age $=20.43$, SD $=2.64$ ), (ii) optimism and no-pain ( $n=$ 20, 5 males, mean age $=21.55, \mathrm{SD}=3.25)$, (iii) no-optimism and pain $(n=20,3$ males, mean age $=22.40, \mathrm{SD}=7.19)$ and (iv) no-optimism and no-pain $(n=20,4$ males, mean age $=21.05, S D=2.28$ ). During recruitment, participants were informed that they would experience a procedure that could be perceived as unpleasant. Participation was rewarded with a gift voucher of 10 Euro or course credits. The local ethical committee of the Faculty of Psychology and Neuroscience, Maastricht University approved the study protocol.

\section{Manipulations}

\section{Optimism manipulation}

Optimism was induced by the Best Possible Self (BPS) manipulation, a positive future thinking technique based on work by King [24]. Previous research has proven the effectiveness of the BPS in increasing positive affect, positive future expectancies and decreasing negative affect and negative future expectancies [5; 19; 35]. Participants either received the BPS manipulation, which required them to write about a life in the future where everything turned out for the best, or the neutral manipulation, which consisted of writing about a Typical Day (TD).

The instructions were as follows [35]: BPS condition, "'Think about your best possible self' means that you imagine yourself in the future, after everything has gone as well as it possibly could. You have worked hard and succeeded at accomplishing all the goals of your life. Think of this as the realization of your dreams, and that you have reached your full potential."' TD condition, "'Think about your typical day' means that you take notice of ordinary details of your day that you usually don't think about. These might include particular classes or meetings you attend to, people you meet, things you do, typical thoughts you have during the day. Think of this as moving through your typical day, hour after hour." 
Both manipulations followed the same procedure: 1 minute thinking about what to write followed by uninterrupted writing for 15 minutes and ending with 5 minutes of imagining the story that was just written. Instructions were given both verbally and in writing.

\section{Pain manipulation}

In the pain condition ( $n=41$ ) the Cold Pressor Task (CPT) was used as a painful stimulus. The water tank in which the CPT was performed consisted of a plexiglas box (JULABO Labortechnik $\mathrm{GmbH}$, Seelbach, Germany) filled with water that was kept constant at $2^{\circ} \mathrm{C}$ using an electrical immersion cooler (JULABO type FT200) and a circulation pump (JULABO type ED-19). Participants were instructed to submerge their right hand as long as possible (pain tolerance) but were allowed to stop the task at any point without any consequences.

Participants in the no-pain condition $(n=40)$ followed the same procedure, with the exception that the water temperature was held constant at a comfortable $34^{\circ} \mathrm{C}$ (warm water control task; WWCT). Furthermore, to match immersion times of the CPT, participants were randomly requested to remove their hand from the water at 1,2 , or 3 minutes after immersion.

\section{Measures}

Working memory: 2-back task

The 2-back task is considered as a working memory task that predominantly measures the ability to monitor and update working memory representation [20; 22]. In the 2back task, stimuli (i.e., letters) are presented one-by-one on a computer screen, and participants have to indicate for each stimulus whether this stimulus corresponds to the stimulus that was presented 2 stimuli ago. For example, when the stimuli sequence is TH-P-J-P the participant will only respond with 'yes' to the last letter, as the letter P was also presented two letters ago. All the other letters in this example sequence have to be categorized by the participant as 'no'.

The stimuli consisted of the consonants of the alphabet, excluding the letter $x$. The letters were black, bold and presented in Arial with a font size of 70 . Within one trial, a single letter was presented centrally on screen for $500 \mathrm{~ms}$, followed by a blank screen for 1500 ms. The response had to be given within these 2000 ms. The next trial (i.e. presentation of letter) started when 2000 ms (letter + blank screen) had passed. Responses were provided on a two button response box. Participants had to press the left button if the current letter was not presented two letters ago (i.e. 'no') and the right button if the current letter matched (i.e. 'yes'). The word yes and no were visually presented below the corresponding buttons on the response box. Participants were instructed, to rest their index fingers on the response buttons to ensure a fast response. 
The 2-back task consisted of a practice phase and a testing phase. The practice phase consisted of 20 trials. To ensure that participants understood the task instructions, we added the possibility to repeat the practice phase. After the practice phase, an accuracy percentage was displayed centrally on the screen. If the percentage fell below $50 \%$ chance level, participants had to repeat the practice phase. When the accuracy percentage was between 50 and $65 \%$, the participant was given the choice to continue or repeat the practice phase. Participants continued immediately with the testing phase when the accuracy level was $65 \%$ or more. The testing phase of the task consisted of 90 trials, with 30 target letters (response: 'yes') and 60 non-target letters (response: 'no'). In the testing phase, we introduced a break between every block of 30 letters. The duration of the break was self-paced; the next block began when the participant either pressed the space bar or 'yes' on the response box.

Dependent variables in the task are hits (sum correctly identified targets), misses (sum missed targets), correct rejections (sum correctly identified non-targets), false alarms (sum non-targets identified as targets), accuracy percentage (summation hits and correct rejections percentage), and sensitivity accuracy (sum hits minus false alarms). Non-responses are not reported.

\section{Baseline questionnaires}

The Life Orientation Test-Revised (LOT-R) [38] was used to assess the level of dispositional optimism. The LOT-R consists of 10 items: 3 positively phrased items (e.g., 'I'm always optimistic about my future'), 3 negatively phrased items (e.g., 'I rarely count on good things happening to me') and 4 filler items (e.g., 'It's important for me to keep busy') that are rated on a 5-point Likert scale, ranging from 1 (strongly disagree) to 5 (strongly agree). The total LOT-R score is obtained by summation of the scores on the positively phrased items and the reversed scores on the negatively phrased items and ranges from 10 to 30. Higher scores reflect higher levels of dispositional optimism. The LOT-R has been demonstrated to be a reliable and valid measurement instrument [38].

Pain Catastrophizing was measured by the Pain Catastrophizing Scale (PCS) [46]. Participants indicate to what degree they experienced each of 13 stated thoughts and feelings while experiencing pain on a 5 - point Likert scale, ranging from 0 (not at all) to 4 (all the time). An example of an item is 'I keep thinking about how much it hurts'. The total PCS score is obtained by summing the responses of all the 13 items (scores range from 0 to 52). Higher scores on the PCS indicate greater pain catastrophizing [34]. The PCS has been found to be a reliable and valid measurement instrument [34].

\section{Manipulation checks}

Effectiveness of the optimism induction was assessed by means of the The Future Expectancies Scale (FEX) [19] and the Positive and Negative Affect Schedule (PANAS) [50]. 
The FEX measures positive and negative future expectancies. It consists of 20 statements about positive ( $n=10$; e.g., 'people will admire you') and negative ( $n=10$; e.g., 'things will not turn out as you had hoped") future events in 5 different domains (work, health, personal, social and general). Participants rate the likelihood that they will experience the specific events on a 7-point Likert scale, ranging from 1 (not at all likely to occur) to 7 (extremely likely to occur). Higher scores reflect a higher estimated likelihood of positive (FEX-Pos) or negative (FEX-Neg) future events, with scores ranging from 10 to 70. The internal consistency of the FEX has been demonstrated to be satisfactory [19].

The PANAS consists of 20 items that measure positive (PA, 10 items) and negative (NA, 10 items) affect. Participants indicate the degree to which a certain feeling is present at that moment on a 5-point Likert scale ranging from 1 (not at all) to 5 (extremely). Subscale scores can range from 10 to 50, with higher scores on NA items reflecting higher levels of emotional distress. In contrast, high PA scores correspond to experiencing more pleasurable feelings. The PANAS has been demonstrated to be valid and reliable [9].

To assess whether the pain manipulation was successful, Visual Analogue Scales (VAS) were administered to measure experienced pain intensity, and fear of pain. Each VAS was anchored 0 (no pain/ fear of pain at all) to 100 (extreme pain/ fear of pain).

\section{Procedure}

Participants first received information about the CPT and WWCT procedure (i.e. whether the water temperature was $2{ }^{\circ} \mathrm{C}$ versus $34^{\circ} \mathrm{C}$, respectively) and were informed that the procedure could be perceived as painful before they signed the informed consent. Then the FEX, PANAS, LOT-R and the PCS questionnaires were administered via computer. Subsequently, participants performed the practice phase and test phase of the 2back task (baseline) followed by a second administration of the PANAS via computer. Next, participants either received the BPS manipulation (optimism) or the TD manipulation (no-optimism) followed by administration of the FEX and the PANAS. Participants were then guided to another lab room by the experimenter for the CPT or WWCT manipulation. The pain manipulation was conducted in another lab to avoid that the noise as caused by the CPT/WWCT apparatus would exert an undesired influence on working memory task performance. Participants were instructed to submerge their right hand as long as possible (pain tolerance). Unknown to the participants, the maximum immersion duration was set at 3 minutes. If the 3 minutes maximum was reached, the experimenter signalled the participant to remove the hand from the water. In the no-pain condition, participants completed the WWCT with a pre-set immersion time of 1,2 , or 3 minutes. Immediately after immersion, participants rated the pain experience on the VAS's. Next, participants performed the 2-back task for a second time (post measurement) after which they were thanked for their participation and received their compen- 
sation. Participants were debriefed via e-mail after study completion. In total, the duration of the experimental lab session was approximately 1 hour.

\section{Data analyses}

Data were checked for a normal distribution and reliability analyses were performed on the FEX, LOT-R, PCS and the PANAS questionnaires. One-way analyses of variances (ANOVAs) were conducted to check for baseline differences between the four conditions ((i) BPS and pain (ii) BPS and no-pain (iii) TD and pain (iv) TD and no-pain) on selfreported pain catastrophizing (PCS), optimism (LOT-R, FEX), positive and negative affect (PANAS). Similarly, to check for baseline differences between conditions on 2-back outcome variables one-way ANOVAs were performed.

The effectiveness of the optimism manipulation on positive and negative affect and positive and negative future expectancies was tested with ANCOVAs with optimism condition (BPS vs TD) as between subjects factor and baseline scores of positive and negative affect (centered) and positive and negative future expectancies (centered) as covariates. The manipulation is successful when results show a significant main effect of optimism. This method of analysing is more powerful and precise than using repeated measures ANOVA in a randomized pre-post design [48].

The effectiveness of the pain manipulation was tested with one-way ANCOVAs with pain condition (CPT vs WWCT) as between subject variable and experienced pain ratings (i.e., intensity, fear of pain) as dependent variables. The PCS score (centered), CPT time (centered) and sex were entered as covariates, as high scores on the PCS, duration of pain and sex may influence pain intensity reports [14].

To test the hypotheses that pain deteriorates subsequent working memory task performance and optimism can counteract the negative impact of pain, $2 \times 2$ ANCOVAs with optimism and pain condition as between subject factors, 2-back performance variables (i.e., hits, misses, correct rejections, false alarms, accuracy percentage, sensitivity accuracy) as dependent variables and baseline 2-back task performance as covariates were conducted.

\section{RESULTS}

\section{Baseline descriptives}

The internal consistency (Cronbach's alpha) was satisfactory for all the questionnaires (range .71-.94). Although participants $(N=81)$ were randomly assigned to a condition, a one-way ANCOVA revealed a significant difference at baseline on the PCS questionnaire only $\left(F(3,77)=3.00, p=0.04, n p^{2}=.11\right)$. Pairwise comparisons showed that participants in the TD and CPT condition $(M=18.45, S D=6.75)$ reported significantly more 
pain catastrophizing than participants in the BPS and WWCT condition $(M=12.45, S D=$ 5.09), with $p=.01$. Comparisons between the TD and CPT group and the other two groups were not statistically significant at $p>.05$ (BPS and CPT $M=14.67$, SD = 5.15; TD and WWCT $M=14.75, S D=8.21$ ). As pain catastrophizing may influence pain intensity reports pain catastrophizing is added as a covariate to relevant subsequent analyses [29]. Results of the ANOVAs did not reveal baseline differences between the four conditions on the 2-back performance variables (all p-values $>$.05). We identified two participants as outliers as their scores deviated with more than 3 standard deviations from the overall mean on several 2-back performance variables, indicating a dominant response style bias (i.e. tendency to reject targets). These participants were removed from data analysis concerning working memory task performance. The remaining 79 participants (16 males) had a mean age of 21.3 years $(S D=4.33)$.

\section{Optimism manipulation check}

Corroborating earlier findings $[5 ; 19 ; 35]$ the ANCOVAs revealed a significant main effect of the optimism manipulation, controlling for the effect of baseline scores, on positive future expectancies $\left(F(1,78)=21.58, p=0.00, n p^{2}=.22\right)$, positive affect $(F(1,78=$ 27.52, $\left.p=0.00, n p^{2}=.26\right)$ and negative future expectancies $(F(1,78)=19.12, p=0.00$, $\left.\eta p^{2}=.20\right)$. The optimism main effect was not significant for negative affect $(F(1,78)=$ $\left.0.82, p=0.37, n p^{2}=.01\right)$. Participants in the BPS condition $(n=41)$ scored higher on positive future expectancies $(M=56.14, S D=3.68 \mathrm{vs} . M=53.43, S D=3.73)$ and positive affect $(M=33.53, S D=6.70$ vs. $M=27.73, S D=7.05)$, and scored lower on negative future expectancies $(M=25.30, S D=6.13$ vs. $M=29.14, S D=5.63)$ than participants in the TD condition $(n=40)$. Participants did not differ on negative affect $(M=13.09, S D=$ 3.54 vs. $M=12.58, S D=3.58)$.

\section{Pain manipulation check}

Supporting the effectiveness of the pain manipulation, results of the one-way ANCOVA, with PCS score, sex and CPT-time as covariates, showed a significant main effect of the pain manipulation on pain intensity $\left(F(1,76)=268.06, p<0.001, n p^{2}=.78\right)$ and fear of pain $\left(F(1,76)=17.70, p<0.001, n p^{2}=.19\right)$. Participants in the CPT condition $(n=41)$ reported more pain intensity $(M=59.98, S D=19.11$ vs. $M=2.20, S D=6.51)$ and more fear of pain $(M=27.10, S D=24.17$ vs. $M=5.07, S D=10.34)$ than participants in the WWCT condition ( $n=40$ ). The CPT time covariate was found to be significant in the model with experienced pain intensity as dependent variable only, with $F(1,76)=6.58$, $p=0.01, n p^{2} .08$. The covariates PCS score and sex were not significant in these analyses. 


\section{Working memory task performance}

First, we conducted several ANCOVAs with baseline 2-back score as covariates and 2back performance variables as dependent variables. Estimated mean and standard deviations of scores on the 2-back task are displayed per condition in Table 1. In contrast to our first hypothesis, the results did not support a main effect of pain condition on any of the dependent variables (all $p$ values $>$.24). As pain did not deteriorate task performance, it was not possible to examine whether optimism can be regarded as a protective factor against pain-induced executive task deterioration. Paired t-tests showed that 2-back performance improved over time (i.e., learning effect). Results of the paired t-tests are presented in Table 2. The main analysis was repeated once again in a sample that did not include the ten participants $(n=69)$ who reached the pre-set cold pressor task maximum and thus did not reach pain tolerance. Results were similar to the results as found in the whole sample.

Table 1. Estimated mean (M) and Standard Deviation (SD) scores on the 2-back dependent variables, displayed per condition.

\begin{tabular}{|c|c|c|c|c|}
\hline & \multicolumn{2}{|c|}{ Best Possible Self (optimism) } & \multicolumn{2}{|c|}{ Typical day (no-optimism) } \\
\hline & $\begin{array}{l}\text { Pain condition } \\
(n=20)\end{array}$ & $\begin{array}{l}\text { No-pain condition } \\
(n=20)\end{array}$ & $\begin{array}{l}\text { Pain condition } \\
(n=19)\end{array}$ & $\begin{array}{l}\text { No-pain condition } \\
(n=20)\end{array}$ \\
\hline & $M(S D)$ & $M(S D)$ & $M(S D)$ & $M(S D)$ \\
\hline hits & $26.21(5.09)$ & $25.78(5.08)$ & $26.45(5.28)$ & $26.19(5.10)$ \\
\hline misses & $3.64(5.06)$ & $4.14(5.04)$ & $3.50(5.25)$ & $2.69(5.08)$ \\
\hline correct rejections & $58.33(2.88)$ & $59.14(2.88)$ & $58.97(2.96)$ & $58.51(2.88)$ \\
\hline false alarms & $1.18(2.18)$ & $0.58(2.18)$ & $0.62(2.23)$ & $0.96(2.19)$ \\
\hline accuracy percentage & $93.93(6.89)$ & $94.36(6.85)$ & $94.94(7.15)$ & $94.12(6.87)$ \\
\hline sensitivity accuracy & $24.99(5.73)$ & $25.21(5.71)$ & $25.86(5.95)$ & $25.19(5.76)$ \\
\hline
\end{tabular}

Notes: hits = sum targets; misses = sum missed targets; correct rejections = sum non-targets; false alarms = sum incorrect targets; accuracy percentage = sum hits + correct rejections; sensitivity accuracy = hits minus false alarms. Non responses are not reported.

Table 2. Results of the paired t-tests with mean (M) and standard deviation (SD) scores on the 2-back dependent variables, displayed per time-point.

\begin{tabular}{|c|c|c|c|c|c|}
\hline & \multirow{2}{*}{$\frac{\text { Time-point } 1}{M(S D)}$} & \multicolumn{4}{|l|}{ Time-point 2} \\
\hline & & $M(S D)$ & t value & Cohen's d & 95\% Confidence Interval of $d$ \\
\hline hits & $24.06(3.66)$ & $26.15(2.95)$ & $5.72 * * *$ & 1.29 & $0.95-1.64$ \\
\hline misses & $5.76(3.56)$ & $3.75(2.88)$ & $5.51 * * *$ & 1.25 & $0.90-1.59$ \\
\hline correct rejections & $58.24(2.07)$ & $58.73(1.69)$ & $2.33^{*}$ & 0.53 & $0.21-0.85$ \\
\hline false alarms & $1.26(1.58)$ & $0.84(1.21)$ & $2.59 *$ & 0.59 & $0.27-0.91$ \\
\hline accuracy percentage & $91.44(4.60)$ & $94.33(3.90)$ & $5.97 * * *$ & 1.35 & $1.00-1.70$ \\
\hline sensitivity accuracy & $22.78(3.98)$ & $25.30(3.28)$ & $6.17 * * *$ & 0.69 & $1.05-1.75$ \\
\hline
\end{tabular}

Notes: hits = sum targets; misses = sum missed targets; correct rejections = sum non-targets; false alarms = sum incorrect targets; accuracy percentage = sum hits + correct rejections; sensitivity accuracy = hits minus false alarms. ${ }^{*}=\mathrm{P}<.05 ;{ }^{* *}=\mathrm{P}<.01 ; * *=\mathrm{P}<.001$. Non responses are not reported. 


\section{DISCUSSION STUDY 1}

In this first study, cold pressor pain did not affect subsequent 2-back task performance. Therefore, we were not able to examine the protective effect of induced optimism on pain-related performance decrements. The absence of an effect of the pain induction on the 2-back task is in contrast to our earlier study [5], in which subsequent performance on a working memory task (i.e. operation-span task) was found to be impaired after the cold pressor task. Furthermore, a number of studies have demonstrated that 2-back task performance is negatively influenced by experimentally induced pain [31; 32]. However, these latter studies used dual-task paradigms that present painful stimuli during task performance, whereas our study delivered the pain stimulation prior to task performance. It is possible that the 2-back task may not be as sensitive to sustained pain-induced effects as the operation-span task. Nevertheless, the results of this study once again do emphasise the effectiveness of the optimism manipulation in an experimental lab setting $[5 ; 19 ; 35]$. Because study 1 failed to find an effect of pain on 2-back performance and this is a necessary condition to test the second hypothesis concerning the protective effect of optimism, in study 2 we used an exact replication of previous study designs [31; 32] that have shown pain-induced deterioration in 2-back task performance. These studies used contact heat as the pain stimulus and a within-subjects design for pain stimulation, i.e. participants completed the 2-back task twice: once without and once while experiencing painful heat stimulation. We added the optimism condition (BPS vs TD) as a between-subject factor. It was hypothesized that (i) concurrent pain impairs 2-back task performance; (ii) this pain-induced deterioration can be reduced with an optimism manipulation.

\section{STUDY 2}

\section{METHODS}

\section{Participants}

A total of 65 healthy undergraduates from Maastricht University were recruited for this study. Due to technical difficulties during testing, 4 participants had to be excluded from data analysis. The remaining 61 participants (16 males) had a mean age of 21.84 (SD = 2.22). Exclusion criteria were suffering from a chronic pain disorder or currently experiencing pain, being pregnant, suffering from heart or vascular diseases, wearing an electronic implant, being diagnosed with a psychopathological disorder in the past three months, and taking anxiolytics or antidepressants. Study 2 had a 2 (optimism: BPS vs. TD) $\times 2$ (pain: pain vs. no-pain) mixed factorial design, with optimism as between subjects factor and pain as within subjects factor. Participants were randomly assigned to 
one of the two conditions: (i) BPS ( $n=32 ; 8$ males, mean age $=21.91, S D=2.29$ ), (ii) TD ( $n=29 ; 8$ males, mean age $=21.76, S D=2.17$ ). During recruitment, participants were informed that they would experience heat stimulation, which could be unpleasant. Participation was rewarded with a gift voucher of 15 Euro or course credit. The local ethical committee of the Faculty of Psychology and Neuroscience, Maastricht University approved the study protocol.

\section{Manipulations}

\section{Optimism manipulation}

The optimism manipulation was identical to the manipulation described in study 1.

\section{Pain manipulation}

The Medoc Pathway Advanced Thermal Stimulator (ATS) was used to induce painful heat stimulation via a metal plate $(3 * 3 \mathrm{~cm})$ that was attached on the inner side of the wrist of the non-dominant hand. Individual pain thresholds of participants were identified through the Medoc search protocol [32]. During this search protocol (i.e. calibration phase), heat stimulation started at baseline temperature of $32^{\circ} \mathrm{C}$ and participants could increase or decrease the temperature by pressing one of two buttons. Each button press would respectively increase or decrease temperature with $1.6^{\circ} \mathrm{C}$. The heat stimulation during the pain manipulation was modelled after the stimulus temperature that was selected as pain threshold in the calibration phase (up to a maximum of $48^{\circ} \mathrm{C}$; all participants with thresholds higher than this were tested at a temperature of $48^{\circ} \mathrm{C}$, thereby complying with safety protocol for heat pain stimulation). The heat stimulus started at the baseline temperature $\left(32^{\circ} \mathrm{C}\right)$ to increase at a rate of $8^{\circ} \mathrm{C} / \mathrm{s}$ to $1^{\circ} \mathrm{C}$ above the participant's subjective 'just painful' threshold, where it oscillated for 10 oscillations $1^{\circ} \mathrm{C}$ above and $1^{\circ} \mathrm{C}$ below the threshold, before returning to baseline [32]. This cycle was repeated continuously until the cognitive task was completed (duration $=3$ minutes).

\section{Measures}

\section{Working memory: 2-back task}

As in Study 1, the 2-back task was used to measure working memory. However, we no longer introduced the opportunity for a self-paced break after each block of 30 trials, meaning that following a practice phase (20 trials), a total of 90 trials were presented consecutively in the test phase [32]. Furthermore, as the Medoc probe for administration of the pain stimulus was attached to the participant's non-dominant wrist, participants responded with the index and middle finger of the dominant hand. 


\section{Questionnaires}

Future expectancies, optimism, affect, pain ratings, and pain catastrophizing were assessed as in study 1.

\section{Procedure}

After signing the informed consent, participants completed the FEX, PANAS, LOT-R and the PCS questionnaires via computer. Next, participants completed the calibration phase with the following instructions: 'When the procedure starts, the starting temperature will not be perceived as painful. The aim is to find the moment that you perceive the temperature as just painful. In order to detect this moment, you will be able to increase and decrease the temperature in little steps by clicking on the right or left button. Please let me know when you feel you have found that moment.' When participants indicated that the temperature was 'just painful', participants had to indicate how painful the heat stimulation was on a scale of 0 (not at all painful) to 10 (extremely painful). Next, the heat stimulus was presented for $10 \mathrm{sec}$, after which participants rated the stimulus again. If participants rated the heat stimulation after $10 \mathrm{sec}$ below a 4 , participants were asked again if they considered this temperature as 'just painful'. If this was not the case, participants were asked again to adjust the temperature until they identified their subjective pain threshold. Individual threshold temperatures generated from the calibration phase were then used during the pain manipulation.

After the calibration phase, participants performed the practice phase of the 2-back task. Subsequently, the PANAS and FEX (baseline) were administered via computer again as baseline measurement for the optimism manipulation check. Next, participant either received the BPS manipulation (optimism) or the TD manipulation (no-optimism). FEX and PANAS (post measurement) were administered again to check whether the manipulation was successful.

Next, the 2-back task was completed once with and once without simultaneously being exposed to the painful heat stimulation. The order was counterbalanced. The heat stimulation started immediately when the participant pressed on the 'yes' button after reading the task instructions of the 2-back task and stopped when the task was completed (duration $=3$ minutes). Only after task completion with painful heat stimulation, participants completed the VAS pain ratings on paper. Participants were then thanked for their participation and received their compensation. In total, the duration of the experimental lab session was approximately 1.5 hours. Participants were fully debriefed via e-mail after study completion. 


\section{Data analyses}

Data were checked for a normal distribution and reliability analyses were performed on the FEX, LOT-R, PCS and the PANAS questionnaires. One-way ANOVAs were conducted to check for baseline differences between conditions (BPS VS. TD) on self-reported pain catastrophizing (PCS), optimism (LOT-R, FEX) and positive and negative affect (PANAS).

The effectiveness of the optimism manipulation on positive and negative affect and positive and negative future expectancies (post measurement) was tested with ANCOVAs with optimism condition as between subjects factor and baseline scores of positive and negative affect (centered) and positive and negative future expectancies (centered) as covariates.

Two-way (optimism condition $x$ pain) repeated measures ANOVAs with 2-back performance variables (i.e., hits, misses, correct rejections, false alarms, accuracy percentage, sensitivity accuracy) as dependent variables were conducted to test the hypotheses that pain deteriorates working memory task performance and that optimism can protect against this deterioration effect.

\section{RESULTS}

\section{Baseline descriptives}

The internal consistency (Cronbach's alpha) was satisfactory for all the questionnaires (range .72-.88). Results of several ANOVAs with optimism as between subject's factor indicated that randomization was successful, as results did not reveal any significant differences between the BPS and TD condition at baseline (all p-values >.05). Three participants were excluded from data analysis concerning working memory, as they scored below chance level ( $<50 \%$ ) on baseline 2-back accuracy percentage scores or demonstrated a dominant response style bias (i.e. tendency to over identify targets), indicated by an extreme number of false alarms. The remaining 58 participants (16 males) had a mean age of 21.9 years $(S D=2.20)$.

\section{Optimism manipulation check}

The ANCOVAs revealed a significant main effect of optimism condition, controlling for the effect of scores obtained before the manipulation, for positive future expectancies $\left(F(1,58)=3.95, p=0.05, n p^{2}=.06\right)$, positive affect $\left(F\left(1,58=5.09, p=0.03, n p^{2}=.08\right)\right.$ and negative future expectancies $\left(F(1,58)=5.09, p=0.03, n p^{2}=.08\right)$. The optimism condition main effect was not significant for negative affect $(F(1,58)=0.04, p=0.85$, $\left.\eta \mathrm{p}^{2}=.00\right)$. Participants in the BPS condition $(n=32)$ scored higher on positive future expectancies $(M=56.06, S D=4.05$ vs. $M=54.55, S D=4.25)$ and positive affect $(M=$ 
29.42, $S D=5.61$ vs. $M=27.06, S D=5.90)$, and scored lower on negative future expectancies $(M=27.12, S D=4.47$ vs. $M=29.00, S D=4.70)$ than participants in the TD condition ( $n=29)$. Participants did not differ on negative affect $(M=13.80, S D=2.51$ vs. $M$ $=13.71, S D=2.64)$.

\section{Pain manipulation}

Individual pain threshold was identified during the calibration phase. Minimal obtained threshold temperature was $33.5^{\circ} \mathrm{C}$ and maximal threshold temperature $47.0{ }^{\circ} \mathrm{C}$, with a mean of $42.74{ }^{\circ} \mathrm{C}(S D=2.94)$. The mean intensity score of the individual pain threshold during calibration was $4.06(S D=2.14)$. Following the 2-back task completion with concurrent heat stimulation, participants reported on VAS scales a mean pain intensity of $44.90(S D=23.98)$ and a mean fear of pain of $24.38(S D=23.01)$.

\section{Working memory task performance}

Mean and standard deviations scores on the 2-back variables are displayed in Table 3. The optimism condition $\mathrm{x}$ pain interactions were not significant (all $p$ values $>.60$ ). Similar, main effects of optimism condition were not significant (all $p$ values $>.24$ ). Results did indicate a main effect of pain on correct rejections $\left(F(1,56)=7.55, p=0.01, \eta p^{2}=\right.$ $.12)$, false alarms $\left(F(1,56)=7.92, p=0.01, n p^{2}=.12\right)$, accuracy percentage $(F(1,56)=$ 8.49, $\left.p=0.01, \eta p^{2}=.13\right)$, sensitivity accuracy $\left(F(1,56)=8.45, p=0.01, n p^{2}=.13\right)$. Main effect of pain on hits and miss showed the same trend but did not reach significance: hits $\left(F(1,56)=3.54, p=0.07, n p^{2}=.06\right)$ and misses $\left(F(1,56)=3.35, p=0.07, n p^{2}=\right.$ .06). These results indicate that pain deteriorated 2-back task performance. 


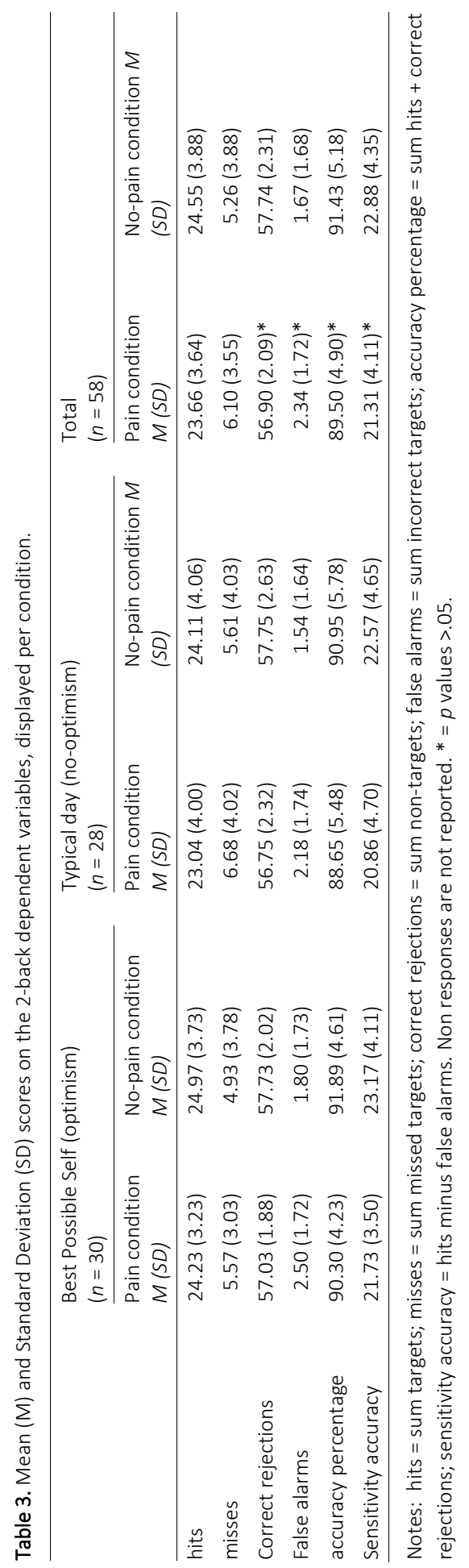




\section{GENERAL DISCUSSION}

The aim of the two successive experiments was to examine whether experimental pain negatively affects subsequent or concurrent working memory task performance as measured by the 2-back task, and whether optimism can protect against this deteriorating effect. Study 1 showed that cold pressor pain did not affect subsequent 2-back task performance, however 2-back task performance was impaired when heat pain was applied during task execution (study 2). This latter finding replicates previous studies showing that concurrent heat pain impairs 2-back task performance. In fact, the pain induced task deterioration seemed more robust than previously reported, as it affected more 2-back task parameters [31; 32]. The second hypothesis that induced optimism protects against pain-induced deterioration in task performance was not supported. We were only able to test this hypothesis in the second study where pain-induced task performance decrements were found. These decrements were comparable in the BPS and the TD condition.

Recently, experimentally induced pain was found to impair performance on a subsequent working memory task [5]. More specifically, participants who underwent a cold pressor task showed poorer performance on the operation-span task compared to those who were not exposed to pain. One of the aims of study 1 was to replicate this finding using a different working memory task, namely the 2-back task. This measure of working memory functioning entails both maintenance and operation of stored material. The current findings indicate that 2-back task performance was not affected by a preceding pain experience. To our knowledge, the effects of pain on 2-back performance have previously only been tested with concurrent pain stimulation $[6 ; 12 ; 31$; 32]. In study 2 we could replicate the finding of these studies that painful heat stimulation during task execution does impair performance on the 2-back task. It is therefore conceivable that the 2-back task is less sensitive for a previous pain experience compared to other working memory tasks, such as the operation-span task [5; 41]. It should be noted that both studies used different methods to experimentally induce pain, namely cold-pressor pain versus painful heat stimulation, which arguable could also have caused the difference in results. However, the latter explanation seems less likely, since previous studies have shown that the cold pressor task is able to induce subsequent task performance deterioration [5; 41]. It is relevant to note that performance deterioration by the cold pressor task is also proposed to be caused by the experience of stress, with larger cortisol responses resulting in larger working memory impairments [41]. With the current experimental set-up in study 1 it is not possible to disentangle the influence of pain and stress. Pain research may benefit from studies that further explore stress as confounder and whether it is possible to untangle these factors. Another explanation for the absence of a pain effect in study 1 is the procedural format of the 2-back task. In study 1, the 2-back task included self-paced breaks between blocks, 
which might have decreased task difficulty, consequently moderating the interruptive effect of pain.

In contrast to our earlier study [5], the present study did not find a protective effect of induced optimism on pain-induced task performance decrements. Several explanations might be given to explain the absence of the protective effect of optimism in the present study. First, previous research has shown that optimistic individuals show more goal attainment [7] and more effort to reach personal and health goals despite pain [1; 13]. It could be reasoned that this increased goal perseverance may be the pathway by which optimism exerts its protective effect against pain-induced executive task performance deficits. But this increased goal perseverance may only be activated when the task has a particular duration. The 2-back task has a completion time of 3 minutes, whereas the operation-span task [47] as used in our previous study took around 12 minutes to complete. Moreover, contrary to the 2-back task, participants in the operation-span task are required to verbally state to the experimenter whether a mathematical problem is correct, which may lead to fear of negative evaluation and stereotype threat $[28 ; 45]$ reducing task performance. It is possible that optimism, like coping sense of humour [17], buffers against the negative performance effects partly because it decreases performance anxiety and increases self-efficacy [42].

Second, it is possible that optimism can only act as a protective factor, if a certain amount of executive resources is dedicated to task performance. The amount of executive resources that are given to a certain task partly depends on task difficulty and contextual factors. The operation-span task requires participants to solve arithmetic problems while simultaneously remembering and recall unrelated words in their order of presentation. The presentation sequence of trials in the operation-span was randomized, which eliminates any strategy that is built on knowledge about the amount of words that need to be remembered [16]. This absence of strategy may have increased task demand $[4 ; 25 ; 37]$, resulting that more executive resources are allocated towards this task compared to the 2-back task. Taken together, the discussion above addresses the importance of matching task characteristics when examining the generalisability of an effect.

Not only the amount of executive resources dedicated to task performance may be an important factor, but also which cognitive processes are involved. Executive functioning is an umbrella term that describes multiple cognitive processes that allows us to effortful guide our behaviour to a certain goal, especially in non-routine situations [2; 3 ; 15]. Although the operation-span task and the 2-back task are regarded both as working memory tasks that require executive functioning, the reported correlation between these tasks is low [21]. Furthermore, when the two tasks are used to predict performance on a general fluid intelligence measure, both explained a portion of the variances independently from each other [20; 21]. These findings indicate that although both tasks are considered to measure executive functioning, namely updating and monitoring of working memory representations [30], they in fact may measure a different 
construct or different parts of the same construct. Future research should attempt to gain more insight in differences and or similarities between tasks that are considered to measure executive functioning.

In summary, this study replicated previous studies showing that pain can negatively affect working memory task performance. It is important to explore factors that may diminish the negative impact of pain on executive functions, because this may have implications for people experiencing persistent pain. The ability to actively monitor behaviour, memory, and inhibiting certain responses is necessary to function in daily life, despite pain being present. In study 2 , we were not able to replicate our previous finding that optimism can act as a protective factor against pain-induced deterioration in task performance. Compared to our previous study, the present study used a different executive functioning task and a different pain stimulus. We are planning to conduct future studies that should shed further light on the conditions, contexts and executive operations for which optimism can act as a protective factor.

\section{ACKNOWLEDGEMENTS}

We would like to thank Dr. David Moore and colleagues for providing us with the 2-back task [31] and Katrin Blum and Nadia Hutten for their help in the data collection. 


\section{REFERENCES}

[1] Affleck G, Tennen H, Zautra A, Urrows S, Abeles M, Karoly P. Women's pursuit of personal goals in daily life with fibromyalgia: A value-expectancy analysis. Journal of Consulting and Clinical Psychology 2001;69(4):587-596.

[2] Banich MT. Executive function the search for an integrated account. Current Directions in Psychological Science 2009;18(2):89-94.

[3] Berryman C, Stanton TR, Bowering KJ, Tabor A, McFarlane A, Moseley GL. Do people with chronic pain have impaired executive function? A meta-analytical review. Clinical Psychology Review 2014;34(7):563579.

[4] Bingel U, Rose M, Gläscher J, Büchel C. fMRI Reveals How Pain Modulates Visual Object Processing in the Ventral Visual Stream. Neuron 2007;55(1):157-167.

[5] Boselie JJ, Vancleef LM, Smeets T, Peters ML. Increasing optimism abolishes pain-induced impairments in executive task performance. Pain 2014;155(2):334-340.

[6] Buhle J, Wager TD. Performance-dependent inhibition of pain by an executive working memory task. Pain 2010;149(1):19-26.

[7] Carver CS, Scheier MF, Segerstrom SC. Optimism. Clinical Psychology Review 2010;30(7):879-889.

[8] Chamberlain K, Petrie K, Azariah R. The role of optimism and sense of coherence in predicting recovery following surgery. Psychology and Health 1992;7(4):301-310.

[9] Crawford JR, Henry JD. The Positive and Negative Affect Schedule (PANAS): Construct validity, measurement properties and normative data in a large non-clinical sample. British Journal of Clinical Psychology 2004;43(3):245-265.

[10] Crombez G, Eccleston C, Baeyens F, Eelen P. The disruptive nature of pain: An experimental investigation. Behaviour Research and Therapy 1996;34(11-12):911-918.

[11] Crombez G, Eccleston C, Baeyens F, Eelen P. Habituation and the interference of pain with task performance. Pain 1997;70(2):149-154.

[12] Crombez G, Eccleston C, Baeyens F, Eelen P. Attentional disruption is enhanced by the threat of pain. Behaviour Research and Therapy 1998;36(2):195-204.

[13] Duke J, Leventhal H, Brownlee S, Leventhal EA. Giving up and replacing activities in response to illness. The Journals of Gerontology: Series B: Psychological Sciences and Social Sciences 2002;57B(4):P367P376.

[14] Ehde DM, Jensen MP. Coping and catastrophic thinking: The experience and treatment of chronic pain. In: D David, SJ Lynn, A Ellis, editors. Rational and irrational beliefs: Research, theory, and clinical practice. New York, NY US: Oxford University Press, 2010. pp. 265-288.

[15] Elliott R. Executive functions and their disorders Imaging in clinical neuroscience. British Medical Bulletin 2003;65(1):49-59.

[16] Engle RW, Cantor J, Carullo JJ. Individual differences in working memory and comprehension: A test of four hypotheses. Journal of Experimental Psychology: Learning, Memory, and Cognition 1992;18(5):972992.

[17] Ford TE, Ferguson MA, Brooks JL, Hagadone KM. Coping sense of humor reduces effects of stereotype threat on women's math performance. Personality and Social Psychology Bulletin 2004;30(5):643-653.

[18] Gilbert SJ, Burgess PW. Executive function. Current Biology 2008;18(3):R110-R114.

[19] Hanssen MM, Peters ML, Vlaeyen JW, Meevissen YM, Vancleef LM. Optimism lowers pain: Evidence of the causal status and underlying mechanisms. Pain 2013;154(0):53-58.

[20] Jaeggi SM, Buschkuehl M, Perrig WJ, Meier B. The concurrent validity of the N-back task as a working memory measure. Memory 2010;18(4):394-412.

[21] Kane MJ, Conway ARA, Miura TK, Colflesh GJH. Working memory, attention control, and the n-back task: A question of construct validity. Journal of Experimental Psychology: Learning, Memory, and Cognition 2007;33(3):615-622. 
[22] Kane MJ, Engle RW. The role of prefrontal cortex in working-memory capacity, executive attention, and general fluid intelligence: An individual-differences perspective. Psychonomic Bulletin \& Review 2002;9(4):637-671.

[23] King KB, Rowe MA, Kimble LP, Zerwic JJ. Optimism, coping, and long-term recovery from coronary artery surgery in women. Research in nursing \& health 1998;21(1):15-26.

[24] King LA. The health benefits of writing about life goals. Personality and Social Psychology Bulletin 2001;27(7):798-807.

[25] Legrain V, Crombez G, Mouraux A. Controlling attention to nociceptive stimuli with working memory. 2011.

[26] Lezak MD, Howieson DB, Loring DW. Neuropsychological assessment: Oxford University Press, USA, 2004.

[27] Mahler H, Kulik J. Optimism, pessimism and recovery from coronary bypass surgery: Prediction of affect, pain and functional status. Psychology, health \& medicine 2000;5(4):347-358.

[28] Mesagno C, Harvey JT, Janelle CM. Choking under pressure: The role of fear of negative evaluation. Psychology of Sport and Exercise 2012;13(1):60-68.

[29] Miller GA, Chapman JP. Misunderstanding analysis of covariance. Journal of abnormal psychology 2001;110(1):40.

[30] Miyake A, Friedman NP, Emerson MJ, Witzki AH, Howerter A. The unity and diversity of executive functions and their contributions to complex 'frontal lobe' tasks: A latent variable analysis. Cognitive Psychology 2000;41(1):49-100.

[31] Moore DJ, Keogh E, Eccleston C. The interruptive effect of pain on attention. The Quarterly Journal of Experimental Psychology 2012;65(3):565-586.

[32] Moore DJ, Keogh E, Eccleston C. The effect of threat on attentional interruption by pain. Pain 2013;154(1):82-88.

[33] Moriarty O, McGuire BE, Finn DP. The effect of pain on cognitive function: a review of clinical and preclinical research. Progress in Neurobiology 2011;93(3):385-404.

[34] Osman A, Barrios FX, Gutierrez PM, Kopper BA, Merrifield T, Grittmann L. The Pain Catastrophizing Scale: Further psychometric evaluation with adult samples. Journal of Behavioral Medicine 2000;23(4):351365.

[35] Peters ML, Flink IK, Boersma K, Linton SJ. Manipulating optimism: Can imagining a best possible self be used to increase positive future expectancies? The Journal of Positive Psychology 2010;5(3):204-211.

[36] Rasmussen HN, Wrosch C, Scheier MF, Carver CS. Self-regulation processes and health: the importance of optimism and goal adjustment. J Pers 2006;74(6):1721-1747.

[37] Romero YR, Straube T, Nitsch A, Miltner WH, Weiss T. Interaction between stimulus intensity and perceptual load in the attentional control of pain. Pain 2013;154(1):135-140.

[38] Scheier MF, Carver CS, Bridges MW. Distinguishing optimism from neuroticism (and trait anxiety, selfmastery, and self-esteem): A reevaluation of the Life Orientation Test. Journal of Personality and Social Psychology 1994;67(6):1063-1078.

[39] Scheier MF, Matthews KA, Owens JF, Magovern GJ, Lefebvre RC, Abbott RA, Carver CS. Dispositional optimism and recovery from coronary artery bypass surgery: the beneficial effects on physical and psychological well-being. Journal of Personality and Social Psychology 1989;57(6):1024.

[40] Scheier MF, Matthews KA, Owens JF, Schulz R, Bridges MW, Magovern GJ, Carver CS. Optimism and rehospitalization after coronary artery bypass graft surgery. Archives of internal medicine 1999;159(8):829-835.

[41] Schoofs D, Wolf OT, Smeets T. Cold pressor stress impairs performance on working memory tasks requiring executive functions in healthy young men. Behavioral Neuroscience 2009;123(5):1066-1075.

[42] Siddique HI, LaSalle-Ricci VH, Glass CR, Arnkoff DB, Díaz RJ. Worry, optimism, and expectations as predictors of anxiety and performance in the first year of law school. Cognitive Therapy and Research 2006;30(5):667-676.

[43] Smith EE, Jonides J. Storage and executive processes in the frontal lobes. Science 1999;283(5408):16571661. 


\section{Chapter 3}

[44] Solberg Nes L, Segerstrom SC, Sephton SE. Engagement and Arousal: Optimism's Effects During a Brief Stressor. Personality and Social Psychology Bulletin 2005;31(1):111-120.

[45] Steele CM, Spencer SJ, Aronson J. Contending with group image: The psychology of stereotype and social identity threat. Advances in experimental social psychology 2002;34:379-440.

[46] Sullivan MJL, Bishop SR, Pivik J. The Pain Catastrophizing Scale: Development and validation. Psychological Assessment 1995;7(4):524-532.

[47] Turner ML, Engle RW. Is working memory capacity task dependent? Journal of Memory and Language 1989;28(2):127-154.

[48] Van Breukelen GJP. ANCOVA versus change from baseline had more power in randomized studies and more bias in nonrandomized studies. Journal of Clinical Epidemiology 2006;59(9):920-925.

[49] Van Ryckeghem DM, Crombez G, Eccleston C, Liefooghe B, Van Damme S. The interruptive effect of pain in a multitask environment: an experimental investigation. The Journal of Pain 2012;13(2):131-138.

[50] Watson D, Clark LA, Tellegen A. Development and validation of brief measures of positive and negative affect: The PANAS scales. Journal of Personality and Social Psychology 1988;54(6):1063-1070. 


\section{Chapter four}

\section{Increasing optimism protects against pain-induced impairments in task shifting performance}

Published as: Boselie JJLM, Vancleef LM, Peters ML. Increasing optimism protects against pain-induced impairments in task shifting performance. The Journal of Pain 2017; 18(4): 446-455. 


\section{ABSTRACT}

Persistent pain can lead to difficulties in executive task performance. Three core executive functions that are often postulated are inhibition, updating and shifting. Optimism, the tendency to expect that good things happen in the future, has been shown to protect against pain-induced performance deterioration in the executive function updating. This study tested whether this protective effect of a temporary optimistic state by means of a writing and visualization exercise extended to the executive function shifting. In a 2 (optimism: optimism vs. no-optimism) x 2 (pain: pain vs. no-pain) mixed factorial design, participants $(\mathrm{N}=61)$ completed a shifting task once with and once without concurrent painful heat stimulation following an optimism or neutral manipulation. Results demonstrated that shifting performance was impaired when experimental heat pain was applied during task execution, and that optimism counteracted this paininduced deterioration in shifting performance. 


\section{INTRODUCTION}

Persistent pain can lead to difficulties in executive task performance. Prior studies on the interruptive effect of pain have routinely adopted dual-task paradigms that present painful stimuli during executive tasks performance $[11 ; 49-51]$ to examine the ability of pain to capture attention at the expense of other ongoing activities [16-18; 21; 41; 42; $62 ; 80]$. Attention is a cognitive process that facilitates some information and inhibits other information from receiving further processing [57]. Attention relies on executive functioning, which is described as the ability to actively monitor behaviour, inhibit or facilitate certain responses, and optimise one's approach to unfamiliar circumstances [31; 46; 69]. Three core executive functions are postulated, namely inhibition of prepotent responses (inhibition), updating and monitoring of working memory representations (updating), and shifting between mental sets or tasks (shifting) [46]. Studies have demonstrated that experimental $[8 ; 11 ; 16-18 ; 49]$ and persistent pain $[5 ; 6 ; 52]$ impairs the performance on tasks that tap into these executive functions.

The ability to shift between mental sets or tasks requires individuals to allocate their attentional resources flexibly and fluently between multiple demands, by inhibiting irrelevant and facilitating relevant responses [31; 47; 69]. For instance, shifting ability enables a person to continuously switch between different languages in a conversation. Research has shown that shifting between tasks comes with a certain cost. More specifically, responses after a task switch are typically slower and less accurate compared to responses when repeating a task, which is called switch costs $[2 ; 60 ; 81]$. Experimentally induced pain in healthy participants has been found to increase these switch costs, leading to task shifting performance deterioration [49; 50; 79]. Moreover, persistent pain impairs task shifting performance in chronic pain patients [6; 51].

A possible factor that may counteract these pain-induced shifting impairments is optimism, the tendency to expect that good things will happen in the future [14]. Optimism, has been associated with beneficial coping strategies [59; 74], applying different coping strategies more flexibly [59; 74], reduced pain intensity [33; 44] and more goal attainment despite pain $[1 ; 19]$. We recently demonstrated that increasing optimism can diminish the deteriorating effect of experimentally induced pain on the executive function updating [8]. Drawn from the broaden-and-build theory [25-27], optimism may act as a protective factor, by (re)directing an individual's attention (i.e., the broaden hypothesis) towards accurate task performance and/or increasing cognitive or selfregulation resources (i.e., the build hypothesis). In the competing limited resources theory, both cognitive and self-regulatory (i.e., the ability to control or alter thoughts, emotion and behaviour [12; 13]) resources are considered to be limited. Experiencing pain may fatigue these resources causing executive task performance to decline $[21 ; 70$; 73]. Optimism may diminish self-regulatory fatigue by increasing cognitive or selfregulation resources, counteracting pain-induced task performance deterioration [35; 71-73]. In the integrative neurocognitive model, bottom-up and top-down variables can 
modulate the ability of pain to capture an individual's attention at the expense of accurate task performance [43]. Optimism may increase modulation by top-down variables such as goal perseverance and effort leading to higher goal attainment $[1 ; 14 ; 19 ; 64$; 86].

This study examined whether the protective effect of manipulated optimism also extends to the task shifting performance. Participants completed a shifting task once with and once without concurrent painful heat stimulation. Half of the participants received an optimism manipulation prior to the completion of the shifting tasks. It was hypothesized that (i) pain will decrease task shifting performance and (ii) the optimism induction counteracts the deteriorating effect of pain on task shifting performance.

\section{METHODS}

\section{Participants}

A total of 65 healthy undergraduates from Maastricht University were recruited for this study. A minimal sample size of 40 participants (20 per group) was required and determined with $\mathrm{G}^{*}$ Power [22] with the following parameters: $\alpha=.05$, power $=.95$, correlation among two repeated measures $=0.5$ and an effect size of $n p^{2}=.08$ (derived from our previous study [8]). Exclusion criteria were suffering from a chronic pain disorder or currently experiencing pain, being pregnant, suffering from heart or vascular diseases, wearing an electronic implant, being diagnosed with a psychopathological disorder in the past three months, taking anxiolytics or antidepressants, or having participated in comparable prior experiments. Adherence to these criteria was verbally checked prior to scheduling the test appointment. As all the instructions and stimulus materials were presented in Dutch, good comprehension of the Dutch language was required. Participants could enrol themselves for participating at a specific timeslot via an online system. A random allocation sequence was generated before the start of the study by the first author, which was used by the research assistants (i.e., experimenters) to assign the participants to a specific condition. Randomization was stratified for gender. Participants were not aware of the allocation.

Due to technical difficulties during testing, 2 participants had to be excluded from data analysis. Furthermore, although participants were informed that currently experiencing pain was an exclusion criterion; two participants did report to experience pain at baseline and were therefore excluded from further data analyses. The remaining 61 participants (6 males) had a mean age of 21.48 ( $S D=2.47)$.

A 2 (optimism: optimism vs. no-optimism) x 2 (pain: pain vs. no-pain) mixed factorial design was employed, with optimism as between subjects factor and pain as within subjects factor. Participants were randomly assigned to one of the two conditions: (i) optimism ( $n=31 ; 1$ males, mean age $=21.65, S D=2.97$ ), (ii) no-optimism $(n=30 ; 5$ 
males, mean age $=21.30, S D=1.86)$. During recruitment, participants were informed that they would experience heat stimulation, which could be unpleasant. Participation was rewarded with a gift voucher of 15 Euro or course credits. The ethical review committee of the Faculty of Psychology and Neuroscience, Maastricht University (ERCPN) approved the study protocol.

\section{Manipulations}

\section{Optimism manipulation}

Optimism was induced by the Best Possible Self (BPS) manipulation, a positive future thinking technique based on work by King [38]. Previous research has proven the effectiveness of the BPS in increasing positive affect, positive future expectancies and decreasing negative future expectancies $[8 ; 33 ; 55]$. Participants either received the BPS manipulation or the neutral manipulation (Typical Day: TD). In the BPS condition participants wrote about a life in the future where everything turned out for the best. In the TD condition participants wrote about a typical day. The instructions in the BPS and TD condition were identical to previous studies [8; 9; 55]. Both manipulations followed the same procedural format: 1 minute to think about what to write followed by uninterrupted writing for 15 minutes and ending with 5 minutes of imaging the story they just wrote. Instructions were given both verbally and in writing.

\section{Pain manipulation}

The Medoc Pathway Advanced Thermal Stimulator (ATS; Medoc Advanced Medical Systems, Ramat Yishai, Israel) was used to induce painful heat stimulation via a metal plate $\left(3^{*} 3 \mathrm{~cm}\right)$ that was attached on the inner side of the wrist of the non-dominant hand. During a calibration phase, individual pain thresholds of participants were identified through the Medoc search protocol [50]. In this search protocol, heat stimulation started at baseline temperature of $32^{\circ} \mathrm{C}$ and participants could subsequently increase or decrease the temperature by pressing one of two buttons. Each button press would respectively increase or decrease temperature with $1.6^{\circ} \mathrm{C}$. The heat stimulation during the pain manipulation was based on the stimulus temperature that was selected as pain threshold in the calibration phase (up to a maximum of $48^{\circ} \mathrm{C}$; all participants with thresholds higher than this were tested at a temperature of $48^{\circ} \mathrm{C}$, thereby complying with safety protocol for heat pain stimulation). The heat stimulus started at the baseline temperature $\left(32^{\circ} \mathrm{C}\right)$ to increase at a rate of $8^{\circ} \mathrm{C} / \mathrm{s}$ to $1^{\circ} \mathrm{C}$ above the participant's pain threshold, where it oscillated for 10 oscillations $1^{\circ} \mathrm{C}$ above and $1^{\circ} \mathrm{C}$ below the threshold, before returning to baseline [50]. This cycle was repeated continuously until the shifting task was completed (duration between 4-8 minutes). 


\section{Measures}

\section{Executive functioning: task shifting}

The task shifting paradigm is widely used to study mental set shifting $[48 ; 68 ; 81]$ as a component of executive functioning [47], with reliability scores (e.g., calculated by adjusting split-half (odd-even) correlations with the Spearman-Brown prophecy formula) ranging from .46 to .91 [3; 34; 46; 68]. In the task shifting paradigm that we adopted here, 8 single-digit numbers $(1,2,3,4,6,7,8$, and 9) are presented one-by-one on a computer screen. Participants need to follow a discrete task rule on each trial, that can either change (i.e., switch trial) or remain the same (i.e., repetition trials) from one trial to the next. More precisely, participants were to follow one of the following 2 task rules: (I) indicate whether the target number was higher or lower than 5 , and (II indicating whether the target number was even or odd. The task rule (i.e., higher/lower or odd/even) that needed to be applied to each trial was briefly primed (500 ms) before the presentation of the target number [37; 45]. To keep the length of the priming cue similar, only the first two letters were given of each word (i.e. hi/lo or od/ev). The response time was not restricted; the target number was shown until a response was given by the participant on a two button response box. The mapping of response keys was randomized across participants. For example, the mapping could be that the participant had to press button $\mathrm{E}$ when the target number was lower than 5 or an even number. In contrast, the participant had to press button $U$ when the target number was higher than 5 or an odd number. Which button corresponded to which option (e.g. E = lower/even and $U=$ higher/odd) was simultaneously presented with the target number in order to ensure that participants were aware of the required sorting options.

Responses on a switch trial are typically slower and less accurate compared to responses on a repetition trial (i.e., switch costs). Additionally, the task distinguishes between congruent and incongruent trials. Congruent trials are trials for which the correct response is mapped to the same response button under both task rules, while for incongruent trials the correct response differs depending on the task rule. Responses on congruent trials are faster and more accurate compared to responses on incongruent trials (i.e., congruency effect) [2]. Sensitive switch costs are switch costs (i.e., switch minus repeat trials) on incongruent trials.

The shifting task consisted of a practice phase and testing phase. The practice phase included 12 trials, with six trials cueing the participant to classify the target number as higher as or lower than 5 and six trials where they had to classify the target number as odd or even. In the testing phase 192 trials were presented, with 96 switch trials of which 48 were congruent. The presentation of target numbers was fixed semirandomized to ensure the previously mentioned distribution of switch and congruent trials. Additionally, the same priming cue was not allowed to be presented for more than 4 consecutive trials. Figure 1 depicts an example of two consecutive trials. 
The total duration of the shifting task ranged from 4 to 8 minutes. Reaction times and accuracy were registered. The main outcome variables of the task are (sensitive) switch costs. The (sensitive) reaction time switch cost score is computed by subtracting (incongruent) repeat trials from (incongruent) switch trials, such that higher positive (sensitive) values are indicative that participants were slower to respond to switch trials than to repetition trials (i.e., larger switching cost). The (sensitive) accuracy switch cost score is computed by subtracting the proportion of correct responses on (incongruent) switch trials from the proportion of correct responses on the (incongruent) repeat trials, such that higher positive (sensitive) values are indicative that participants were less accurate on switch trials compared to repetition trials (i.e., larger switching cost).

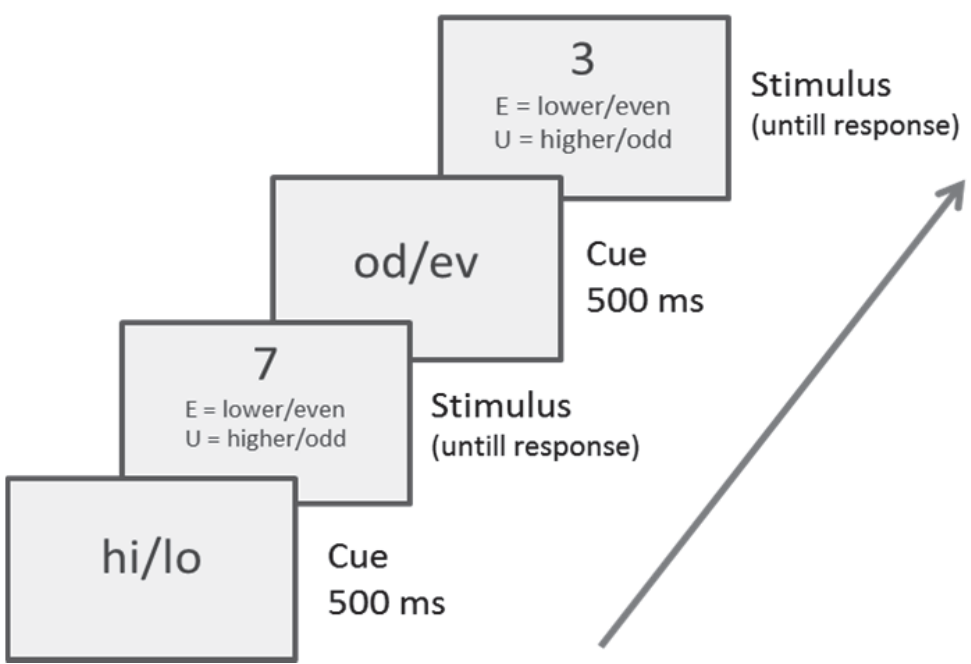

Figure 1. Timeline of events in the task shifting paradigm, showing two consecutive runs of trials.

\section{Baseline questionnaires}

The Life Orientation Test-Revised (LOT-R) [63] measures dispositional optimism and consists of 10 items: 3 positively phrased items (e.g. 'I'm always optimistic about my future'), 3 negatively phrased items (e.g. 'I rarely count on good things happening to me'), and 4 filler items (e.g., 'it's important for me to keep busy'). The items are rated on a 5 -point Likert scale, ranging from 1 (strongly disagree) to 5 (strongly agree). The total LOT-R score is obtained by summation of the scores on the positively phrased items and the reversed scores on the negatively phrased items and ranges from 10 to 30. Higher scores reflect higher levels of dispositional optimism. The LOT-R has been demonstrated to be a reliable and valid measurement instrument [63]. 
Pain Catastrophizing was measured by the Pain Catastrophizing Scale (PCS) [76]. Participants indicate to what degree they experienced each of 13 stated thoughts and feelings while experiencing pain on a 5- point Likert scale, ranging from 0 (not at all) to 4 (all the time). An example of an item is 'I keep thinking about how much it hurts'. The total PCS score is obtained by summing the responses of all the 13 items (scores range from 0 to 52). Higher scores on the PCS indicate greater pain catastrophizing [54]. The PCS has been found to be a reliable and valid measurement instrument [54].

\section{Manipulation checks}

Effectiveness of the optimism induction was assessed by means of the The Future Expectancies Scale (FEX) [19] and the Positive and Negative Affect Schedule (PANAS) [82]. The FEX measures positive and negative future expectancies. It consists of 20 items that make statements about positive ( $n=10$; e.g., 'people will admire you') and negative $(n=$ 10; e.g., 'things will not turn out as you had hoped") future events. The 20 statements cover 5 different domains (work, health, personal, social and general). Participants rate the likelihood that they will experience the specific events on a 7-point Likert scale, ranging from 1 (not at all likely to occur) to 7 (extremely likely to occur). Higher scores reflect a higher estimated likelihood of positive (FEX-Pos) or negative (FEX-Neg) future events, with scores ranging from 10 to 70. The internal consistency of the FEX subscales has been demonstrated to be satisfactory [33].

The PANAS consists of 20 items that measure positive (PA, 10 items) and negative (NA, 10 items) affect. Participants indicate the degree to which a certain feeling is present at that moment on a 5-point Likert scale ranging from 1 (not at all) to 5 (extremely). Examples of PA items are 'excited' and 'inspired'. Examples of NA items are 'nervous' and 'afraid'. Subscale scores can range from 10 to 50, with higher scores on NA items reflecting higher levels of emotional distress. In contrast, high PA scores correspond to experiencing more pleasurable feelings. The PANAS subscales have been demonstrated to be valid and reliable [15].

To assess whether the pain manipulation was successful, two Visual Analogue Scales (VASs) were administered to measure experienced pain intensity and fear of pain. Each VAS was anchored 0 (no pain/ fear of pain al all) to 100 (extreme pain / fear of pain).

\section{Procedure}

Before participants signed an informed consent, they were explicitly informed verbally about the procedure. Then, participants completed the FEX, PANAS, LOT-R and the PCS questionnaires via computer. Next, participants completed the calibration phase to determine their individual pain threshold level with the following instructions: 'When the procedure starts, the starting temperature will not be perceived as painful. The aim is to find the moment that you perceive the temperature as just painful. In order to detect this moment, you will be able to increase and decrease the temperature in little 
steps by clicking on the right or left mouse button. Please let me know when you feel you have found that moment.' When participants indicated that the temperature was 'just painful', they had to indicate next how painful the heat stimulation was verbally on a scale of 0 (not at all painful) to 10 (extremely painful). Next, the selected heat stimulus was presented for $10 \mathrm{sec}$, after which participants rated the selected stimulus again. If participants rated the selected heat stimulus after 10 seconds below a 4, participants were asked again if they considered this temperature as 'just painful'. If this was not the case, participants were asked again to adjust the temperature until they identified their subjective pain threshold. The final rating was noted down by the experimenter. Individual pain threshold temperature as generated during the calibration phase was then used during the pain manipulation.

After the calibration phase, participants performed the practice phase of the shifting task. Subsequently, PANAS and FEX were administered via computer again as baseline measurement for the optimism manipulation check. Next, participant either received the BPS manipulation (optimism) or the TD manipulation (no-optimism). FEX and PANAS were administered again to check whether the manipulation was successful in increasing optimism and positive affect.

Next, the shifting task was completed once with and once without concurrent painful heat stimulation. The order was counterbalanced. The heat stimulation started immediately when the participant pressed on the 'yes' button after reading the task instructions of the shifting task and stopped when the task was completed. Only after task completion with painful heat stimulation, participants completed the VAS pain ratings on paper. See Figure 2 for an overview of the experimental procedure. Participants were then thanked for their participation and received their compensation. Participants were debriefed via e-mail after study completion. In total, the duration of the experimental lab session was approximately 1.5 hours.

\section{Data analyses}

Data were checked for a normal distribution and reliability analyses were performed on the FEX, LOT-R, PCS and the PANAS questionnaires. One-way analyses of variances (ANOVAs) were used to check for baseline differences between the conditions (BPS vs. TD) on self-reported pain catastrophizing (PCS), optimism (LOT-R, FEX) and positive and negative affect (PANAS). Individual responses below $250 \mathrm{~ms}$, or responses that deviated more than $3 \times$ SD above group mean reaction time were omitted from further analysis (2, $36 \%)$. Furthermore, reaction time analyses were conducted on correct responses only $(5,79 \%$ trials were omitted).

The effectiveness of the optimism manipulation on positive and negative affect and positive and negative future expectancies was tested with ANCOVAs with optimism condition (BPS vs TD) as between subjects factor and baseline scores of positive and negative affect (centered) and positive and negative future expectancies (centered) as 
covariates. The manipulation is successful when results show a significant main effect of optimism. This method of analysing is more powerful and precise than using repeated measures ANOVA in a randomized pre-post design [78].

Mixed ANOVAs, with optimism condition as between subjects variable, pain as within subjects variable and task shifting performance variables as dependent variables, were conducted to test the hypothesized interaction effect of pain and optimism on executive task performance. The dependent task shifting performance variables were switch cost reaction time (i.e., reaction time on a switch trial minus a repeat trial) and switch cost accuracy (i.e., accuracy percentage on a repeat trial minus a switch trial). Sensitive switch costs were calculated in the same way, but only incongruent trials were used. Planned follow-up analyses were conducted to test the hypothesis that pain has a deteriorating effect on executive task performance in the TD condition, but not in the BPS condition.

\section{RESULTS}

\section{Baseline descriptives}

The internal consistency (Cronbach's alpha) was satisfactory for all the questionnaires (range .77-.90). Results of several ANOVAs with optimism as between subject's factor revealed no significant differences between the BPS and TD condition at baseline (all $p$ values $>$.05).

\section{Optimism (BPS) manipulation check}

The ANCOVAs revealed a significant main effect of optimism condition, controlling for the effect of scores obtained before the manipulation, for positive future expectancies $\left(F(1,58)=9.01, p<0.01, n p^{2}=.13\right)$, positive affect $\left(F\left(1,58=13.65, p<0.001, n p^{2}=\right.\right.$ .19) and negative future expectancies $\left(F(1,58)=6.49, p=0.01, n p^{2}=.10\right)$. The optimism condition main effect was not significant for negative affect $(F(1,58)=0.21, p=$ $\left.0.65, n p^{2}=.00\right)$. Participants in the BPS condition scored higher on positive future expectancies $(M=55.25, S D=3.41$ vs. $M=53.38, S D=3.46)$ and positive affect $(M=31.24$, $S D=5.34$ vs. $M=27.62, S D=5.43)$, and scored lower on negative future expectancies ( $M$ $=28.17, S D=4.91$ vs. $M=30.46, S D=5.00)$ than participants in the TD condition. Participants did not differ on negative affect $(M=12.48, S D=3.45$ vs. $M=12.77, S D=3.50)$.

\section{Pain manipulation}

Individual pain threshold was identified during the calibration phase. The minimal obtained threshold temperature was $36.6^{\circ} \mathrm{C}$ and the maximal threshold temperature was $46.5^{\circ} \mathrm{C}$, with a mean of $43.07^{\circ} \mathrm{C}(S D=2.28)$. The mean intensity score of the individual 
pain threshold during calibration was 5.11 (SD = 1.33). Following the task shifting completion with concurrent heat stimulation, participants reported on VAS scales a mean pain intensity of $44.28(S D=21.76)$ and a mean fear of pain of $24.21(S D=22.39)$.

\section{Task shifting performance}

Overall mean reaction times ((i) pain (mean $=1355.86 \mathrm{~ms}, S D=519.09$ ) and (ii) no-pain $($ mean $=1253.15 \mathrm{~ms}, S D=508.70)$ ) and accuracy scores (i) pain (mean $=94.26 \%, S D=$ 6.43 ) and (ii) no-pain (mean $=95.06 \%, S D=6.27$ ) were inspected to identify outliers (mean scores $>3 \times$ SDs above/below the group mean). Six participants (reaction time $n=1$, accuracy $n=5$ ) were removed from analyses that included the task shifting variables. Mean and standard deviation scores on the dependent task shifting variables are displayed in Table 1.

Results indicated a trend towards significance for the optimism condition $x$ pain interaction effect on switch cost reaction time $\left(F(1,53)=3.75, p=0.06, \eta p^{2}=.07\right)$ and a significant optimism condition $x$ pain interaction effect on sensitive switch cost reaction time $\left(F(1,53)=6.67, p=0.01, n p^{2}=.11\right)$. Sensitive switch costs per condition are displayed in Figure 3. Interaction effects on accuracy variables were not significant (all $p$ values >.34). Planned follow-up paired t-tests indicated that participants in the TD condition were slower to respond when in pain (switch cost reaction time: $t(25)=3.25, p<$ $.01, d=1.30,95 \% \mathrm{Cl}$ of $d$ [0.69 to 1.91]; sensitive switch cost reaction time: $t(25)=$ $3.85, p<.01, d=1.54,95 \% \mathrm{Cl}$ of $d$ [0.91 to 2.17]). Of crucial importance, the deteriorating effect of pain on task shifting performance was not present in the BPS condition (switch cost reaction time: $t(28)=0.03, p=.97, d=0.01,95 \% \mathrm{Cl}$ of $d$ [-0.51 to 0.54]; sensitive switch cost reaction time: $t(28)=0.28, p=.78, d=0.11,95 \% \mathrm{Cl}$ of $d[-0.42$ to $0.63])$. Main effects of optimism condition and pain condition respectively on accuracy switch cost variables were not-significant (all $p$ values $>.42$; all $p$ values $>.58$ ).

Following visual inspection of Figure 3 , t-tests within the pain condition and the no pain condition respectively were conducted. No significant differences between BPS and TD were observed on any of the outcome variables (pain: switch cost reaction time: $t(53)=1.10, p=.28, d=0.30,95 \% \mathrm{Cl}$ of $d[-0.24$ to 0.84$]$; sensitive switch cost reaction time: $t(53)=1.60, p=.12, d=0.44,95 \% \mathrm{Cl}$ of $d$ [-0.10 to 0.99]; no-pain: switch cost reaction time: $t(53)=0.99, p=.33, d=0.27,95 \% \mathrm{Cl}$ of $d[-0.27$ to 0.81$]$; sensitive switch cost reaction time: $t(53)=1.77, p=.08, d=0.49,95 \% \mathrm{Cl}$ of $d$ [-0.06 to 1.03]).

We repeated the analysis excluding the 6 male participants and results yielded comparable results, with the optimism $x$ pain interaction effect on switch cost reaction time not reaching significance $\left(F(1,48)=2.86, p=0.10, n p^{2}=.06\right)$, but the optimism $x$ pain interaction effect on sensitive switch cost reaction time remaining significant $(F(1,48)=$ $5.14, p=0.03, n p^{2}=.10$ ). More importantly, the pattern remained the same in that only participants in the TD condition showed pain-induced task deterioration. 


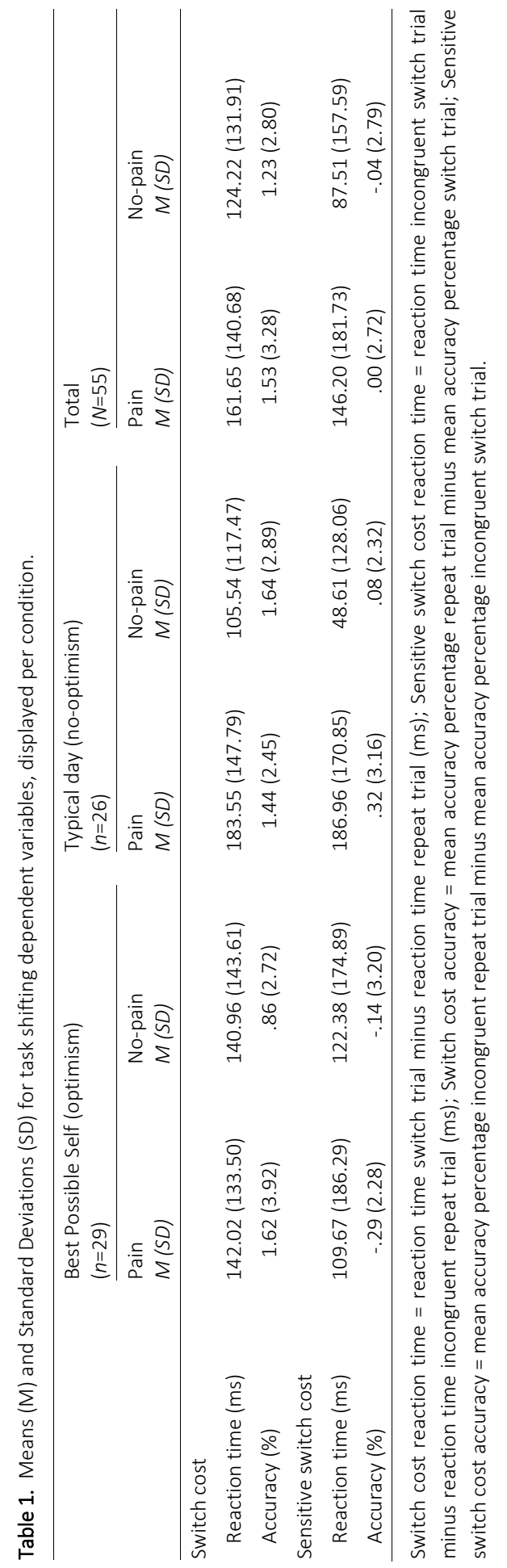




\section{DISCUSSION}

The aim of the study was to examine whether experimental pain negatively affects concurrent executive task performance as measured by the shifting task, and whether optimism can protect against this deteriorating effect. Results demonstrate that shifting performance was impaired when experimental heat pain was applied during task execution, and that inducing a temporary optimistic state can counteract pain-induced deteriorating in task shifting performance. To be more precise, results indicated that decrements on (sensitive) switch cost reaction times were only apparent in the TD condition. Irrespective of pain, participants in the BPS condition showed comparable response times.

Prior research $[11 ; 16-18 ; 21 ; 36 ; 41 ; 42 ; 49-51 ; 62 ; 80]$ has shown that pain attracts our attention which leads to pain-induced interference effects on concurrent task performance. The ability to shift requires individuals to switch their attention flexibly between multiple demands, by inhibiting irrelevant responses and facilitating relevant responses. In the context of pain, an individual not only needs to inhibit responding to the irrelevant task but also needs to inhibit responding to the pain stimulus. The ability to shift becomes compromised if attention towards the pain stimuli is prioritized over giving attention towards the shifting task or when pain decreases the existing resources that are necessary for fast and accurate task performance. The present results showed that pain indeed interferes with this shifting ability as responses after a task switch were slower. However, in contrast to prior studies [36; 50; 51], the presence of pain did not deteriorate task shifting accuracy. Thus, participants needed more time to arrive at the same accurate response when they experienced concurrent pain.

The primary purpose of this study was to examine whether optimism can protect against these pain-induced shifting impairments. Results showed that inducing a temporary optimistic state, by means of the Best Possible Self writing and visualization exercise was able to counteract the pain-induced interference effect on concurrent task shifting performance. There are several possibilities why optimism may act as a protective factor in this context. Within the context of the competing limited resources theory [20; 21] two potential mechanisms are proposed. First, optimism may increase cognitive or self-regulation resources, leading to an adaptation of the challenges of coping with pain while simultaneously performing a task [71-73]. Second, optimism may increase an individual's ability to prioritize attention towards accurate shifting performance and by preventing a predominant response to be interrupted by the pain. This protective effect of optimism may also be explained within the context of the integrative neurocognitive model, which proposes that top-down variables can modulate the ability of pain to capture an individual's attention at the expense of accurate task performance [43]. Optimism may increase top-down modulation by variables such as goal perseverance and effort, leading to higher goal attainment despite experiencing pain $[1 ; 14 ; 19 ; 64$; 86]. Both increasing resources and attention (i.e., by either prioritizing of attention or 
modulating top-down variables) are viable explanations of the protective ability of optimism from the perspective of the broaden-and-build theory [25]. This theory states that positive emotions are able to broaden an individual's attention and thinking pattern and build personal resources, causing an upward spiral to ensue in which building durable resources results in further positive emotions, in turn enhancing an individual's subsequent emotional well-being [25; 26; 28-30].

There are three core executive functions that are often postulated: inhibition, updating and shifting [46]. The current finding that optimism protects against the negative effects of pain on shifting ability is in line with our prior study that found a similar effect on the executive function updating [8]. However, it should be noted that inconsistencies in these latter findings have been found. Hence, the protective effect of optimism was shown when updating was measured with the operation-span task [8] but not when using the 2-back task [7]. It is possible that optimism can only act as a protective factor when task demands are high, increasing the attentional load, ensuing more executive resources to be allocated to performing the task [40; 42; 61]. It might be suggested that the task load is higher in the shifting and operation-span task compared to the 2-back task. Taken together, these findings indicate that future research should examine whether task load is an important factor to consider when investigating pain and optimism effects on executive task performance.

The current findings might have clinical implications. Most of the prior discussed studies used experimental pain to examine its influence on time-limited and brief tasks in healthy participants, but persistent pain has also been shown to impair executive functioning in chronic pain patients [6;52]. The current finding suggests that these paininduced impairments may be an obstacle to accurately perform everyday tasks. As such, these impairments may have a marked impact on work performance. Indeed, one in four chronic pain patients report that their pain impacted their employment status [10] and pain is associated with marked loss in productive time due to reduced work performance [75]. Prior research has found that optimism is associated with experiencing less goal barriers and more goal attainment despite experiencing chronic pain [1; 14; 19].

Taken together with the current finding that optimism counteracts executive task deterioration, it is imperative to examine whether chronic pain patients can benefit from interventions aimed to increase optimism and positive emotions, such as acceptance and commitment therapy [77; 83], mindfulness-based cognitive therapy [32; 84], positive psychotherapy [65] or implementing positive psychology exercises [58; 66; 67; 85] in current treatment approaches such as cognitive-behavioural therapy [53]. Results of a recent published pilot study confirmed the feasibility and acceptability of an intervention based on positive psychology techniques such as the Best Possible Self exercise in chronic pain patients [24]. Similarly, a recently completed randomized controlled trial showed that this intervention can be delivered online. More importantly the intervention significantly increased happiness and optimism, and decreased pain catastrophizing and anxiety in chronic pain patients [56]. Next to these improvements 
on positive and negative trait and state variables, it should be further explored whether this positive psychology internet intervention can also counteract pain-induced cognitive impairments.

It should be noted that the current study had some limitations. The generalization of these results towards a chronic pain population is limited as the study sample consisted of healthy students that experienced experimentally induced pain. However, the pain stimulus was designed in a way to mimic the experience of persistent pain by using a continuous stimulation that fluctuates over time compared to a phasic stimulation. Furthermore, although the task switching paradigm is widely used as an approach to study mental set shifting and switch cost are a robust finding [48; 68; 81], reliability scores of the task shifting task vary (ranging from .46 to .91) [3; 34; 46; 68]. Future research should attempt to gain more insight how reliability can be improved so it is possible to compare outcomes. Additionally, pain was not measured during task performance, as the very act of rating pain intensity would have disrupted task performance [39]. As a consequence, it is not possible to disentangle the effects of pain on task performance in function of the experienced pain intensity. Moreover, both positive affect and optimism were changed by the manipulation, reflecting the intertwined nature of affect and optimism. However, as we cannot separate these constructs, it remains unclear whether the protective effect demonstrated in this study is not merely the result of an overall positive emotional state. Furthermore, as the written narratives of the optimism manipulation were not analysed for their content, we cannot check the degree to which participants adhered to the instructions. However, based on the manipulation checks, we have no reason to assume that the instructions were not followed. Future research might include content analyses though, in order to gain better insight in factors that influence effectiveness of the manipulation. Lastly, it is noteworthy to mention that predominantly female students participated in the study. Although females may exhibit greater pain sensitivity (e.g., lower pain threshold, tolerance and higher pain intensity) than males [4; 23], a potential bias effect of gender is weakened in this study by using a calibration procedure to identify individual pain threshold levels.

In conclusion, the present study shows that experimentally induced pain impairs shifting task performance. Additionally, a brief optimism manipulation counteracted this pain-induced deterioration of shifting task performance. We aim to extend these findings to chronic pain patients and examine whether increasing optimism can also protect against executive functioning impairments due to chronic pain.

\section{ACKNOWLEDGEMENTS}

The authors thank Nick van der Sluiszen for programming the task and Fauves van Kervinck and Linda Vos for their help in the data collection. 


\section{REFERENCES}

[1] Affleck G, Tennen H, Zautra A, Urrows S, Abeles M, Karoly P. Women's pursuit of personal goals in daily life with fibromyalgia: A value-expectancy analysis. Journal of Consulting and Clinical Psychology 2001;69(4):587-596.

[2] Altmann EM, Gray WD. An integrated model of cognitive control in task switching. Psychological Review 2008;115(3):602.

[3] Attridge N, Crombez G, Van Ryckeghem D, Keogh E, Eccleston C. The Experience of Cognitive Intrusion of Pain: scale development and validation. Pain 2015;156(10):1978.

[4] Berkley KJ. Sex differences in pain. Behavioral and Brain Sciences 1997;20(03):371-380.

[5] Berryman C, Stanton TR, Bowering KJ, Tabor A, McFarlane A, Moseley GL. Evidence for working memory deficits in chronic pain: a systematic review and meta-analysis. Pain 2013;154(8):1181-1196.

[6] Berryman C, Stanton TR, Bowering KJ, Tabor A, McFarlane A, Moseley GL. Do people with chronic pain have impaired executive function? A meta-analytical review. Clinical Psychology Review 2014;34(7):563579.

[7] Boselie JJ, Vancleef LM, Peters ML. The effects of experimental pain and induced optimism on working memory task performance. Scandinavian Journal of Pain 2016;12:25-32.

[8] Boselie JJ, Vancleef LM, Smeets T, Peters ML. Increasing optimism abolishes pain-induced impairments in executive task performance. Pain 2014;155(2):334-340.

[9] Boselie JJLM, Vancleef LMG, Peters ML. The effects of experimental pain and induced optimism on working memory task performance. Scandinavian Journal of Pain 2016.

[10] Breivik H, Collett B, Ventafridda V, Cohen R, Gallacher D. Survey of chronic pain in Europe: Prevalence, impact on daily life, and treatment. Eur J Pain 2006;10(4):287-333.

[11] Buhle J, Wager TD. Performance-dependent inhibition of pain by an executive working memory task. Pain 2010;149(1):19-26.

[12] Carver CS, Scheier MF. Origins and functions of positive and negative affect: A control-process view. Psychological Review 1990;97(1):19-35.

[13] Carver CS, Scheier MF. On the self-regulation of behavior. New York, NY US: Cambridge University Press, 1998.

[14] Carver CS, Scheier MF, Segerstrom SC. Optimism. Clinical Psychology Review 2010;30(7):879-889.

[15] Crawford JR, Henry JD. The Positive and Negative Affect Schedule (PANAS): Construct validity, measurement properties and normative data in a large non-clinical sample. British Journal of Clinical Psychology 2004;43(3):245-265.

[16] Crombez G, Eccleston C, Baeyens F, Eelen P. The disruptive nature of pain: An experimental investigation. Behaviour Research and Therapy 1996;34(11-12):911-918.

[17] Crombez G, Eccleston C, Baeyens F, Eelen P. Habituation and the interference of pain with task performance. Pain 1997;70(2):149-154.

[18] Crombez G, Eccleston C, Baeyens F, Eelen P. Attentional disruption is enhanced by the threat of pain. Behaviour Research and Therapy 1998;36(2):195-204.

[19] Duke J, Leventhal H, Brownlee S, Leventhal EA. Giving up and replacing activities in response to illness. The Journals of Gerontology: Series B: Psychological Sciences and Social Sciences 2002;57B(4):P367P376.

[20] Eccleston C. Chronic pain and attention: A cognitive approach. British Journal of Clinical Psychology 1994;33(4):535-547.

[21] Eccleston C, Crombez G. Pain demands attention: A cognitive-affective model of the interruptive function of pain. Psychological Bulletin 1999;125(3):356-366.

[22] Faul F, Erdfelder E, Lang A-G, Buchner A. G* Power 3: A flexible statistical power analysis program for the social, behavioral, and biomedical sciences. Behavior research methods 2007;39(2):175-191.

[23] Fillingim RB, Maixner W. Gender differences in the responses to noxious stimuli, Proceedings of the Pain forum, Vol. 4: Elsevier, 1996. pp. 209-221. 
[24] Flink IK, Smeets E, Bergbom S, Peters ML. Happy despite pain: Pilot study of a positive psychology intervention for patients with chronic pain. Scandinavian Journal of Pain 2015;7:71-79.

[25] Fredrickson BL. What good are positive emotions? Review of general psychology 1998;2(3):300.

[26] Fredrickson BL. The role of positive emotions in positive psychology: The broaden-and-build theory of positive emotions. American psychologist 2001;56(3):218.

[27] Fredrickson BL. The broaden-and-build theory of positive emotions. Philosophical transactions-royal society of london series b biological sciences 2004:1367-1378.

[28] Fredrickson BL. Positive emotions broaden and build. Advances in experimental social psychology 2013;47(1):53.

[29] Fredrickson BL, Joiner T. Positive emotions trigger upward spirals toward emotional well-being. Psychological Science 2002;13(2):172-175.

[30] Garland EL, Fredrickson B, Kring AM, Johnson DP, Meyer PS, Penn DL. Upward spirals of positive emotions counter downward spirals of negativity: Insights from the broaden-and-build theory and affective neuroscience on the treatment of emotion dysfunctions and deficits in psychopathology. Clinical Psychology Review 2010;30(7):849-864.

[31] Gilbert SJ, Burgess PW. Executive function. Current Biology 2008;18(3):R110-R114.

[32] Grossman P, Niemann L, Schmidt S, Walach H. Mindfulness-based stress reduction and health benefits: A meta-analysis. J Psychosom Res 2004;57(1):35-43.

[33] Hanssen MM, Peters ML, Vlaeyen JW, Meevissen YM, Vancleef LM. Optimism lowers pain: Evidence of the causal status and underlying mechanisms. Pain 2013;154(0):53-58.

[34] Hart RP, Martelli MF, Zasler ND. Chronic pain and neuropsychological functioning. Neuropsychology review 2000;10(3):131-149.

[35] In Den Bosch-Meevissen Y, Peters ML, Alberts HJ. Dispositional optimism, optimism priming, and prevention of ego depletion. European Journal of Social Psychology 2014;44(6):515-520.

[36] Keogh E, Cavill R, Moore DJ, Eccleston C. The effects of menstrual-related pain on attentional interference. Pain 2014;155(4):821-827.

[37] Kiesel A, Steinhauser M, Wendt M, Falkenstein M, Jost K, Philipp AM, Koch I. Control and interference in task switching-A review. Psychological Bulletin 2010;136(5):849.

[38] King LA. The health benefits of writing about life goals. Personality and Social Psychology Bulletin 2001;27(7):798-807.

[39] Koyama Y, Koyama T, Kroncke AP, Coghill RC. Effects of stimulus duration on heat induced pain: the relationship between real-time and post-stimulus pain ratings. Pain 2004;107(3):256-266.

[40] Legrain V, Crombez G, Mouraux A. Controlling attention to nociceptive stimuli with working memory. 2011.

[41] Legrain V, Crombez G, Verhoeven K, Mouraux A. The role of working memory in the attentional control of pain. Pain 2011;152(2):453-459.

[42] Legrain V, Damme SV, Eccleston C, Davis KD, Seminowicz DA, Crombez G. A neurocognitive model of attention to pain: behavioral and neuroimaging evidence. Pain 2009;144(3):230-232.

[43] Legrain V, Van Damme S, Eccleston C, Davis KD, Seminowicz DA, Crombez G. A neurocognitive model of attention to pain: behavioral and neuroimaging evidence. Pain 2009;144(3):230-232.

[44] Mahler H, Kulik J. Optimism, pessimism and recovery from coronary bypass surgery: Prediction of affect, pain and functional status. Psychology, health \& medicine 2000;5(4):347-358.

[45] Meiran N. Reconfiguration of processing mode prior to task performance. Journal of Experimental Psychology: Learning, Memory, and Cognition 1996;22(6):1423.

[46] Miyake A, Friedman NP, Emerson MJ, Witzki AH, Howerter A. The unity and diversity of executive functions and their contributions to complex 'frontal lobe' tasks: A latent variable analysis. Cognitive Psychology 2000;41(1):49-100.

[47] Miyake A, Friedman NP, Emerson MJ, Witzki AH, Howerter A, Wager TD. The Unity and Diversity of Executive Functions and Their Contributions to Complex "Frontal Lobe" Tasks: A Latent Variable Analysis. Cognitive Psychology 2000;41(1):49-100.

[48] Monsell S. Task switching. Trends in Cognitive Sciences 2003;7(3):134-140. 
[49] Moore DJ, Keogh E, Eccleston C. The interruptive effect of pain on attention. The Quarterly Journal of Experimental Psychology 2012;65(3):565-586.

[50] Moore DJ, Keogh E, Eccleston C. The effect of threat on attentional interruption by pain. Pain 2013;154(1):82-88.

[51] Moore DJ, Keogh E, Eccleston C. Headache impairs attentional performance. Pain 2013;154(9):18401845.

[52] Moriarty O, McGuire BE, Finn DP. The effect of pain on cognitive function: a review of clinical and preclinical research. Progress in Neurobiology 2011;93(3):385-404.

[53] Morley S, Eccleston C, Williams A. Systematic review and meta-analysis of randomized controlled trials of cognitive behaviour therapy and behaviour therapy for chronic pain in adults, excluding headache. Pain 1999;80(1):1-13.

[54] Osman A, Barrios FX, Gutierrez PM, Kopper BA, Merrifield T, Grittmann L. The Pain Catastrophizing Scale: Further psychometric evaluation with adult samples. Journal of Behavioral Medicine 2000;23(4):351365.

[55] Peters ML, Flink IK, Boersma K, Linton SJ. Manipulating optimism: Can imagining a best possible self be used to increase positive future expectancies? The Journal of Positive Psychology 2010;5(3):204-211.

[56] Peters ML, Smeets, E., Feijge, M., van Breukelen, G., Andersson, G., Buhrman, M., \& Linton, S. J. Happy despite pain: a randomized controlled trial of an 8-week internet-delivered positive psychology intervention for enhancing well-being in patients with chronic pain. Clinical journal of pain in press.

[57] Posner MI, Boies SJ. Components of attention. Psychological review 1971;78(5):391.

[58] Rashid T, Ostermann RF. Strength-based assessment in clinical practice. Journal of clinical psychology 2009;65(5):488-498.

[59] Rasmussen HN, Wrosch C, Scheier MF, Carver CS. Self-regulation processes and health: the importance of optimism and goal adjustment. J Pers 2006;74(6):1721-1747.

[60] Rogers RD, Monsell S. Costs of a predictible switch between simple cognitive tasks. Journal of Experimental Psychology: General 1995;124(2):207.

[61] Romero YR, Straube T, Nitsch A, Miltner WH, Weiss T. Interaction between stimulus intensity and perceptual load in the attentional control of pain. Pain 2013;154(1):135-140.

[62] Ryckeghem D, Crombez G, Eccleston C, Legrain V, Damme S. Keeping pain out of your mind: The role of attentional set in pain. Eur J Pain 2013;17(3):402-411.

[63] Scheier MF, Carver CS, Bridges MW. Distinguishing optimism from neuroticism (and trait anxiety, selfmastery, and self-esteem): A reevaluation of the Life Orientation Test. Journal of Personality and Social Psychology 1994;67(6):1063-1078.

[64] Schmitz U, Saile H, Nilges P. Coping with chronic pain: Flexible goal adjustment as an interactive buffer against pain-related distress. Pain 1996;67(1):41-51.

[65] Seligman ME, Rashid T, Parks AC. Positive psychotherapy. American psychologist 2006;61(8):774.

[66] Seligman ME, Steen TA, Park N, Peterson C. Positive psychology progress: empirical validation of interventions. American psychologist 2005;60(5):410.

[67] Sheldon KM, Lyubomirsky S. How to increase and sustain positive emotion: The effects of expressing gratitude and visualizing best possible selves. The Journal of Positive Psychology 2006;1(2):73-82.

[68] Smeets E, Neff K, Alberts H, Peters M. Meeting suffering with kindness: Effects of a brief self-compassion intervention for female college students. Journal of Clinical Psychology 2014;70(9):794-807.

[69] Smith EE, Jonides J. Storage and executive processes in the frontal lobes. Science 1999;283(5408):16571661.

[70] Solberg Nes L, Carlson CR, Crofford LJ, de Leeuw R, Segerstrom SC. Self-regulatory deficits in fibromyalgia and temporomandibular disorders. Pain 2010;151(1):37-44.

[71] Solberg Nes L, Carlson CR, Crofford LJ, de Leeuw R, Segerstrom SC. Individual differences and selfregulatory fatigue: optimism, conscientiousness, and self-consciousness. Personality and Individual Differences 2011;50(4):475-480.

[72] Solberg Nes L, Carlson CR, Crofford LJ, Leeuw Rd, Segerstrom SC. Self-regulatory deficits in fibromyalgia and temporomandibular disorders. Pain 2010;151(1):37-44. 
[73] Solberg Nes L, Roach AR, Segerstrom SC. Executive functions, self-regulation, and chronic pain: A review. Annals of Behavioral Medicine 2009;37(2):173-183.

[74] Solberg Nes L, Segerstrom SC, Sephton SE. Engagement and Arousal: Optimism's Effects During a Brief Stressor. Personality and Social Psychology Bulletin 2005;31(1):111-120.

[75] Stewart WF, Ricci JA, Chee E, Morganstein D, Lipton R. Lost productive time and cost due to common pain conditions in the US workforce. Jama 2003;290(18):2443-2454.

[76] Sullivan MJL, Bishop SR, Pivik J. The Pain Catastrophizing Scale: Development and validation. Psychological Assessment 1995; 7(4):524-532.

[77] Thorsell J, Finnes A, Dahl J, Lundgren T, Gybrant M, Gordh T, Buhrman M. A comparative study of 2 manual-based self-help interventions, acceptance and commitment therapy and applied relaxation, for persons with chronic pain. The Clinical journal of pain 2011;27(8):716-723.

[78] Van Breukelen GJP. ANCOVA versus change from baseline had more power in randomized studies and more bias in nonrandomized studies. Journal of Clinical Epidemiology 2006;59(9):920-925.

[79] Van Ryckeghem DM, Crombez G, Eccleston C, Liefooghe B, Van Damme S. The interruptive effect of pain in a multitask environment: an experimental investigation. The Journal of Pain 2012;13(2):131-138.

[80] Vancleef LM, Peters ML. The interruptive effect of pain on attention. J Pain 2006;7(1):21-22.

[81] Vandierendonck A, Liefooghe B, Verbruggen F. Task switching: interplay of reconfiguration and interference control. Psychological Bulletin 2010;136(4):601.

[82] Watson D, Clark LA, Tellegen A. Development and validation of brief measures of positive and negative affect: The PANAS scales. Journal of Personality and Social Psychology 1988;54(6):1063-1070.

[83] Wetherell JL, Afari N, Rutledge T, Sorrell JT, Stoddard JA, Petkus AJ, Solomon BC, Lehman DH, Liu L, Lang AJ. A randomized, controlled trial of acceptance and commitment therapy and cognitive-behavioral therapy for chronic pain. Pain 2011;152(9):2098-2107.

[84] Wong SY-S, Chan FW-K, Wong RL-P, Chu M-C, Lam Y-YK, Mercer SW, Ma SH. Comparing the effectiveness of mindfulness-based stress reduction and multidisciplinary intervention programs for chronic pain: a randomized comparative trial. The Clinical journal of pain 2011;27(8):724-734

[85] Worthington Jr EL, Kurusu TA, Collins W, Berry JW. Forgiving usually takes time: A lesson learned by studying interventions to promote forgiveness. Journal of Psychology and Theology 2000;28(1):3.

[86] Wrosch C, Scheier MF. Personality and quality of life: The importance of optimism and goal adjustment. Quality of Life Research: An International Journal of Quality of Life Aspects of Treatment, Care \& Rehabilitation 2003;12(Suppl1):59-72. 



\section{Chapter five}

Family matters: exploring the working mechanism of the Best Possible Self manipulation to induce optimism working mechanism of the Best Possible Self manipulation to induce optimism. 


\section{ABSTRACT}

The Best Possible Self (BPS) is an effective manipulation to temporarily increase optimism (i.e., increasing positive future expectancies and decreasing negative future expectancies) and positive affect. The BPS is a positive future thinking technique in which participants write about and imagine a life in the future where everything turned out for the best. In the control condition, participants describe a typical day (TD). This study examined possible factors that contribute to the effectiveness of the BPS manipulation by analysing narratives that participants wrote in a number of studies using the BPS manipulation. In total, 111 BPS descriptions and 108 TD descriptions were digitalized. Linguistic analyses and qualitative ratings showed that the BPS manipulation was more effective when BPS participants wrote more about personal family life (i.e., family, friends, sex and social relationships), used more positive emotion words and wrote less about physical health and described fewer materialistic goals. Future research may want to consider instructing participants to write specifically about family and friends to increase the effectiveness of the BPS manipulation. 


\section{INTRODUCTION}

Optimism is the tendency to expect that good things will happen in the future [5]. This tendency to hold global positive future expectancies has been associated with beneficial coping strategies [28; 34], applying different coping strategies more flexibly [28; 34] increased subjective well-being and decreased illness [20]. Recently, research adapted a focus on studying the causal influence of optimism. One way to do this is using a manipulation to increase optimism, such as the Best Possible Self (BPS) manipulation [26]. The BPS is a positive future thinking technique based on work by King [20]. Participants are asked to write about and imagine a life in the future where everything turned out for the best. In the control condition, participants describe a typical day (TD). Numerous studies $[1 ; 3 ; 4 ; 17 ; 26]$ demonstrated that the BPS manipulation is effective in increasing optimism (i.e., increasing positive future expectancies and decreasing negative future expectancies) and positive affect. However, no research so far has explored possible working mechanisms that contribute to the effectiveness of the BPS manipulation. The present study explored whether content and quality of the BPS written descriptions predict BPS effectiveness.

In total, 111 BPS descriptions and 108 TD descriptions from prior studies were digitalized $[1 ; 3 ; 17]$. The content was analysed in two ways. First, linguistic analysis was used to investigate differences in word use in BPS descriptions, as compared to TD descriptions. Linguistic analysis (i.e., Linguistic Inquiry and Word Count (LIWC; [25]) allows researchers to use language as a tool for providing insight into psychological processes and identifying emotions that occur during writing [36]. The LIWC computer program categorizes words into categories. We hypothesized that the BPS descriptions will be more positively framed (i.e., more positive emotions and less negative emotions), and have more words that fall within the category personal family life and professional life, compared to the TD descriptions. Second, the BPS descriptions were rated qualitatively: the numbers of goals/wishes within 10 domains were rated. The BPS instructions do not specify any writing domains; therefore, we described 10 domains (i.e., family, love life, career, education, leisure, social life, social involvement, personal growth, physical health and materialism) that are proposed to be relevant to the BPS manipulation. We hypothesized that more goals or wishes within domains increases the efficacy of the BPS exercise in eliciting positive feelings and increasing optimism. Moreover, it could be that especially writing and visualizing about certain domains makes the BPS exercise more effective.

With regard to the quality, the BPS descriptions were rated on 9 qualitative classification domains (i.e., effort, concreteness, writing term, argumentation, realism, openness, creativity, certainty, and writer's perspective). We hypothesized that especially more effort, concreteness, openness and creativity predict a greater change in positive feelings and optimism after the BPS manipulation. We speculate that higher writing 
quality will lead to more detailed BPS descriptions, which may increase vividness of the BPS imagery, which in turn may increase the efficacy of the BPS manipulation.

In sum, we hypothesized that (i) specific content (i.e., words related to positive emotions, personal family life and professional life) are more present in BPS descriptions compared to TD descriptions, (ii) more goals (i.e., within the domains: family, love life, career, social life, social involvement and personal growth) and (iii) better quality (i.e., more effort, concreteness, openness and creativity) of the BPS narratives will predict more effectiveness of the BPS manipulation.

\section{METHOD}

\section{Participants}

A total of 219 (45 males; mean age $=22.0(S D=3.4)$ years) healthy undergraduates from Maastricht University were included in this study. Participants were randomly assigned to the Best Possible Self (BPS) condition ( $n=111 ; 24$ males; mean age $=22.0$ $(S D=2.9)$ years) or the Typical Day (TD) control condition ( $n=108 ; 21$ males; mean age $=21.9$ (SD = 3.8 years). The BPS and TD written descriptions that were used in the present study were derived from prior studies [1; 3; 17]. Only Dutch descriptions were included, as we used a Dutch dictionary for the linguistic analysis.

\section{Optimism manipulation}

Participants were instructed to carry out the Best Possible Self (BPS) writing and imagery exercise. Participants in the BPS condition were required to write about a life in the future where everything turned out for the best. Participants in the control condition had to write about a typical day (TD). The instructions were as follows [26; 31]. BPS condition: "Think about your best possible self' means that you imagine yourself in the future, after everything has gone as well as it possibly could. You have worked hard and succeeded at accomplishing all the goals of your life. Think of this as the realization of your dreams, and that you have reached your full potential". TD condition: "Think about your typical day' means that you take notice of ordinary details of your day that you usually don't think about. These might include particular classes or meetings you attend to, people you meet, things you do, typical thoughts you have during the day. Think of this as moving through your typical day, hour after hour".

Both manipulations had the same procedural format: participants were requested to think for 1 minute about what to write, then to write uninterrupted for 15 minutes, followed by 5 minutes of imaging the story they had just finished writing. Instructions were given both verbally and in writing. 


\section{Rating}

The raters used a scoring form, which is divided into classifications about content and quality. The content classification consists of 10 domains (i.e., family, love life, career, education, leisure, social life, social involvement, personal growth, physical health and materialism). Eight of these domains were used in a prior study that examined the effectiveness of a positive psychology intervention that included the BPS exercise [27] and we added the domains physical health and materialism. Raters were asked to rate the number of goals/wishes within these 10 domains. For instance, within the family domain, a participant may wish for a child or that his or her parents grow old together. Similar, within the personal growth domain, a participant could wish for a healthy mental status or being more satisfied with life. The quality classification consists of 9 domains: effort, concreteness, writing term, argumentation, realism, openness, creativity, certainty, and writer's perspective. These classifications were rated on a 5-point Likert scale, ranging from 1 (no effort/ not concrete/ short-term/ not a lot of argumentation/ not realistic/ not open/ not creative/ not certain) to 5 (a lot of effort/ concrete/ long term/ a lot of argumentation/ very realistic/ very open/ very creative/ very certain), except for the writer's perspective (i.e., only 2: first person or third person view) classification. In case of doubt, raters were instructed to choose the lower option. For instance, is the BPS description predominately about short-term goals and wishes (e.g., graduation, first job) or about more long-term goals and wishes (e.g., growing old, pension and grandchildren)? In the case of openness: does the BPS description contain a personal component that reveals a part of themselves? Certainty relates to whether the BPS description is written as a fact, or more something that could possibly happen. From a total of 111 BPS descriptions, 34 BPS descriptions (30.6 \%) were rated by both raters to calculate the inter-rater reliability. Stratified randomization was used to select these 34 BPS descriptions, such that BPS descriptions from each study were selected. The remaining 77 BPS descriptions were rated independently (i.e., rater $1 \mathrm{n}=39$; rater 2 $n=38$ ), which were randomly assigned to the raters with the restriction that both raters rated BPS descriptions from the 3 studies.

\section{Linguistic analysis}

The Linguistic Inquiry and Word Count (LIWC) [25] program with the Dutch dictionary [40] was used to analyze the BPS and TD written descriptions linguistically. The LIWC computer program categorizes words into categories and computes the percentages of words judged to reflect these content categories. Categories can be divided into language categories (e.g., pronouns, future tense) and psychological processes, such as positive (e.g., love, nice) and negative (e.g., hurt, nasty) emotion words [25]. The Dutch LIWC has been determined as a valid instrument to examine emotional expressions [41]. In the present study we used the content categories as generated from LIWC (I, 
We, Self, You, Present, Future, Money, Physical health) and we combined some categories that were similar in content to reduce the number of independent variables, namely personal family life (i.e., Family, Humans, Friends, Sexual and Social), professional life (i.e., Achieve, Job, School and Occupation), positive emotions (Positive emotions, Positive feelings and Optimism), negative emotions (Negative emotions, Anxiety, Anger and Sad), leisure (i.e., Leisure, Sports, TV and Music) and daily activities (i.e., Eating, Sleep and Groom).

\section{Questionnaires}

\section{Optimism}

The Life Orientation Test-Revised (LOT-R) [30] measures dispositional optimism and consists of 10 items: 3 positively phrased items (e.g. 'I'm always optimistic about my future'), 3 negatively phrased items (e.g. 'I rarely count on good things happening to me') and 4 filler items (e.g., 'It's important for me to keep busy'). The items are rated on a 5 -point Likert scale, ranging from 1 (strongly disagree) to 5 (strongly agree). The total LOT-R score is obtained by summation of the scores on the positively phrased items and the reversed scores on the negatively phrased items and ranges from 10 to 30 . Higher scores reflect higher levels of dispositional optimism. The LOT-R has been demonstrated to be a reliable and valid measurement instrument [30] and internal consistency was satisfactory in this study with a Cronbach's alpha of .74.

\section{Affect}

In two studies [1; 3] affect was measured with the Positive and Negative Affect Schedule (PANAS) [38]. The PANAS consists of 20 items that measure positive (PA, 10 items) and negative (NA, 10 items) affect. Examples of PA items are 'excited' and 'inspired'. Examples of NA items are 'nervous' and 'afraid'. Patients indicate the degree to which a certain feeling is present at that moment on a 5-point Likert scale ranging from 1 (not at all) to 5 (extremely). Subscale scores can range from 10 to 50, with higher scores on NA items reflecting higher levels of emotional distress. In contrast, high PA scores correspond to experiencing more pleasurable feelings. The PANAS subscales have been demonstrated to be valid and reliable [6]. Cronbach's alphas in the present study for the positive and negative subscale were .85 and .86 respectively.

\section{Future expectancies}

The Future Expectancies Scale (FEX) [19] measures positive and negative future expectancies. It consists of 20 items that make statements about positive ( $n=10$; e.g., 'people will admire you') and negative ( $n=10$; e.g., 'things will not turn out as you had hoped") future events. The 20 statements cover 5 different domains (work, health, personal, social and general). Participants rate the likelihood that they will experience the specific events on a 7-point Likert scale, ranging from 1 (not at all likely to occur) to 
7 (extremely likely to occur). Higher scores reflect a higher estimated likelihood of positive (FEX-Pos) or negative (FEX-Neg) future events, with scores ranging from 10 to 70. The internal consistency of the FEX subscales has been demonstrated to be satisfactory [17]. Both subscales had a Cronbach's alpha of .84 in the present study.

\section{Procedure}

First, all the handwritten BPS and TD descriptions were digitalized and saved as .txt files. Only BPS descriptions were rated on the 10 content classification domains and 9 quality classification domains by two independent raters. In order to reach an acceptable level of agreement, raters could first practice on 8 excluded BPS descriptions (i.e., English descriptions that were translated to Dutch). Next, two excluded BPS descriptions and their ratings were discussed in more detail by the two raters and the authors. When necessary, explanations of the ratings scales were adjusted or information was added to reach more agreement among raters what a certain classification entailed [39]. Subsequently, both raters rated 34 BPS descriptions that were used to calculate interrater reliability, after which the other 77 BPS descriptions were divided among the raters and rated independently from each other.

\section{Data analyses}

Data were checked for a normal distribution and reliability analyses were performed on the LOT-R, PANAS positive, PANAS negative, FEX positive, and the FEX negative questionnaires. Independent-samples t-tests were used to check for baseline differences between the conditions (BPS vs. TD) for optimism and age and a Chi-Square Test for the categorical variable sex. The effectiveness of the optimism manipulation on positive and negative affect and positive and negative future expectancies was tested with ANCOVAs with optimism condition (BPS vs TD) as between subjects factor and baseline scores of positive and negative affect (PANAS centered) and positive and negative future expectancies (FEX centered) as covariates. The manipulation is successful when results show a significant main effect of optimism. This method of analysing is more powerful and precise than using repeated measures ANOVA in a randomized pre-post design [37]. The intra class correlation coefficient (ICC) was calculated as a measure of inter-rater reliability, with a two way fixed model (i.e., participants are random and raters fixed) and absolute agreement among the raters [21;32].

To examine linguistic differences between the BPS descriptions and TD descriptions, independent-samples t-tests were performed with condition (BPS vs. TD) as between subjects variable and the LIWC variables (I, We, Self, You, Present, Future, Money, Physical health, personal family life, professional life, positive emotions, negative emotions, leisure and daily activities) as dependent variables. To examine predictors of improvement on positive future expectancies (change score; post- minus pre-measurement), 
negative future expectancies (change score; pre- minus post- measurement), positive affect (change score; post- minus pre-measurement), and negative affect (change score; pre- minus post- measurement), following the BPS manipulation, three multiple regressions (content, quality and LIWC categories as predictors) were computed using the backward stepwise method. The first model that reached (near) significance, and was the most parsimonious, is reported.

\section{RESULTS}

\section{Baseline descriptives}

Results of the independent-samples t-tests and Chi-Square Tests revealed no significant differences between the BPS and TD condition in age, sex or optimism at baseline (all $p$ values $>$.56).

\section{Optimism (BPS) effect}

The ANCOVAs revealed a significant main effect of optimism condition, controlling for the effect of scores obtained before the manipulation, for positive future expectancies $\left(F(1,216)=39.22, p<0.001, n p^{2}=.15\right)$, PANAS positive affect $(F(1,145=35.38, p<$ $\left.0.001, \eta p^{2}=.20\right)$ and negative future expectancies $\left(F(1,216)=45.44, p<0.001, \eta p^{2}=\right.$ .17). The optimism condition main effect was not significant for PANAS negative affect $\left(F(1,145)=0.55, p=0.46, n p^{2}=.00\right)$. Participants in the BPS condition scored higher on positive future expectancies and PANAS positive affect, and scored lower on negative future expectancies than participants in the TD condition. Participants did not differ on PANAS negative affect. See Table 1 for the estimated means and standard deviation scores for the post manipulation measures.

\section{Inter-rater reliability}

The average ICC ranged from acceptable to excellent for the quantitative classification domains family (.85), love life (.82), leisure (.91), education (.90), social involvement (.84), personal growth (.81), physical health (.73) and materialism (.70). The ICC for the domains social life (.69) and career (.65) were just below acceptable. The average ICC ranged from acceptable to good for the qualitative classification domains effort (.81), concreteness (.74), and certainty (.83). The ICC for the domains writing term (.38), argumentation (.41), realism (.59), openness (.44), and creativity (.67) were below acceptable. The writer's perspective domain did not generate an ICC as raters were in total agreement. Only domains above .60 were used in the analysis and writer's per- 
spective was omitted as almost every BPS description was written in first person perspective.

\section{Linguistic analyses}

Results from the independent-samples t-tests showed that participants in the BPS condition used more the pronoun 'we', words that indicate future tense, and words that relate to money, family life, professional life and positive emotions compared to participants in the TD condition. Moreover, participants in the BPS condition used less the pronoun ' $\mathrm{l}$ ', words that indicate present tense, and words that relate to physical health, negative emotions, leisure and daily activities compared to participants in the TD condition. Results of independent t-tests are presented in Table 2.

\section{Predictors BPS efficacy}

\section{Linguistic categories}

For the linguistic analyses, we used the LIWC categories (I, We, Present, Future, Money, Physical, personal family life, professional life, positive emotions, negative emotions, leisure and daily activities). See Table 3 for the results from the multiple regressions with backward stepwise method. Change in positive future expectancies was significantly predicted by the model $\left(R^{2}=.15, F(2,216)=19.95, p<.001\right)$ including the predictors physical health and personal family life, with all excluded predictors $p>20$. Less physical health words predicted more positive future expectancies and more words indicative of personal family life predicted more positive future expectancies. Change in negative future expectancies was significantly predicted by the model $\left(R^{2}=.13, F(3,215)=\right.$ $11.88, p<.001$ ) including the predictors future, personal family life, and positive emotions, with all excluded predictors $p>$.17. BPS descriptions with more words indicative of future, personal family life and positive emotions were predictive of more reduction in negative future expectancies. Change in positive affect was significantly predicted by the model $\left(R^{2}=.18, F(2,145)=17.42, p<.001\right)$ including the predictors personal family life and positive emotions, with all excluded predictors $p>$.15. BPS descriptions with more words indicative of personal family life and positive emotions predicted more positive affect. Change in negative affect was significantly predicted by the model $\left(R^{2}=\right.$ $.04, F(2,145)=3.66, p=.03)$ including the predictors we and daily activities, with all excluded predictors $p>$.34. BPS narratives that contained more often the pronoun we and words related to daily activities predicted more reduction in negative affect. 


\section{Content classifications}

Participants described in total between the 8 and 46 goals ( $m=25.34 ; S D=7.42)$, with family domain ranging from 0 to 15 ( $m=4.86$; $S D=3.19)$ love life ranging from 0 to 7 ( $m$ $=2.76 ; S D=1.55)$, career ranging from 0 to $10(m=4.23 ; S D=1.90)$, education ranging from 0 to $6(m=1.59 ; S D=1.71)$, leisure ranging from 0 to $10(m=4.23 ; S D=2.47)$, social life ranging from 0 to $8(m=2.45 ; S D=1.66)$, social involvement ranging from 0 to $4(m=0.65 ; S D=1.12)$, personal growth ranging from 0 to $10(m=1.92 ; S D=2.05)$, physical health ranging from 0 to $4(m=0.77 ; S D=1 ., 04)$, and materialism ranging from 0 to 6 ( $m=1.87 ; S D=1.80)$.

See Table 4 for the results from the multiple regressions with backward stepwise method. Results showed that change in positive future expectancies was not significantly predicted by any of the models. The best model $\left(R^{2}=.03, F(2,108)=2.56, p=.08\right)$ included the predictors personal growth and materialism, with all excluded predictors $p$ >.32. Change in negative future expectancies was significantly predicted by the model $\left(R^{2}=.03, F(1,109)=4.09, p=.05\right)$ including the predictor materialism, with all excluded predictors $p>$.12. Less materialistic goals predicted more reduction in negative future expectancies. Change in positive affect was not significantly predicted by any of the models. The best model $\left(\mathrm{R}^{2}=.07, F(2,71)=2.80, p=.07\right)$ included the predictors career and leisure, with all excluded predictors $p>$.23. Similar, change in negative affect was not significantly predicted by any of the models. The best model $\left(R^{2}=.12, F(5,68)\right.$ $=1.90, p=.11$ ) included the predictors career, education, personal growth, physical health, and materialism, with all excluded predictors $p>32$.

\section{Quality classifications}

For the qualitative analyses, we used the classification domains effort, concreteness, certainty and creativity. See Table 5 for the results from the multiple regressions with backward stepwise method. Results indicated that change in positive future expectancies was not significantly predicted by any of the models. The best model $\left(R^{2}=.05, F(1\right.$, $109)=1.48, p=.23$ ) included the predictor certainty, with all excluded predictors $p$ >.32. Change in negative future expectancies was not significantly predicted by any of the models. The best model $\left(R^{2}=.01, F(2,108)=1.49, p=.23\right)$ included the predictors effort and creativity, with all excluded predictors $p>32$. Change in positive affect was not significantly predicted by any of the models. The best model $\left(R^{2}<.001, F(1,72)=\right.$ 1.02, $p=.32$ ) included the predictor certainty, with all excluded predictors $p>.40$. Change in negative affect was not significantly predicted by any of the models. The best model $\left(R^{2}=.03, F(1,72)=3.22, p=.08\right)$ included the predictor certainty, with all excluded predictors $p>.29$. 
Table 1. Estimated mean (M), standard deviation (SD) scores and 95\% Confidence Intervals (95\% CI) of future expectancies and affect after the optimism manipulation, displayed per condition.

\begin{tabular}{|c|c|c|c|c|c|c|}
\hline & \multicolumn{3}{|c|}{ Best Possible Self (BPS) } & \multicolumn{3}{|c|}{ Typical Day (TD) } \\
\hline & $n$ & $M(S D)$ & $95 \% \mathrm{Cl}$ & $n$ & $\mathrm{M}(\mathrm{SD})$ & $95 \% \mathrm{Cl}$ \\
\hline Positive future expectancies & 111 & $56.91(4.04)$ & 55.80 to 56.87 & 108 & $53.91(4.08)$ & 53.36 to 54.45 \\
\hline Negative future expectancies & 111 & $26.06(5.62)$ & 25.31 to 26.08 & 108 & $29.70(5.70)$ & 28.94 to 30.46 \\
\hline Positive affect & 74 & $33.12(6.80)$ & 32.00 to 34.22 & 74 & $28.43(6.80)$ & 27.33 to 29.53 \\
\hline Negative affect & 74 & $12.11(3.36)$ & 11.57 to 12.66 & 74 & $12.40(3.36)$ & 11.86 to 12.95 \\
\hline
\end{tabular}

Best Possible Self (BPS) = optimism condition; Typical Day (TD) $=$ control condition.

Table 2. Results of independent t-tests with mean (M) standard deviation (SD) scores examining linguistic differences between BPS and TD descriptions, displayed per condition.

\begin{tabular}{|c|c|c|c|c|c|c|}
\hline & $\begin{array}{l}\text { Best Possible Self } \\
\text { (BPS) }\end{array}$ & $\begin{array}{l}\text { Typical Day (TD) } \\
n=108\end{array}$ & & & & \\
\hline & $\mathrm{M}(\mathrm{SD})$ & $M(S D)$ & t value & $p$ value & Cohen's $d$ & $\begin{array}{l}95 \% \mathrm{Cl} \text { of } \\
\text { Cohen's } d\end{array}$ \\
\hline I & $9.07(2.95)$ & $10.40(3.42)$ & 3.07 & .002 & 0.42 & 0.15 to 0.69 \\
\hline We & $.41(.69)$ & $.13(.32)$ & 3.85 & .000 & 0.52 & 0.25 to 0.79 \\
\hline Present & $13.88(2.26)$ & $15.20(2.68)$ & 3.96 & .000 & 0.54 & 0.27 to 0.81 \\
\hline Future & $1.99(2.11)$ & $.31(.50)$ & 8.04 & .000 & 1.09 & 0.81 to 1.38 \\
\hline Money & $.44(.49)$ & $.28(.39)$ & 2.55 & .012 & 0.35 & 0.08 to 0.61 \\
\hline Physical health & $.83(.67)$ & $2.66(1.43)$ & 12.16 & .000 & 1.65 & 1.34 to 1.96 \\
\hline Personal family life & $9.62(4.05)$ & $3.54(1.89)$ & 14.17 & .000 & 1.92 & 1,60 to 2.25 \\
\hline Professional life & $4.58(2.12)$ & $3.77(2.25)$ & 2.73 & .007 & 0.37 & 0.10 to 0.64 \\
\hline Positive emotions & $4.72(2.27)$ & $1.70(1.26)$ & 12.10 & .000 & 1.64 & 1.33 to 1.95 \\
\hline Negative emotions & $.69(.76)$ & $1.19(1.16)$ & 3.72 & .000 & 0.50 & 0.23 to 0.77 \\
\hline leisure & $2.10(1.59)$ & $3.03(1.89)$ & 3.95 & .000 & 0.54 & 0.27 to 0.81 \\
\hline Daily activities & $.38(.43)$ & $2.67(1.53)$ & 15.13 & .000 & 2.05 & 1.73 to 2.38 \\
\hline
\end{tabular}

Best Possible Self (BPS) = optimism condition; Typical Day (TD) $=$ control condition . 
Table 3. Results from the multiple regressions with linguistic domains as predictors of BPS efficacy.

\begin{tabular}{|c|c|c|c|c|c|c|}
\hline & $\mathrm{n}$ & $M(S D)$ & $b$ (Beta) & $t$ value & $p$ value & $\begin{array}{l}95 \% \text { Confidence } \\
\text { Interval }\end{array}$ \\
\hline \multicolumn{7}{|c|}{ Positive Future Expectancies } \\
\hline physical health & 219 & $1.73(1.44)$ & -.179 & 2.586 & .01 & -.682 to -.092 \\
\hline personal family life & 219 & $6.62(4.39)$ & .283 & 4.095 & .00 & .104 to .298 \\
\hline \multicolumn{7}{|c|}{ Negative Future Expectancies } \\
\hline future & 219 & $1.16(1.75)$ & .124 & 1.905 & .06 & -.011 to .639 \\
\hline personal family life & 219 & $6.62(4.39)$ & .248 & 3.595 & .00 & .113 to .387 \\
\hline positive emotions & 219 & $3.23(2.38)$ & .140 & 2.036 & .04 & .008 to .514 \\
\hline \multicolumn{7}{|l|}{ Positive Affect } \\
\hline personal family life & 148 & $6.37(4.36)$ & .325 & 4.013 & .00 & .205 to .602 \\
\hline Positive emotions & 148 & $3.13(2.30)$ & .195 & 2.403 & .02 & .081 to .835 \\
\hline \multicolumn{7}{|l|}{ Negative Affect } \\
\hline we & 148 & $.28(.57)$ & .157 & 1.908 & .06 & -.032 to 1.854 \\
\hline daily activities & 148 & $1.51(1.54)$ & .182 & 2.218 & .03 & .043 to .744 \\
\hline
\end{tabular}

Table 4. Results from the multiple regressions with content classifications as predictors of BPS efficacy.

\begin{tabular}{|c|c|c|c|c|c|c|}
\hline & $n$ & $M(S D)$ & $b$ (Beta) & $t$ value & $p$ value & $\begin{array}{l}\text { 95\% Confidence } \\
\text { Interval }\end{array}$ \\
\hline \multicolumn{7}{|c|}{ Positive Future Expectancies } \\
\hline personal growth & 111 & $1.92(2.05)$ & .181 & 1.895 & .06 & -.012 to .546 \\
\hline materialism & 111 & $1.87(1.80)$ & .148 & 1.552 & .12 & -.069 to .568 \\
\hline \multicolumn{7}{|c|}{ Negative Future Expectancies } \\
\hline materialism & 111 & $1.87(1.80)$ & -.190 & 2.202 & .05 & -.943 to -.010 \\
\hline \multicolumn{7}{|l|}{ Positive Affect } \\
\hline career & 74 & $4.34(1.95)$ & -.182 & 1.587 & .12 & -1.111 to .126 \\
\hline leisure & 74 & $4.16(2.71)$ & -.187 & 1.636 & .11 & -1.013 to .100 \\
\hline \multicolumn{7}{|l|}{ Negative Affect } \\
\hline personal growth & 74 & $1.82(2.07)$ & .167 & 1.369 & .18 & -.110 to .592 \\
\hline materialism & 74 & $1.82(1.74)$ & .201 & 1.698 & .09 & -.060 to .749 \\
\hline career & 74 & $4.34(1.95)$ & -.167 & 1.432 & .16 & -.612 to .101 \\
\hline education & 74 & $1.77(1.80)$ & .163 & 1.424 & .16 & -.109 to .650 \\
\hline physical health & 74 & $0.72(0.97)$ & -.207 & 1.700 & .09 & -1.376 to .110 \\
\hline
\end{tabular}


Table 5. Results from the multiple regressions with quality classifications as predictors of BPS efficacy.

\begin{tabular}{lcccccc}
\hline \multicolumn{1}{c}{$\mathrm{n}$} & $\mathrm{M}(\mathrm{SD})$ & $b$ (Beta) & $t$ value & $p$ value & $\begin{array}{l}\text { 95\% Confidence } \\
\text { Interval }\end{array}$ \\
\hline $\begin{array}{l}\text { Positive Future Expectancies } \\
\text { certainty }\end{array}$ & 111 & $3.97(1.35)$ & .116 & 1.217 & .23 & -.163 to .683 \\
$\begin{array}{l}\text { Negative Future Expectancies } \\
\text { effort }\end{array}$ & 111 & $3.20(.98)$ & .162 & 1.567 & .12 & -.196 to 1.682 \\
$\begin{array}{l}\text { creativity } \\
\begin{array}{l}\text { Positive Affect } \\
\text { certainty }\end{array} \\
\begin{array}{l}\text { Negative Affect } \\
\text { certainty }\end{array}\end{array}$ \\
\hline
\end{tabular}

\section{DISCUSSION}

The present study was set-up to examine possible factors that contribute to the effectiveness of the BPS manipulation in increasing optimism and positive affect. Results demonstrated that participants in the BPS condition scored higher on positive future expectancies and positive affect, and scored lower on negative future expectancies than participants in the TD condition. Participants did not differ on negative affect. These results are in line with prior studies that used the BPS manipulation [1-3; 18]. Furthermore, participants in the BPS condition used more the pronoun we, future tense and words that relate to money, personal family life, professional life and positive emotions and less the pronoun I, present tense, and words that relate to physical health, negative emotions, leisure and daily activities compared to participants in the TD condition. Additionally, the BPS manipulation was more effective when BPS participants wrote more about personal family life (i.e., family, friends, sex and social relationships), positive emotions (positive emotions, positive feelings and optimism) and less about physical health and had fewer materialistic goals.

Results of the linguistic analyses support the premise that participants adhere to the BPS and TD instructions. Verb tense (e.g., present or future) provides information about the focus of attention [36]. In this case, the focus of BPS descriptions is towards the future compared to the present in the TD descriptions. Similarly, TD descriptions include more words related to daily activities, such as showering or eating breakfast, which indicates that participants write about a typical day. More importantly, the BPS descriptions contain more words related to family, social relationships and positive emotions and less negative emotions, which is associated with better well-being [7-9; 14; 15]. We did not have any specific hypotheses about pronoun use. However, prior findings indicate that people who are in physical or emotional pain use more often the first-person 
singular pronoun (i.e., I). In contrast, the use of the first-person plural pronoun (i.e., we) can indicate that a person feels more socially connected to a group [29] and reflects a motivation to affiliate [33]. Increased use of the pronoun we was also found in a prior study that used linguistic analysis to investigate psychological changes after applying acceptance and positive reappraisal as an emotion strategy [24]. The combination of using more positive emotion words and the pronoun we is line in with the broaden-andbuild theory [9-11]. This theory states that strengthening positive behaviours, emotions and cognitions causes an upward spiral to ensue, in which broadening thinking patterns and building durable personal resources results in further positive emotions and enhanced social integration [9; 10; 12-15].

With regards to the analyses on content and quality classifications, the findings did not confirm our hypotheses that more goals (i.e., within the domains: family, love life, career, social life, social involvement and personal growth) and better quality (i.e., more effort, concreteness, openness and creativity) of the BPS narratives predict BPS efficacy in increasing optimism and positive affect. Only change in negative future expectancies was significantly predicted by fewer goals within the materialism domain. In other words, fewer materialistic goals predicted more decrease in negative future expectancies. These findings imply that neither quantity (i.e., number of goals) nor quality of the narrative is a significant predictor of BPS efficacy.

The BPS manipulation did not significantly decrease negative affect, which is in line with prior studies using the BPS manipulation $[1 ; 2 ; 16 ; 17 ; 22 ; 26]$. Nonetheless, overall change in negative affect was predicted by more words indicative of daily activities and the pronoun we. This may explain the contradicting finding in a prior study, namely that both the BPS and TD manipulation decreased negative affect [3]. As mentioned before, the use of the pronoun we may reflect feelings of social connectedness [29]. It could be that especially when participants write about social connections, whether in the context of daily activities or future goals, this could result in an increase awareness of strong social bonds, resulting in less negative feelings.

It should be noted that this is a first attempt to quantify qualitative data to examine which components are predictive for the effectiveness of the BPS manipulation in increasing optimism and positive affect. But both linguistic analysis and qualitative methodology come with their limitations. Word categories are selective, and findings may not hold for other contexts or can be generalized to other groups of people [36]. Using a predetermined coding framework to quantify the data, is more inflexible and can bias the whole analysis process [35]. It is also possible to use conventional qualitative content analysis. In this approach, the coding framework is derived directly and inductively from the raw data [19]. But as this study had the purpose to explore a particular phenomenon and possibly verify preliminary hypotheses, using a predetermined coding framework was more suitable. Nevertheless, it is possible that there where relevant domains that were not covered within our coding framework. Future research may 
want to consider generating an initial coding framework, but also allowing adding new coding categories that emerge inductively within the course of the analysis [23].

In sum, the BPS is an effective manipulation to increase optimism and positive affect. The BPS manipulation was more effective when participants wrote more about personal family life (i.e., family, friends, sex and social relationships), used more positive emotion words and wrote less about physical health and described fewer materialistic goals. Future research may want to consider instructing participants to write specifically about family and friends to increase the effectiveness of the BPS manipulation. 


\section{REFERENCES}

[1] Boselie JJ, Vancleef LM, Peters ML. The effects of experimental pain and induced optimism on working memory task performance. Scandinavian Journal of Pain 2016;12:25-32.

[2] Boselie JJ, Vancleef LM, Peters ML. Increasing optimism protects against pain-induced impairments in task shifting performance. The Journal of Pain 2016.

[3] Boselie JJ, Vancleef LM, Smeets T, Peters ML. Increasing optimism abolishes pain-induced impairments in executive task performance. Pain 2014;155(2):334-340.

[4] Boselie JJLM, Vancleef, L. M., \& Peters, M. L. . Increasing optimism protects against pain-induced impairments in task shifting performance. The Journal of Pain submitted for publication.

[5] Carver CS, Scheier MF, Segerstrom SC. Optimism. Clinical Psychology Review 2010;30(7):879-889.

[6] Crawford JR, Henry JD. The Positive and Negative Affect Schedule (PANAS): Construct validity, measurement properties and normative data in a large non-clinical sample. British Journal of Clinical Psychology 2004;43(3):245-265.

[7] Diener E, Ryan K. Subjective well-being: a general overview. South African Journal of Psychology 2009;39(4):391-406.

[8] Diener E, Seligman ME. Very happy people. Psychological science 2002;13(1):81-84.

[9] Fredrickson BL. What good are positive emotions? Review of general psychology 1998;2(3):300.

[10] Fredrickson BL. The role of positive emotions in positive psychology: The broaden-and-build theory of positive emotions. American psychologist 2001;56(3):218

[11] Fredrickson BL. The broaden-and-build theory of positive emotions. Philosophical transactions-royal society of london series b biological sciences 2004:1367-1378.

[12] Fredrickson BL. Positive emotions broaden and build. Advances in experimental social psychology 2013;47(1):53.

[13] Fredrickson BL, Cohn MA, Coffey KA, Pek J, Finkel SM. Open hearts build lives: positive emotions, induced through loving-kindness meditation, build consequential personal resources. Journal of personality and social psychology 2008;95(5):1045.

[14] Fredrickson BL, Joiner T. Positive emotions trigger upward spirals toward emotional well-being. Psychological Science 2002;13(2):172-175.

[15] Garland EL, Fredrickson B, Kring AM, Johnson DP, Meyer PS, Penn DL. Upward spirals of positive emotions counter downward spirals of negativity: Insights from the broaden-and-build theory and affective neuroscience on the treatment of emotion dysfunctions and deficits in psychopathology. Clinical Psychology Review 2010;30(7):849-864.

[16] Geschwind N, Meulders M, Peters ML, Vlaeyen JW, Meulders A. Can experimentally induced positive affect attenuate generalization of fear of movement-related pain? The Journal of Pain 2015;16(3):258269.

[17] Hanssen MM, Peters ML, Vlaeyen JW, Meevissen YM, Vancleef LM. Optimism lowers pain: Evidence of the causal status and underlying mechanisms. Pain 2013;154(0):53-58.

[18] Hanssen MM, Vancleef LM, Vlaeyen JW, Peters ML. More optimism, less pain! The influence of generalized and pain-specific expectations on experienced cold-pressor pain. Journal of behavioral medicine 2014;37(1):47-58.

[19] Hsieh H-F, Shannon SE. Three approaches to qualitative content analysis. Qualitative health research 2005;15(9):1277-1288.

[20] King LA. The health benefits of writing about life goals. Personality and Social Psychology Bulletin 2001;27(7):798-807.

[21] McGraw KO, Wong SP. Forming inferences about some intraclass correlation coefficients. Psychological methods 1996;1(1):30.

[22] Meevissen YMC, Peters ML, Alberts HJEM. Become more optimistic by imagining a best possible self: Effects of a two week intervention. Journal of Behavior Therapy and Experimental Psychiatry 2011;42(3):371-378. 
[23] Miles MB, Huberman AM. Qualitative data analysis: An expanded sourcebook: sage, 1994.

[24] North RJ, Meyerson RL, Brown DN, Holahan CJ. The language of psychological change: Decoding an expressive writing paradigm. Journal of Language and Social Psychology 2013;32(2):142-161.

[25] Pennebaker JW, Francis ME, Booth RJ. Linguistic inquiry and word count: LIWC 2001. Mahway: Lawrence Erlbaum Associates 2001;71:2001.

[26] Peters ML, Flink IK, Boersma K, Linton SJ. Manipulating optimism: Can imagining a best possible self be used to increase positive future expectancies? The Journal of Positive Psychology 2010;5(3):204-211.

[27] Peters ML, Smeets, E., Feijge, M., van Breukelen, G., Andersson, G., Buhrman, M., \& Linton, S. J. Happy despite pain: a randomized controlled trial of an 8-week internet-delivered positive psychology intervention for enhancing well-being in patients with chronic pain. Clinical journal of pain in press.

[28] Rasmussen HN, Wrosch C, Scheier MF, Carver CS. Self-regulation processes and health: the importance of optimism and goal adjustment. J Pers 2006;74(6):1721-1747.

[29] Rude S, Gortner E-M, Pennebaker J. Language use of depressed and depression-vulnerable college students. Cognition \& Emotion 2004;18(8):1121-1133.

[30] Scheier MF, Carver CS, Bridges MW. Distinguishing optimism from neuroticism (and trait anxiety, selfmastery, and self-esteem): A reevaluation of the Life Orientation Test. Journal of Personality and Social Psychology 1994;67(6):1063-1078.

[31] Sheldon KM, Lyubomirsky S. How to increase and sustain positive emotion: The effects of expressing gratitude and visualizing best possible selves. The Journal of Positive Psychology 2006;1(2):73-82.

[32] Shrout PE, Fleiss JL. Intraclass correlations: uses in assessing rater reliability. Psychological bulletin 1979;86(2):420.

[33] Slatcher RB, Vazire S, Pennebaker JW. Am "I" more important than "we"? Couples' word use in instant messages. Personal Relationships 2008;15(4):407-424.

[34] Solberg Nes L, Segerstrom SC, Sephton SE. Engagement and Arousal: Optimism's Effects During a Brief Stressor. Personality and Social Psychology Bulletin 2005;31(1):111-120.

[35] Spencer L, Ritchie J, O'Connor W. Analysis: practices, principles and processes. Qualitative research practice: A guide for social science students and researchers 2003:199-218.

[36] Tausczik YR, Pennebaker JW. The psychological meaning of words: LIWC and computerized text analysis methods. Journal of language and social psychology 2010;29(1):24-54.

[37] Van Breukelen GJP. ANCOVA versus change from baseline had more power in randomized studies and more bias in nonrandomized studies. Journal of Clinical Epidemiology 2006;59(9):920-925.

[38] Watson D, Clark LA, Tellegen A. Development and validation of brief measures of positive and negative affect: The PANAS scales. Journal of Personality and Social Psychology 1988;54(6):1063-1070.

[39] Zhang Y, Wildemuth BM. Qualitative Analysis of Content. Applications of Social Research Methods to Questions in Information and Library Science 2016:318.

[40] Zijlstra H, Van Meerveld T, Van Middendorp H, Pennebaker JW, Geenen R. De Nederlandse versie van de 'linguistic inquiry and word count'(LIWC). Gedrag Gezond 2004;32:271-281.

[41] Zijlstra H, Van Middendorp H, Van Meerveld T, Geenen R. Validiteit van de Nederlandse versie van de Linguistic Inquiry and Word Count (LIWC). Netherlands journal of psychology 2005;60(3):50-58. 



\section{Chapter six}

\section{Filling the glass: effects of a positive psychology intervention on executive task performance in chronic pain patients}

Boselie JJLM, Vancleef LM, Peters ML. Filling the glass: effects of a positive psychology intervention on executive task performance in chronic pain patients. 


\section{ABSTRACT}

Chronic pain is associated with emotional problems as well as difficulties in cognitive functioning. Prior studies have shown that optimism, the tendency to expect that good things happen in the future, and positive emotions can counteract pain-induced task performance deficits in healthy participants. More specifically, induced optimism was found to buffer against the negative effects of experimental pain on executive functioning. This study examined whether this beneficial effect can be extended to a chronic pain population. Patients $(\mathrm{N}=122)$ were randomized in a positive psychology internetbased intervention (PPI; $n=74$ ) or a waiting list control condition (WLC; $n=48$ ). The PPI consisted of positive psychology exercises that particularly target optimism, positive emotions and self-compassion. Results demonstrated that patients in the PPI condition scored higher on happiness, optimism, positive future expectancies, positive affect, selfcompassion and ability to live a desired life despite pain, and scored lower on pain catastrophizing, depression and anxiety compared to patients in the WLC condition. However, executive task performance did not improve following completion of the PPI intervention, compared to the WLC condition. It is imperative to further explore amendable psychological factors that may reduce the burden of living with chronic pain. 


\section{INTRODUCTION}

Chronic pain is associated with marked behavioural and emotional changes, impacting social relationships, mood and quality of life [18; 48; 61]. Persistent pain can also lead to difficulties in cognitive functioning $[11 ; 12 ; 72 ; 75 ; 114]$, resulting in an inability to perform daily activities, loss of work productivity and even unemployment [18; 19; 105]. These pain-related deteriorations in cognitive functioning are thought to reflect the capacity of pain to consume attentional resources needed for accurate task performance $[21 ; 27 ; 58 ; 73 ; 89 ; 115]$. Attention is a cognitive process that enables the processing of information, whereby it is possible to selectively attend to some aspects of information, while disregarding other aspects [85]. Attention relies on executive functioning, an umbrella term that describes multiple high-level cognitive processes and behavioural abilities $[7 ; 12 ; 41 ; 69]$. Executive functioning is typically decomposed in three core domains that represent specific functions, i.e.: inhibition, updating and shifting [69]. Inhibition refers to the ability to purposely inhibit automatic prepotent responses. An example in daily life is refraining from using the clutch when driving an automatic car [69]. Updating is being able to actively update, manipulate and monitor relevant information held in working memory. For instance, performing mental math requires keeping partial results in mind while solving the problem [76]. Shifting is the ability to switch flexibly and fluently between mental sets or tasks [41; 70; 101], enabling a person for example to switch between different languages in a conversation. Research has shown that experimental $[21 ; 28 ; 72 ; 114]$ and persistent pain $[11 ; 12 ; 54$; $74 ; 75]$ impair the performance on tasks that tap into these executive functions.

A possible factor that may improve executive functioning is optimism, the tendency to expect that good things will happen in the future [23]. We recently demonstrated that increasing optimism and positive affect, by means of writing and visualizing about a positive future, can reduce pain-induced deteriorations in updating [16] and shifting [17] task performance. However, these studies used experimental pain and were conducted in healthy patients. Building on these prior findings, the current study was specifically set up to examine whether these findings extend to a chronic pain population. For this purpose, pain patients were assigned to an 8-week internet-based positive psychology intervention or a waiting list control condition. A previous study demonstrated that this intervention led to significant increases in optimism and positive emotions in chronic pain patients [83]. The current study assessed the effects of the intervention on executive task performance in addition to its effect on positive and negative states and traits. Several tests covering the three domains of executive functioning (i.e., inhibition, updating and shifting) were administered before and after the intervention or waiting list period.

In summary, it was hypothesized that the positive psychology intervention, compared to the waiting list condition, would lead to (1) an increase in positive and de- 
crease in negative states and traits and (2) improved executive (i.e., updating, shifting and inhibition) task performance.

\section{METHODS}

\section{Patients}

Recruitment took place from January to August 2014 through an advertisement in a magazine and on the website of the Dutch Society for Fibromyalgia patients. Patients could apply by e-mail or through a link on a dedicated website, after which they received further information about the study via email. In total, 180 patients signed up for the study and were contacted by phone for a screening interview to check compliance with in- and/or exclusion criteria (see Table 1). Following screening, 53 patients were excluded: 16 because they could not be reached and 37 because they did not fulfil inclusion criteria. Patients were informed via email whether they were included in the study and were subsequently randomized into the positive psychology intervention (PPI) or waiting list condition (WLC). Randomization occurred by a 2:1 ratio, with more patients being allocated to the PPI condition so that more patients would benefit from the intervention. A minimal sample size of 68 patients was determined with G*Power [36] with the following parameters: $\alpha=.05$, power $=.90$, and an effect size of .40 (as based on a prior RCT study with the PPI intervention [83]). The unequal allocation scheme requires that $12,5 \%$ more patients (i.e., 77; PPI > 52 and WLC > 26) should be tested to obtain the same statistical precision as with an equal allocation scheme [57; 66]. Six (PPI $n=3 ; W L C n=3$ ) patients did not fill out all the pre-treatment measures leaving a total of 121 (PPI $n=73$; WLC $n=48$ ) patients in the study.

Table 1. Inclusion and exclusion criteria

\begin{tabular}{ll}
\hline Inclusion criteria & Exclusion criteria \\
\hline$>$ 18 years & $>60$ years \\
Chronic pain lasting longer than 3 months & Psychological or multidisciplinary pain treatment in the \\
& past 3 months \\
Having musculoskeletal pain, generalized (i.e. & Diagnosed with psychopathological disorders in the \\
Fibromyalgia) or in back, neck or shoulders & past 3 months \\
Good mastery Dutch language (also in reading) & Diagnosed with a neurological disorder (such as a \\
& stroke or epilepsy) \\
Having access to the Internet & Being pregnant \\
Able to spend 3 hours a week on the program & Not being able to perform tasks on a computer \\
\hline
\end{tabular}




\section{METHODS}

\section{Intervention}

The positive psychology intervention (PPI) 'happy despite pain' was offered as an 8week online intervention, whereby patients performed positive psychology exercises that aim to increase optimism, positive emotions and self-compassion [83]. Patients received instructions about the exercises via the online platform, and conducted each exercise individually at home (see Figure 1 for an overview of the exercises per module). The PPI consists of 4 modules (i.e. (1), self-compassion, (2) positive focus, (4) savoring, and (5) optimism) that were consecutively targeted in weeks 1-7 of the intervention.

Module 1 targets self-compassion, which refers to fully accepting oneself, the ability to treat oneself with kindness rather than self-criticism and recognizing that everyone experiences failures [78; 79]. During the 'awareness of suffering' exercise, patients switch a bracelet from one arm to the other, every time they are aware of their own suffering or self-criticism. Increasing awareness of suffering raises attention to moments where the patient could be more self-compassionate. In the self-compassion diary, patients write down events with the three components of self-compassion in mind: self-kindness, common humanity (i.e., all humans suffer and make mistakes) and mindfulness (i.e., non-judgmental observing, feeling and accepting of thoughts and emotions). During moments of suffering, patients can repeat a mantra, remembering themselves that suffering is part of living and that they are worthy to receive selfcompassion. Patients also write a self-compassion letter to themselves about their perceived shortcomings and failures, but from a friend's perspective. Module 2 requires patients to practice the 'three good things' exercise on a daily basis. Patients write down three good things that happened that day and why they happened. This exercise aims to shift the focus from a negative orientation towards a more positive one, by raising awareness for the good things in life [95; 96]. Module 3 contains savoring techniques that promote the frequency and intensity of positive experiences in daily life. Patients actively plan pleasant activities, so called 'mini vacations' of 20 minutes. In these mini vacations, patients do something for themselves that they enjoy. Similar, patients are asked to actively recall pleasant memories. Patients also write down normal typical things that they enjoy during the day in their savoring diary. Both modules 2 and 3, aim to increase positive emotions in daily life. In module 4, patients practice the Best Possible Self (BPS) exercise [65; 82], which is used to increase optimism. In the BPS exercise, patients write about and imagine an ideal future life despite the pain. Patients select 3 unique domains from a list of eight life domains (i.e., family life, romantic life, social life, professional life, leisure and hobby, educational life, societal commitment and personal growth). Within these 3 domains, patients formulate concrete and obtainable future (i.e., over 5 years) goals, wishes and expectations. Then patients write down a detailed narrative of how their ideal future will look like, despite pain, within these 3 
selected domains. Patients also visualise every day for 5 minutes this ideal future in one of the three domains. The last week (i.e., week 8) of the PPI aims to prevent relapse. In this week, patients develop a personalised plan concerning future use of the learned exercises. This plan contains information pertaining to which exercises they are planning to keep on using, when they will do this and how they will implement this in their daily routines.

Regular contact moments were organised within the 8-week PPI. These contact moments were primarily used to give support, enhance adherence to the program and to prevent drop-out. Patients were contacted by either telephone (weeks 1, 3, 5, and 7) or email (weeks 2, 4, 6 and 8). In the semi-structured telephone calls, patients were asked whether they had questions or had encountered problems regarding the assignments. The mean duration of the telephone support was $10.56(S D=7.74)$ minutes. The semi-standardized emails encouraged patients to continue with the exercises and to send an email if they encountered problems.

\section{Questionnaires}

\section{Optimism}

The Life Orientation Test-Revised (LOT-R) [91] measured dispositional optimism and consisted of 10 items: 3 positively phrased items (e.g. 'I'm always optimistic about my future'), 3 negatively phrased items (e.g. 'I rarely count on good things happening to me') and 4 filler items (e.g., 'it's important for me to keep busy'). The items were rated on a 5-point Likert scale, ranging from 1 (strongly disagree) to 5 (strongly agree). The total LOT-R score was obtained by summation of the scores on the positively phrased items and the reversed scores on the negatively phrased items and ranged from 10 to 30. Higher scores reflect higher levels of dispositional optimism. The LOT-R has been demonstrated to be a reliable and valid measurement instrument [91] and internal consistency was satisfactory in this study with a Cronbach's alpha of .77.

\section{Future expectancies}

The Future Expectancies Scale FEX [19] measured positive and negative future expectancies. It consisted of 20 items that make statements about positive ( $n=10$; e.g., 'people will admire you') and negative ( $n=10$; e.g., 'things will not turn out as you had hoped") future events. The 20 statements covered 5 different domains (work, health, personal, social and general). Patients rated the likelihood that they will experience the future events on a 7-point Likert scale, ranging from 1 (not at all likely to occur) to 7 (extremely likely to occur). Higher scores reflect a higher estimated likelihood of positive (FEX-Pos) or negative (FEX-Neg) future events, with scores ranging from 10 to 70. The internal consistency of the FEX subscales has been demonstrated to be satisfactory [46]. Cronbach's alphas in the present study for the positive and negative subscale were .87 and .83 respectively. 
Effects of a PP intervention on executive task performance in patients

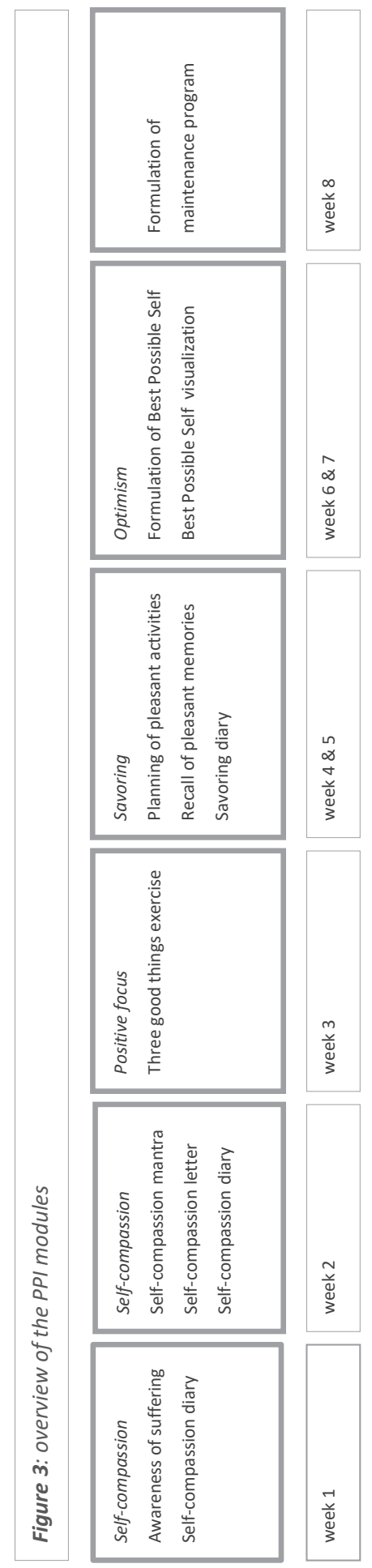




\section{Self-compassion}

The Self-Compassion Scale Short Form (SCS-SF) [77] consisted of 12 items divided over six subscales. These subscales corresponded to the to six components of selfcompassion: Self-Kindness (e.g., 'When I'm going through a very hard time, I give myself the caring and tenderness I need'), Self-Judgment (e.g., 'I'm disapproving and judgmental about my own flaws and inadequacies'), Common Humanity (e.g., 'I try to see my failings as part of the human condition'), Isolation (e.g., 'When I fail at something that's important to me, I tend to feel alone in my failure'), Mindfulness (e.g., 'When something upsets me I try to keep my emotions in balance') and Over-Identification (e.g., 'When I'm feeling down I tend to obsess and fixate on everything that's wrong') [77]. In the present study, the items were rated on a 7-point Likert scale [119], ranging from 1 (almost never) to 7 (almost always) and scores ranged from 12 to 84 . The total selfcompassion score was computed by adding all subscale scores, after reversing the negative subscale items (i.e., items of the subscales Self-Judgment, Isolation and OverIdentification). The SCS-SF demonstrated adequate internal consistency and a nearperfect correlation with the long form SCS [86]. In this study, internal consistency was good with a Cronbach's alpha of .89.

\section{Depression and anxiety}

The Hospitality And Depression Scale (HADS) [124] measured depressive and anxiety symptoms in medical outpatient clinics. The HADS consisted of 14 items (including 6 reversed items): 7 measured depressive symptoms (e.g., I feel as if I am slowed down') and 7 measured anxiety symptoms (e.g., 'I get a sort of frightened feeling as if something awful is about to happen'). Items were rated on a 4-point Likert scale ranging from 0 (indicating no depressive or anxiety symptoms) to 3 (indicating a high level of depressive or anxiety symptoms). The total depression or anxiety score was obtained by summation of the scores on the negatively phrased items and the reversed scores on the positively phrased items. Scores for the subscales ranges from 0 to 21 , with scores 0-7 indicating 'normal', scores 8-10 indicating 'mild', scores 11-14 indicating 'moderate' and scores 15-21 indicating 'severe' presence of symptoms [124]. The HADS has been demonstrated to be a reliable measurement instrument [104]. Cronbach's alphas for the anxiety and depression subscale were both .82 .

\section{Happiness}

Happiness was assessed via a single question that inquired about the degree of happiness one feels at this moment. Answers were scored on a 6-point Likert scale with scores 1 (very unhappy), 2 (unhappy), 3 (more unhappy then happy), 4 (more happy then unhappy), 5 (happy), to 6 (very happy). A higher score reflects greater happiness. Measuring happiness by single-item questions has been proven to be reliable and valid [1]. 


\section{Pain Catastrophizing}

The Pain Catastrophizing Scale (PCS) [108] consisted of 13 items reflecting catastrophic thoughts and emotions regarding pain (e.g. 'I keep thinking about how much it hurts'). Patients indicated to what degree they experienced each of 13 stated thoughts and feelings while experiencing pain on a 5-point Likert scale, ranging from 0 (not at all) to 4 (all the time). The total PCS score was obtained by summing the responses of all the 13 items (scores range from 0 to 52). Higher scores on the PCS indicate greater pain catastrophizing [81]. Reliability and validity of the PCS total and subscales were adequate [98]. In this study, internal consistency was good with a Cronbach's alpha of .93.

\section{Affect}

The Positive and Negative Affect Schedule (PANAS) [118] consisted of 20 items that measure positive (PA, 10 items) and negative (NA, 10 items) affect. Examples of PA items are 'excited' and 'inspired'. Examples of NA items are 'nervous' and 'afraid'. Patients indicated the degree to which a certain feeling was present at that moment on a 5-point Likert scale ranging from 1 (not at all) to 5 (extremely). Subscale scores ranged from 10 to 50, with higher scores on NA items reflecting higher levels of emotional distress. In contrast, high PA scores correspond to experiencing more pleasurable feelings. The PANAS subscales have been demonstrated to be valid and reliable [26]. Cronbach's alphas in the present study for the positive and negative subscale were .87 and .88 respectively.

\section{Pain}

Three Visual Analogue Scales (VASs) were administered to measure the patient's experience of pain at that moment, namely experienced pain intensity, burden of pain, and ability to live a desired life despite the pain. Each VAS was anchored 0 (no pain at all/ no burden at all/ not at all able) to 100 (extreme pain / extreme burden/ completely able).

\section{Pain disability}

The Pain Disability Index (PDI) [84] measured the impact that pain has on the ability of a person to participate in 7 categories of life activities: family and home responsibilities, recreation, social activity, occupation, sexual behaviour, self-care, and life-support activity. Patients indicated the level of disability that they typically experience on an 11-point Likert-scale with 0 (no disability) to 10 (total disability). The total PDI score was obtained by the summation of the 7 items and ranged from 0 to 70, with greater scores indicating greater disability due to pain. The PDI has shown to be a valid and reliable measure of pain-related disability [109]. In this study, internal consistency was good with a Cronbach's alpha of .84. 


\section{Task experience}

Four Visual Analogue Scales (VASs) measured the patients experience concerning the execution of the executive functioning tasks, namely experienced fatigue, difficulty, level of pain during task execution, and ability to concentrate on task execution. Each VAS was anchored 0 (not fatiguing at all / not at all difficult / no pain at all / not at all difficult to concentrate) to 100 (extremely fatiguing / extremely difficult / extremely painful / extremely difficult to concentrate).

\section{Executive functioning}

\section{Inhibition}

Stop-signal task

Inhibition, or the ability to suppress prepotent responses [69], was assessed with the stop-signal task $[10 ; 25 ; 62]$. In this reaction time paradigm, patients were instructed to respond to a stimulus as quickly as possible (by pressing a button), unless a specific cue (i.e. stop-signal) was presented in which case the response needs to be inhibited. Hence, patients need to inhibit an initiated motor action when this is suddenly no longer appropriate. Reaction times on so-called stop-trials versus go-trails are used to infer difficulties in inhibition (see below).

The stop-signal task consisted of 160 trials. Each trial started with a fixation cross that was presented for 500 ms in the middle of the computer screen, followed by either a black arrow (i.e., the go-stimulus) pointing to the left or right. Patients were required to press the " $E$ " key on the keyboard if the arrow pointed to the left or the " $U$ " key when the arrow pointed towards the right. When the arrow turned red (i.e., stopsignal), which was the case on $25 \%$ of the trials (i.e., 40 trials); patients were expected to inhibit their response and refrain from pressing a button. The time interval between the go-stimulus and the stop-signal (i.e., stop-signal delay) was initially set to $250 \mathrm{~ms}$, and then adjusted dynamically depending on the patient's responses during task performance. The stop-signal delay was increased or decreased by $50 \mathrm{~ms}$ on the next stopsignal trial when subjects succeeded or failed to stop, respectively. Increasing the stopsignal delay makes it more difficult to inhibit the next stop-signal trial, while decreasing makes it easier to inhibit the next stop-signal trial. Adjusting the stop-signal delay dynamically during task performance ensures that patients have an approximately equal number of failed as successful stop-trials [10].

The task started with a practice phase, in which 30 go-trials were presented. Response feedback was given on each trial ('correct' or 'incorrect'). Moreover, patients were urged to respond faster on every trial with a message that appeared below the arrow stimulus, irrespective of their reaction time. The test phase of the task consisted of four blocks containing 40 trials each (i.e., 30 go-trials and 10 stop-trials). Patients were allowed to take short self-paced breaks in between blocks. Task instructions were 
displayed in the left and right upper corners of the computer screen, 'press E for left' and 'press $U$ for right' respectively. In the middle bottom part of the computer screen, patients could follow their progress, via an indicator that displayed the number of completed and uncompleted trials for that block (e.g., 1/30). In the test phase, a feedback message was only given when responses on the go-trials became too slow (i.e., >2SD above individual cut-off score, which was calculated on the basis of the mean RT and SD as obtained in the practice phase). This message urged patients to respond faster, preventing patients to use this response slowing in order to improve accuracy on stopsignal trials [13]. The total duration of the stop-signal task was approximately 10 minutes. The main outcome variable of the task was the stop-signal RT (SSRT) that is calculated by subtracting the mean stop-signal delay (i.e., time between the go-stimulus and the stop-signal) from the mean RT on correct go-trials. Higher SSRTs indicates that the patient needed more time to inhibit a response, reflecting less inhibitory control [10].

\section{Updating}

Reverse digit span

The reverse digit span originates from the WAIS-III [119]. A series of digits (1, 2, 3, 4, 6, 7,8 , and 9) of increasing length were presented one-by-one on a computer screen, starting with a series of three digits to a maximum of eight digits. After the last digit was presented, patients had to repeat the numbers in the reverse order, by clicking with the left mouse button on the corresponding numbers in a numeric pad that was presented on the bottom part of the computer screen. Following each successful trial, a digit was added to the next trial. The score (i.e., correctly recalled digits) was shown in the upper part of the screen. The task ended when a patient failed to accurately reproduce a series of digits of the same length on two successive trials. The total score was calculated by summing the total number of digits correctly recalled. The digit span had good internal consistency reliabilities for clinical groups, ranging from .78 to .94 [123] and sufficient validity [88; 90]. The total duration of the reverse digit span was less than 6 minutes.

\section{Shifting}

\section{Task shifting}

The task-shifting paradigm is widely used to study mental set shifting $[69 ; 71 ; 100 ; 116]$. In the shifting task, 8 single-digit numbers $(1,2,3,4,6,7,8$, and 9) were presented oneby-one on a computer screen. Patients needed to follow a discrete task rule on each trial, which can either change (i.e., switch trial) or remain the same (i.e., repetition trials) from one trial to the next. Responses on a switch trial are typically slower and less accurate compared to responses on a repetition trial (i.e., switch costs). Patients had to 
follow 2 task rules, namely indicating whether the target number was higher or lower than 5 and indicating whether the target number was even or odd. One of both task rules (i.e., higher/lower or odd/even) was briefly primed (500 ms) on screen before the presentation of the next target number $[56 ; 67]$. The target number was then shown until the patient gave a response. The mapping of response keys to task rules was counterbalanced across patients. For example, the mapping could be that the patient had to press the ' $E$ ' key on the computer keyboard when the target number was lower than 5 or an even number. In contrast, the patient had to press the ' $U$ ' key on the computer keyboard when the target number was higher than 5 or an odd number. Which key corresponded to which answer type (e.g. $E=$ lower/even and $U=$ higher/odd) was simultaneously presented with the target number in order to ensure that patients were aware of the required sorting options.

The shifting task consisted of a practice phase and testing phase. The practice phase included 12 trials, with 6 trials cueing the patient to classify the target number as higher as or lower than 5 and 6 trials where they had to classify the target number as odd or even. In the testing phase 192 trials were presented, with 96 switch trials of which 48 were congruent (i.e., trials for which the correct response is mapped to the same key under both task rules [2]). The presentation of target numbers was fixed semirandomized to ensure the previously mentioned distribution of switch and congruent trials. Additionally, the same priming cue was not presented for more than 4 consecutive trials, to prevent an automatic response flow.

The total duration of the shifting task was less than 15 minutes. Reaction times (RT) and accuracy were registered. The main dependent variables used in this study were RT switch costs and accuracy switch costs. The RT switch cost score was computed by subtracting RT on repeat trials from switch trials, such that higher positive values indicate that patients were slower to respond to switch trials than to repetition trials. The accuracy switch cost score was computed by subtracting the proportion of correct responses on switch trials from the proportion of correct responses on the repeat trials, such that higher positive values indicate that patients were less accurate on switch trials compared to repetition trials.

\section{Wisconsin card sorting task}

The Wisconsin card sorting task (WCST) [44; 49] measured the ability to shift between cognitive strategies in response to changing feedback [69; 106]. We used a modified, computerized WCST version [110]. In its conventional form [49], the task can be discontinued when 6 categories (i.e., a sequence of ten correct responses to one specific sorting rule) are completed. We required that all 128 response cards had to be sorted [45].

In the WCST, 4 stimulus cards were presented on the bottom half of the computer screen and 1 response card on the upper half of the computer screen. The response card changed every trial; the 4 stimulus cards remained unchanged (i.e., card 1 with a red triangle, card 2 with two green stars, card 3 with three yellow crosses and card 4 
with four blue circles on them). Every response card had 3 possible attributes: form, number, and colour. Every attribute had 4 possible features: form (triangle, star, cross and circles), number (1, 2, 3, and 4) and colour (red, green, yellow and blue). Patients had to match the response card (128 in total) to one of the four stimulus cards by clicking with the left mouse button on the selected stimulus card. Patients were not informed about the sorting rule (i.e., sorting by form, number or colour). Patients had to find the correct sorting rule by trial and error. Computer feedback (i.e., 'right' or 'wrong') was displayed on the computer screen after matching the response card to a stimulus card. After ten consecutive correct matches, the sorting rule changed without warning, requiring the patient to shift their cognitive strategy.

The sequence of sorting rules was counterbalanced, but with the restriction that within a counterbalance condition, the sequence of the rules remained the same (e.g., colour, form, number, colour, form, number, and so on). Patients received an identical stimulus list in the pre- and post-measurement. The number of categories completed was the main outcome variable. Any time a patient interrupted a sequence of correct responses by making an error, the category of that sorting rule was not obtained. The same sorting rule applied until 10 correct matches with that specific rule was achieved. Task duration was less than 15 minutes.

\section{Procedure}

The study took place between February 2014 and January 2015. After randomization and informing patients via email about the condition to which they had been assigned, patients received an email invitation to complete the pre-measurement via Internet. The pre-measurement consisted of two sessions. Session 1 contained questionnaires on medication use and happiness, and VASs on pain and task perception. Only in session 1 in the pre-measurement, demographic information, was measured. Moreover, the first two executive functioning tasks were administered (i.e., stop-signal task, WCST). We also administered the 2-back task [14], but we do not report this data as too many patients ( $n=84,68.9 \%$ ) scored an accuracy score below chance level $(<54 \%$ correct, as determined by a binomial calculator). After completion of session 1, patients were thanked for their effort. Patients were invited via email to complete session 2 the next day. This session contained the PANAS, PCS, FEX, LOT-r, HADS, PDI, SCS-sf, the VASs on task perception and the two remaining executive functioning tasks (i.e., shifting task, reverse digit-span). We decided to divide the pre-and-post measurement in two sessions to avoid fatiguing patients. Patients were instructed to complete the sessions in a quiet environment and to take sufficient self-paced breaks between the questionnaires or tasks. However, they were requested to always complete a questionnaire or task once they had started.

Following completion of the pre-measurement, patients in the PPI condition received their username and password via email after activating a link to the site where 
the intervention was hosted. Patients could access the site through the username and password and a six-digit security code that was provided to their mobile phone or email at every login. The intervention consisted of eight weeks. In the first week, only the exercises of that week could be accessed. The following exercises became consecutively available exactly one week after the previous one. Patients were informed on which day a new week with exercises would become available to them. The complete program was available after seven weeks. Mean duration of the intervention for intervention completers was 9.9 (SD = 2.1) weeks (range 8-17 weeks). Each online module consisted of information about the topic of that week and practical assignments. Patients were also sent a printed workbook at the start of the intervention that contained a summary of the online information and the corresponding assignments. Patients could also complete the assignments in this workbook and use it as a future reference book. However, it was emphasized that patients should first and foremost complete the assignments online.

After completion of the intervention, patients were invited via email to complete the post-measurement via Internet. The post-measurement again consisted of two sessions using the same partitioning of tasks and questionnaires as during the premeasurement. Following completion of the post-measurement, patients were thanked for their participation and were given the opportunity to save the information and exercises in PDF format prior to expiration of their access to the intervention. In the WLC condition, after completion of the pre-measurement, patients were informed of the 8week waiting period and when they would receive the invitation for their postmeasurement. After completion of the post-measurement, patients received their username and password for the internet-site to start with the intervention. Patients in WLC condition did not receive the weekly support of an assistant by telephone or email. After completion of the post-measurement, all patients received a gift (lantern bag) to thank them for participation in the study.

\section{Data analyses}

Data were checked for a normal distribution and reliability analyses were performed on the LOT-R, FEX, PANAS, SCSsf, PCS, HADS, and the PDI questionnaires. Independentsamples t-tests were used to check for baseline differences between the conditions (PPI vs. WLC) on questionnaire scores, executive functioning and pain duration and ChiSquare Tests for categorical variables (demographic characteristics). To examine possible predictors of drop-out, a logistic regression analyses was performed with condition (PPI vs WLC) and all the baseline variables as predictors.

Executive functioning data were screened for outliers. On the reaction time (RT) tasks, RT $<250$ ms or 3xSD above individual mean RT were replaced with the cut-off value (i.e., 3xSD above individual mean RT). Furthermore, incorrect trials were omitted 
(shifting task $12.0 \%$ (pre-measurement) and $11.0 \%$ (post-measurement); stop-signal $2.8 \%$ (pre-measurement) and $0.9 \%$ (post-measurement) trials).

The effectiveness of the PPI on emotional functioning was tested with several ANCOVAs with condition (PPI vs WLC) as between subjects factor and baseline (premeasurement) scores of the emotional variables (mean centered) as covariates. The intervention is successful in increasing positive and decreasing negative states and traits when results show a significant main effect of condition. This method of analysing is more powerful and precise than using repeated measures ANOVA in a randomized prepost design [112].

Similar, the effectiveness of the PPI on executive functioning was tested with several ANCOVAs with condition (PPI vs WLC) as between subjects factor and baseline (premeasurement) scores of the executive functioning variables (mean centered) as covariates. The intervention is successful in improving executive task performance (i.e., updating, shifting and inhibition) when results show a significant main effect of condition. Additionally, regression analyses were used to test whether improvements in positive affect and optimism are significant predictors of task performance improvement

\section{RESULTS}

\section{Baseline descriptives}

In total, 33 patients (PPI $n=18,24.7 \%$; WLC $n=15,31.3 \%$ ) did not complete the intervention and/or did not complete all the measurements within the 2 pre- and posttreatment sessions. In the analyses we included every available data point, resulting in different sample sizes per task/questionnaire (range $n=87$ - 121).

We checked for outliers on the general outcome variables (i.e., shifting switch cost RT and accuracy, WCST score, reversed digit span score and stop-signal SSRT score), with outlier values defined as 3xSD below or above the overall mean (i.e., cut-off values). Outlier scores were replaced with these cut-off values. Additionally, patients that obtained an accuracy score below chance level on the shifting task $(<53 \%$ correct, as determined by a binomial calculator) were omitted from further analysis for that specific task ( $n=2,2.25 \%)$.

Results of the independent-samples t-tests and Chi-Square Tests revealed no significant differences between the PPI and WLC condition at baseline (emotional functioning all $p$-values $>$.12; executive functioning all $p$-values $>$.30; patient characteristics all $p$ values $\mathbf{2 1}$.21). Patient characteristics per condition are displayed in Table 2.

Results of the logistic regression analyses indicated that drop-out was predicted by lower education level ( $B=-.08, t(95)=-3.37, p<.01,95 \% \mathrm{Cl}$ of $B[-0.125$ to -0.032$]$ ), more self-reported ability to live desired life despite pain $(B=.01, t(95)=2.99, p<.01$, $95 \% \mathrm{Cl}$ of $B$ [0.002 to 0.010]) and more negative future expectancies $(B=.01, t(95)=$ 
2.19, $p=.03,95 \% \mathrm{Cl}$ of $B$ [0.001 to 0.025$])$. A significant proportion of variance was explained with, $R^{2}=.28, F(18,95)=2.04, p=.01$. All other baseline characteristics, premeasurements and condition were not significant predictors (all $p^{\prime} s>.11$ ).

Table 2. Patient characteristics, displayed per condition.

\begin{tabular}{lllc}
\hline & $\begin{array}{l}\text { Positive Psychology } \\
\text { Intervention (PPI) } \\
n=73\end{array}$ & $\begin{array}{l}\text { Waiting List Control } \\
(\text { WLC) } \\
n=48\end{array}$ & $\begin{array}{l}\text { Total } \\
n=121\end{array}$ \\
\hline Age (mean; SD) & $45.59(9.77)$ & $43.15(9.70)$ & $44.63(9.82)$ \\
Female (n, \%) & $70(95.9)$ & $47(97.9)$ & $117(96.7)$ \\
Education level (n, \%) & $14(19.2)^{\circ}$ & & $26(21.5)^{\circ}$ \\
low & $32(43.8)$ & $12(25.0)$ & $49(40.5)$ \\
medium & $26(35.6)$ & $17(35.4)$ & $45(37.2)$ \\
high & $13.34(9.64)^{\circ}$ & $19(39.6)$ & $12.70(9.38)^{\circ 0}$ \\
Pain duration in years (mean; SD) & $11.77(9.00)$ & $18(14.9)$ \\
Employment (n, \%) & $10(13.7)$ & $8(16.7)$ & $44(36.4)$ \\
Full-time & $22(30.1)$ & $21(43.8)$ & $12(9.9)$ \\
Part-time & $9(12.3)$ & $3(6.3)$ & $4(3.3)$ \\
Stay-at home parent & $2(2.7)$ & $2(4.2)$ & $2(1.7)$ \\
Student & $1(1.4)$ & $1(2.1)$ & $20(16.5)$ \\
Sick leave & $14(19.2)$ & $6(12.5)$ & $10(8.3)$ \\
Disability pension & $5(6.9)$ & $5(10.4)$ & $12(9.9)$ \\
Pension & $10(13.7)$ & $2(4.2)$ & \\
Unemployed & & & \\
\hline
\end{tabular}

- 1 patient did not report education level; ${ }^{\circ} 2$ patients did not report pain duration.

\section{Emotional functioning}

The ANCOVAs revealed a significant main effect of PPI condition, controlling for the effect of scores obtained before the intervention, for happiness $(F(1,90)=4.58, p=$ $\left..04, \eta p^{2}=.05\right)$, optimism $\left(F(1,86)=7.34, p=.01, n p^{2}=.08\right)$, positive future expectancies $\left(F(1,86)=15.15, p<.001, \eta p^{2}=.15\right)$, positive affect $\left(F\left(1,86=5.47, p=.02, \eta p^{2}=\right.\right.$ $.06)$, self-compassion $\left(F\left(1,86=12.18, p>.01, n p^{2}=.12\right)\right.$, pain catastrophizing $(F(1,86$ $\left.=13.92, p>.001, \eta p^{2}=.14\right)$, depression $\left(F\left(1,86=6.36, p=.01, \eta p^{2}=.07\right)\right.$, anxiety $(F(1$, $\left.86=6.21, p=.02, n p^{2}=.07\right)$ and ability to live a desired life despite pain $(F(1,89=5.68$, $\left.p=.02, n p^{2}=.06\right)$. The PPI condition main effect was not significant for negative future expectancies $\left(F(1,86)=3.78, p=.06, n p^{2}=.04\right)$, negative affect $(F(1,86)=2.70, p=$ $\left..10, n p^{2}=.03\right)$, pain disability $\left(F(1,86)=1.31, p=.26, n p^{2}=.02\right)$ and pain intensity $(F(1$, $89)=2.05, p=.16, n p^{2}=.02$ ). Estimated mean and standard deviation scores on the emotional functioning variables are displayed in Table 3. Patients in the PPI condition 
scored higher on happiness, optimism, positive future expectancies, positive affect, selfcompassion and ability to live a desired life despite pain, compared to patients in the WLC condition. In contrast, patients in the PPI condition scored lower on pain catastrophizing, depression and anxiety compared to patients in the WLC condition.

Table 3. Estimated mean (M), standard deviation (SD) scores and $95 \%$ Confidence Intervals (95\% Cl) on the emotional functioning variables for the post-measurement, displayed per condition.

\begin{tabular}{|c|c|c|c|c|c|c|}
\hline & \multicolumn{3}{|c|}{ Positive Psychology Intervention } & \multicolumn{3}{|c|}{ Waiting List Control } \\
\hline & $\mathrm{n}$ & $M(S D)$ & $95 \% \mathrm{Cl}$ & $\mathrm{n}$ & $M(S D)$ & $95 \% \mathrm{Cl}$ \\
\hline \multicolumn{7}{|l|}{ Positive traits } \\
\hline Happiness & 57 & $4.34(1.04)$ & 4.12 to 4.56 & 36 & $3.96(1.32)$ & 3.68 to 4.24 \\
\hline Optimism & 56 & $21.84(3.58)$ & 21.09 to 22.59 & 33 & $20.16(4.62)$ & 19.17 to 21.13 \\
\hline Self-compassion & 56 & $56.73(10.84)$ & 54.44 to 59.02 & 33 & $50.10(14.15)$ & 47.11 to 53.09 \\
\hline \multicolumn{7}{|l|}{ Positive states } \\
\hline Positive affect & 56 & $28.36(8.49)$ & 26.57 to 30.15 & 33 & $24.90(11.03)$ & 22.57 to 27.23 \\
\hline Positive future expectancies & 56 & $47.78(9.24)$ & 45.83 to 49.72 & 33 & $41.50(12.07)$ & 38.96 to 44.04 \\
\hline \multicolumn{7}{|l|}{ Negative traits } \\
\hline Pain catastrophizing & 56 & $12.95(8.30)$ & 11.20 to 14.70 & 33 & $18.36(10.84)$ & 16.07 to 20.64 \\
\hline \multicolumn{7}{|l|}{ Negative states } \\
\hline Anxiety & 56 & 7.09 (3.49) & 6.35 to 7.83 & 33 & $8.61(4.53)$ & 7.65 to 9.57 \\
\hline Depression & 56 & $5.10(3.77)$ & 4.30 to 5.90 & 34 & $6.77(5.00)$ & 5.73 to 7.82 \\
\hline Negative affect & 56 & $16.42(7.36)$ & 14.87 to 17.98 & 33 & $18.53(9.62)$ & 16.50 to 20.55 \\
\hline Negative future expectancies & 56 & $33.46(9.62)$ & 31.43 to 35.49 & 33 & $36.74(12.64)$ & 34.09 to 39.39 \\
\hline \multicolumn{7}{|l|}{ Pain variables } \\
\hline Pain disability & 56 & $33.86(12.45)$ & 31.24 to 36.49 & 33 & $36.36(16.23)$ & 32.93 to 39.78 \\
\hline $\begin{array}{l}\text { Ability to live a desired life } \\
\text { despite pain }\end{array}$ & 57 & $55.40(23.21)$ & 50.60 to 60.21 & 35 & $46.06(29.64)$ & 39.93 to 52.19 \\
\hline Pain intensity & 57 & $56.68(26.47)$ & 51.20 to 62.16 & 35 & $63.18(33.95)$ & 56.15 to 70.22 \\
\hline
\end{tabular}

\section{Executive functioning}

No effect of PPI condition was found for any of the executive functioning tasks (reversed digit span $\left(F(1,85)=0.33, p=.33, n p^{2}<.01 ; \mathrm{RT}\right.$ switch cost $\left(F(1,84)=0.28, p=.60, n p^{2}\right.$ $<.01$; switch cost accuracy $\left(F(1,84)=0.03, p=.86, \eta p^{2}<.001\right.$; WCST score $(F(1,88)=$ $\left.0.21, p=.65, \eta p^{2}<.01\right)$; stop-signal SSRT score $\left(F(1,87)=0.02, p=.90, \eta p^{2}<.001\right)$. Mean and standard deviation scores of the executive task performance variables are displayed in Table 4. We repeated the analyses on de executive functioning dependent variables with age and medication use (yes vs. no) as covariates; again, the condition effect was not significant (all $p$ values $>$.06). To examine a possible learning effect, we conducted several paired-samples t-tests. The WCST $(t(90)=3.29, p<.01, d=0.69,95 \%$ 
$\mathrm{Cl}$ of $d$ [0.39 to 0.99]) and the stop-signal task ( $t(89)=2.97, p<.01, d=0.63,95 \% \mathrm{Cl}$ of $d$ [0.33 to 0.93]) showed significant practice effects (all other $p$ values $>.13$ )

We examined with regression analyses whether improvements in positive affect and optimism were significantly related to improvements in task performance, irrespective of condition. No consistent associations between changes in either positive affect or optimism and improvements in task performance were found. Additionally, we examined whether the task experience (i.e., fatiguing, difficulty, level of pain during task and ability to concentrate on task) changed after the PPI compared to WLC. None of the time (pre-measurement vs. post-measurement) $x$ condition interaction effects were significant (all $p$ values $>.08$ )

Table 4. Mean (M), standard deviation (SD) scores on the executive functioning variables for the pre- and post-measurement, displayed per condition.

\begin{tabular}{|c|c|c|c|c|c|c|}
\hline & \multicolumn{3}{|c|}{ Positive Psychology Intervention (PPI) } & \multicolumn{3}{|c|}{ Waiting List Control (WLC) } \\
\hline & $\mathrm{n}$ & $\begin{array}{l}\text { Pre-measurement } \\
\mathrm{M}(\mathrm{SD})\end{array}$ & $\begin{array}{l}\text { Post-measurement } \\
\mathrm{M}(\mathrm{SD})\end{array}$ & $n$ & $\begin{array}{l}\text { Pre-measurement } \\
\mathrm{M}(\mathrm{SD})\end{array}$ & $\begin{array}{l}\text { Post-measurement } \\
\mathrm{M}(\mathrm{SD})\end{array}$ \\
\hline \multicolumn{7}{|l|}{ Updating } \\
\hline Reverse digit span & 55 & $29.13(21.85)$ & $31.39(21.12)$ & 33 & $28.07(23.22)$ & $33.56(26.61)$ \\
\hline \multicolumn{7}{|l|}{ Shifting } \\
\hline \multicolumn{7}{|l|}{ Switch cost } \\
\hline Reaction time (ms) & 55 & $175.31(257.97)$ & $172.42(200.06)$ & 32 & $140.92(162.59)$ & $140.12(184.61)$ \\
\hline Accuracy (sum) & 55 & $1.67(3.91)$ & $2.50(3.26)$ & 32 & $1.69(4.26)$ & $2.38(3.65)$ \\
\hline WCST & 57 & $5.04(3.21)$ & $6.05(3.08)$ & 34 & $5.06(3.24)$ & $5.82(3.55)$ \\
\hline \multicolumn{7}{|l|}{ Inhibition } \\
\hline Stop-signal SSRT & 56 & $397.66(91.14)$ & $378.48(58.25)$ & 34 & $404.17(58.93)$ & $379.61(47.82)$ \\
\hline
\end{tabular}

Reverse digit span score = correctly recalled digits; Switch cost reaction time = reaction time switch trial minus reaction time repeat trial (ms); Switch cost accuracy = accuracy repeat trial minus accuracy switch trial; WCST score = sum categories completed; Stop-signal SSRT score = mean RT on correct go-trial minus mean stopsignal delay.

\section{DISCUSSION}

The current study examined whether an internet-based positive psychology intervention can counteract deteriorations in executive functioning in chronic pain patients. As expected, the intervention led to increases in positive affect and optimism compared to a wait list control condition. However, the results did not confirm that executive task performance improved in patients that completed the intervention, compared to patients in the waiting list condition.

We hypothesized that increasing optimism and positive emotions would protect against executive functioning impairments due to chronic pain, because there is theo- 
retical [39; 59] and empirical $[15 ; 16]$ basis for this assumption. Within the context of the competing limited resources theory [31; 32] two potential mechanisms are probable. First, both cognitive and self-regulatory resources are considered to be limited and proposed to be fatigued by pain $[32 ; 102 ; 103]$. Experiencing positive emotions and optimism may increase motivation to continue allocating resources towards task performance, despite less resources being available. Second, optimism and positive emotions may increase an individual's ability to preserve attention for accurate task performance. Chronic pain patients often worry and ruminate about their pain experience and report more pain catastrophizing $[33 ; 51 ; 63 ; 94]$. As optimism is associated with less worry, rumination and pain catastrophizing $[43 ; 47 ; 64 ; 111]$ all available attention resources can be dedicated towards task performance instead of being consumed by negative thought patterns. Furthermore, optimism and positive affect may increase topdown variables (e.g., motivation, goal perseverance and effort $[30 ; 87 ; 92 ; 113 ; 122]$ that modulate the ability of pain to interrupt and capture an individual's attention at the expense of accurate task performance $[58 ; 60]$. Besides these theoretical underpinnings, we also demonstrated it empirically in two lab studies [15; 16]. Results from these studies demonstrated that experimentally induced pain deteriorated executive task performance (i.e., updating and shifting) in predominantly healthy university students. Increasing optimism with a writing and visualisation exercise counteracted these pain-induced deteriorations in task performance.

The present study findings imply that the protective effect of optimism and positive emotions on executive functioning do not extend to a chronic pain patients population. In contrast to a patient sample, a healthy student sample is more homogeneous, the age range is more restricted and students are generally more familiar with performing on these types of computer tasks that measure executive functioning. It is possible that the absence of improvement in executive task performance may be due to the online computerized assessment method. We included extended practice phases, elaborated task instruction and showed the instructions during task execution to ensure good comprehension of the task by patients. However, these measures to increase task comprehension may not compensate for lack of computer experience or anxiety for completing computerized tests, which have a negative influence on task performance [20; 120]. This may be especially the case in tasks that measure reaction time and have restricted response windows, such as the shifting task. Furthermore, the current tasks may not be sensitive enough to measure possible improvements in executive functioning. The tasks were carefully selected to ensure that the three core domains of executive functioning (i.e., inhibition, updating and shifting) were measured and could be implemented online. Moreover, the selected tasks have been previously used to examine the effects of experimentally induced pain $[14 ; 17 ; 41 ; 53 ; 72 ; 73 ; 93]$, naturally occurring acute pain $[5 ; 6 ; 54 ; 74]$, and chronic pain $[80 ; 97 ; 117]$ on task performance. However, there are some limitations with these tasks that should be considered, such as task impurity (i.e., also measuring essential cognitive processes not of interest [12; 
13], different versions of the same task [67] and weak associations between tasks that are thought to measure the same executive function $[40 ; 52 ; 68]$.

Additionally, in order to measure improvement in executive functioning, the same tasks were used for the pre- and post-measurement. However, performing a task twice often leads to improved task performance (i.e., practice effects [35; 62; 116]), which may have masked the effects of the intervention on executive functioning. Practice effects may be reduced by applying an alternate form of the task on the postmeasurement [10; 35], although this method is not effective when comparing tasks where a strategy or rule has to be learned (i.e., WCST) as a rule generally cannot be easily unlearned [8; 35]. Future research may consider implementing a task twice at baseline to minimize practice effects, the influence of computer experience and task incomprehension. Implementing the task twice gives patients the time to fully grasp the requirements of the different tasks, increasing the likelihood that executive functioning is measured, not mere task comprehension [35].

A further difficulty is that performance on experimental tasks may have little or no predictive value for how a patient will perform on naturalistic tasks encountered in everyday life [22; 24; 99]. For example, patients may be perfectly able to switch between sorting rules in the WCST, but unable to switch between different languages in a conversation, although both require shifting ability. These findings emphasise the need for more ecological valid measurements of executive functioning. Proposed solutions are developing tasks based on themes essential for survival (e.g., increasing social alliances and cooperation, parenting and avoidance of predators), increasing complexity (i.e., multiple steps to obtain one overarching goal, such as driving or cooking) or even using virtual reality to mimic complex real world situations [24; 55]. Similarly, it is possible that patients perceived executive functioning improvement, although the tasks did not indicate improvement due to the intervention. Prior research showed that chronic pain patients performed equally well on an inhibition task as healthy controls, but showed irregular brain activation, proposed to compensate for less available neural resources due to pain perception [42]. This compensatory plasticity may come with additional costs that may only be perceived by patients. Future research may want to include instruments to measure the perception of executive dysfunction in patients to address this issue.

We did replicate the findings of a previously conducted randomized control trial [83] in that the intervention was successful in increasing happiness, optimism, positive future expectancies, positive affect, self-compassion and ability to live a desired life despite pain, and lowering pain catastrophizing, depression and anxiety. These findings emphasize the possibility to decrease distress and increase well-being in chronic pain patients through an online self-help positive psychology intervention. Better chronic pain adjustment by increasing optimism and positive emotions is in line with the broaden-and-build theory, which states that strengthening positive behaviours, emotions and cognitions causes an upward spiral to ensue, in which broadening thinking patterns and building durable resources results in further positive emotions, in turn enhancing emo- 
tional well-being [37-39]. The intervention did not decrease pain intensity and disability, which is not an uncommon outcome when examining psychological treatments for chronic pain $[34 ; 83 ; 121]$. That pain persists validates the importance of having selfhelp techniques to reduce the burden of living with chronic pain. Moreover, these significant improvements were achieved via minimal guidance, making it an attractive treatment option for chronic pain patients.

The current study had some limitations. First, although delivering an intervention via internet has several advantages, such as high accessibility, lower threshold to participate, reducing therapist time and waiting lists and cost-effectiveness $[3 ; 4 ; 9 ; 29 ; 50$; 107], disadvantages to the online data collection can be identified as well. For example, the online mode of administration restricted the possibility to give clarification about the tasks or to intervene when patients did not follow the instructions. Furthermore, although we applied rigorous data screening methods, it cannot be excluded that task performance was affected by test environment or that patients did not dedicate the appropriate amount of effort. Both noise and less effort have previously been associated with poorer task performance [5]. Second, the generalization of these results towards other pain disorders or patients in other settings is limited as the study sample consisted of only self-reported diagnosed fibromyalgia patients who self-selected to participate in this study. However, prior research has indicated that fibromyalgia patients have poorer treatment response to CBT than other pain disorders [107], thus finding a successful intervention for this pain disorder is imperative. Lastly, the intervention consisted of several evidence-based positive psychology exercises, but it is unclear what the distinctive effect of each technique was on treatment outcome. Future studies may consider having intermediate measurements following the completion of every module so it is possible to examine the distinctive effect of each module.

In conclusion, the present study shows that an 8-week online self-help positive psychology intervention is able to improve emotional well-being in chronic pain patients. The intervention did not improve executive task performance. As pain itself often cannot be relieved, it is imperative to have self-help techniques to reduce the burden of living with chronic pain. 


\section{SUPPLEMENTARY MATERIALS}

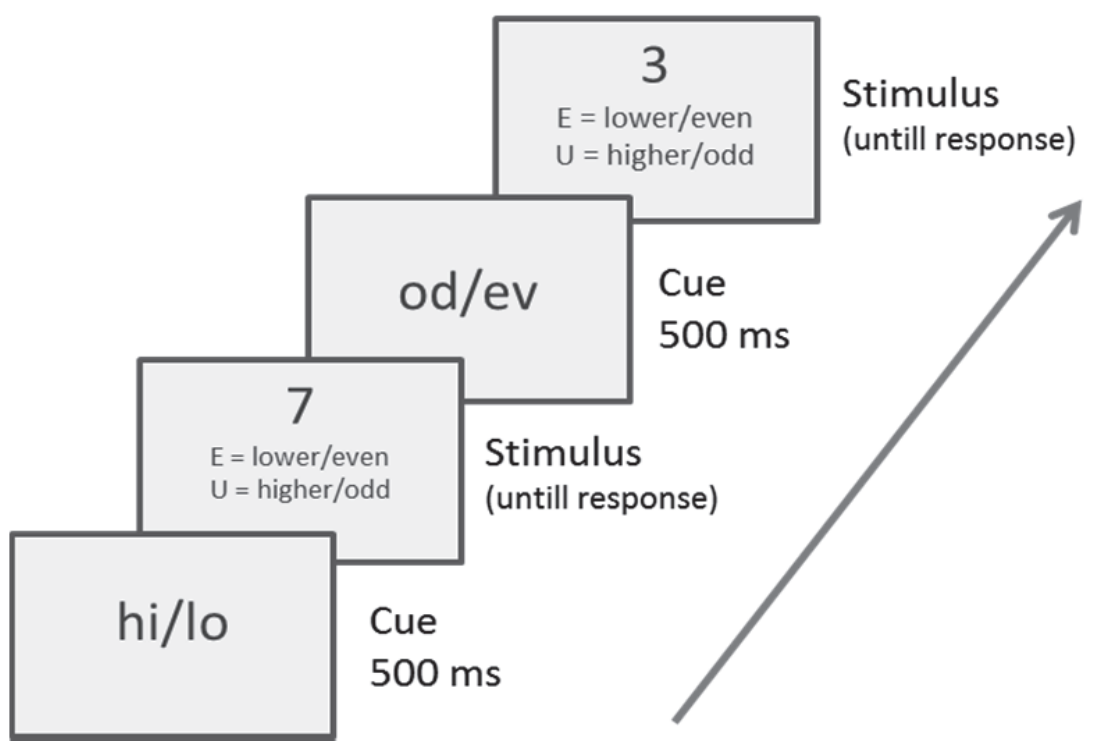

Figure 1. Timeline of events in the task shifting paradigm, showing two consecutive runs of trials.

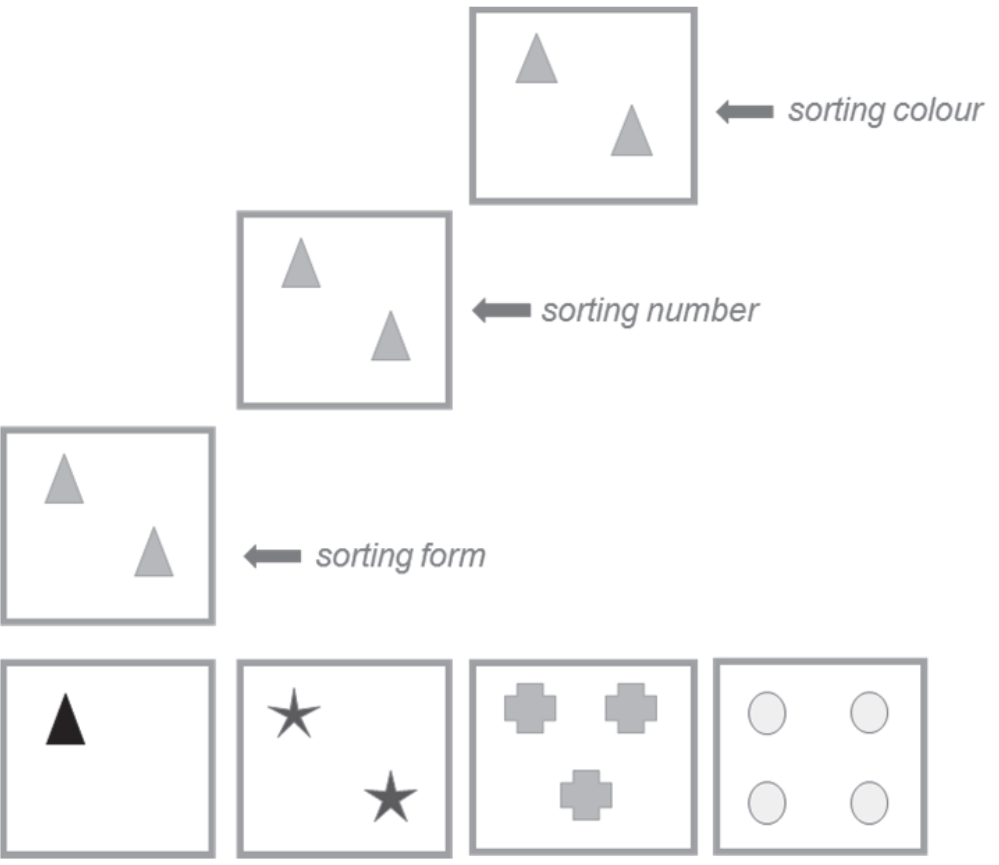

Figure 2. Example of the sorting rules in the Wisconsin card sorting task. Note: colour is not an accurate depiction of the colour used in the task. 


\section{REFERENCES}

[1] Abdel-Khalek AM. Measuring happiness with a single-item scale. Social Behavior and Personality: an international journal 2006;34(2):139-150.

[2] Altmann EM, Gray WD. An integrated model of cognitive control in task switching. Psychological Review 2008;115(3):602.

[3] Andersson G. Using the Internet to provide cognitive behaviour therapy. Behaviour Research and Therapy 2009;47(3):175-180.

[4] Andersson G, Titov N. Advantages and limitations of Internet-based interventions for common mental disorders. World Psychiatry 2014;13(1):4-11.

[5] Attridge N, Keogh E, Eccleston C. The effect of pain on task switching: pain reduces accuracy and increases reaction times across multiple switching paradigms. Pain 2016.

[6] Attridge N, Noonan D, Eccleston C, Keogh E. The disruptive effects of pain on n-back task performance in a large general population sample. Pain 2015;156(10):1885.

[7] Banich MT. Executive function the search for an integrated account. Current Directions in Psychological Science 2009;18(2):89-94.

[8] Basso MR, Bornstein RA, Lang JM. Practice effects on commonly used measures of executive function across twelve months. The Clinical Neuropsychologist 1999;13(3):283-292.

[9] Bender JL, Radhakrishnan A, Diorio C, Englesakis M, Jadad AR. Can pain be managed through the Internet? A systematic review of randomized controlled trials. PAIN ${ }^{\circledR}$ 2011;152(8):1740-1750.

[10] Benedict RH, Zgaljardic DJ. Practice effects during repeated administrations of memory tests with and without alternate forms. Journal of Clinical and Experimental Neuropsychology 1998;20(3):339-352.

[11] Berryman C, Stanton TR, Bowering KJ, Tabor A, McFarlane A, Moseley GL. Evidence for working memory deficits in chronic pain: a systematic review and meta-analysis. Pain 2013;154(8):1181-1196.

[12] Berryman C, Stanton TR, Bowering KJ, Tabor A, McFarlane A, Moseley GL. Do people with chronic pain have impaired executive function? A meta-analytical review. Clinical Psychology Review 2014;34(7):563579.

[13] Bialocerkowski AE. Measurement error and reliability testing: Application to rehabilitation. International Journal of Therapy \& Rehabilitation 2008;15(10).

[14] Boselie JJ, Vancleef LM, Peters ML. The effects of experimental pain and induced optimism on working memory task performance. Scandinavian Journal of Pain 2016;12:25-32.

[15] Boselie JJ, Vancleef LM, Peters ML. Increasing optimism protects against pain-induced impairments in task shifting performance. The Journal of Pain 2016.

[16] Boselie JJ, Vancleef LM, Smeets T, Peters ML. Increasing optimism abolishes pain-induced impairments in executive task performance. Pain 2014;155(2):334-340.

[17] Boselie JJLM, Vancleef, L. M., \& Peters, M. L. . Increasing optimism protects against pain-induced impairments in task shifting performance. The Journal of Pain submitted for publication.

[18] Breivik H, Collett B, Ventafridda V, Cohen R, Gallacher D. Survey of chronic pain in Europe: Prevalence, impact on daily life, and treatment. Eur J Pain 2006;10(4):287-333.

[19] Breivik H, Eisenberg E, O'Brien T. The individual and societal burden of chronic pain in Europe: the case for strategic prioritisation and action to improve knowledge and availability of appropriate care. BMC Public Health 2013;13:1229.

[20] Browndyke JN, Albert AL, Malone W, Schatz P, Paul RH, Cohen RA, Tucker KA, Gouvier WD. Computerrelated anxiety: Examining the impact of technology-specific affect on the performance of a computerized neuropsychological assessment measure. Applied Neuropsychology 2002;9(4):210-218.

[21] Buhle J, Wager TD. Performance-dependent inhibition of pain by an executive working memory task. Pain 2010;149(1):19-26.

[22] Burgess PW, Alderman N, Evans J, Emslie H, Wilson BA. The ecological validity of tests of executive function. Journal of the international neuropsychological society 1998;4(06):547-558.

[23] Carver CS, Scheier MF, Segerstrom SC. Optimism. Clinical Psychology Review 2010;30(7):879-889. 
[24] Chan RC, Shum D, Toulopoulou T, Chen EY. Assessment of executive functions: Review of instruments and identification of critical issues. Archives of Clinical Neuropsychology 2008;23(2):201-216.

[25] Chelune GJ, Naugle RI, Lüders H, Sedlak J, Awad IA. Individual change after epilepsy surgery: Practice effects and base-rate information. Neuropsychology 1993;7(1):41.

[26] Crawford JR, Henry JD. The Positive and Negative Affect Schedule (PANAS): Construct validity, measurement properties and normative data in a large non-clinical sample. British Journal of Clinical Psychology 2004;43(3):245-265.

[27] Crombez G, Eccleston C, Baeyens F, Eelen P. The disruptive nature of pain: An experimental investigation. Behaviour Research and Therapy 1996;34(11-12):911-918.

[28] Crombez G, Eccleston C, Baeyens F, Eelen P. Attentional disruption is enhanced by the threat of pain. Behaviour Research and Therapy 1998;36(2):195-204.

[29] Cuijpers $P$, van Straten A, Andersson G. Internet-administered cognitive behavior therapy for health problems: a systematic review. Journal of Behavioral Medicine 2008;31(2):169-177.

[30] Duke J, Leventhal H, Brownlee S, Leventhal EA. Giving up and replacing activities in response to illness. The Journals of Gerontology: Series B: Psychological Sciences and Social Sciences 2002;57B(4):P367P376.

[31] Eccleston C. Chronic pain and attention: A cognitive approach. British Journal of Clinical Psychology 1994;33(4):535-547.

[32] Eccleston C, Crombez G. Pain demands attention: A cognitive-affective model of the interruptive function of pain. Psychological Bulletin 1999;125(3):356-366.

[33] Eccleston C, Crombez G, Aldrich S, Stannard C. Worry and chronic pain patients: a description and analysis of individual differences. Eur J Pain 2001;5(3):309-318.

[34] Eccleston C, Williams ACdC, Morley S. Psychological therapies for the management of chronic pain (excluding headache) in adults. The cochrane library 2009.

[35] Falleti MG, Maruff P, Collie A, Darby DG. Practice effects associated with the repeated assessment of cognitive function using the CogState battery at 10-minute, one week and one month test-retest intervals. Journal of Clinical and Experimental Neuropsychology 2006;28(7):1095-1112.

[36] Faul F, Erdfelder E, Lang A-G, Buchner A. G* Power 3: A flexible statistical power analysis program for the social, behavioral, and biomedical sciences. Behavior research methods 2007;39(2):175-191.

[37] Fredrickson BL. What good are positive emotions? Review of general psychology 1998;2(3):300.

[38] Fredrickson BL. The role of positive emotions in positive psychology: The broaden-and-build theory of positive emotions. American psychologist 2001;56(3):218.

[39] Fredrickson BL. The broaden-and-build theory of positive emotions. Philosophical transactions-royal society of london series b biological sciences 2004:1367-1378.

[40] Friedman NP, Miyake A, Corley RP, Young SE, DeFries JC, Hewitt JK. Not all executive functions are related to intelligence. Psychological science 2006;17(2):172-179.

[41] Gilbert SJ, Burgess PW. Executive function. Current Biology 2008;18(3):R110-R114.

[42] Glass JM, Williams DA, Fernandez-Sanchez ML, Kairys A, Barjola P, Heitzeg MM, Clauw DJ, SchmidtWilcke T. Executive function in chronic pain patients and healthy controls: different cortical activation during response inhibition in fibromyalgia. J Pain 2011;12(12):1219-1229.

[43] Goodin BR, Glover TL, Sotolongo A, King CD, Sibille KT, Herbert MS, Cruz-Almeida Y, Sanden SH, Staud R, Redden DT. The association of greater dispositional optimism with less endogenous pain facilitation is indirectly transmitted through lower levels of pain catastrophizing. The Journal of Pain 2013;14(2):126135.

[44] Grant DA, Berg E. A behavioral analysis of degree of reinforcement and ease of shifting to new responses in a Weigl-type card-sorting problem. Journal of experimental psychology 1948;38(4):404.

[45] Greve KW, Stickle TR, Love JM, Bianchini KJ, Stanford MS. Latent structure of the Wisconsin Card Sorting Test: a confirmatory factor analytic study. Archives of Clinical Neuropsychology 2005;20(3):355-364.

[46] Hanssen MM, Peters ML, Vlaeyen JW, Meevissen YM, Vancleef LM. Optimism lowers pain: Evidence of the causal status and underlying mechanisms. Pain 2013;154(0):53-58. 
[47] Hanssen MM, Vancleef LM, Vlaeyen JW, Peters ML. More optimism, less pain! The influence of generalized and pain-specific expectations on experienced cold-pressor pain. Journal of behavioral medicine 2014;37(1):47-58.

[48] Hart RP, Martelli MF, Zasler ND. Chronic pain and neuropsychological functioning. Neuropsychology review 2000;10(3):131-149.

[49] Heaton R, Chelune G, Talley J, Kay G, Curtiss G. Wisconsin card sorting test manual revised and expanded. Lutz, FL: Psychological Assessment Resources: Inc, 1993.

[50] Hedman E, Ljótsson B, Lindefors N. Cognitive behavior therapy via the Internet: a systematic review of applications, clinical efficacy and cost-effectiveness. Expert review of pharmacoeconomics \& outcomes research 2012;12(6):745-764.

[51] Kane MJ, Brown LH, McVay JC, Silvia PJ, Myin-Germeys I, Kwapil TR. For whom the mind wanders, and when: An experience-sampling study of working memory and executive control in daily life. Psychological science 2007;18(7):614-621.

[52] Kane MJ, Conway ARA, Miura TK, Colflesh GJH. Working memory, attention control, and the n-back task: A question of construct validity. Journal of Experimental Psychology: Learning, Memory, and Cognition 2007;33(3):615-622.

[53] Karsdorp P, Geenen R, Vlaeyen J. Response inhibition predicts painful task duration and performance in healthy individuals performing a cold pressor task in a motivational context. Eur J Pain 2014;18(1):92100.

[54] Keogh E, Cavill R, Moore DJ, Eccleston C. The effects of menstrual-related pain on attentional interference. Pain 2014;155(4):821-827.

[55] Keogh E, Moore DJ, Duggan GB, Payne SJ, Eccleston C. The disruptive effects of pain on complex cognitive performance and executive control. PloS one 2013;8(12):e83272.

[56] Kiesel A, Steinhauser M, Wendt M, Falkenstein M, Jost K, Philipp AM, Koch I. Control and interference in task switching-A review. Psychological Bulletin 2010;136(5):849.

[57] Korn EL, Freidlin B. Outcome-Adaptive Randomization: Is It Useful? Journal of Clinical Oncology 2011;29(6):771-776.

[58] Legrain V, Crombez G, Verhoeven K, Mouraux A. The role of working memory in the attentional control of pain. Pain 2011;152(2):453-459.

[59] Legrain V, Damme SV, Eccleston C, Davis KD, Seminowicz DA, Crombez G. A neurocognitive model of attention to pain: behavioral and neuroimaging evidence. Pain 2009;144(3):230-232.

[60] Legrain V, Van Damme S, Eccleston C, Davis KD, Seminowicz DA, Crombez G. A neurocognitive model of attention to pain: behavioral and neuroimaging evidence. Pain 2009;144(3):230-232.

[61] Linton SJ, Bergbom S. Understanding the link between depression and pain. Scandinavian Journal of Pain 2011;2(2):47-54.

[62] McCaffrey RJ, Ortega A, Haase RF. Effects of repeated neuropsychological assessments. Archives of Clinical Neuropsychology 1993;8(6):519-524.

[63] McCracken LM, Iverson GL. Predicting complaints of impaired cognitive functioning in patients with chronic pain. Journal of pain and symptom management 2001;21(5):392-396.

[64] McGregor BA, Bowen DJ, Ankerst DP, Andersen MR, Yasui Y, McTiernan A. Optimism, perceived risk of breast cancer, and cancer worry among a community-based sample of women. Health Psychology 2004;23(4):339.

[65] Meevissen YMC, Peters ML, Alberts HJEM. Become more optimistic by imagining a best possible self: Effects of a two week intervention. Journal of Behavior Therapy and Experimental Psychiatry 2011;42(3):371-378.

[66] Meinert CL. Clinical Trials Design, Conduct, and Analysis. . New York: Oxford University Press, 1986.

[67] Meiran N. Reconfiguration of processing mode prior to task performance. Journal of Experimental Psychology: Learning, Memory, and Cognition 1996;22(6):1423.

[68] Miller K, Price C, Okun M, Montijo H, Bowers D. Is the n-back task a valid neuropsychological measure for assessing working memory? Archives of Clinical Neuropsychology 2009;24(7):711-717. 
[69] Miyake A, Friedman NP, Emerson MJ, Witzki AH, Howerter A. The unity and diversity of executive functions and their contributions to complex 'frontal lobe' tasks: A latent variable analysis. Cognitive Psychology 2000;41(1):49-100.

[70] Miyake A, Friedman NP, Emerson MJ, Witzki AH, Howerter A, Wager TD. The Unity and Diversity of Executive Functions and Their Contributions to Complex "Frontal Lobe" Tasks: A Latent Variable Analysis. Cognitive Psychology 2000;41(1):49-100.

[71] Monsell S. Task switching. Trends in Cognitive Sciences 2003;7(3):134-140.

[72] Moore DJ, Keogh E, Eccleston C. The interruptive effect of pain on attention. The Quarterly Journal of Experimental Psychology 2012;65(3):565-586.

[73] Moore DJ, Keogh E, Eccleston C. The effect of threat on attentional interruption by pain. Pain 2013;154(1):82-88.

[74] Moore DJ, Keogh E, Eccleston C. Headache impairs attentional performance. Pain 2013;154(9):18401845.

[75] Moriarty O, McGuire BE, Finn DP. The effect of pain on cognitive function: a review of clinical and preclinical research. Progress in Neurobiology 2011;93(3):385-404.

[76] Morris N, Jones DM. Memory updating in working memory: The role of the central executive. British journal of psychology 1990;81(2):111-121.

[77] Neff KD. The development and validation of a scale to measure self-compassion. Self and identity 2003;2(3):223-250.

[78] Neff KD, Germer CK. A pilot study and randomized controlled trial of the mindful self-compassion program. Journal of clinical psychology 2013;69(1):28-44.

[79] Neff KD, Vonk R. Self-compassion versus global self-esteem: Two different ways of relating to oneself. Journal of personality 2009;77(1):23-50.

[80] Oosterman JM, Derksen LC, van Wijck AJ, Veldhuijzen DS, Kessels RP. Memory functions in chronic pain: examining contributions of attention and age to test performance. The Clinical journal of pain 2011;27(1):70-75.

[81] Osman A, Barrios FX, Gutierrez PM, Kopper BA, Merrifield T, Grittmann L. The Pain Catastrophizing Scale: Further psychometric evaluation with adult samples. Journal of Behavioral Medicine 2000;23(4):351365.

[82] Peters ML, Flink IK, Boersma K, Linton SJ. Manipulating optimism: Can imagining a best possible self be used to increase positive future expectancies? The Journal of Positive Psychology 2010;5(3):204-211.

[83] Peters ML, Smeets, E., Feijge, M., van Breukelen, G., Andersson, G., Buhrman, M., \& Linton, S. J. Happy despite pain: a randomized controlled trial of an 8-week internet-delivered positive psychology intervention for enhancing well-being in patients with chronic pain. Clinical journal of pain in press.

[84] Pollard CA. Preliminary validity study of the pain disability index. Perceptual and motor skills 1984.

[85] Posner MI, Boies SJ. Components of attention. Psychological review 1971;78(5):391.

[86] Raes F, Pommier E, Neff KD, Van Gucht D. Construction and factorial validation of a short form of the self-compassion scale. Clinical psychology \& psychotherapy 2011;18(3):250-255.

[87] Rasmussen HN, Wrosch C, Scheier MF, Carver CS. Self-Regulation Processes and Health: The Importance of Optimism and Goal Adjustment. J Pers 2006;74(6):1721-1747.

[88] Ryan JJ, Paolo AM. Exploratory factor analysis of the WAIS-III in a mixed patient sample. Archives of Clinical Neuropsychology 2001;16(2):151-156.

[89] Ryckeghem D, Crombez G, Eccleston C, Legrain V, Damme S. Keeping pain out of your mind: The role of attentional set in pain. Eur J Pain 2013;17(3):402-411.

[90] Saklofske DH, Hildebrand DK, Gorsuch RL. Replication of the factor structure of the Wechsler Adult Intelligence Scale-Third Edition with a Canadian Sample. Psychological Assessment 2000;12(4):436.

[91] Scheier MF, Carver CS, Bridges MW. Distinguishing optimism from neuroticism (and trait anxiety, selfmastery, and self-esteem): A reevaluation of the Life Orientation Test. Journal of Personality and Social Psychology 1994;67(6):1063-1078.

[92] Schmitz U, Saile H, Nilges P. Coping with chronic pain: Flexible goal adjustment as an interactive buffer against pain-related distress. Pain 1996;67(1):41-51. 
[93] Schoofs D, Wolf OT, Smeets T. Cold pressor stress impairs performance on working memory tasks requiring executive functions in healthy young men. Behavioral Neuroscience 2009;123(5):1066-1075.

[94] Segerstrom SC, Tsao JC, Alden LE, Craske MG. Worry and rumination: Repetitive thought as a concomitant and predictor of negative mood. Cognitive Therapy and Research 2000;24(6):671-688.

[95] Seligman ME, Rashid T, Parks AC. Positive psychotherapy. American psychologist 2006;61(8):774.

[96] Seligman ME, Steen TA, Park N, Peterson C. Positive psychology progress: empirical validation of interventions. American psychologist 2005;60(5):410.

[97] Seo J, Kim S-H, Kim Y-T, Song H-j, Lee J-j, Kim S-H, Han SW, Nam EJ, Kim S-K, Lee HJ. Working memory impairment in fibromyalgia patients associated with altered frontoparietal memory network. PloS one 2012;7(6):e37808.

[98] Severeijns R, van den Hout MA, Vlaeyen JW, Picavet HSJ. Pain catastrophizing and general health status in a large Dutch community sample. Pain 2002;99(1):367-376.

[99] Shallice T, Burgess PW. Deficits in strategy application following frontal lobe damage in man. Brain 1991;114(2):727-741.

[100] Smeets E, Neff K, Alberts H, Peters M. Meeting suffering with kindness: Effects of a brief selfcompassion intervention for female college students. Journal of Clinical Psychology 2014;70(9):794807.

[101] Smith EE, Jonides J. Storage and executive processes in the frontal lobes. Science 1999;283(5408):16571661.

[102] Solberg Nes L, Carlson CR, Crofford L, de Leeuw R, Segerstrom SC. Self-regulatory deficits in fibromyalgia and temporomandibular disorders. Pain 2010;151(1):37-44.

[103] Solberg Nes L, Roach AR, Segerstrom SC. Executive functions, self-regulation, and chronic pain: A review. Annals of Behavioral Medicine 2009;37(2):173-183.

[104] Spinhoven P, Ormel J, Sloekers P, Kempen G, Speckens A, Van Hemert A. A validation study of the Hospital Anxiety and Depression Scale (HADS) in different groups of Dutch subjects. Psychological medicine 1997;27(02):363-370.

[105] Stewart WF, Ricci JA, Chee E, Morganstein D, Lipton R. Lost productive time and cost due to common pain conditions in the US workforce. Jama 2003;290(18):2443-2454.

[106] Strauss E, Sherman EM, Spreen O. A compendium of neuropsychological tests: Administration, norms, and commentary: American Chemical Society, 2006.

[107] Sturgeon JA. Psychological therapies for the management of chronic pain. Psychology research and behavior management 2014;7:115.

[108] Sullivan MJL, Bishop SR, Pivik J. The Pain Catastrophizing Scale: Development and validation. Psychological Assessment 1995;7(4):524-532.

[109] Tait RC, Chibnall JT, Krause S. The pain disability index: psychometric properties. Pain 1990;40(2):171182.

[110] Tien AY, Spevack TV, Jones DW, Pearlson GD, Schlaepfer TE, Strauss ME. Computerized Wisconsin card sorting test: comparison with manual administration. Kaohsiung J Med Sci 1996;12(8):479-485.

[111] Tucker RP, Wingate LR, O'Keefe VM, Mills AC, Rasmussen K, Davidson CL, Grant DM. Rumination and suicidal ideation: The moderating roles of hope and optimism. Personality and Individual Differences 2013;55(5):606-611.

[112] Van Breukelen GJP. ANCOVA versus change from baseline had more power in randomized studies and more bias in nonrandomized studies. Journal of Clinical Epidemiology 2006;59(9):920-925.

[113] Van Damme S, Legrain V, Vogt J, Crombez G. Keeping pain in mind: a motivational account of attention to pain. Neuroscience \& Biobehavioral Reviews 2010;34(2):204-213.

[114] Van Ryckeghem DM, Crombez G, Eccleston C, Liefooghe B, Van Damme S. The interruptive effect of pain in a multitask environment: an experimental investigation. The Journal of Pain 2012;13(2):131138.

[115] Vancleef LM, Peters ML. The interruptive effect of pain on attention. J Pain 2006;7(1):21-22.

[116] Vandierendonck A, Liefooghe B, Verbruggen F. Task switching: interplay of reconfiguration and interference control. Psychological Bulletin 2010;136(4):601. 
[117] Verdejo-García A, López-Torrecillas F, Calandre EP, Delgado-Rodríguez A, Bechara A. Executive function and decision-making in women with fibromyalgia. Archives of Clinical Neuropsychology 2009;24(1):113122.

[118] Watson D, Clark LA, Tellegen A. Development and validation of brief measures of positive and negative affect: The PANAS scales. Journal of Personality and Social Psychology 1988;54(6):1063-1070.

[119] Wechsler D. WAIS-III: Administration and scoring manual: Wechsler adult intelligence scale: Psychological Corporation, 1997.

[120] Wiechmann D, Ryan AM. Reactions to computerized testing in selection contexts. International Journal of Selection and Assessment 2003;11(2-3):215-229.

[121] Williams AC, Eccleston C, Morley S. Psychological therapies for the management of chronic pain (excluding headache) in adults. Cochrane Database Syst Rev 2012;11:CD007407.

[122] Wrosch C, Scheier MF. Personality and quality of life: The importance of optimism and goal adjustment. Quality of Life Research: An International Journal of Quality of Life Aspects of Treatment, Care \& Rehabilitation 2003;12(Suppl1):59-72.

[123] ZHU J, TULSKY DS, PRICE L, Chen H-Y. WAIS-III reliability data for clinical groups. Journal of the International Neuropsychological Society 2001;7(07):862-866.

[124] Zigmond AS, Snaith RP. The hospital anxiety and depression scale. Acta psychiatrica scandinavica 1983;67(6):361-370. 
Chapter seven

General Discussion 



\section{GENERAL DISCUSSION}

Experiencing chronic pain causes marked emotional, behavioural, physiological and executive functioning problems. Pain grasps our attention, compromising accurate executive task performance. Impairments in executive functioning can be devastating and disabling, impacting employment status [12; 13; 41; 102] and self-perceived burden among chronic pain patients [46]. Since the pain itself often persists, having means to diminish the burden of living with chronic pain and reducing executive functioning impairments due to chronic pain is imperative. The overall aim of this dissertation was to examine whether optimism can act as a protective factor against pain related executive functioning impairments. In the five empirical chapters of this dissertation, six studies are presented that examined (I) whether experimentally induced pain deteriorates executive task performance in healthy participants; (II) whether Induced optimism counteracts pain-induced deteriorations in executive task performance in healthy participants; (III) whether possible protective effects of optimism generalises to different executive functions (i.e., updating, shifting); (IV) which factors contribute to the effectiveness of the manipulation to induce (temporary) optimism in healthy participants; $(V)$ whether increasing the emotional well-being of chronic pain patients via an online positive psychology intervention improves executive task performance (i.e., inhibition, updating and shifting). In this chapter, overviews of the main findings of these studies are presented, including possible implications and limitations of the studies. Throughout this chapter, findings are discussed and recommendations for future research will be made.

\section{PAIN AND EXECUTIVE FUNCTIONING}

Findings in this dissertation show that experimentally induced pain deteriorates concurrent and subsequent executive task performance. More specifically, experimentally induced heat pain deteriorated concurrent 2-back task performance (i.e., measuring updating ability; chapter 3 ) and task shifting performance (i.e., measuring shifting ability; chapter 4). These findings are in line with prior studies that show that experimentally induced pain impairs executive task performance $[18-20 ; 25 ; 67 ; 68 ; 77 ; 78 ; 92 ; 108]$. Notably, the findings corroborated prior studies using the same executive functioning tasks [4; 5; 77; 78]. For instance, Moore, Keogh and Eccleston [77] conducted seven experiments that examined the effect of pain on cognitive tasks performance. Participants completed various tasks with no-stimulation, concurrent warm stimulation and concurrent painful heat stimulation. These studies showed that pain interferes with task performance, although selectively. Similar to our findings, heat pain impaired performance on the 2-back task and shifting task. Additionally, Moore and colleagues found that heat pain impaired divided attention. But heat pain did not impair other tasks 
measuring inhibition of attention, sustained attention, and selective attention. Taken together, these findings indicate that especially tasks that require higher executive functions are affected by concurrent pain. This effect seems to be consistent across different types of pain. In another study by Moore et al. [79] participants completed the 2-back and shifting task twice: once when experiencing a natural occurring headache episode, and once without experiencing any pain. Headache impaired the performance both tasks. In a similar experimental set-up, Keogh and colleagues [63] found that menstrual pain deteriorated 2-back and shifting task performance. Attridge and colleagues examined the effects of natural occurring pain on 2-back task performance [5] and task shifting performance [4] in large samples recruited from a general population and tested via internet. Findings reported in these studies showed that pain disrupted task performance. Furthermore, participants who reported high pain intensity showed more 2back task performance decrements compared to participants with low pain intensity [5]. Additionally, only concurrent pain deteriorated shifting task performance [4]. The findings reported in chapter 3 and 4 corroborate prior research findings that support theoretical models proposing that pain competes with accurate task performance for limited (attention) resources. This may be especially the case when the task requires executive functioning, as both pain processing and executive functioning engage overlapping neural networks and interconnected brain regions [87; 98; 110].

We also showed that experimentally induced cold water pain deteriorated subsequent task performance (chapter 2). This finding is along the lines of findings presented in the study by Van Ryckeghem et al. [107]. In this study, participants were randomly assigned to a low and high pain intensity condition and performed 3 randomly alternating tasks. Participants either had to decide and verbally state whether the target stimulus was a square or triangle (i.e., shape task), had a pale or dark grey colour (i.e., colour task) or if the target stimulus was vertically or diagonally orientated (i.e., orientation task). During one of these tasks the target stimulus onset was paired with a painful electrocutaneous stimulus. Next to the effect of concurrent pain, the researchers also examined whether pain interferes with the performance on a subsequent task. The findings indicated that pain during a task trial impedes the performance on a subsequent task trial, with high pain intensity being more disruptive than low pain intensity. It should be noted that this study used a different task and only examined the prolonged interference effect of pain within the task (i.e., trial-by-trial analyses), whereas we employed the pain stimulus prior task execution. Similar to our design, Schoofs et al. [93] demonstrated that after a cold water induction subsequent operation-span task performance deteriorated. The findings of these studies indicate that even when pain has dissipated; it may still deteriorate executive task performance. A possible explanation for this prolonged interference effect of pain is that resources are fatigued. Coping with pain and exerting effort towards accurate executive task performance requires resources. But resources are considered to be limited [24; 25]. Consequently, directing resources towards the pain demand will render them unavailable for additional de- 
mands, causing resources to be fatigued $[7 ; 8 ; 45]$. In case of fatigued resources, we are more inclined to preserve resources to avoid depletion [33], causing a shift in motivation $[21 ; 57 ; 68 ; 106]$. Thus, coping with pain may reduce motivation to exert effort in accurate executive task performance in order to preserve resources.

However, the finding that pain deteriorated subsequent task performance was not consistently found in this dissertation. Cold water pain deteriorated operation-span task performance (chapter 2), but not 2-back task performance (chapter 3), even though both are considered to measure updating ability [76]. There are several plausible explanations for this discrepancy that need further elaboration, such as task differences, resource utilization and construct differences. First, we elaborate on differences between the operation-span and 2-back task. The operation-span task requires a participant to read a mathematical problem (e.g., is $(6 / 2)+5=8$ ) aloud, and then verbally state whether the offered solution is correct or incorrect (i.e., yes or no), followed by reading the word aloud (e.g., bread). After a set of 2 to 5 such equation and word combinations (e.g., is $(6 / 2)+5=8$ (yes or no) bread) the participant has to recall the words in order of presentation. In contrast, the 2-back task requires participants to indicate (i.e., yes or no) for each one-by-one presented letter on a computer screen, whether it corresponds to the letter presented 2 letters ago (e.g., T-J-P-J = no-no-no-yes). Looking at these task descriptions, both tasks meet the definition of updating ability: stored information is monitored and updated when necessary [76]. However, they differ in that the operation-span task requires participants to hold information (i.e., a group of words), in the face of proactive information interference (i.e., prior group of words), while also performing a demanding secondary task (i.e., giving the solution to the mathematical problems) [32]. Processing the mathematical problems interferes with recruitment of strategies, such as rehearsal or grouping, to maintain the stored information (i.e., the words) until recall. In contrast, the 2-back task allows covert rehearsal and active updating of the current memory set. Additionally, the presentation sequence of trials in the operation-span was randomized, which eliminates any strategy that is built on knowledge about the amount of words that need to be remembered [31]. Another notable distinction between the operation-span task and 2-back task is that retrieval is based on recall (i.e., words in order of presentation) or recognition (i.e., have I seen this letter before), respectively [61].

Both the absence of strategy possibilities and the necessity of recall may have increased the task demand of the operation-span task $[11 ; 24 ; 66 ; 90]$. Thus, pain may only have a sustained negative effect on executive task performance when task demand is high. Pain fatigues resources, rendering them temporarily unavailable for subsequent task performance $[7 ; 8 ; 45]$. Participants may be able to cope with pain and subsequently perform accurately on a task as long as the secondary task is less demanding (e.g., 2back task). However, when a task is more demanding (i.e., operation-span task), it will utilize more resources. If the subsequent task utilizes more resources, having fewer resources available is detrimental for accurate task performance. On the other hand, 
when pain is induced during task performance, pain competes for attention. As pain has the ability to capture attention at the expense of other activities, even the performance on less demanding task, such as the 2-back task, will suffer when attention is directed towards the pain experience.

Second, although both tasks are considered to measure the construct executive function updating, they may in fact measure different constructs or different parts of the same construct [30]. The reported correlation between these tasks is low [59; 61; 89]. Furthermore, when the two tasks are used to predict performance on a general fluid intelligence measure, both explained a portion of the variances independently from each other [59; 61]. However, higher correlations are obtained when both tasks use visuospatial content (e.g., arrows, shapes or symbols) [89] and require similar recall processes [59]. For example, Shelton and colleagues [99; 100] observed a stronger relationship between operation-span task performance and 2-back, when they used a recall version of the 2 -back. In this version of the 2 -back, words are presented one-by-one and participants are asked to recall for instance the second to last word that was presented during that trial.

\section{INCREASING OPTIMISM}

Supporting prior findings $[38 ; 47 ; 85]$, we demonstrated that the Best Possible Self (BPS) manipulation was effective in inducing a temporary optimistic state in healthy participants in the lab (chapter 2, 3, 4 and 5). Having a brief manipulation that increases optimism consistently in the laboratory is imperative as it allows us to examine (I) the causal relationship between optimism and pain and (2) whether optimism should be considered as an important protective factor in the context of pain. Linguistic analyses and qualitative ratings showed that the BPS manipulation was more effective when BPS participants wrote more about personal family life (i.e., family, friends, sex and social relationships), used more positive emotion words and wrote less about physical health and described fewer materialistic goals (chapter 5). This finding is in line with a prior study that showed that increases in social network predict increases in optimism, while more income does not predict increases in optimism [94]. Similar, optimism increases when women experience fewer problems within their relationship with their romantic partner [3]. In line with the self-determination theory [91], the BPS will be effective when the BPS narrative satisfies the basic psychological needs: relatedness (i.e., feeling connected to others), competence (i.e., ability to succeed in valued domains) and autonomy (i.e., level of choice). Both competence and autonomy are fostered in the BPS instruction (i.e., 'you have worked hard and succeeded at accomplishing all the goals of your life. Think of this as the realization of your dreams, and that you have reached your full potential'). The current BPS instructions do not specify any writing domains. Given the findings in this dissertation, future research may want to consider instructing partic- 
ipants to write for example about family and friends to also satisfy the need for relatedness, increasing the effectiveness of the BPS manipulation in the laboratory.

In the BPS manipulation, participants are asked to write and imagine a life in the future where everything turned out for the best. It is not hard to imagine that the BPS exercise is effective in increasing a temporary optimistic state in a healthy student population. A bright future (still) awaits for these young individuals, with numerous positive life events (e.g., graduating, marriage, buying a house and starting a family) to look forward too. However, writing and thinking about a best possible future may be more daunting for a person combatting chronic pain. It may trigger rumination about the development of pain, increasing thoughts and worry that the pain will only become more disabling, which in turn may increase awareness of the pain experience or even cause more pain $[21 ; 22 ; 26]$. One could imagine that the BPS exercise may even be potentially harmful for chronic pain patients when it elicits awareness between a selfperceived greater discrepancy between the actual self (i.e., who you are now) and the ideal self (i.e., who you want to be) and a smaller discrepancy between the actual self and the feared self (i.e., who you fear to be) [15; 52]. According to the Self Discrepancy Theory (SDT [52]), perceived self-discrepancies initiate behaviours to reduce (in case of actual and ideal self) or increase (in case of actual and feared self) these discrepancies. Self-discrepancies are associated with higher levels of pain, depression, anxiety, and distress, and lower levels of acceptance of pain in chronic pain patients $[44 ; 64 ; 111]$. This is especially true when the ideal (hoped-for self) is conditional on the absence of pain (i.e., high self-pain enmeshment) [81; 82; 104]. In other words, the BPS exercise may increase the risk for maladjustment towards pain when self-discrepancies cause effortful attempts to pursue the (often) unachievable goal to abolish pain. In order to account for this potential negative impact, we modified the BPS instructions for chronic pain patients. The instructions were more directive and concrete, as patients were asked to formulate concrete and obtainable future (i.e., over 5 years) goals, wishes and expectations. More importantly, patients were asked to write down a detailed narrative of how their best possible future will look like, despite pain. Formulating a BPS narrative despite pain may increase the acceptance of the pain experience, decreasing perceived self-discrepancies, which in turn will increase engagement in meaningful activities [71]. Thus, the therapeutic goal of the BPS exercise is not pain relief, but disengaging from the pursuit to abolish the pain experience and fostering an individual's ability to life a desired life despite the presence of pain.

Findings in this dissertation show that it is possible to increase optimism and positive affect in chronic pain patients with an internet-based positive psychology intervention (PPI). Patients in the PPI condition reported increases in optimism (state and trait), compared to patients in the waiting list control (WLC) condition (chapter 6). These findings are in line with a prior conducted randomized control trial, which showed that optimism (trait) significantly increased in chronic pain patients in the PPI condition compared to patients in the WLC condition, up to 6 months follow-up [86]. In addition 
to the modified BPS exercise, the PPI intervention contained self-compassion, positive focus and savouring exercises. These exercises promote treating oneself with kindness rather than self-criticism, shifting the focus from a negative orientation towards a more positive one and the frequency and intensity of positive experiences in daily life, respectively. However, having several positive psychology exercises within the PPI prevents us to examine the distinctive effect of the modified BPS exercise in increasing optimism. Future studies may want to consider using only the BPS exercise to determine whether this exercise is sufficient to increase optimism in chronic pain patients.

\section{PAIN, EXECUTIVE FUNCTIONING AND OPTIMISM}

We demonstrated that inducing a temporary optimistic state protects against paininduced deterioration in updating (i.e. operation-span task; chapter 2) and shifting performance (i.e., shifting task chapter 4). We propose two explanations why optimism may protect against executive functioning impairments due to pain, namely (I) optimism increases allocation of resources towards accurate executive task performance and (II) optimism increases attention towards accurate executive task performance. These explanations are not necessarily mutually exclusive. First, optimism may increase motivation to continue allocating (cognitive and self-regulatory) resources to accurate executive task performance, despite resources being fatigued by pain. As described previously, coping with pain and performing an executive task both require resources, but as these resources are limited [24; 25], exerting effort in both pain coping and task performance will fatigue resources $[7 ; 8 ; 45]$. Consequently, in order to preserve resources to avoid depletion [33] motivation to continue employing resources to both resource demands will decrease. In this case, given the aversive nature of pain, effort to cope with pain is continued at the expense of accurate executive task performance. However, optimism may increase motivation to continue allocating resources towards executive task performance, despite less resources being available. According to the expectancy-value model of motivation [16], motivation is determined by the expectancy of goal attainment. An optimist's tendency to expect positive outcomes will foster continued effort towards accurate executive task performance.

The second possible explanation is that optimism conserves or redirects attention towards executive task performance. Both pain and performing on the executive task compete for attention. But given the aversive nature of pain, attention is more likely directed towards pain at the expense of accurate executive task performance. Optimism may increase an individual's ability to preserve attention for accurate executive task performance, by either decreasing pain intensity or pain-induced negative thought patterns. The first and most intuitive explanation is the reduction of pain intensity. Research supports the protective ability of optimism on pain perception [42; 88]. For instance, optimism is associated with less pain after a coronary bypass surgery [70]. 
Moreover, increasing optimism with the BPS manipulation showed that participants reported less pain during a cold water task [47]. Decreasing pain intensity will decrease the aversive salience of pain, reducing the interruptive nature of pain, making it possible to direct attention towards accurate executive task performance. However, our findings do not support this explanation. Induced optimism did not decrease the intensity of experimentally induced pain (chapter 2, 3, and 4). Alternatively, optimism may reduce pain-induced distressing thoughts that consume attention. Pain is associated with worry, rumination and pain catastrophizing $[27 ; 60 ; 72 ; 96]$. As optimism is associated with less worry, rumination and pain catastrophizing $[43 ; 48 ; 73 ; 105]$ all available attention resources can be dedicated towards task performance instead of being consumed by negative thought patterns.

It should be noted that the protective effect of optimism on updating ability was not consistent. Optimism protected against pain-induced deterioration in operation-span task performance (chapter 2) but not 2-back task performance (chapter 3). As discussed earlier, there are differences between the operation-span and 2-back task (e.g., task demand) that may have contributed to these mixed findings. Optimism may only act as a protective factor when the task demand is high, requiring more resources to perform the executive task accurately. We propose that task demand is higher for the operationspan task compared to the 2-back task, due to the lack of strategy possibilities and an active retrieval process (i.e., recall).

Alternatively, the operation-span task may elicit more willingness to employ resources, despite being fatigued. Hess [50] proposed a framework to explain how agerelated decreases in cognitive resources effects cognitive functioning. Older adults are more selective in their engagement of cognitive resources. Cognitive engagement is determined by the perceived benefit of engagement relative to the costs (e.g., effort needed to perform the task, fatigue). This selective employment of resources could be considered adaptive as it conserves cognitive resources and only allocates resources to valued tasks. Although the framework was proposed to understand a general decline in cognitive engagement in older adults compared to younger adults, we argue this mechanism is also relevant for executive functioning in the context of pain. As described earlier, optimism may increase motivation to continue allocating resources towards accurate executive task performance, despite resources being fatigued by pain. But this increased motivation by optimism may only occur when the task is perceived as important and personally relevant [106]. The operation-span task requires a participant to verbally state whether the offered solution to the mathematical problem is correct. This may have increased the emotional valence of the task (e.g., fear of negative evaluation [75]) and increased accountability. For example, in a prior study by Hess and colleagues [51] accountability was manipulated. Participants were asked to form and write down an impression of a narrator, which was evaluated by other study participants (i.e., high accountability) or not (i.e., low accountability). Then participants were given an unexpected recall test of the narrative. In the low accountability condition, older participants 
remembered less from the narratives relative to younger participants. In contrast, when participants were held accountable for their responses, older participants performed equally well on the recall task as younger participants. These findings imply that accountability increases cognitive engagement, probably by increasing protective selfpresentation concerns (i.e., wanting to avoid disapproval [2]).

In sum, individuals in pain may be more selective in engaging fatigued resources towards executive task performance. However, optimism may increase motivation towards accurate task performance, especially when the task is valuable for an individual. Future studies are necessary to examine whether the protective effect of optimism on pain-induced deterioration in executive functioning is moderated by motivation and to elucidate the importance of task relevance. One future direction proposed by Jacobsen and Reme [58] is using an emotional 2-back task to examine whether increasing the valence of the stimuli elicits the protective ability of optimism. For example, faces or pain catastrophizing words can be used as emotional stimuli in the 2-back task [58; 69]. But one could also think of increasing protective self-presentation concerns by asking the participant to verbally state the solution to the letter 2-back task.

\section{CHRONIC PAIN, EXECUTIVE FUNCTIONING AND OPTIMISM}

Most of the work reported in this dissertation used experimentally induced pain in healthy participants. The lab studies established overall three things: (I) experimentally induced pain deteriorates subsequent and concurrent task performance, (II) it is possible to increase optimism in healthy participants and (III) manipulated optimism protects against pain-induced deterioration in executive task performance (i.e., updating and shifting). But there are fundamental differences between experimentally induced pain and natural occurring persistent pain. Experimentally induced pain is in most cases predictable, temporary and is evaluated as less threatening than chronic pain [29]. Furthermore, chronic pain is not experienced in isolation. Chronic pain always occurs within a context of daily life, with various constraints and demands of its own. Therefore, it is necessary to examine whether possible beneficial effects of optimism can be extended to a chronic pain population. Findings in this dissertation (chapter 6) demonstrated that it is possible to improve emotional well-being in chronic pain patients with a positive psychology internet-based intervention (PPI). Patients in the PPI condition reported increases in happiness, optimism, positive future expectancies, positive affect, selfcompassion and ability to live a desired life despite pain, compared to patients in the waiting list control (WLC) condition. Moreover, pain catastrophizing, depression and anxiety decreased for PPI patients compared to WLC patients. These findings are in line with the broaden-and-build theory in that enhancing positive behaviours, emotions and cognitions causes an upward spiral to ensue, in which broadening thinking patterns and building durable resources results in further positive emotions, in turn enhancing emo- 
tional well-being [34-36]. The finding that emotional well-being is improved in chronic pain patients with the PPI is particularly noteworthy given that the mean pain duration reported by patients was 13 years, patients received minimal guidance during the PPI and that Fibromyalgia patients have poorer treatment response to CBT than other pain disorders [103]. The intervention did not decrease pain intensity and disability, which is not an uncommon outcome when examining psychological treatments for chronic pain $[28 ; 86 ; 112]$. The fact that pain persists validates the importance of having self-help techniques that focus on improving well-being despite the pain experience. Taken together, this online self-help positive psychology intervention is suggested to be an attractive intervention option for chronic pain patients to increase emotional well-being.

Numerous reviews and meta-analysis have demonstrated that chronic pain patients suffer from executive functioning impairments [9; 10; 39-41; 49; 80; 84]. The main objective of the study described in chapter 6 was to examine whether increasing the emotional well-being of chronic pain patients via an online positive psychology intervention improves executive task performance (i.e., inhibition, updating and shifting). However, findings indicated that executive task performance did not improve in patients in the PPI condition, compared to patients in the WLC condition. Performance on the Wisconsin Card Sorting task (i.e., shifting) and the stop-signal task (i.e., inhibition) did improve significantly over time (i.e., practice effects). As discussed in chapter 6 , it is possible that the absence of improvement in executive task performance may be due to practice effects, the online computerized assessment method or that the tasks were not sensitive enough to measure possible improvements in executive functioning. Some future directions were already proposed in chapter 6 , such as implementing an executive task twice (to ensure that one measures executive functioning as opposed to task comprehension), using more ecological valid tasks and measuring the patient's self-perceived improvement in executive functioning. Additionally, future research may want to employ the executive functioning tasks in a laboratory setting, where the test procedure can be optimized, by reducing interference due to discomfort, distraction and task incomprehension. Furthermore, studies could employ other tasks that measure executive functioning (inhibition, updating and shifting) to determine whether the current finding that optimism did not improve task performance in chronic pain patients extends to other tasks measuring the same constructs. More importantly, we advocate for replication. The ultimate aim of science is to establish facts and facts are replicable. Consequently, when a study demonstrates that the finding replicates, given the specified conditions, the finding is likely to be true. We believe that optimism can act as a protective factor against pain-induced executive functioning, given theoretical and empirical evidence. But we also acknowledge that optimism may not protect (or not enough) against executive impairments due to chronic pain.

Although it is clear that experiencing pain-induced decrements in executive functioning is undesirable, there may also be an adaptive function of diminished cognitive resources, eventually causing impairments in executive task performance. Goals are 
organised in a hierarchical structure [16]. As pain fatigues resources, it may force a patient to be more selective in engaging cognitive resources. Consequently, persisting with the task is determined by the perceived benefit of engagement relative to the costs. This selective employment of resources may prevent the pursuit of less valued goals in order to facilitate behaviours to obtain higher valued goals [53; 113]. In this light, task performance decrements may reflect a change by priorities as opposed to incapability [57].

\section{CLINICAL IMPLICATIONS AND FUTURE DIRECTIONS}

This dissertation provides clear evidence that (I) the Best Possible Self manipulation can induce an optimistic state in healthy participants and (II) that a positive psychology intervention increases emotional well-being in chronic pain patients. This dissertation made the first step in examining the possible working mechanism that underpins the effectiveness of the BPS manipulation by analysing the content of BPS narratives. However, other possible working mechanism should be further explored. For instance, the instructions of the BPS in our lab studies did not specify any specific writing domains. However, a prior study with the BPS specified 3 writing domains, namely a personal domain, a relational domain and a professional domain [74]. In contrast, the BPS in the PPI (chapter 6) instructed patients to select 3 unique domains from a list of eight writing domains (i.e., family life, romantic life, social life, professional life, leisure and hobby, educational life, societal commitment and personal growth). Findings in this dissertation showed that writing about personal family domains increased the efficacy of the BPS. But it remains unclear whether specifying writing domains or letting participants select writing domains from a list of domains will increase the BPS effectiveness. Similar, the BPS exercise contains writing and imagining elements. The imagery element was added to the BPS exercise as imagery evokes stronger affective responses compared to verbal processing [54-56]. However, it remains elusive whether imagery is a necessary element for the effectiveness of the BPS exercise. Similarly, future studies are necessary to determine whether there is a dose-response relationship between the number of times the BPS exercise is repeated and the effectiveness of the BPS exercise.

We argue that by increasing optimism with the BPS exercise, individuals with chronic pain will experience more motivation to show persistent goal pursuit, which in turn will increase goal attainment. But despite increased motivation towards goal attainment, chronic pain patients may not always be successful in translating it to effective goaldirected behaviour. Mental contrasting with implementation intentions (MCII) was developed to improve effective goal pursuit [62; 83]. In order to attain goals, an individual first needs to imagine fulfilling these goals while also be conscious of the obstacles that must be overcome to realize the goal (i.e., mental contrasting). Mental contrasting will increase the expectation of goal attainment, which in turn will increase tenacious 
goal pursuit. Obstacles for goal attainment can be overcome with if-then statements (i.e., implementation intentions). For example, Christiansen and colleagues [17] adapted the $\mathrm{MCll}$ intervention for chronic back pain patients with mental contrasting about improved mobility and implementation intentions (e.g., If I am afraid for the movement, then I will remember that movement heals pain). Patients in the $\mathrm{MCll}$ condition were more physically active compared to patients in the treatment as usual condition at 3 weeks and 3 months follow-up, irrespective of patients unchanged pain experience. One future research direction is investigating whether combining the BPS with implementation intentions will improve goal attainment in chronic pain patients.

An additional future direction is examining whether effectiveness of the BPS exercise for chronic pain patients can be improved. Writing more about personal family domains predicted effectiveness of the BPS in healthy participants. We think that the effectiveness of the BPS exercise can be improved when patients are instructed to write and visualise about family and close social partners. Especially when this leads to a higher preference for emotional close family members and friends compared to less emotional rewarding partners. Higher preference for family and friends is associated with higher social satisfaction. In contrast, higher preference for knowledgeable social partners for instance, is associated with social strain [65]. Particularly for patients that battle fatigued resources; cultivating social resources relative to draining them to cope with social strain should contribute to better emotional well-being [95]. In addition to the BPS exercise, the PPI consisted of several evidence-based positive psychology exercises (i.e., self-compassion [101], three good things [97] and savoring techniques [14]). It should be investigated whether the combination of these exercises is necessary for PPI's beneficial effects on the emotional well-being of chronic pain patients.

In addition to future studies that examine how the BPS and PPI can be improved, it is essential to examine underlying mechanism of the effectiveness of the PPI. This research direction is inspired by a patient's statement regarding the PPI intervention. After the PPI intervention she considered 'happiness as a light switch: something that I can switch on'. This statement entails both a sense of control (i.e., happiness is not solely dependent on chance) and self-efficacy (i.e., the belief that one has the ability to perform behaviours that are required to obtain the desired goal [6]). In this situation, the patient believed she gained the necessary tools to realise happiness despite pain (i.e., I can switch happiness on). Future research is necessary to determine whether sense of control and self-efficacy are crucial aspects of the effectiveness of the PPI for increasing emotional well-being in chronic pain patients.

Another future direction is examining whether combining the PPI with other interventions (e.g., exposure, CBT) has additional benefits. Optimism is associated with more goal attainment despite pain [1; 23] and greater commitment to a treatment [37]. Furthermore, the PPI alleviates affective symptoms as depression and pain catastrophizing (chapter 6). Taken together, applying the PPI before for instance exposure treatment may increase motivation to adhere to the treatment, decreasing drop-out rates (be- 
tween 30 to $50 \%$ for exposure [109]). Similarly, the PPI may prevent relapse by increasing motivation to continue putting effort in their recovery.

\section{CONCLUSIONS}

Findings reported in this dissertation show a relatively consistent pattern across studies that increasing optimism protects against (experimentally) pain-induced executive task performance (i.e., updating, shifting) deteriorations in healthy participants (confirming objectives I, II, and III). However, no evidence was found that increasing emotional wellbeing of chronic pain patients via an online positive psychology intervention improves executive task performance (disconfirming objective $\mathrm{V}$ ). Writing about personal family life (i.e., family, friends, sex and social relationships) was identified as a factor that contributes to the effectiveness of the BPS manipulation to induce (temporary) optimism in healthy participants (confirming objectives IV).

These findings enhance our understanding about factors that reduce the burden of living with chronic pain. More specifically, optimism is identified as a possible protective factor against the negative affective and executive functioning impairments due to the experience of chronic pain. Future directions are examining the importance of personal task relevance, ecological valid tasks, employing other conceptual related tasks, possible underlying mechanisms of the effectiveness of the BPS exercise (e.g., imagery component, specific writing domains) and whether combining the BPS exercise with implementation intentions improves goal attainment. Furthermore, future research could examine possible underlying mechanisms of the PPI (e.g., control, self-efficacy) and whether combining the PPI with other evidence-based treatments can decrease dropout and relapse rates. Most importantly, we advocate for replicating these studies. The ultimate aim of science is to establish what is true and the truth is replicable.

Chronic pain often persists. It is therefore imperative to find an amendable psychological factor that alleviates the burden of chronic pain, and enables an individual to live a desired life despite pain. This dissertation significantly adds to our knowledge about the protective ability of optimism and how it can be cultivated, making optimism a promising factor to consider in the context of pain. 


\section{REFERENCES}

[1] Affleck G, Tennen H, Zautra A, Urrows S, Abeles M, Karoly P. Women's pursuit of personal goals in daily life with fibromyalgia: A value-expectancy analysis. Journal of Consulting and Clinical Psychology 2001;69(4):587-596.

[2] Arkin RM. Self-presentation styles. Impression management theory and social psychological research 1981;311:334.

[3] Atienza AA, Stephens MAP, Townsend AL. Role stressors as predictors of changes in womens' optimistic expectations. Personality and Individual Differences 2004;37(3):471-484.

[4] Attridge N, Keogh E, Eccleston C. The effect of pain on task switching: pain reduces accuracy and increases reaction times across multiple switching paradigms. Pain 2016.

[5] Attridge N, Noonan D, Eccleston C, Keogh E. The disruptive effects of pain on n-back task performance in a large general population sample. Pain 2015;156(10):1885.

[6] Bandura A. Self-efficacy: toward a unifying theory of behavior change. Psychological Review 1977 84:191-215.

[7] Baumeister RF, Heatherton TF, Tice DM. Losing control: Academic Press San Diego, CA, 1994.

[8] Baumeister RFHTF. Self-Regulation Failure: An Overview. Psychological Inquiry 1996;7(1):1.

[9] Berryman C, Stanton TR, Bowering KJ, Tabor A, McFarlane A, Moseley GL. Evidence for working memory deficits in chronic pain: a systematic review and meta-analysis. Pain 2013;154(8):1181-1196.

[10] Berryman C, Stanton TR, Bowering KJ, Tabor A, McFarlane A, Moseley GL. Do people with chronic pain have impaired executive function? A meta-analytical review. Clinical Psychology Review 2014;34(7):563579.

[11] Bingel U, Rose M, Gläscher J, Büchel C. fMRI Reveals How Pain Modulates Visual Object Processing in the Ventral Visual Stream. Neuron 2007;55(1):157-167.

[12] Breivik H, Collett B, Ventafridda V, Cohen R, Gallacher D. Survey of chronic pain in Europe: Prevalence, impact on daily life, and treatment. Eur J Pain 2006;10(4):287-333.

[13] Breivik H, Eisenberg E, O'Brien T. The individual and societal burden of chronic pain in Europe: the case for strategic prioritisation and action to improve knowledge and availability of appropriate care. BMC Public Health 2013;13:1229.

[14] Bryant FB, Veroff J. Savoring: A new model of positive experience: Lawrence Erlbaum Associates Publishers, 2007.

[15] Carver CS, Lawrence JW, Scheier MF. Self-discrepancies and affect: Incorporating the role of feared selves. Personality and social psychology bulletin 1999;25(7):783-792.

[16] Carver CS, Scheier MF. On the self-regulation of behavior. New York, NY US: Cambridge University Press, 1998.

[17] Christiansen S, Oettingen G, Dahme B, Klinger R. A short goal-pursuit intervention to improve physical capacity: A randomized clinical trial in chronic back pain patients. Pain 2010;149(3):444-452.

[18] Crombez G, Eccleston C, Baeyens F, Eelen P. The disruptive nature of pain: An experimental investigation. Behaviour Research and Therapy 1996;34(11-12):911-918.

[19] Crombez G, Eccleston C, Baeyens F, Eelen P. Habituation and the interference of pain with task performance. Pain 1997;70(2):149-154.

[20] Crombez G, Eccleston C, Baeyens F, Eelen P. Attentional disruption is enhanced by the threat of pain. Behaviour Research and Therapy 1998;36(2):195-204.

[21] Crombez G, Eccleston C, Van Damme S, Vlaeyen JW, Karoly P. Fear-avoidance model of chronic pain: the next generation. The Clinical journal of pain 2012;28(6):475-483.

[22] Crombez G, Eccleston C, Van den Broeck A, Goubert L, Van Houdenhove B. Hypervigilance to pain in fibromyalgia: the mediating role of pain intensity and catastrophic thinking about pain. The Clinical journal of pain 2004;20(2):98-102. 
[23] Duke J, Leventhal H, Brownlee S, Leventhal EA. Giving up and replacing activities in response to illness. The Journals of Gerontology: Series B: Psychological Sciences and Social Sciences 2002;57B(4):P367P376.

[24] Eccleston C. Chronic pain and attention: A cognitive approach. British Journal of Clinical Psychology 1994;33(4):535-547.

[25] Eccleston C, Crombez G. Pain demands attention: A cognitive-affective model of the interruptive function of pain. Psychological Bulletin 1999;125(3):356-366.

[26] Eccleston C, Crombez G. Worry and chronic pain: a misdirected problem solving model. Pain 2007;132(3):233-236.

[27] Eccleston C, Crombez G, Aldrich S, Stannard C. Worry and chronic pain patients: a description and analysis of individual differences. Eur J Pain 2001;5(3):309-318.

[28] Eccleston C, Williams ACdC, Morley S. Psychological therapies for the management of chronic pain (excluding headache) in adults. The cochrane library 2009.

[29] Edens JL, Gil KM. Experimental induction of pain: Utility in the study of clinical pain. Behavior Therapy 1995;26(2):197-216.

[30] Engle RW. Working memory capacity as executive attention. Current directions in psychological science 2002;11(1):19-23.

[31] Engle RW, Cantor J, Carullo JJ. Individual differences in working memory and comprehension: A test of four hypotheses. Journal of Experimental Psychology: Learning, Memory, and Cognition 1992;18(5):972992.

[32] Engle RW, Kane MJ. Executive attention, working memory capacity, and a two-factor theory of cognitive control. Psychology of learning and motivation 2003;44:145-199.

[33] Evans DR, Boggero IA, Segerstrom SC. The nature of self-regulatory fatigue and "ego depletion" lessons from physical fatigue. Personality and Social Psychology Review 2016;20(4):291-310.

[34] Fredrickson BL. What good are positive emotions? Review of general psychology 1998;2(3):300.

[35] Fredrickson BL. The role of positive emotions in positive psychology: The broaden-and-build theory of positive emotions. American psychologist 2001;56(3):218

[36] Fredrickson BL. The broaden-and-build theory of positive emotions. Philosophical transactions-royal society of london series b biological sciences 2004:1367-1378.

[37] Geers AL, Wellman JA, Seligman LD, Wuyek LA, Neff LA. Dispositional optimism, goals, and engagement in health treatment programs. Journal of behavioral medicine 2010;33(2):123-134.

[38] Geschwind N, Meulders M, Peters ML, Vlaeyen JW, Meulders A. Can experimentally induced positive affect attenuate generalization of fear of movement-related pain? The Journal of Pain 2015;16(3):258269.

[39] Glass JM. Cognitive dysfunction in fibromyalgia and chronic fatigue syndrome: new trends and future directions. Current rheumatology reports 2006;8(6):425-429.

[40] Glass JM. Cognitive dysfunction in fibromyalgia syndrome. Journal of Musculoskeletal Pain 2010;18(4):367-372.

[41] Glass JM, Park DC. Cognitive dysfunction in fibromyalgia. Current rheumatology reports 2001;3(2):123127.

[42] Goodin BR, Bulls HW. Optimism and the experience of pain: benefits of seeing the glass as half full. Current pain and headache reports 2013;17(5):329.

[43] Goodin BR, Glover TL, Sotolongo A, King CD, Sibille KT, Herbert MS, Cruz-Almeida Y, Sanden SH, Staud R, Redden DT. The association of greater dispositional optimism with less endogenous pain facilitation is indirectly transmitted through lower levels of pain catastrophizing. The Journal of Pain 2013;14(2):126135.

[44] Goossens ME, Kindermans HP, Morley SJ, Roelofs J, Verbunt J, Vlaeyen JW. Self-discrepancies in workrelated upper extremity pain: relation to emotions and flexible-goal adjustment. Eur J Pain 2010;14(7):764-770.

[45] Gopher D, Armony L, Greenshpan Y. Switching tasks and attention policies. Journal of Experimental Psychology: General 2000;129(3):308-339. 
[46] Greve KW, Love JM, Sherwin E, Mathias CW, Ramzinski P, Levy J. Wisconsin Card Sorting Test in chronic severe traumatic brain injury: Factor structure and performance subgroups. Brain Injury 2002;16(1):2940.

[47] Hanssen MM, Peters ML, Vlaeyen JW, Meevissen YM, Vancleef LM. Optimism lowers pain: Evidence of the causal status and underlying mechanisms. Pain 2013;154(0):53-58.

[48] Hanssen MM, Vancleef LM, Vlaeyen JW, Peters ML. More optimism, less pain! The influence of generalized and pain-specific expectations on experienced cold-pressor pain. Journal of behavioral medicine 2014;37(1):47-58.

[49] Hart RP, Martelli MF, Zasler ND. Chronic pain and neuropsychological functioning. Neuropsychology review 2000;10(3):131-149.

[50] Hess TM. Selective engagement of cognitive resources motivational influences on older adults' cognitive functioning. Perspectives on Psychological Science 2014;9(4):388-407.

[51] Hess TM, Rosenberg DC, Waters SJ. Motivation and representational processes in adulthood: the effects of social accountability and information relevance. Psychology and aging 2001;16(4):629.

[52] Higgins ET. Self-Discrepancy Theory: What Patterns of Self-Beliefs Cause People to Suffer? In: B Leonard, editor. Advances in Experimental Social Psychology, Vol. Volume 22: Academic Press, 1989. pp. 93-136.

[53] Hockey GRJ. A motivational control theory of cognitive fatigue. Cognitive fatigue: Multidisciplinary perspectives on current research and future applications 2011:167-187.

[54] Holmes EA, Arntz A, Smucker MR. Imagery rescripting in cognitive behaviour therapy: Images, treatment techniques and outcomes. Journal of behavior therapy and experimental psychiatry 2007;38(4):297-305.

[55] Holmes EA, Lang TJ, Shah DM. Developing interpretation bias modification as a" cognitive vaccine" for depressed mood: imagining positive events makes you feel better than thinking about them verbally. Journal of abnormal psychology 2009;118(1):76.

[56] Holmes EA, Mathews A, Mackintosh B, Dalgleish T. The causal effect of mental imagery on emotion assessed using picture-word cues. Emotion 2008;8(3):395.

[57] Inzlicht M, Schmeichel BJ, Macrae CN. Why self-control seems (but may not be) limited. Trends in cognitive sciences 2014;18(3):127-133.

[58] Jacobsen HB, Reme SE. Working memory, optimism and pain: An elusive link. Scandinavian Journal of Pain 2016;12:128-129.

[59] Jaeggi SM, Buschkuehl M, Perrig WJ, Meier B. The concurrent validity of the N-back task as a working memory measure. Memory 2010;18(4):394-412.

[60] Kane MJ, Brown LH, McVay JC, Silvia PJ, Myin-Germeys I, Kwapil TR. For whom the mind wanders, and when: An experience-sampling study of working memory and executive control in daily life. Psychological science 2007;18(7):614-621.

[61] Kane MJ, Conway ARA, Miura TK, Colflesh GJH. Working memory, attention control, and the n-back task: A question of construct validity. Journal of Experimental Psychology: Learning, Memory, and Cognition 2007;33(3):615-622.

[62] Kappes A, Oettingen G. The emergence of goal pursuit: Mental contrasting connects future and reality. Journal of Experimental Social Psychology 2014;54:25-39

[63] Keogh E, Cavill R, Moore DJ, Eccleston C. The effects of menstrual-related pain on attentional interference. Pain 2014;155(4):821-827.

[64] Kindermans HP, Huijnen IP, Goossens ME, Roelofs J, Verbunt JA, Vlaeyen JW. "Being" in pain: The role of self-discrepancies in the emotional experience and activity patterns of patients with chronic low back pain. PAIN ${ }^{\circledR}$ 2011;152(2):403-409.

[65] Lang FR, Carstensen LL. Time counts: future time perspective, goals, and social relationships. Psychology and aging 2002;17(1):125.

[66] Legrain V, Crombez G, Mouraux A. Controlling attention to nociceptive stimuli with working memory. 2011.

[67] Legrain V, Crombez G, Verhoeven K, Mouraux A. The role of working memory in the attentional control of pain. Pain 2011;152(2):453-459. 
[68] Legrain V, Damme SV, Eccleston C, Davis KD, Seminowicz DA, Crombez G. A neurocognitive model of attention to pain: behavioral and neuroimaging evidence. Pain 2009;144(3):230-232.

[69] Levens SM, Gotlib IH. The effects of optimism and pessimism on updating emotional information in working memory. Cognition \& emotion 2012;26(2):341-350.

[70] Mahler H, Kulik J. Optimism, pessimism and recovery from coronary bypass surgery: Prediction of affect, pain and functional status. Psychology, health \& medicine 2000;5(4):347-358.

[71] McCracken LM, Carson JW, Eccleston C, Keefe FJ. Acceptance and change in the context of chronic pain. Pain 2004;109(1-2):4-7.

[72] McCracken LM, Iverson GL. Predicting complaints of impaired cognitive functioning in patients with chronic pain. Journal of pain and symptom management 2001;21(5):392-396.

[73] McGregor BA, Bowen DJ, Ankerst DP, Andersen MR, Yasui Y, McTiernan A. Optimism, perceived risk of breast cancer, and cancer worry among a community-based sample of women. Health Psychology 2004;23(4):339.

[74] Meevissen YMC, Peters ML, Alberts HJEM. Become more optimistic by imagining a best possible self: Effects of a two week intervention. Journal of Behavior Therapy and Experimental Psychiatry 2011;42(3):371-378.

[75] Mesagno C, Harvey JT, Janelle CM. Choking under pressure: The role of fear of negative evaluation. Psychology of Sport and Exercise 2012;13(1):60-68.

[76] Miyake A, Friedman NP, Emerson MJ, Witzki AH, Howerter A. The unity and diversity of executive functions and their contributions to complex 'frontal lobe' tasks: A latent variable analysis. Cognitive Psychology 2000;41(1):49-100.

[77] Moore DJ, Keogh E, Eccleston C. The interruptive effect of pain on attention. The Quarterly Journal of Experimental Psychology 2012;65(3):565-586.

[78] Moore DJ, Keogh E, Eccleston C. The effect of threat on attentional interruption by pain. Pain 2013;154(1):82-88.

[79] Moore DJ, Keogh E, Eccleston C. Headache impairs attentional performance. Pain 2013;154(9):18401845.

[80] Moriarty O, McGuire BE, Finn DP. The effect of pain on cognitive function: a review of clinical and preclinical research. Progress in Neurobiology 2011;93(3):385-404.

[81] Morley S. The self in pain. Reviews in pain 2010;4(1):24-27.

[82] Morley S, Davies C, Barton S. Possible selves in chronic pain: self-pain enmeshment, adjustment and acceptance. Pain 2005;115(1):84-94.

[83] Oettingen G. Future thought and behaviour change. European review of social psychology 2012;23(1):163.

[84] Park DC, Glass JM, Minear M, Crofford L. Cognitive function in fibromyalgia patients. Arthritis \& Rheumatism 2001;44(9):2125-2133.

[85] Peters ML, Flink IK, Boersma K, Linton SJ. Manipulating optimism: Can imagining a best possible self be used to increase positive future expectancies? The Journal of Positive Psychology 2010;5(3):204-211.

[86] Peters ML, Smeets, E., Feijge, M., van Breukelen, G., Andersson, G., Buhrman, M., \& Linton, S. J. Happy despite pain: a randomized controlled trial of an 8-week internet-delivered positive psychology intervention for enhancing well-being in patients with chronic pain. Clinical journal of pain in press.

[87] Peyron R, Laurent B, Garcia-Larrea L. Functional imaging of brain responses to pain. A review and metaanalysis (2000). Neurophysiologie Clinique/Clinical Neurophysiology 2000;30(5):263-288.

[88] Pulvers K, Hood A. The role of positive traits and pain catastrophizing in pain perception. Current pain and headache reports 2013;17(5):1-11.

[89] Redick TS, Lindsey DR. Complex span and n-back measures of working memory: A meta-analysis. Psychonomic bulletin \& review 2013;20(6):1102-1113.

[90] Romero YR, Straube T, Nitsch A, Miltner WH, Weiss T. Interaction between stimulus intensity and perceptual load in the attentional control of pain. Pain 2013;154(1):135-140.

[91] Ryan RM, Deci EL. Self-determination theory and the facilitation of intrinsic motivation, social development, and well-being. American psychologist 2000;55(1):68. 
[92] Ryckeghem D, Crombez G, Eccleston C, Legrain V, Damme S. Keeping pain out of your mind: The role of attentional set in pain. Eur J Pain 2013;17(3):402-411.

[93] Schoofs D, Wolf OT, Smeets T. Cold pressor stress impairs performance on working memory tasks requiring executive functions in healthy young men. Behavioral Neuroscience 2009;123(5):1066-1075.

[94] Segerstrom SC. Optimism and resources: Effects on each other and on health over 10 years. J Res Pers 2007;41(4):772-786.

[95] Segerstrom SC, Geiger PJ, Combs HL, Boggero IA. Time perspective and social preference in older and younger adults: Effects of self-regulatory fatigue. Psychology and aging 2016;31(6):594.

[96] Segerstrom SC, Tsao JC, Alden LE, Craske MG. Worry and rumination: Repetitive thought as a concomitant and predictor of negative mood. Cognitive Therapy and Research 2000;24(6):671-688.

[97] Seligman ME, Steen TA, Park N, Peterson C. Positive psychology progress: empirical validation of interventions. American psychologist 2005;60(5):410.

[98] Seminowicz DA, Davis KD. Pain enhances functional connectivity of a brain network evoked by performance of a cognitive task. Journal of neurophysiology 2007;97(5):3651-3659.

[99] Shelton JT, Elliott EM, Hill B, Calamia MR, Gouvier WD. A comparison of laboratory and clinical working memory tests and their prediction of fluid intelligence. Intelligence 2009;37(3):283-293.

[100] Shelton JT, Metzger RL, Elliott EM. A group-administered lag task as a measure of working memory. Behav Res Methods 2007;39(3):482-493.

[101] Smeets E, Neff K, Alberts H, Peters M. Meeting suffering with kindness: Effects of a brief selfcompassion intervention for female college students. Journal of Clinical Psychology 2014;70(9):794807.

[102] Stewart WF, Ricci JA, Chee E, Morganstein D, Lipton R. Lost productive time and cost due to common pain conditions in the US workforce. Jama 2003;290(18):2443-2454.

[103] Sturgeon JA. Psychological therapies for the management of chronic pain. Psychology research and behavior management 2014;7:115.

[104] Sutherland R, Morley S. Self-pain enmeshment: future possible selves, sociotropy, autonomy and adjustment to chronic pain. PAIN ${ }^{\circledR} 2008 ; 137(2): 366-377$.

[105] Tucker RP, Wingate LR, O'Keefe VM, Mills AC, Rasmussen K, Davidson CL, Grant DM. Rumination and suicidal ideation: The moderating roles of hope and optimism. Personality and Individual Differences 2013;55(5):606-611.

[106] Van Damme S, Legrain V, Vogt J, Crombez G. Keeping pain in mind: a motivational account of attention to pain. Neuroscience \& Biobehavioral Reviews 2010;34(2):204-213.

[107] Van Ryckeghem DM, Crombez G, Eccleston C, Liefooghe B, Van Damme S. The interruptive effect of pain in a multitask environment: an experimental investigation. The Journal of Pain 2012;13(2):131138.

[108] Vancleef LM, Peters ML. The interruptive effect of pain on attention. J Pain 2006;7(1):21-22.

[109] Vlaeyen J, Morley S, Linton SJ, Boersma K, de Jong J. Pain-related fear: exposure based treatment for chronic pain: IASP press, 2012.

[110] Wager TD, Smith EE. Neuroimaging studies of working memory. Cognitive, Affective, \& Behavioral Neuroscience 2003;3(4):255-274.

[111] Waters SJ, Keefe FJ, Strauman TJ. Self-discrepancy in chronic low back pain: relation to pain, depression, and psychological distress. Journal of pain and symptom management 2004;27(3):251-259.

[112] Williams AC, Eccleston C, Morley S. Psychological therapies for the management of chronic pain (excluding headache) in adults. Cochrane Database Syst Rev 2012;11:CD007407.

[113] Williams ACdC, Eccleston C, Morley S. Psychological therapies for the management of chronic pain (excluding headache) in adults. The cochrane library 2012. 

Valorisation Addendum 

Valorisation refers to the process of creating value from knowledge, by either making this knowledge available for social use or translating this knowledge into practical products. In this section of the dissertation, I will discuss the valorisation potential of this dissertation project, by outlining the relevance of the project, by describing the target groups for whom it is relevant and possible activities and products. Furthermore, I will discuss the innovative character of these possible activities and products and how they can be implemented.

\section{RELEVANCE}

Chronic pain constitutes a major health care problem in the western world, with almost 1 out of 5 adult Europeans reporting chronic pain of moderate to severe intensity [2]. In a large cross-sectional Internet-based survey it was estimated that about a third of the population in the United States suffers from chronic pain [13]. Patients report living with chronic pain to be devastating and disabling, causing marked emotional, behavioural and physiological problems [2; 4]. It has a negative impact on mood, social relationships, and quality of life and is associated with social isolation $[2 ; 11 ; 15]$. Pain is an aversive experience, making it hard to ignore. It is therefore not surprising that many people with chronic pain report executive functioning deficits. In a study by McCracken and Iverson [16] the most frequently reported cognitive complaints by chronic pain patients were forgetfulness, difficulty finishing tasks and difficulty with attention, with more than half of the patients endorsing at least one of these complaints. Many chronic patients even state that these deficits in executive functioning are more disturbing and disabling than the pain experience itself, especially when it compromises a patient's family live, their professional work productivity and employment status [2; 3; 10; 23]. Furthermore, greater emotional distress is associated with a greater perception of cognitive dysfunction [16].

Given the aversive nature of pain, it is not hard to imagine that experiencing chronic pain is associated with a relentless search for pain relief and when unexplained, a search for a medical explanation for the pain. However, in some cases, a clear medical diagnosis cannot be provided and pain is insufficiently reduced by medical treatments. In an attempt to solve the problem of experiencing chronic pain, the patient will focus on finding a solution to remove the pain experience. This search for pain relief will become problematic when attempts fail and worry is fuelled. A 'perseverance loop' is established in which increased worry increases motivation to continue the search for solving the problem [7]. This eagerness to pursue pain relief solutions and medical explanations will lead to a high demand for medical and health services, resulting in high economic costs. The healthcare costs due to chronic pain in de United States is estimated to be more than $\$ 70$ billion per year [9]. The cost even increases to $\$ 150$ billion annually when taken indirect costs and related expenses into account [9]. In the Nether- 
lands, the direct and indirect costs of chronic pain (e.g., due to loss work productivity, unemployment and disability payments $[2 ; 3 ; 5 ; 23]$ ) are as high as 7,4 billion euro per year [1].

Since the pain itself often cannot be remediated, having means to diminish the burden of living with chronic pain is imperative, especially when you consider the individual, social and economic consequences. Both the reduction of emotional distress and improvements in executive functioning should lessen the burden of living with chronic pain. Our research indicates that optimism is an amendable psychological factor that can reduce the negative impact of pain on executive functioning. Moreover, it is possible to increase optimism, positive emotions and decrease emotional distress with an internet-based positive psychology intervention. Consequently, these improvements in the general well-being of chronic pain patients may also serve an economical interest, as it might help in reducing the direct and indirect costs associated with chronic pain.

\section{TARGET GROUPS}

In addition to the academic community, the dissertation findings might be of interest for three target groups, namely (1) patients, family and friends, (2) healthcare providers and (3) society. Firstly, the most apparent target group that may benefit from these findings are individuals that suffer from acute pain and chronic pain patients. Almost 1 out of 5 Europeans report chronic pain of moderate to severe intensity, which is experienced as devastating and disabling. But not only patients are devastated by the experience of chronic pain. Loved ones of patients, such as partners, children, parents, siblings and friends also experience the distressing effects of chronic pain [6]. First of all, seeing a loved one in agony due to pain is an overwhelming experience for family members and friends, with some even experiencing this agony themselves [8]. Additionally, the negative emotions, irritability, and feelings of anger that chronic pain patients often experience, can result in conflicts with family members [12]. Moreover, family members often become caregivers to their loved ones, providing emotional, social and instrumental support. As a result of these new responsibilities, caregivers feel burdened, causing feelings of sadness, frustration and impotence, impacting in turn their social and professional life [18]. But also patients commonly report that they feel as a burden to their loved ones, especially when the support they receive outweighs the support they provide. This perceived imbalance can cause feelings of loss and a decreased sense of autonomy [14]. The perception of being a burden for loved ones can even fuel the desire for suicide $[14 ; 24 ; 25]$.

It is clear that the experience of chronic pain has detrimental effects on both patients as their close social circle, making it imperative that we identify amendable psychological factors that protect against the negative effects of pain and help individuals to cope better with the experience of pain. The current dissertation findings identified 
optimism as a possible protective factor against the debilitating effects of (chronic) pain, lessening emotional distress, disability, and improving quality of life. Furthermore, this dissertation provided evidence that improving optimism is possible with an internetbased positive psychology intervention. These improvements were already achieved via minimal guidance of research assistants. Furthermore, the intervention is highly assessable as it is given online, making it an attractive treatment option for chronic pain patients that may not be able to travel to a therapy setting.

Secondly, the results are interesting for health care providers, such as doctors, psychologists, rehabilitation therapists, occupational therapists and social workers. As mentioned above, the internet-based positive psychology intervention can be easily implemented to improve the current well-being of chronic pain patients. With minimal guidance, health care providers can deliver an evidence-based intervention. But the internet-based positive psychology intervention may also be implemented to provide patients with an intervention while waiting for standard treatment or as a method to prevent relapse of treated patients.

Thirdly, the findings may have an influence on society. As mentioned before, chronic pain is associated with high societal costs, due to rising health care costs, disability payments, unemployment and loss of work productivity. Research also indicates that these negative effects even extend to the social environment of chronic pain patients. Insurance companies and policy makers should acknowledge the enormous societal impact of chronic pain and promote research that examines possible psychological factors that may reduce this impact.

\section{ACTIVITIES AND PRODUCTS}

The findings in this dissertation showed that optimism can protect against the negative effects of pain. The Best Possible Self manipulation and the internet-based positive psychology intervention can increase optimism in both healthy individuals and chronic pain patients, respectively. The research with the BPS has driven the development of a mobile app to practice the BPS to cultivate optimism. Additionally, the internet-based positive psychology intervention can be easily implemented on a large scale in clinical practices. Currently, the intervention (happy despite pain / gelukkig ondanks pijn) is available online for health practitioners via a commercial company and has also been made available for a wider audience by means of a self-help book. In this 8-week online intervention, patients perform positive psychology exercises that aim to increase optimism, positive emotions and self-compassion [20]. Patients receive instructions about the exercises via the online platform, and conduct each exercise individually at home. The intervention consists of 4 modules (i.e. (1), self-compassion, (2) positive focus, (4) savoring, and (5) optimism. Self-compassion (module 1) refers to fully accepting oneself, the ability to treat oneself with kindness rather than self-criticism and recognizing that 
everyone experiences failures [17]. Module 2 aims to shift the focus from a negative orientation towards a more positive one, by raising awareness for the good things in life [22]. Module 3 contains savoring techniques that promote the frequency and intensity of positive experiences in daily life. In module 4, patients practice the Best Possible Self (BPS) exercise [19], which is used to increase optimism. The last week (i.e., week 8) of the PPI aims to prevent relapse.

\section{INNOVATION}

Problem-focused psychology has been dominant for decades. In this type of psychology, the focus is on 'fixing what is wrong'. In contrast, positive psychology focusses on what makes life worth living, i.e., 'building what is strong' [21]. Positive psychology is concerned with both making the lives of people fulfilling as with healing pathology. The intent of positive psychology is to have a more complete and balanced scientific understanding of the human experience-the peaks, the lows, and everything in between. Positive psychology should complement and extend to the problem-focused psychology. An important aspect of positive psychology research is validating innovative techniques and interventions that both improve well-being and relieve suffering. The current dissertation findings validated the Best Possible Self as a technique to increase optimism. As stated before, these findings have driven the development of a mobile app. Although there were several app's available to cope with chronic pain, an app that focussed on building optimism was not available. Furthermore, our research also validated that the internet-based intervention was able to improve the emotional wellbeing and relieve the suffering of chronic pain patients. Similar to the app, the online interventions that were available until now for chronic pain patients were predominantly based on cognitive behavioural therapy. Additionally, there is growing evidence that both acute and chronic pain have deteriorating effects on executive functioning, fuelling even more the devastating experience of pain. However, we are not aware of any research that attempted to protect individuals from this pain-induced deteriorating in executive functioning. The results of this dissertation can therefore be regarded as innovative as it indicates that optimism may indeed be a protective factor in this context.

\section{SCHEDULE AND IMPLEMENTATION}

At this moment, 3 chapters are published articles in international peer-reviewed scientific journals, making the findings available to the scientific and clinical community. The additional two chapters are submitted and are expected to be accessible within a year. Furthermore, we will continue with disseminating the research findings by presenting 
the findings at national and international conferences. The positive psychology intervention, described in this dissertation, is at the moment already available for clinicians that have an account on an online commercial platform, which provides various online interventions. Clinicians have to pay a small fee per patient if a patient wants to use the online intervention. However, we plan to promote the widespread use of this intervention, by communicating these clinical relevant results to health care providers involved in treating chronic pain patients. Patients and their loved ones should receive the information via magazines of online platforms of various patient organizations. There are already established links with e.g. rehabilitation centres, pain outpatient's clinics, the pain expertise centre and patient organizations to promote the communication if these clinical relevant results. The BPS mobile app to cultivate optimism, will become available within a half year. There are plans to further develop this app to a more encompassing positive psychology app for chronic pain patients. The estimated time frame of this comprehensive app is 3 years. Furthermore, given the enormous effect of having a loved one being in constant pain, we will continue our research examining the interpersonal effects of the experience of chronic pain and whether optimism can relief the burden both experienced by the patient and their close environment. 


\section{REFERENCES}

[1] Boonen A, van den Heuvel R, van Tubergen A, Goossens M, Severens JL, van der Heijde D, van der Linden S. Large differences in cost of illness and wellbeing between patients with fibromyalgia, chronic low back pain, or ankylosing spondylitis. Annals of the Rheumatic Diseases 2005;64(3):396-402.

[2] Breivik H, Collett B, Ventafridda V, Cohen R, Gallacher D. Survey of chronic pain in Europe: Prevalence, impact on daily life, and treatment. Eur J Pain 2006;10(4):287-333.

[3] Breivik H, Eisenberg E, O'Brien T. The individual and societal burden of chronic pain in Europe: the case for strategic prioritisation and action to improve knowledge and availability of appropriate care. BMC Public Health 2013;13:1229.

[4] Chapman CR, Gavrin J. Suffering: the contributions of persistent pain. The Lancet 1999;353(9171):22332237.

[5] Dansie E, Turk DC. Assessment of patients with chronic pain. British journal of anaesthesia 2013;111(1):19-25.

[6] Dueñas M, Ojeda B, Salazar A, Mico JA, Failde I. A review of chronic pain impact on patients, their social environment and the health care system. Journal of Pain Research 2016;9:457.

[7] Eccleston C, Crombez G. Worry and chronic pain: a misdirected problem solving model. Pain 2007;132(3):233-236

[8] Ferrell B. Pain observed: the experience of pain from the family caregiver's perspective. Clinics in geriatric medicine 2001;17(3):595-609.

[9] Gatchel RJ, Okifuji A. Evidence-Based Scientific Data Documenting the Treatment and Cost-Effectiveness of Comprehensive Pain Programs for Chronic Nonmalignant Pain. The Journal of Pain 2006;7(11):779793.

[10] Glass JM, Park DC. Cognitive dysfunction in fibromyalgia. Current rheumatology reports 2001;3(2):123127.

[11] Hart RP, Martelli MF, Zasler ND. Chronic pain and neuropsychological functioning. Neuropsychology review 2000;10(3):131-149.

[12] Henwood P, Ellis JA. Chronic neuropathic pain in spinal cord injury: the patient's perspective. Pain research and Management 2004;9(1):39-45.

[13] Johannes CB, Le TK, Zhou X, Johnston JA, Dworkin RH. The prevalence of chronic pain in United States adults: results of an Internet-based survey. The Journal of Pain 2010;11(11):1230-1239.

[14] Kowal J, Wilson KG, McWilliams LA, Péloquin K, Duong D. Self-perceived burden in chronic pain: Relevance, prevalence, and predictors. Pain 2012;153(8):1735-1741.

[15] Linton SJ, Bergbom S. Understanding the link between depression and pain. Scandinavian Journal of Pain 2011;2(2):47-54.

[16] McCracken LM, Iverson GL. Predicting complaints of impaired cognitive functioning in patients with chronic pain. Journal of pain and symptom management 2001;21(5):392-396.

[17] Neff KD, Vonk R. Self-compassion versus global self-esteem: Two different ways of relating to oneself. Journal of personality 2009;77(1):23-50

[18] Ojeda B, Salazar A, Dueñas M, Torres LM, Micó JA, Failde I. The impact of chronic pain: The perspective of patients, relatives, and caregivers. Families, Systems, \& Health 2014;32(4):399.

[19] Peters ML, Flink IK, Boersma K, Linton SJ. Manipulating optimism: Can imagining a best possible self be used to increase positive future expectancies? The Journal of Positive Psychology 2010;5(3):204-211.

[20] Peters ML, Smeets, E., Feijge, M., van Breukelen, G., Andersson, G., Buhrman, M., \& Linton, S. J. Happy despite pain: a randomized controlled trial of an 8-week internet-delivered positive psychology intervention for enhancing well-being in patients with chronic pain. Clinical journal of pain in press.

[21] Seligman ME. Positive psychology, positive prevention, and positive therapy. Handbook of positive psychology 2002;2:3-12.

[22] Seligman ME, Steen TA, Park N, Peterson C. Positive psychology progress: empirical validation of interventions. American psychologist 2005;60(5):410. 
[23] Stewart WF, Ricci JA, Chee E, Morganstein D, Lipton R. Lost productive time and cost due to common pain conditions in the US workforce. Jama 2003;290(18):2443-2454.

[24] Van Orden KA, Lynam ME, Hollar D, Joiner TE. Perceived burdensomeness as an indicator of suicidal symptoms. Cognitive Therapy and Research 2006;30(4):457-467.

[25] Wilson KG, Chochinov HM, McPherson CJ, Skirko MG, Allard P, Chary S, Gagnon PR, Macmillan K, De Luca M, O'shea F. Desire for euthanasia or physician-assisted suicide in palliative cancer care. Health Psychology 2007;26(3):314. 

Samenvatting

Dutch Summary 



\section{PIJN}

Pijn is meestal een waarschuwingssignaal dat er ergens in het lichaam een daadwerkelijke of potentiële 'beschadiging' optreedt. Pijn is daarom moeilijk te negeren. Het zorgt ervoor dat we ons gedrag aanpassen, om erger te voorkomen of herhaling te vermijden. Om te overleven is dit mechanisme erg adaptief. Maar het heeft ook zijn keerzijde, vooral wanneer acute pijn overgaat in chronische pijn. Chronische pijn is pijn die langer duurt dan drie maanden. Ongeveer één op de 5 volwassen Nederlanders lijdt aan chronische pijn. Het continu ervaren van pijn heeft een negatieve impact op de kwaliteit van leven en gaat vaak gepaard met problemen op persoonlijk, sociaal en maatschappelijk vlak, zoals het ervaren van depressieve gevoelens en sociale isolatie en veranderingen in de arbeidsstatus.

\section{EXECUTIEF FUNCTIONEREN}

Executief functioneren is een overkoepelende term voor verschillende hogere cognitieve processen en gedragingen. Executieve functies stellen een persoon in staat om accuraat te plannen en gedrag, emoties en cognities te veranderen. Dit zijn essentiële capaciteiten om goed te functioneren in het dagelijks leven. Er worden vaak drie kern executieve functies gedefinieerd, namelijk: (I) inhiberen van gedrag en reacties (i.c., inhibitie), (II) updating en monitoring van werkgeheugen representaties (i.c., updating), en (III) switchen tussen mentale representaties en taken (i.e., switchen). Inhibitie betekent het vermogen om doelbewust automatische reacties te inhiberen. Wanneer je bijvoorbeeld een automaat rijdt, moet de automatische reactie om de koppeling te gebruiken worden genegeerd. Updating is het vermogen om actief informatie in het werkgeheugen bij te werken en te manipuleren. Een voorbeeld van updating is het uitvoeren van een rekentaak. Switchen is het vermogen om flexibel en vloeiend over te gaan van de ene taak naar de andere taak. Dit heb je nodig wanneer je bijvoorbeeld verschillende talen moet spreken in een conversatie. Een cognitief proces dat executief functioneren faciliteert is aandacht. Aandacht is een cognitief proces dat, onder andere, het mogelijk maakt om selectief te richten op bepaalde informatie, terwijl andere informatie genegeerd kan worden.

\section{PIJN EN EXECUTIEF FUNCTIONEREN}

Pijn heeft de primaire functie om ons te waarschuwen voor gevaar. Het grijpt onze aandacht en is vaak moeilijk te negeren. Als pijn onze aandacht grijpt, leidt dit tot een onderbreking van de dingen waar we mee bezig zijn. Pijn is geassocieerd met een verslechtering in executief functioneren. Taak prestatie op executieve taken verslechtert 
wanneer gezonde proefpersonen experimentele pijn ervaren. Deze bevinding is al meerdere keren gerepliceerd op diverse taken, die inhibitie, updating en switchen meten. Meta-analyses tonen aan dat chronische pijn patiënten een verslechtering in executief functioneren laten zien. Deze verslechtering wordt door veel patiënten zelfs omschreven als erger dan de pijn, vooral wanneer het hun vermogen aantast om normaal te functioneren.

\section{OPTIMISME}

Optimisme is de neiging om te verwachten dat de toekomst positief uitpakt. Een optimist zal bij onzekerheid eerder de beste uitkomst verwachten en zien hun doelen vaker als haalbaar. Optimisme wordt gezien als een persoonlijkheidskenmerk. Persoonlijkheidskenmerken zijn relatief stabiel over tijd en niet onderhevig aan veranderingen. Echter, verschillende studies hebben aangetoond dat optimisme gedurende het leven wel kan veranderen. Een manipulatie die gericht is op het vergroten van optimisme is de Best Mogelijke Zelf manipulatie. In deze manipulatie wordt aan een deelnemer gevraagd om zichzelf te verplaatsen naar een denkbeeldige toekomst waarbij al zijn/haar gekoesterde doelen en verlangens gerealiseerd zijn. De deelnemers mogen dan 15 minuten schrijven over deze toekomst, waarna ze nog 5 minuten het zojuist beschreven toekomstbeeld zo levendig mogelijk visualiseren. Verschillende onderzoeken hebben herhaaldelijk aangetoond dat het uitvoeren van de Best Mogelijke Zelf interventie mensen optimistischer kan maken.

Optimisme heeft vele voordelen, zoals meer veerkracht in stressvolle situaties, succesvollere studieresultaten en carrière, een betere fysieke gezondheid, beter herstel na ziekte en een langere levensduur. Daarnaast ervaart een optimist meer sociale steun. De voordelen van optimisme zijn ook aangetoond in de context van pijn. Een optimist zal, ook al heeft hij pijn, meer inspanning leveren om zijn doelen te bereiken. Ook kan een optimist beter omgaan met pijn en rapporteert hij zelfs minder pijn te ervaren.

\section{OPTIMISME, PIJN EN EXECUTIEF FUNCTIONEREN}

Aangezien het continu ervaren van pijn een negatieve impact heeft op executief functioneren, is het belangrijk dat we onderzoeken of er psychologische factoren zijn die beschermen tegen dit negatieve effect. Er zijn meerdere theoretische verklaringen en empirische bevindingen waarom optimisme als een beschermende factor kan optreden tegen verslechteringen in executief functioneren door (chronische) pijn. Omgaan met pijn en het uitvoeren van een taak vereist beide cognitieve middelen, maar helaas zijn deze middelen beperkt (limited-resource model). Om middelen te besparen, zal een persoon geneigd zijn om een van deze taken minder goed uit te voeren. Gezien de aver- 
sieve aard van pijn, zullen de middelen eerder aan pijn worden besteed, wat ten koste gaat van de takkprestatie. Optimisme zou echter de motivatie kunnen vergroten, om deze gelimiteerde middelen toch te besteden aan accurate taak prestatie. Een alternatief voorgestelde mechanisme is via aandacht. Optimisme kan de pijn verlagen, of rumineren tegen gaan, waardoor er meer aandacht beschikbaar is voor de taak prestatie (limited-resource model/integrative neurocognitive model). Daarnaast stelt het broadenand-build model dat optimisme en positieve emoties een soort opwaartse positieve spiraal ingang zetten, waardoor een persoon meer aandacht heeft voor de taakprestatie en/of er meer cognitieve middelen beschikbaar zijn.

\section{DOEL PROEFSCHRIFT}

De algemene doelstelling van dit proefschrift was om te onderzoeken of optimisme als een beschermende factor kan werken tegen verslechteringen in executief functioneren door het ervaren van (chronische) pijn. Daarnaast zijn er 5 specifieke doelstellingen geformuleerd:

I. Onderzoeken of experimentele geïnduceerde pijn de taakprestatie van gezonde deelnemers verslechtert

II. Onderzoeken of het vergroten van optimisme pijn-geïnduceerde verslechteringen in taakprestatie in gezonde deelnemers tegengaat

III. Onderzoeken of het beschermende effect van optimisme generaliseert over verschillende uitvoerende functies (i.c., updating en switchen)

IV. Het identificeren van factoren die bijdragen aan de effectiviteit van de manipulatie om (tijdelijk) optimisme te vergroten bij gezonde deelnemers

V. Onderzoeken of het vergroten van het emotionele welbevinden (o.a. door het vergroten van optimisme, positieve emoties en verlagen van depressie) van chronische pijn patiënten, via een online positieve psychologie interventie, executieve taakprestaties verbetert

\section{RESULTATEN PROEFSCHRIFT}

Allereerst tonen de resultaten van de experimentele studies in dit proefschrift dat experimenteel geïnduceerde pijn een verslechtering in takprestatie veroorzaakt (bevestiging doelstelling I). In het onderzoek beschreven in hoofdstuk 2 werden gezonde deelnemers gerandomiseerd in 1 van 4 condities: optimisme en pijn, geen optimisme en pijn, optimisme en geen pijn en geen optimisme en geen pijn. Deelnemers in de pijn conditie moesten hun rechterhand zo lang mogelijk in een bak met water van $2{ }^{\circ} \mathrm{C}$ houden (koud-water taak). De andere helft van de deelnemers hielden hun hand zo lang mogelijk in een bak met warm, comfortabel water $\left(34^{\circ} \mathrm{C}\right)$. Na de koud-water of warm- 
water taak moesten deelnemers een executieve taak (operation-span taak) uitvoeren. In de operation-span taak, moeten deelnemers een rekensom hardop voorlezen, aangeven of de uitkomst correct is en het woord aan het einde van de rekensom onthouden (bijvoorbeeld: is (6/2) $+5=8$ ? Brood). Na 2,3,4 of 5 rekensom en woord combinaties, werd een deelnemer gevraagd om de woorden, in volgorde van presentatie, op te schrijven. De operations-span taak is een taak die de executieve functie updating meet. Resultaten van dit experiment toonden aan dat het ervaren van experimentele pijn ervoor zorgt dat deelnemers slechter presteren op de daaropvolgende executieve taak vergeleken met deelnemers zonder pijn.

We hebben ook gekeken of het ervaren van pijn tijdens het uitvoeren van een executieve taak, de taakprestatie negatief zou beïnvloeden. In de experimentele studies beschreven in hoofdstuk 3 en 4 ervoeren gezonde deelnemers experimenteel geïnduceerde warmte pijn (TSA Medoc). Deelnemers voeren de taak eenmaal uit met en eenmaal zonder deze pijnlijke warmte stimulatie. In de studie beschreven in hoofdstuk 3 moesten deelnemers de 2-back taak maken. In deze taak wordt aan de deelnemers gevraagd om steeds aan te geven met ja of nee, of de letter dat getoond wordt op het computerscherm, dezelfde letter is als twee letters eerder. In de volgende letter reeks T-H-P-J-P moet een deelnemer bijvoorbeeld steeds 'nee' moeten aangeven, behalve bij de laatste letter $\mathrm{P}$, aangezien de letter $\mathrm{P}$ twee letters terug al is gepresenteerd. De 2back is wederom een voorbeeld van een updating taak. In de studie beschreven in hoofdstuk 4 werd het vermogen om te switchen gemeten met de shifting taak. In deze taak zien deelnemers cijfers op het beeldscherm. Bij elke cijfer moesten deelnemers aangeven of het cijfer hoger of lager is dan 5 (regel 1 ) of aangeven of het cijfer een even of oneven cijfer was (regel 2). Welke regel ze moesten volgen, veranderde continue tijdens de taak en werd altijd voor elke cijfer aangegeven. Resultaten toonden aan dat taakprestatie op zowel de 2 back als de shifitng taak significant verslechterde wanneer deelnemers pijn hadden tijdens het uitvoeren van een taak (bevestiging doelstelling I).

De bevestiging van doelstelling I was noodzakelijk om de tweede doelstelling te onderzoeken, namelijk of het vergroten van optimisme in gezonde deelnemers deze pijngeïnduceerde verslechteringen in taakprestatie tegengaat. In elk van de hierboven beschreven studies werd aan de helft van de deelnemers gevraagd om de Best Mogelijke Zelf manipulatie uit te voeren, om optimisme te vergroten. Ten eerste, we vonden in al onze vier lab studies (hoofdstuk 2, 3 en 4) dat het met deze eenvoudige manipulatie mogelijk is om optimisme te vergoten in gezonde deelnemers. Dit is erg belangrijk aangezien een effectieve optimisme manipulatie ons in staat stelt om causale conclusies te trekken. Ten tweede, en misschien wel het belangrijkste, de resultaten van deze studies (hoofdstuk 2 en 4) toonden aan dat er een significante interactie was tussen pijn en optimisme. Deelnemers in de controle conditie (geen optimisme conditie) presteerden inderdaad slechter op een executieve taak wanneer ze pijn ervoor of tijdens de taak ervoeren. Echter, dit was niet het geval voor deelnemers in de Best Mogelijke Zelf conditie (optimisme conditie). Ondanks de pijn, presteerden de deelnemers in de optimis- 
me conditie even goed op de executieve taak. Met andere woorden, het vergroten van optimisme beschermde tegen pijn geïnduceerde verslechtering in executief functioneren in gezonde deelnemers (bevestiging doelstelling II). Bovendien werd dit beschermende effect van optimisme ook aangetoond op verschillende executieve taken, namelijk op een taak die updating (hoofdstuk 2) en shifting (hoofdstuk 4) meet (bevestiging doelstelling III).

Dit proefschrift heeft aangetoond dat de Best Mogelijke Zelf manipulatie effectief is in het vergroten van optimisme. Echter, het was nog onduidelijk wat de werkzame mechanismes zijn van de Best Mogelijke Zelf manipulatie. In het onderzoek in hoofdstuk 5 werd onderzocht wat de Best Mogelijke Zelf manipulatie effectief maakt in het vergroten van optimisme in gezonde deelnemers. De resultaten van deze studie lieten zien dat de Best Mogelijke Zelf manipulatie effectiever is als deelnemers meer positieve woorden gebruikten en meer schreven over hun persoonlijke leven en familie (d.w.z. familie, vrienden, seks en sociale relaties), en minder schreven over fysieke gezondheid en materialistische doelen (doelstelling IV).

De experimentele lab studies in dit proefschrift tonen voor het eerst aan dat optimisme een factor is die kan beschermen tegen pijn-geïnduceerde verslechteringen in taakprestatie. Echter, deze resultaten werden gevonden in lab studies die gebruik maakte van experimentele pijn en gezonde deelnemers. Maar het ervaren van chronische pijn is anders, aangezien het vaak ongecontroleerd en minder voorspelbaar is, en chronische pijn een negatieve impact op het emotionele welbevinden van patiënten heeft. Een belangrijke volgende stap is om te onderzoeken of het mogelijk is om problemen in executief functioneren tegen te gaan door het emotionele welbevinden van chronische pijn patiënten te verhogen, zoals het vergroten van optimisme en positieve emoties en het verlagen van depressie. In de studie beschreven in hoofdstuk 6 wilde we het emotionele welbevinden van chronische pijnpatiënten verhogen met behulp van een online positieve psychologie interventie (gelukkig ondanks pijn interventie). Voor het onderzoek werden de deelnemers die de gelukkig ondanks pijn interventie hebben gevolgd, vergeleken met deelnemers die tijdelijk op een wachtlijst stonden. Resultaten toonden aan dat een online positieve psychologie interventie inderdaad succesvol is in het verbeteren van het emotionele welbevinden van deelnemers. Echter, de deelnemers presteerden niet beter op executieve taken na het doorlopen van de interventie vergeleken met deelnemers die de interventie niet hadden doorlopen. Het onderzoek heeft dus geen bewijs gevonden dat het vergoten van het emotionele welbevinden van chronische pijn patiënten, executief functioneren kan verbeteren (doelstelling $\mathrm{V}$ ).

\section{CONCLUSIE}

Resultaten in dit proefschrift tonen aan dat optimisme kan beschermen tegen experimenteel geïnduceerde verslechteringen in executieve taak prestatie in gezonde deel- 
nemers (bewijs voor doelstelling I, II, en III). Echter, er is geen bewijs dat het vergroten van het emotionele welbevinden van chronische pijn patiënten executief functioneren kan verbeteren (geen bewijs voor doelstelling V). Vooral schrijven over het persoonlijke leven en familie is een factor die de effectiviteit van de Best Mogelijke Zelf manipulatie vergroot (bewijs doelstelling IV). De resultaten in dit proefschrift vergroten onze kennis over factoren die bijdragen aan een beter kwaliteit van leven van personen met chronische pijn. In de toekomst zou ook gekeken kunnen worden naar de invloed van persoonlijk relevante taken of meer ecologisch valide taken. Daarnaast kunnen de onderliggende mechanismen van de effectiviteit van de Best Mogelijke Zelf manipulatie verder worden onderzocht. Toekomstig onderzoek zou ook kunnen bekijken of het toevoegen van implementatie intenties aan de Best Mogelijke Zelf manipulatie, personen kan helpen om hun doelen eerder te behalen. Bovendien zouden de onderliggende mechanismen van de positieve psychologie interventie kunnen worden onderzocht. Er kan ook gekeken worden of de positieve psychologie interventie gecombineerd kan worden met bestaande therapieën om bijvoorbeeld drop-out en relapse tegen te gaan. Bovendien is het uitermate belangrijk dat de studies in dit proefschrift worden gerepliceerd.

Aangezien medische behandelingen maar tot een bepaalde hoogte verlichting kunnen brengen en de pijn in veel gevallen niet meer weggaat, is het belangrijk dat er wordt gekeken naar factoren die een persoon in staat stellen om het leven te leiden wat ze willen, ondanks de pijn. Dit proefschrift vergroot onze kennis over de beschermende kwaliteit van optimisme en hoe optimisme gecultiveerd kan worden, wat optimisme een veelbelovende factor maakt om te overwegen in de context van pijn. 


\section{Dankwoord}

Acknowledgements 


\section{It takes a village.}

Ik wil graag eerst Madelon en Linda bedanken. Madelon, ik ben nog steeds heel erg blij dat ik je vroeg om mijn master thesis te begeleiden. Je liet mij helemaal vrij in het ontwerpen van het experiment (ondanks dat je sceptisch was of het wel zou werken). Die vrijheid gaf je mij ook tijdens de aansluitende promotietijd, maar met de zekerheid dat ik altijd op je kon terugvallen wanneer het nodig was. Ik vind het een voorrecht dat je mijn promotor was. Je raad heeft mij gevormd als wetenschapper en als mens.

Linda, ik betwijfel of er een betere co-promotor is. Je hebt het vermogen om aandacht te schenken aan het ontwikkelen van het promotietraject en de mens die het moet uitvoeren. Ik bewonder je wetenschappelijke integriteit en nauwgezetheid in het opzetten van experimenten. Maar ik bewonder je vooral als mens. Jij toont mij dat je als vrouw geen concessies hoeft te doen in het leven.

Ik wil ook de leden van mijn beoordelingscommissie en corona bedanken voor hun belangrijke bijdrage aan mijn promotie: prof. dr. Johan Vlaeyen, Prof. Dr. Andrea Evers, Dr. Marjolein Hanssen, Dr. Carolien Martijn, Dr. Dimitri van Ryckeghem, en Prof. Dr. Jeanine Verbunt.

Een bron van inspiratie en onmisbare hulp: mijn BM collega's. Dank je wel, Ann, Astrid, Christine, Emma, Hanne, Hugo, Jana, Kai, Marco, Mariëlle, Marieke, Marlies, Marjolein, Rena, Reinhilde, Rilana, Roy, Saskia, Thomas. In het bijzonder nog mijn dank voor Hugo (wat een belevenis om jou te horen vertellen), Astrid (voor de gesprekken) en Kai (voor de effect size calculator en vooruit: je kritische blik). Daarnaast wil ik natuurlijk ook mijn andere CPS collega's bedanken voor jullie bemoediging, bereidheid om te helpen en ambitie. In het bijzonder Arie, Tom en Anita: door jullie wilde ik een wetenschapper worden.

Praktische ondersteuning is onmisbaar voor een promotietraject, ik wil dan ook graag enkele mensen bedanken, namelijk Lindy (voor de leuke gesprekken terwijl ik mijn declaraties kwam afgeven), Charlie en Michiel (voor het programmeerwerk en engelengeduld), Astrid (anders had ik nooit zoveel patiënten kunnen testen), en als laatste Jessie en Marionne (onverschrokken banen jullie je een weg door al het academische papierwerk).

\section{With a little help from my friends (beatles)}

Ghislaine, je blijft mij altijd verrassen en dat maakt het leven nu net wat leuker. Rosanne, blijf altijd aan mij trekken, uitdagen en inspireren. Liselot, jij laat mij zien dat je altijd je eigen pad moet bewandelen. Lorraine, je gaf mij rust wanneer ik het nodig had. Ik ben zo dankbaar voor mijn geweldige, sterke, bemoedigende en liefdevolle vriendinnen. 
Family is not an important thing. it's everything (michael j. fox)

Tom en Mine: jullie maken het mogelijk dat ik kan werken. Ik ben dankbaar dat Bren met zoveel liefde is omgeven. Mine, dank je wel dat ik bij jou mag uitrazen. Guusje, je hulp door het oerwoud dat moederschap heet is mij erg kostbaar. Het maakt mij een betere mama. Bas: klasse. Sjra, eenvoud siert je. Zonder jou geen prachtige ingebonden proefschrift exemplaren. Oma, van jou heb ik mijn gedrevenheid. Tante Jan, ik weet dat ik het te weinig zeg, maar dank je wel voor je eindeloze zorg en aandacht. John, jij bent de belichaming van de bovenstaande uitspraak. Ik blijf je altijd dankbaar voor je grenzeloze liefde voor mijn mama. Anja, ik had geen betere bonusmama voor Hope kunnen wensen. Daan, dank je wel voor je nuchterheid. Klaas, janus, je zorgt dat ik met beide benen op de grond blijf staan. Hope en Juliette, het is een geschenk om jullie te zien opgroeien. Ik kan niet wachten op wat er nog gaat komen. Peet, dank je wel voor je ontwapenende eerlijkheid. Dieuwertje, ik ben zo dankbaar dat ik kan zeggen dat mijn zusje ook mijn beste vriendin is. Je staat altijd voor iedereen klaar, zonder daar iets voor terug te verwachten. Ik heb alleen maar bewondering. Pap, altijd bevlogen en gepassioneerd. Als je niet het uiterste kan geven, dan moet je het niet doen. Je blijft mijn grote held. Mama, het doet nog steeds zeer dat je er niet meer bent. Maar ik ben zo ongelooflijk dankbaar voor de tijd die we samen hadden en de wijsheid die ik heb mogen ervaren. Het heeft mij gevormd tot wie ik ben.

\section{Serendipity: finding something good without looking for it}

Sieb. Ik voel nog steeds elke dag zoveel dankbaarheid voor het feit dat we elkaar vonden. Dankbaar voor je manier van doen, die alles veel lichter maakt. Dankbaar dat ik bij jou de veiligheid heb gevonden die ik zocht. Ik vertrouw op jou, op ons en op de persoon die ik ben door jou. Alles is mogelijk omdat jij grenzeloos gelooft in mij.

To the moon and back

Bren, zo kostbaar en klein. Je kwam juist op het moment dat ik niet meer wanhopig aan het proberen was. Jouw mama zijn is het meest overweldigende, intense, prachtigste, confronterende, vermoeiende, beangstigende, uitdagende, krachtigste en ultiem voldoening gevende ervaring. Ik ben voor altijd anders. 



\section{Curriculum Vitae}

Jantine Johanna Lidwina Maria Boselie was born on June 5th, 1985 in Eindhoven, the Netherlands. In 2003, she graduated from secondary school, Novalis College (Waldorf School) Eindhoven, and finished her pre-university education in 2004 (ROC adult education, Eindhoven). She completed a bachelor in Biological Psychology in 2010 at Maastricht University. In August 2012, she obtained her research master degree (Cognitive and Clinical Neuroscience with the specialisation Psychopathology) at Maastricht University. During her master, she did a clinical internship at a psychiatric ward at the Catharina Hospital in Eindhoven, as well as a research internship at Maastricht University under supervision of prof. Dr. Madelon Peters. After receiving a grant from the DutchFlemish Postgraduate School 'Experimental Psychopathology', she started in September 2012 her doctorate at the Department of Clinical Psychological Science at Maastricht University under the supervision of prof. Dr. Madelon Peters and Dr. Linda Vancleef. Currently she is working as a postdoctoral researcher at the Department of Clinical Psychological Science at Maastricht University. 


\section{LIST OF PUBLICATIONS}

\section{Peer reviewed publications}

- Boselie, J. J. L. M., Vancleef, L. M., Smeets, T., \& Peters, M. L. (2014). Increasing optimism abolishes pain-induced impairments in executive task performance. PAIN, 155(2), 334-340.

- Boselie, J. J. L. M., Vancleef, L. M., \& Peters, M. L. (2016). The effects of experimental pain and induced optimism on working memory task performance. Scandinavian Journal of Pain, 12, 25-32.

- Boselie, J. J. L. M., Vancleef, L. M., \& Peters, M. L. (2017). Increasing optimism protects against pain-induced impairments in task shifting performance. Journal of Pain, 18(4), 446-455.

\section{Other publications}

- Boselie, J. J. L. M. (2016). Optimisme als pijnstiller. In-Mind Nederland. Retrieved from http://nl.in-mind.org/article/optimisme-als-pijnstiller.

\section{Submitted manuscripts}

- Boselie, J. J. L. M., Vancleef, L. M., \& Peters, M. L. Filling the Glass: exploring whether a positive psychology intervention can improve executive task performance in chronic pain patients. In preparation.

- Boselie, J. J. L. M., Vancleef, L. M., Hanssen, M. M., \& Peters, M. L. Family matters: exploring the working mechanism of the Best Possible Self manipulation to induce optimism. In preparation.

\section{Presentations}

- Boselie, J. J. L. M., Vancleef, L. M. G., \& Peters, M. L. (2017). Optimisme en pijn. Invited to give an oral presentation at the Dutch Pain Society Conference. Den Haag, the Netherlands.

- Boselie, J. J. L. M., Vancleef, L. M. G., \& Peters, M. L. (2017). Optimism as protective factor against pain-induced deterioration in executive task performance. Oral presentation at the 6th Annual Association for Researchers in Psychology and Health (ARPH) Conference. Leiden, the Netherlands.

- Boselie, J. J. L. M., Vancleef, L. M. G., Smeets, E., \& Peters, M. L. (2015). Happy despite pain: a positive psychology internet-based intervention for chronic pain patients. Oral presentation at the 6th International Conference on emotions, well-being and health, organized by Tilburg University. Tilburg, the Netherlands. 
- Boselie, J. J. L. M., Vancleef, L. M. G., \& Peters, M. L. (2015). Filling the glass: Increasing optimism to counteract pain-induced impairments in executive functioning. Oral presentation at the annual Pain Research Meeting 2015. Genk, Belgium.

- Boselie, J. J. L. M., Vancleef, L. M. G., Smeets, E., \& Peters, M. L. (2015). A positive psychology internet-based intervention improves emotional, but not cognitive functioning in chronic pain patients. Poster presented at the Association for Psychological Science (APS) $27^{\text {th }}$ annual conference. New York City, the United States of America.

- Boselie, J. J. L. M., Vancleef, L. M. G., \& Peters, M. L. (2015). Filling the glass: Increasing optimism to counteract pain-induced impairments in executive functioning. Oral presentation at the Dutch-Flemish Postgraduate School for Research and Education (EPP) 2015. Heeze, the Netherlands.

- Boselie, J. J. L. M., Vancleef, L. M. G., \& Peters, M. L. (2014). Exploring whether optimism can protect against pain-induced deterioration in executive task performance. Poster presented at the 15th World Congress on Pain, organized by the International Association for the Study of Pain. Buenos Aires, Argentina.

- Boselie, J. J. L. M., Vancleef, L. M. G., Smeets, E. \& Peters, M. L. (2014). Happy despite pain: a positive psychology intervention for patients with chronic musculoskeletal pain. Oral presentation at the International Congress of Behavioral Medicine (ICBM) 2014. Groningen, the Netherlands.

- Boselie, J. J. L. M., Vancleef, L. M. G., Smeets, E. \& Peters, M. L. (2014). Filling the Glass: Does a positive psychology intervention abolish pain-induced deterioration in executive functioning? Poster presented at the 7th European conference on positive psychology, ECPP2014. Amsterdam, the Netherlands.

- Boselie, J. J. L. M., Vancleef, L. M. G., \& Peters, M. L. (2014). Filling the glass: Increasing optimism to counteract pain-induced impairments in executive functioning. Oral presentation at the Research day FPN 2014. Maastricht, the Netherlands.

- Boselie, J. J. L. M., Vancleef, L. M. G., Smeets, T., \& Peters, M. L. (2013). Increasing optimism abolishes pain-induced impairments in executive task performance. Poster presented at the Maastricht University Faculty of Psychology and Neuroscience Research Day 2013. Maastricht, the Netherlands.

- Boselie, J. J. L. M., Vancleef, L. M. G., \& Peters, M. L. (2013). Bridging the gap: Does increasing optimism protect against the deteriorating effect of pain on executive task performance? Invited to give an oral presentation at the annual Dutch-Flemish Postgraduate School for Research and Education EPP Day 2013. Utrecht, the Netherlands.

- Boselie, J. J. L. M., Vancleef, L. M. G., \& Peters, M. L. (2012). Bridging the gap: Does increasing optimism protect against the deteriorating effect of pain on executive task performance? Poster presented at the annual Pain Research Meeting 2012. Marburg, Germany. 
Whot jutw

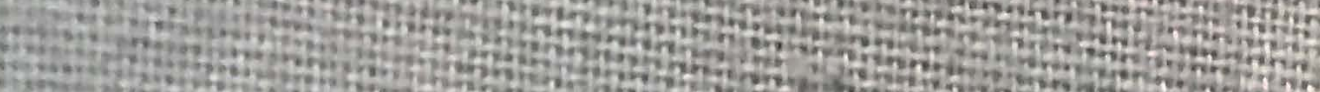

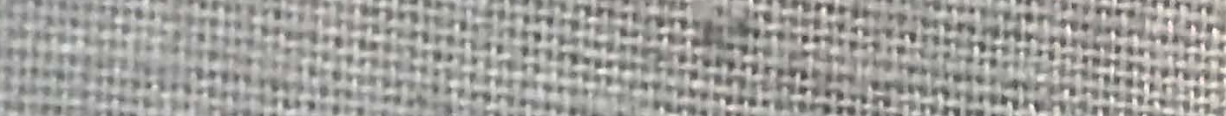
ming

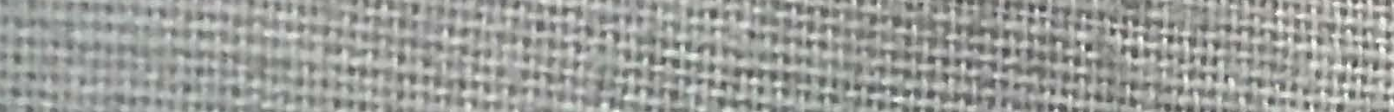

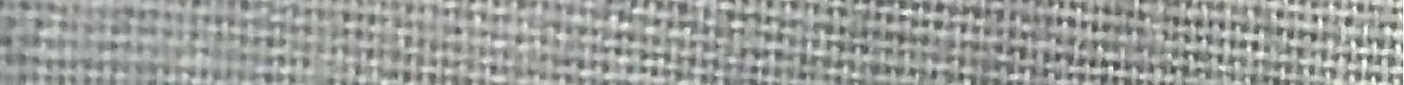

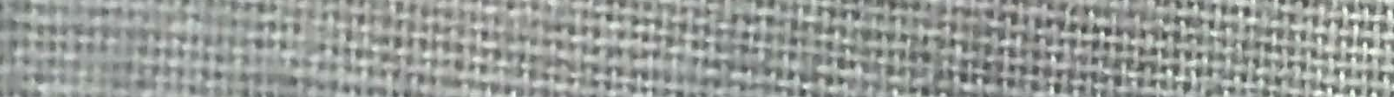

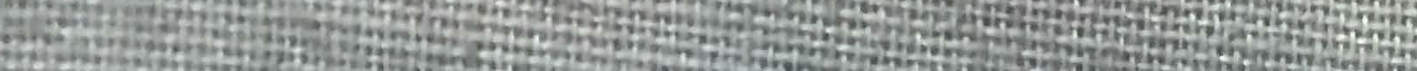
Fivan

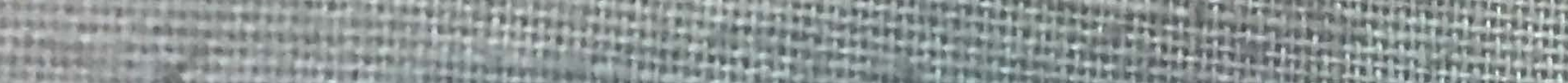

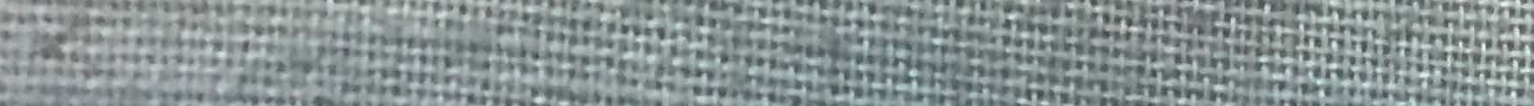
WE

W

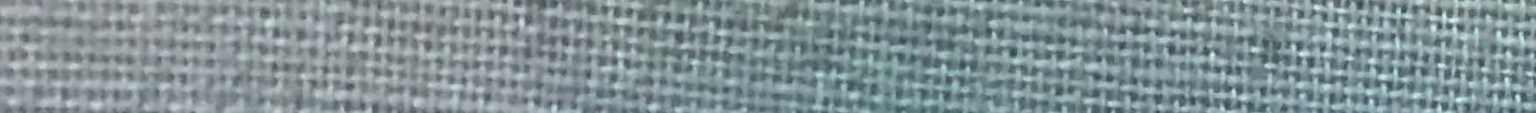

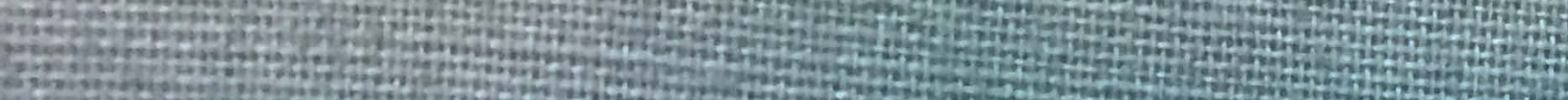

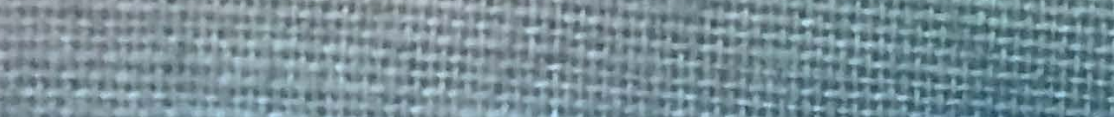

oving

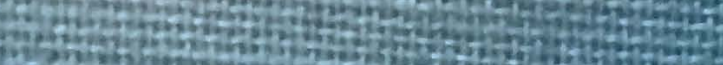

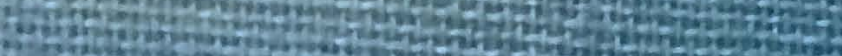

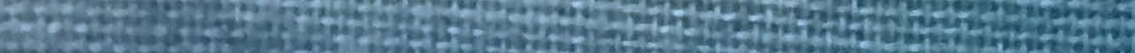

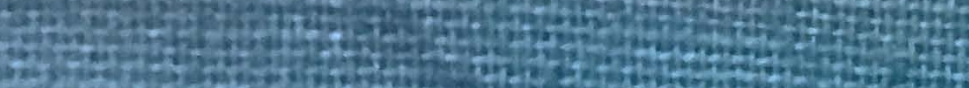

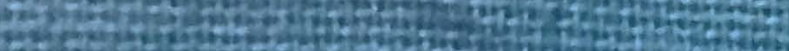

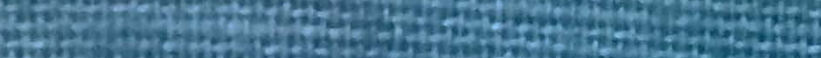

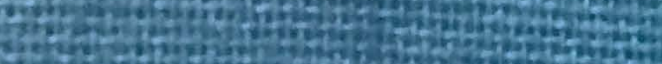

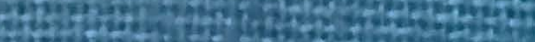

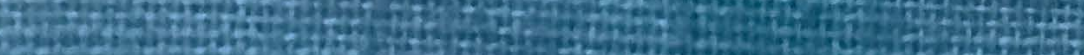

ithis

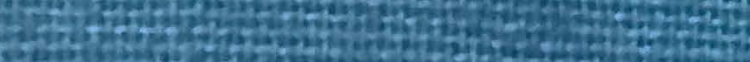

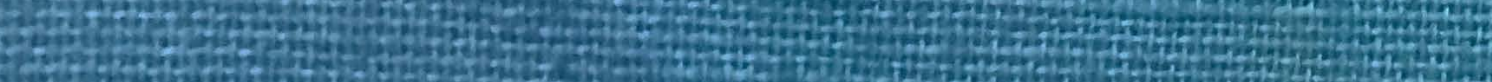

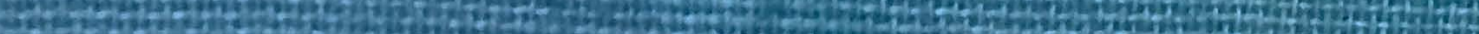
in

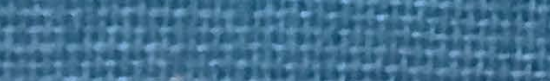

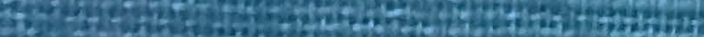

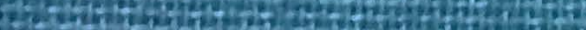

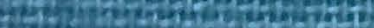

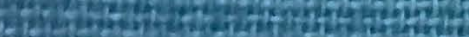

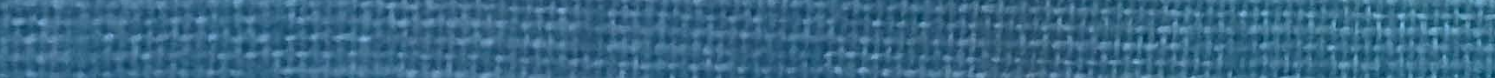
if 